Erythropoietin as a modulator of pathology in a toxicant mouse model of Parkinson's disease

\author{
By
}

Ashley Michelle Elizabeth Thompson

A thesis submitted to the Faculty of Graduate and Postdoctoral Affairs in partial fulfillment of the requirements for the degree of:

Doctor of Philosophy

in

Neuroscience

Carleton University

Ottawa, Ontario

(C) 2019

Ashley Michelle Elizabeth Thompson 


\title{
ERYTHROPOIETIN AS A MODULATOR OF PATHOLOGY IN A TOXICANT MOUSE MODEL OF PARKINSON'S DISEASE
}

\author{
Principal Investigator and Doctoral Supervisor: Dr. Shawn Hayley \\ Department of Neuroscience
}

\begin{abstract}
Parkinson's disease (PD) is the second most common neurodegenerative disorder and has no known disease-modifying treatments. Due to the complexity of the disease pathology, effective treatments for PD will likely involve a combination of treatment factors. The current experiments sought to profile the pro-survival effects of the trophic cytokine, erythropoietin (EPO), in a 6-hydroxydopamine (6-OHDA) mouse model of PD. Methods: To this end, male $\mathrm{C} 57 \mathrm{BI} / 6$ mice were used in a series of four experiments investigating the potential antiapoptotic, anti-inflammatory and antioxidant effects of the trophic cytokine. EPO's ability to protect dopaminergic terminals in the striatum, cell bodies in the substantia nigra (SNc) and modulate 6-OHDA-induced motor deficits was characterized at different doses of 6-OHDA and EPO. Results: Our results did indeed demonstrate EPO's ability to exert pro-survival effects that were brain region-specific. While intra-nigral EPO was ineffective, intra-striatal EPO preserved striatal terminals and nigral soma in two different 6-OHDA lesion models. EPO further attenuated apomorphine-induced rotations at two doses of 6-OHDA. EPO demonstrated antiapoptotic signalling through phosphorylation of Akt and the Bcl-2 associated proteins and antiinflammatory activity through modulation of microglial morphology. Finally, EPO demonstrated antioxidant activity through elevated levels of striatal glutathione peroxidase, in addition to retrograde signalling that resulted in elevated levels of glutathione peroxidase in the SNc in response to EPO treatment. Conclusions: In short, EPO appears to modify antioxidant and antiapoptotic factors and act in a brain-region specific manner to mitigate neuronal loss. Taken together, the results of the current set of experiments indicate EPO's potential for use as an adjuvant therapy in the treatment of PD.
\end{abstract}

Keywords: Parkinson's disease, erythropoietin, 6-hydroxydopamine, cytokine, trophic factor, antioxidant, anti-inflammatory, anti-apoptotic, striatum, substantia nigra, dopamine 


\section{ACKNOWLEDGEMENTS}

To my colleagues in the department of Neuroscience at Carleton University - it has been quite a ride over the last six years! Undoubtedly, without the support of my lab mates, friends, faculty members and departmental administrators, the successful completion of this doctoral degree would not have been possible. To my supervisor, Dr. Shawn Hayley, thank you for all your support and guidance throughout this process. You have challenged me to become a more proficient researcher, have encouraged the development of my critical thinking skills, and have helped me to mature as an academic and as a scientist - thank you!

To my closest friends at Carleton, the ones with whom I spent many evenings and weekends in the lab working, laughing, crying, and sometimes all three: Elyn Rowe, Chris Rudyk, Alexa Derksen, Gareth Rurak, Kathleen Chandler, and Kyle Farmer. Knowing we were all in it together gave me so much strength to push through whenever the hurdles seemed too numerous, too high, or both. The strength and support each of you gave me when I needed it most were essential to my success, whether it was a quick pep talk or a two-hour coffee break. Thank you all for the big (and little) ways you contributed to my success at Carleton. You were all a fundamental part of my success - I could not have done it without you.

To my family and friends: Your unwavering confidence in my ability to succeed at whatever task I choose to pursue gives me an unbelievable amount of courage. The constant encouragement and support you have offered me over the past 6 years (and 13 years of post-secondary in total!) have fostered in me a resilience and perseverance without which I could not have realized this massive accomplishment.

Finally, to my incredible and patient husband, Jason: You have been my number one fan since we met in my first year of my PhD and have always given me unconditional love and full support in all my academic endeavours. Thank you for being so understanding the last few years have not been easy, always coming second to "my mice", but you have given me your untiring support as I have worked countless evenings and weekends to complete this milestone. Your love has given me the strength I need to continually strive for excellence in all I do. I love you - thank you your endless encouragement. 


\section{LIST OF ABBREVIATIONS USED}

\begin{tabular}{|c|c|}
\hline 6-OHDA & 6-hydroxydopamine \\
\hline$\alpha-S Y N$ & alpha-synuclein \\
\hline AIF & apoptosis-inducing factor \\
\hline BBB & blood-brain barrier \\
\hline BDNF & brain-derived neurotrophic factor \\
\hline CDNF & cerebral dopamine neurotrophic factor \\
\hline DA & dopamine \\
\hline EPO & erythropoietin \\
\hline GABA & gamma-amino-butyric acid \\
\hline GDNF & glial cell-derived neurotrophic factor \\
\hline GM-CSF & granulocyte macrophage-colony stimulating factor \\
\hline GPx & glutathione peroxidase \\
\hline GSH & glutathione \\
\hline L-DOPA & levodopa \\
\hline MANF & mesencephalic astrocyte-derived neurotrophic factor \\
\hline MAO-B & monoamine oxidase-B \\
\hline MPTP & 1-methyl-4-phenyl-1,2,3,6-tetrahydropyridine \\
\hline MSN & medium spiny neuron \\
\hline NE & norepinephrine \\
\hline NTF & neurotrophic factor \\
\hline PD & Parkinson's disease \\
\hline ROS & reactive oxygen species \\
\hline SNc & substantia nigra pars compacta \\
\hline TH & tyrosine-hydroxylase \\
\hline
\end{tabular}




\section{TABLE OF CONTENTS}

ACSTRACT

SECTION 1: BACKGROUND AND LITERATURE REVIEW.................................................................

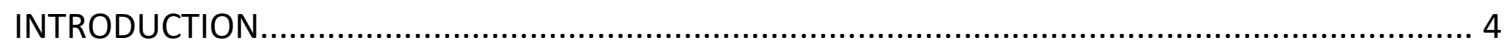

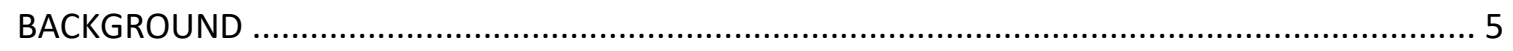

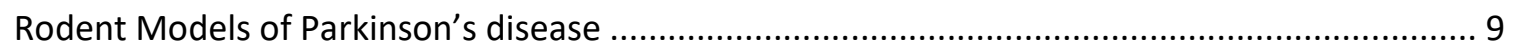

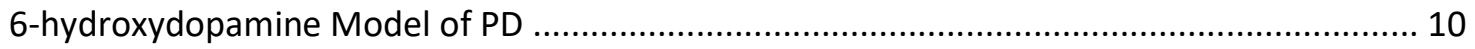

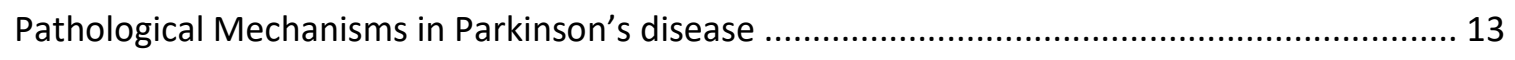

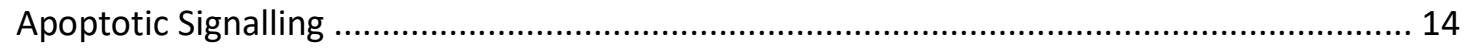

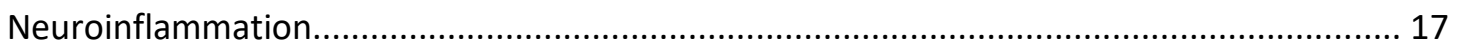

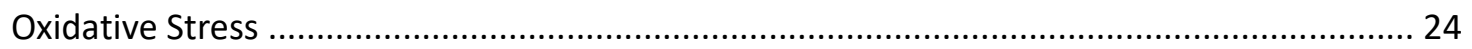

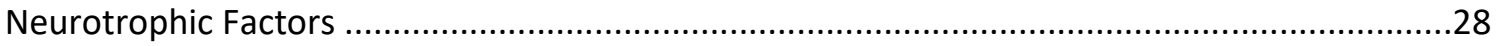

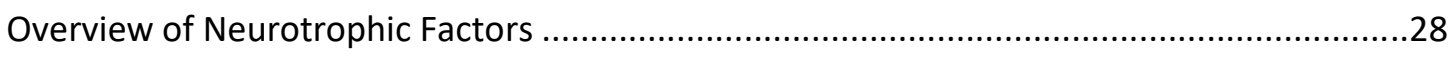

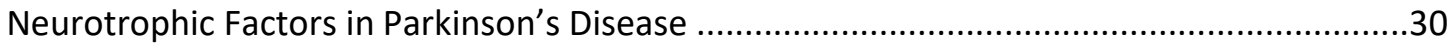

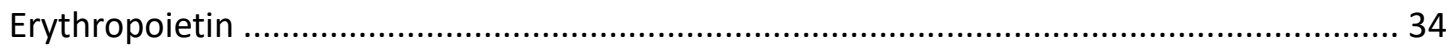

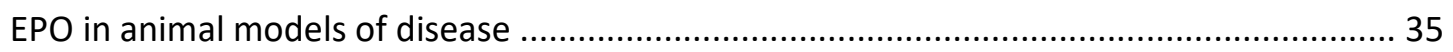

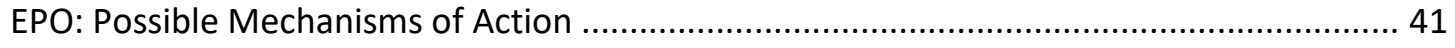

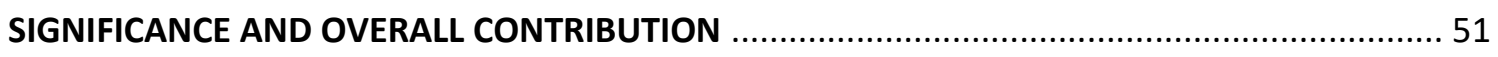

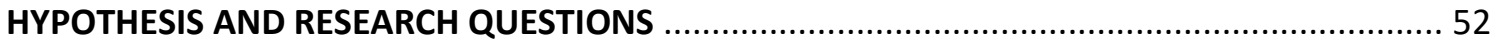

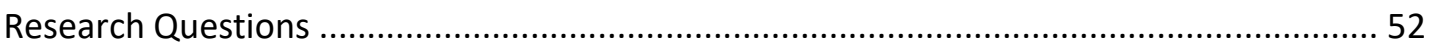

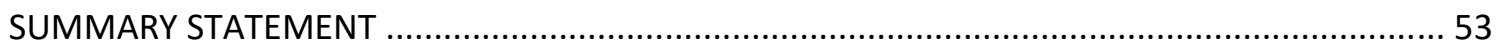




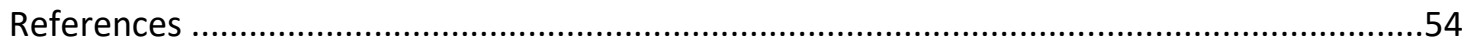

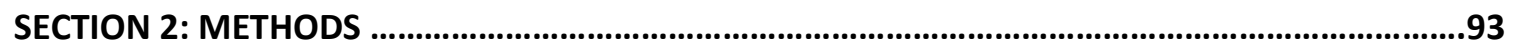

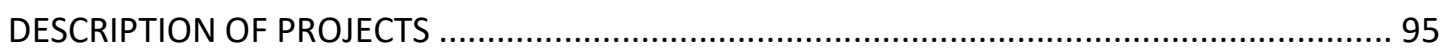

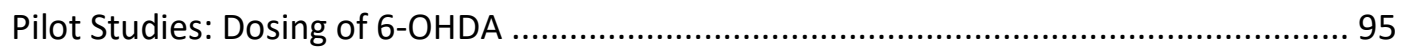

Study 1: Investigating EPO's pro-survival signalling in the first 24 hours ......................... 95

Study 2: Investigating the effects of EPO administration in the substantia nigra ............. 96

Study 3: Investigating the effects of two doses of EPO administered to the striatum...... 96

Study 4: Investigating the effects of EPO with a partial 6-OHDA Lesion ......................... 97

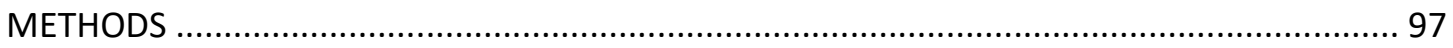

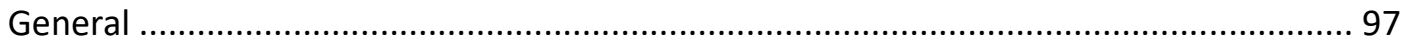

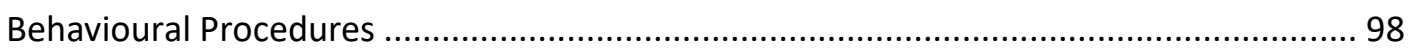

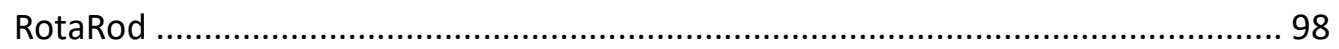

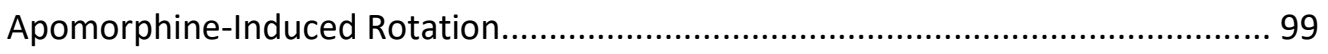

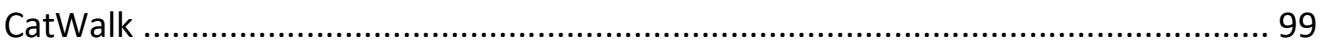

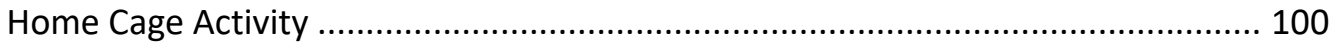

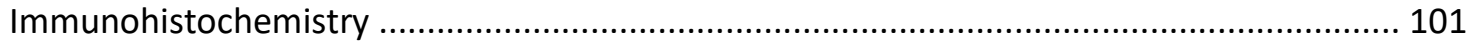

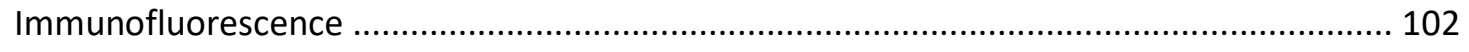

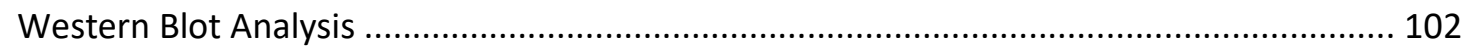

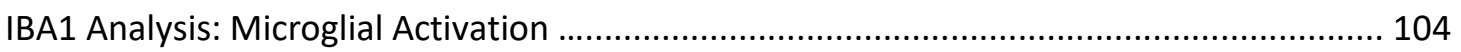

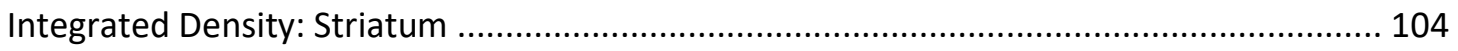

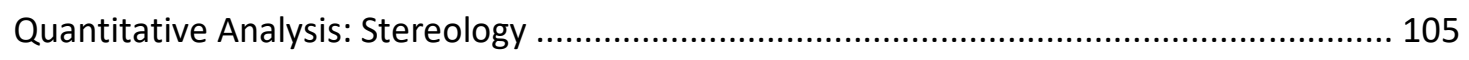

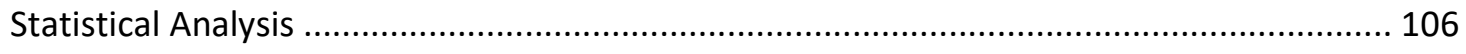

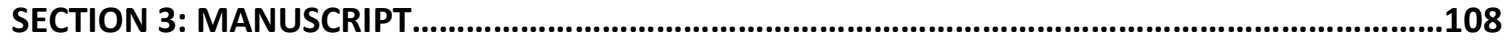

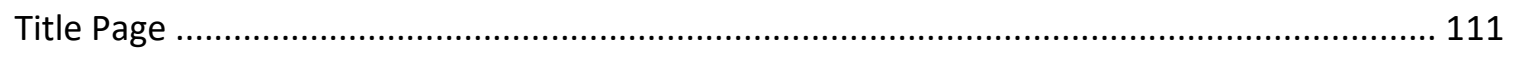

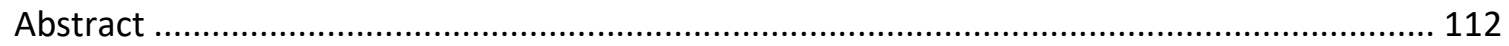

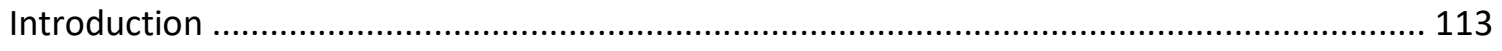

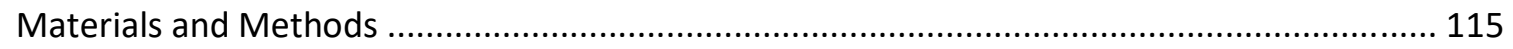

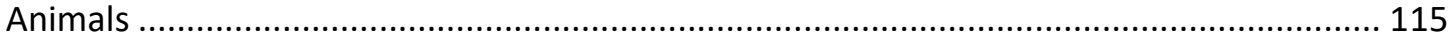

General Stereotaxic Procedures: Cannulations and Infusions of 6-OHDA and EPO .............. 115

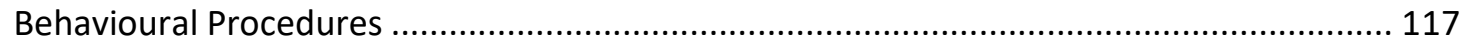


RotaRod

Apomorphine-Induced Rotation

Home Cage Activity 118

CatWalk......

Biological analyses

Immunohistochemistry

Immunofluorescence

Western Blot Analysis

Data Scoring and Statistical Analysis

IBA1 Analysis: Microglial Activation

Quantitative Analysis: Stereological assessment of TH-positive neurons in the substantia.... nigra

Pilot study: Determination of 6-OHDA dose to produce clinically relevant lesion

Experiment 1: Investigating the acute pro-survival signalling of erythropoietin

Experiment 2: Investigating the potential neuroprotective effects of EPO in the substantia...... nigra

Experiment 3: Investigating the neuroprotective properties of two EPO doses in the striatum

Experiment 4: Investigating the effects of EPO with a partial 6-OHDA Lesion

Results

Experiment 1 Results: Investigating the acute pro-survival signalling of erythropoietin....... 128

Western Blot

Experiment 2 Results: Investigating the neuroprotective effects of EPO in the substantia nigra

Striatal Lesion and Stereology

Microglial Activation 132

Behaviours 
Experiments 3 and 4: Comparing two doses of 6-OHDA when EPO is administered in the..........

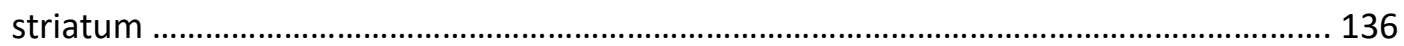

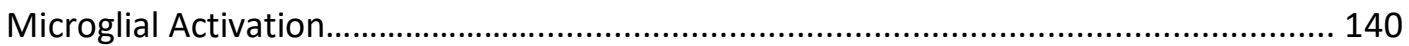

Behaviours: Rotarod and Apomorphine-Induced Rotations ....................................... 144

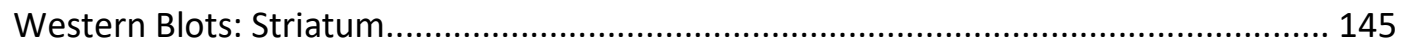

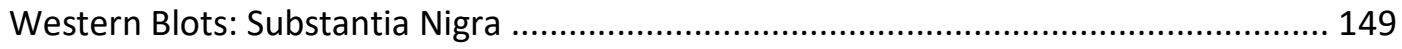

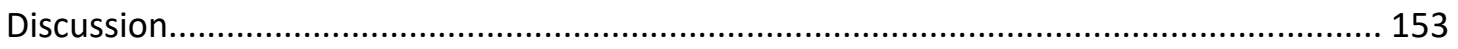

EPO's pro-survival effects are region- and lesion size-dependent ................................ 155

Evidence for EPO's anti-apoptotic, anti-inflammatory and antioxidant actions ............. 156

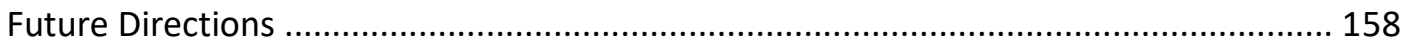

The Heterogeneity of the Striatum ….................................................................. 159

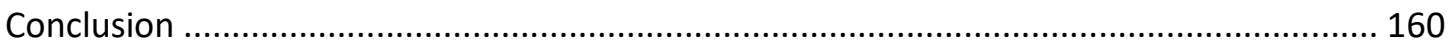

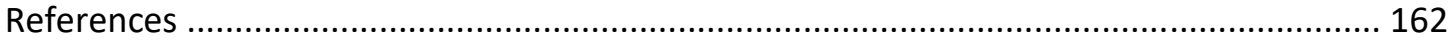

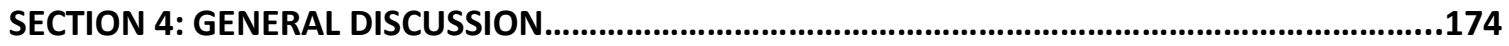

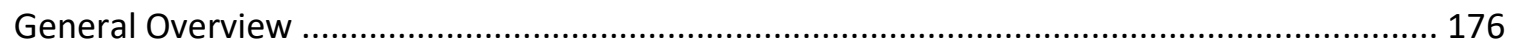

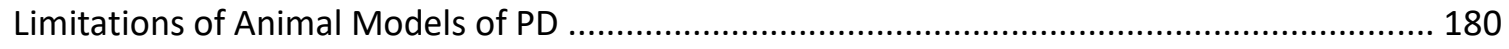

EPO activates pro-survival signalling acutely in the absence of a toxicant .............................. 183

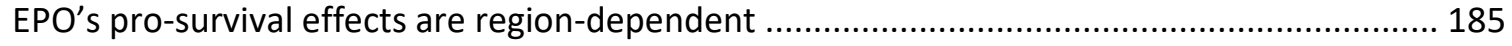

EPO protects nigrostriatal neurons from partial and moderate 6-OHDA lesions ..................... 188

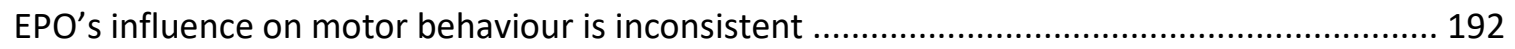

Evidence for EPO's anti-apoptotic, anti-inflammatory and antioxidant actions ...................... 194

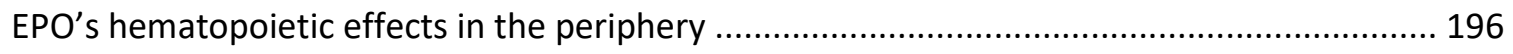

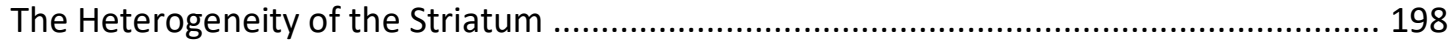

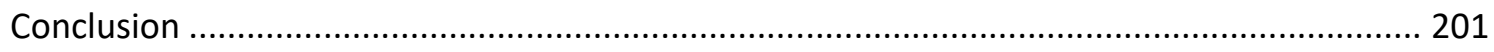

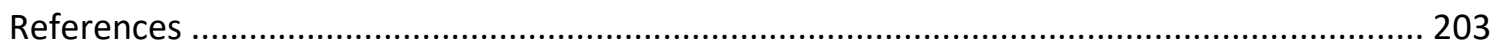

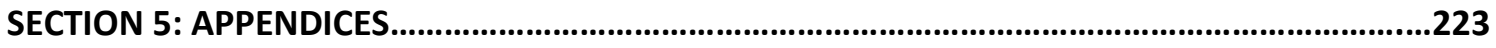

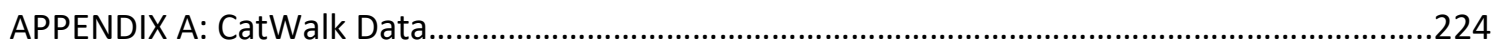

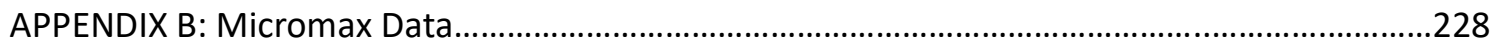




\section{LIST OF TABLES}

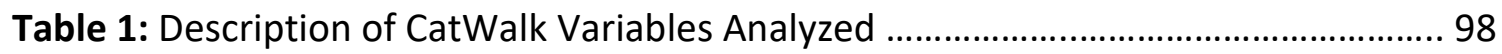

Table 2: Summary of behavioural and biological methodologies employed................ 104

Table 3: Description of behavioural and biological methodologies..............................126 


\section{LIST OF FIGURES}

Figure 1: Exp. 1 - Activation of Acute pro-survival signalling pathways .129

Figure 2: Exp. 2 - Striatal Lesion and Stereology. .131

Figure 3: Exp. 2 - Microglial activation in the striatum and substantia nigra .132

Figure 4: Exp. 2 - Assessing Gait and Balance using the Rotarod Apparatus. .134

Figure 5. Exp. 3/4 - Striatal Lesions .137

Figure 6. Exp. 3/4 - Stereological assessment of neuronal loss .138

Figure 7. Exp. 3/4 - Microglial activation in the striatum and substantia nigra .140

Figure 8. Exp. 3/4 - Motor Activity: Rotarod and Rotational Behaviour. .146

Figure 9. Exp. 3/4 - Western blots in the striatum. .147

Figure 10. Exp. 3/4 - Western blots in the substantia nigra .149 


\section{LIST OF APPENDICES}

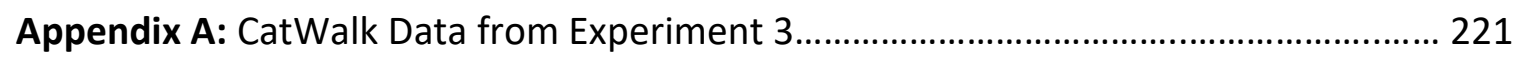

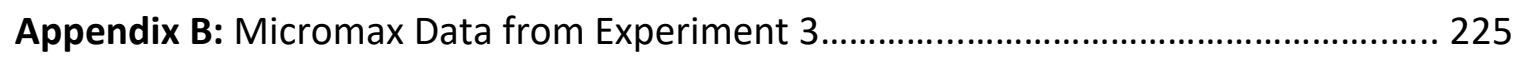




\section{OVERVIEW}

This thesis is divided into five sections:

1. Introduction: Background and Literature Review

2. Methods

3. Manuscript

4. General Discussion

5. Appendices 


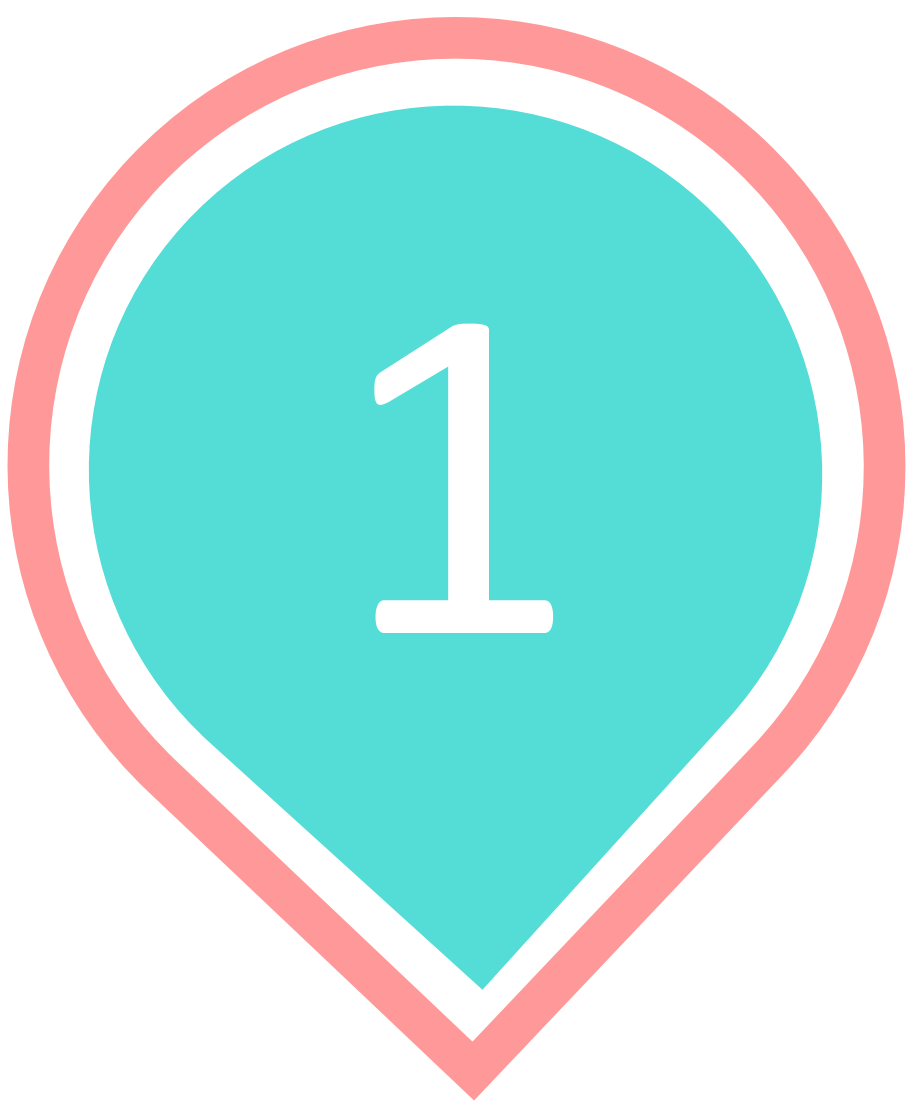

CHAPTER 1:

INTRODUCTION - BACKGROUND

AND LITERATURE REVIEW 
Table of Contents

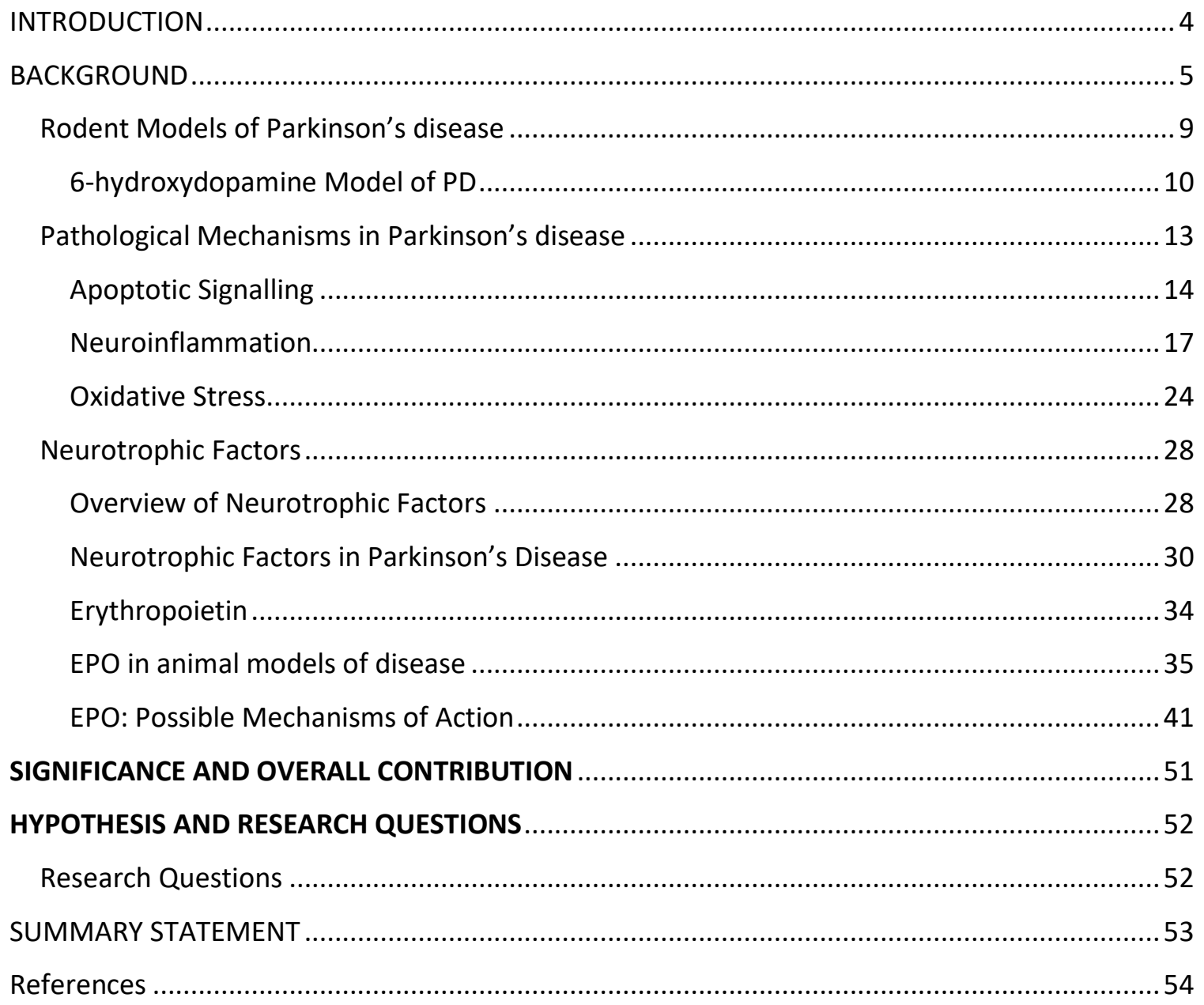




\section{INTRODUCTION}

Parkinson's disease (PD) is a debilitating neurodegenerative disorder that affects more than 4 million people worldwide (Dorsey et al., 2007). Levodopa (L-DOPA), the gold standard in treatment for PD, was developed more than 50 years ago (Cotzias, Papavasiliou, 1967; Cotzias, Van Woert, \& Schiffer, 1967). Although L-DOPA acutely replenishes the dopamine that is lost from dying neurons in the midbrain (Di Monte et al., 1996), it does not slow or reverse the primary neuronal degeneration. Despite its initial contribution to symptom management, the efficacy of L-DOPA diminishes over time, and its chronic use is associated with dyskinesias, characterized by excessive and unwanted involuntary movements (Bastide et al., 2015; Jenner, 2008). Diseasemodifying strategies for PD are an important unmet clinical need; the social and economic burden imposed by PD is cumbersome, and has been well documented (Findley et al., 2011; Guttman, Slaughter, Theriault, Deboer, \& Naylor, 2003; Kowal, Dall, Chakrabarti, Storm, \& Jain, 2013). As the general population continues to age, these burdens will only become more pronounced (Feigin et al., 2017). To develop diseasealtering therapies for PD, more knowledge regarding the pathology of the disease is required.

Broadly, recent research has improved our understanding of some of the pathological processes occurring in the brains of individuals with PD, including oxidative stress and neuroinflammation (Bose \& Beal, 2016, 2019; Cruces-Sande et al., 2019; 
Monzani et al., 2019; Taylor, Main, \& Crack, 2013). As a result, current strategies in PD research seek to intervene at the level of these processes to restore the homeostatic balance disrupted by the disease. One prominent area of focus in this research includes the use of neurotrophic factors (NTFs); NTFs are endogenous secreted proteins that act as brain-nourishing substances, and are grouped into families based on their structures, functions and mechanistic properties (Airavaara, Voutilainen, Wang, \& Hoffer, 2012). Investigation into how these substances may alter the microenvironment of susceptible brain areas in PD may provide insight into the deleterious mechanisms that lead to neuronal death. Indeed, this understanding may lead to the development of novel therapeutic strategies for PD.

\section{BACKGROUND}

Parkinson's disease (PD) is the second most common neurodegenerative disorder after Alzheimer's disease (Delamarre \& Meissner, 2017; L. Hirsch, Jette, Frolkis, Steeves, \& Pringsheim, 2016; Wirdefeldt, Adami, Cole, Trichopoulos, \& Mandel, 2011). The etiology of this chronic, progressive disease is not well understood, but it is likely to involve both genetic and environmental factors (Johnson, Stecher, Labrie, Brundin, \& Brundin, 2019; Patrick, Bell, Weindel, \& Watson, 2019; Ritz, Paul, \& Bronstein, 2016; Wirdefeldt et al., 2011). Although developments in research have revealed the involvement of genetic factors in a minority of cases, approximately $90 \%$ of cases are sporadic with no clear etiology (Dauer \& Przedborski, 2003; Tysnes \& Storstein, 2017). 
The primary motor symptoms of PD include resting tremor, rigidity, bradykinesia and postural instability (Dauer \& Przedborski, 2003). Resting tremor describes an involuntary shakiness that subsides with voluntary movement and is present in $70 \%$ of PD patients (Alberts, Wright, \& Feinstein, 1969; Camara et al., 2015; Lenz et al., 1994; Paré, Curro'Dossi, \& Steriade, 1990). Rigidity refers to the resistance to passive movement exhibited by patients' limbs. Bradykinesia describes a slowness of movement, which greatly influences the quality of life of patients living with PD, as increased time is required to perform everyday self-care activities such as eating and dressing (Dauer \& Przedborski, 2003). Patients with PD can develop a stooped posture, and sometimes exhibit impaired postural reflexes, which can lead to falls, and in some cases, confinement to a wheelchair (Allen, Schwarzel, \& Canning, 2013; Hely, Reid, Adena, Halliday, \& Morris, 2008; Koller, Glatt, Vetere-Overfield, \& Hassanein, 1989). Patients with PD also experience a variety of non-motor symptoms, including autonomic problems, depression, and dementia (Hely et al., 2008; Martinez-Martin et al., 2015; Merola et al., 2011; Pfeiffer, 2016; Schapira, Chaudhuri, \& Jenner, 2017).

The central neuropathological feature of PD is the loss of dopaminergic neurons in the pars compacta region of the substantia nigra (SNc) and the associated depletion of the catecholamine neurotransmitter dopamine (DA) in the striatum (Nutt \& Wooten, 2005). The cell bodies of neurons in the nigrostriatal pathway are found in the SNc; the axons of these neurons project to and terminate in the striatum, where they release DA. As the striatum plays a central role in the basal ganglia's control over voluntary 
movement, the degeneration of neurons in this pathway leads to a dysfunction in multiple excitatory and inhibitory feedback loops. The depletion of DA neurons in the nigrostriatal pathway leads to striatal DA deficiency and ultimately results in the observable motor symptoms of PD (Jenner \& Olanow, 1998; Yarnall, Archibald, \& Burn, 2012). DA signalling from the SNc typically regulates the release of the brain's primary inhibitory neurotransmitter, gamma-amino-butyric acid (GABA), from the medium spiny neurons (MSNs) of the striatum. In the absence of DA input from the SNc, the activity of the MSNs becomes disrupted, and the overall ganglio-thalamo-cortical circuitry becomes dysregulated (Mallet, 2006). These circuits are complex, and involve multiple structures that use tonic inhibition and feed-forward mechanisms; attributing specific motor features with molecular pathophysiology has been a challenge, as the connections within these motor circuits are intricate and incompletely understood (Macphee \& Stewart, 2012; Mallet, 2006).

There is also evidence for the involvement of non-dopaminergic nuclei in the progression of the disease - the loss of serotonin neurons in the raphe nucleus and noradrenaline neurons in the locus coeruleus have also been observed (Blum et al., 2001; Dauer \& Przedborski, 2003; Henrich et al., 2018; Vermeiren \& De Deyn, 2017). The degeneration of these nuclei may contribute to the manifestation of the non-motor symptoms observed in PD; in fact, it is well-known that serotonin and norepinephrine exert notable influences on mood, sleep and attention, all of which are commonly altered in PD. Various nuclei are predictably vulnerable to degeneration in PD, and 
within surviving neurons in these regions, eosinophilic proteinaceous inclusions within the cytoplasm are observed (McNaught \& Olanow, 2006; Nutt \& Wooten, 2005). The cytoplasmic inclusions, termed Lewy bodies, are abnormal protein aggregates composed primarily of $\alpha$-synuclein (Spillantini, Crowther, Jakes, Hasegawa, \& Goedert, 1998). Although the role of Lewy bodies in the pathology of PD is unknown, their presence constitutes a prominent neuropathological feature of the disease (Braak et al., 2002; Dickson, 2018; Spillantini et al., 1998). The formation of Lewy bodies occurs in a predictable topographical manner in PD, with inclusions appearing first in brainstem nuclei in the early, pre-symptomatic stages of the disease (Braak et al., 2002). As the disease progresses into its symptomatic phase, aggregates form in the substantia nigra and other midbrain nuclei. Finally, in end-stage PD, Lewy body pathology extends into areas of the neocortex (Braak et al., 2002).

PD remains difficult to define due to the heterogeneity of clinical presentation, the variability of progression rates, and the different signs and symptoms present in different clinical subtypes (Berg et al., 2013). To date, the clinical diagnosis of PD is based upon the presence of the primary motor symptoms in conjunction with response to dopamine replacement therapy (Brooks, 2012; Postuma et al., 2016; Rao, Hofmann, \& Shakil, 2006) with definitive diagnosis confirmed only at autopsy (Hughes, Daniel, Kilford, \& Lees, 1992; Postuma et al., 2015). To best approach the treatment of PD, it is imperative to further investigate the molecular mechanisms known to contribute to its pathophysiology. Notably, apoptotic signalling, inflammatory processes, and conditions 
of oxidative stress have been strongly implicated in the progression of PD and should be carefully considered in models of the disease (Johnson et al., 2019; Monzani et al., 2019; Obeso et al., 2017).

\section{Rodent Models of Parkinson's disease}

Experimental animal models of PD have elucidated several neuropathological events in PD, which have greatly contributed to an improved understanding of the disease. Although the cause of neuronal death in PD is not yet understood, a predictable pattern of neurodegeneration has allowed researchers to develop experimental models that include both pathological and motor features of the disease. Current animal paradigms possess several limitations, however, as none can fully model the progressive nature of the human illness, reproduce the clinical signs and symptoms of a movement disorder, or replicate the complexity of the pathological and biochemical alterations involved (Blesa, Phani, Jackson-Lewis, \& Przedborski, 2012; Bové, Prou, Perier, \& Przedborski, 2005; Duty \& Jenner, 2011; Gibrat et al., 2009; Iancu, Mohapel, Brundin, \& Paul, 2005; Schober, 2004; Wang et al., 2012). Still, the development of these models has allowed for proliferation of research that improves our understanding of the pathogenic mechanisms involved in PD, and as such, their continued use in PD research is both relevant and necessary.

The two most widely employed neurotoxin-based models of PD involve the use of 1-methyl-4-phenyl-1,2,3,6-tetrahydropyridine (MPTP) and 6-hydroxydopamine 
(6-OHDA) (Blesa et al., 2012; Schober, 2004). The ideal animal model of PD would induce a progressive and selective loss of nigral DA neurons that begins in adulthood. It would further produce quantifiable motor deficits that resemble the symptoms observed in patients, involve the generation of Lewy bodies, and include the loss of other nuclei observed in PD. Presently, the MPTP and 6-OHDA models produce most of the required features, at least in part (Blum et al., 2001; Carelli et al., 2017; Garea-Rodríguez et al., 2016; Janssen et al., 2012; Martin et al., 2016; Ren et al., 2017). While no animal model is without limitations, these neurotoxin-based models of PD have provided a platform upon which prospective neuroprotective and neurorestorative treatments may be investigated. Broadly, the 6-OHDA model of PD is a safe, reliable model of the disease that is effective across strains and species of rodents and non-human primates, is biologically relevant, and allows for unilateral administration of the toxin such that each subject can act as its own control.

\section{6-hydroxydopamine Model of PD}

6-OHDA is a selective catecholaminergic neurotoxin that was first used 50 years ago to produce an animal model of PD by inducing degeneration of the nigrostriatal system (Ungerstedt \& Arbuthnott, 1970). Since then, it has been the most commonly employed toxin-based experimental model in rats (Berger, Przedborski, \& Cadet, 1991; Marshall \& Ungerstedt, 1977; Truong, Allbutt, Kassiou, \& Henderson, 2006; Zhao et al., 2014). More recently, its use in mice has become increasingly common (Chiu et al., 
2014; Grealish, Mattsson, Draxler, \& Björklund, 2010; Jing et al., 2016; Lundblad, Picconi, Lindgren, \& Cenci, 2004; Ren et al., 2017; Schober, 2004). Unlike MPTP, 6-OHDA does not cross the blood-brain barrier, and as such, must be injected centrally. 6-OHDA has long been known to selectively destroy DA neurons both in vitro and in vivo (Michel \& Hefti, 1990). One of the advantages of using 6-OHDA over MPTP is that by unilaterally injecting the toxin, each animal may serve as its own control, whereas systemic administration of MPTP leads to bilateral parkinsonism (Burns et al., 1983; Grünblatt, Mandel, \& Youdim, 2000). MPTP is ineffective in rats, and its efficacy in mice is variable and dependent on strain (Burns et al., 1983). While MPTP is a synthetic substance, the structure of 6-OHDA differs from dopamine by only one hydroxyl group; its oxidation yields superoxide $\left(\mathrm{O}_{2}{ }^{-}\right)$and peroxide $\left(\mathrm{H}_{2} \mathrm{O}_{2}\right)$, both of which are cytotoxic reactive oxygen species (ROS) that are produced during DA metabolism.

Monoamine oxidase (MAO) is the enzyme responsible for the oxidation of catecholamines; MAO-B is the predominant isoform in humans and is responsible for the metabolism of DA, yielding $\mathrm{H}_{2} \mathrm{O}_{2}$ as a by-product of its breakdown (Chiu et al., 2014; Wei, Yeung, Jurma, \& Andersen, 1996). Levels of MAO-B have been shown to increase steadily over the lifespan as well as in conditions of neurodegenerative disease (Mallajosyula et al., 2008; Saura, Richards, \& Mahy, 1994). Not surprisingly, MAO-B inhibitors such as selegiline have been investigated for their potential to reduce the ROS produced in PD (Antonini, 2011; Chiu et al., 2014; Di Monte et al., 1996; Ren et al., 2011; Wu, Shang, Sun, \& Liu, 2007). 
Accumulation of ROS in the SNc may lead to aberrant oxidation of DA, yielding 6-OHDA among other harmful compounds (Damier, Kastner, Agid, \& Hirsch, 1996). This, along with the similarities between the natural metabolites of DA and the ROS produced by the oxidation of 6-OHDA, make it an attractive candidate for an endogenous toxin to model PD. Indeed, early studies reported the presence of 6-OHDA in the brains of rats (Senoh, Witkop, Creveling, \& Udenfriend, 1959; Siro Senoh, Creveling, Udenfriend, \& Witkop, 1959; Siro Senoh \& Witkop, 1959b, 1959a) and PD patients post-mortem (Curtius, Wolfensberger, Steinmann, Redweik, \& Siegfried, 1974), as well as in the urine of patients with PD (Andrew et al., 1993). The toxicity of 6-OHDA has long been linked to its ability to induce neuroinflammation and oxidative stress (Kostrzewa \& Jacobowitz, 1974; Rodriguez-Pallares et al., 2007), the former resulting from the activation of microglia, the resident immune cells of the brain (Aloisi, 2001; Kaminska, Mota, \& Pizzi, 2016), and the latter from an increase in the production of ROS (Latchoumycandane, Anantharam, Jin, Kanthasamy, \& Kanthasamy, 2011; Rodriguez-Pallares et al., 2007). 6-OHDA is readily auto-oxidized to produce peroxide $\left(\mathrm{H}_{2} \mathrm{O}_{2}\right)$ in the extracellular space, a reactive species damaging to membranes, proteins and genetic material (Blum et al., 2001). ROS are sensed by microglia, and an inflammatory cascade is initiated, highlighting the intimate link between oxidative and inflammatory stressors within the brain, processes which often exacerbate one another in the central nervous system.

When evaluating the neuroprotective properties of a substance, the preferred injection site for 6-OHDA is in the dorsolateral striatum, which enters neurons via the 
dopamine transporter found in the plasma membrane of striatal axons and terminals (Hersch, Yi, Heilman, Edwards, \& Levey, 1997). Intra-striatal injections of 6-OHDA cause selective degeneration of dopaminergic axons and terminals surrounding the injection site, followed by the death of the cell bodies in the SNc, which occurs in a retrograde manner over the course of several weeks (Berger et al., 1991; Przedbroski et al., 1995; Sauer \& Oertel, 1994). Indeed, this produces a more localized and progressive loss of DA neurons than injections into other areas of the nigrostriatal tract (Heuer, Smith, Lelos, Lane, \& Dunnett, 2012), and thus, more closely resembles the human illness. When injected unilaterally into the striatum, 6-OHDA selectively destroys DA terminals and neuronal cell bodies, creates conditions of neuroinflammation and oxidative stress, and produces quantifiable motor deficits in mice (Branchi et al., 2010; lancu, Mohapel, Brundin, \& Paul, 2005; Ren et al., 2017; Schober, 2004; Signore et al., 2006). Taken together, these findings support the use of 6-OHDA as a toxin-induced mouse model of PD.

\section{Pathological Mechanisms in Parkinson's disease}

It is well established that apoptotic signalling, neuroinflammation, and oxidative stress all play a significant role in the pathology of PD (Dunn, 2006; Fahn \& Cohen, 1992;

Hirsch, Hunot, \& Hartmann, 2005; Johnson et al., 2019; McGeer, Itagaki, Boyes, \& McGeer, 1988; Monzani et al., 2019; Qian, Flood, \& Hong, 2010; Surmeier, Guzman, Sanchez-Padilla, \& Schumacker, 2011). Studies examining mechanisms of neuronal death in PD consistently demonstrate that each of these pathological mechanisms 
contributes to the disruption of cellular homeostasis and neuronal degeneration observed in the disorder (Hirsch \& Hunot, 2009; Hirsch et al., 2005; Latchoumycandane et al., 2011; McGeer \& McGeer, 2008; Varcin et al., 2011).

\section{Apoptotic Signalling}

As recently as 50 years ago, it was thought that all cell death occurred via necrosis, which involves mitochondrial dysfunction and large transmembrane ion currents that ultimately lead to cellular swelling and rupture. Necrotic cells spill their cellular contents into the extracellular space, and an inflammatory response follows. In the early 1970s, John Kerr and colleagues were the first to describe an alternative form of cellular death that was both distinctly different from necrosis and appeared inherently controlled by the cell (Kerr, Wyllie, \& Currie, 1972). This new form of cellular death involved careful dismantling of the cell, with membranes kept intact and nearby cells phagocytizing membrane-bound cellular components. The authors suggested that this form of cellular death be termed "apoptosis", which comes from the Greek for "falling off", as leaves fall off a tree (Kerr et al., 1972). Kerr and colleagues noted apoptosis could occur under normal physiological conditions or in response to a pathological stimulus, and likened it to a complement of mitosis, representing a controlled and programmed form of cell regulation in animals (Kerr et al., 1972).

Although described nearly 50 years ago, the relevance of apoptosis in neurodegenerative disease was not at the forefront of research until much later (Tatton 
\& Olanow, 1999). In their seminal paper, Tatton and Olanow (1999) were among the first to thoroughly review the role of the mitochondria and apoptosis-inducing factors (AIFs) in apoptosis based on the work of several lines of research, including their own. They highlight the importance of the mitochondria in directing apoptotic mechanisms in pathological conditions through the release of AIFs such as cytochrome $\mathrm{C}$ and caspase 3 , as well as the anti-apoptotic role of B cell lymphoma-2 (Bcl-2) in preventing the release of cytochrome $\mathrm{C}$ from the mitochondria and thus inhibiting apoptosis (Tatton \& Olanow, 1999). Multiple factors likely contribute to the activation of programmed cell death in PD, but the internal push and pull directed by mitochondria and the many pro- and antiapoptotic factors that are internally regulated are notable.

There is an abundance of evidence in support of the role of apoptosis in PD, including findings from cell culture, animal models of PD, and human patients (Anglade et al., 1997; Gong et al., 2016; Hartmann et al., 2000; Hu et al., 2017; Mochizuki, Goto, Mori, \& Mizuno, 1996; Novikova, Garris, Garris, \& Lau, 2006; Zuch et al., 2000). In 1996, Mochizuki et al. were the first to demonstrate DNA fragmentation in the brains of PD patients using the Terminal deoxynucleotidyl transferase dUTP Nick-End Labeling (TUNEL) method, suggesting the presence of apoptotic cells (Gavrieli, 1992; Gold et al., 1994; Mochizuki et al., 1996). In another study, nuclear chromatin condensation was observed in the SNc of patients with PD, changes that were not observed in healthy controls (Anglade et al., 1997). Although some laboratories found results consistent with the findings of Mochizuki et al. (Anglade et al., 1997; Tompkins, Basgall, Zamrini, \& Hill, 
1997) others were unable to replicate these findings (Banati, Daniel, \& Blunt, 1998;

Kingsbury, David Mardsen, \& Foster, 1998; Kösel, Egensperger, von Eitzen, Mehraein, \& Graeber, 1997; Wüllner et al., 1999). Broadly, these null results may have been due to limitations in the technique used to detect apoptotic mechanisms and limitations in defining apoptotic cellular morphology (Venderova \& Park, 2012).

In addition to mounting evidence from various genetic models of PD (laccarino et al., 2007; MacLeod et al., 2006; Venderova \& Park, 2012), more recent findings using updated techniques have continued to support the role of apoptosis in vitro (Yue, Gao, Wang, Ding, \& Teng, 2018), in animal models of PD (Shrivastava et al., 2013; Stott \& Barker, 2014; Yue et al., 2018; Zuch et al., 2000) and in post-mortem studies of patients with PD (Büttner et al., 2013; Hartmann et al., 2000; Mogi et al., 2000). Although the mechanisms underlying cellular death in PD are complex and still under investigation, researchers have consistently implicated the role of mitochondrial dysfunction and the release of AIFs in the apoptotic death of neurons in PD (Dauer \& Przedborski, 2003; Hartmann et al., 2000; C. Perier \& Vila, 2012; Celine Perier, Bové, \& Vila, 2012; Takai et al., 1998; Vila \& Perier, 2008; Viswanath et al., 2001). The presence of dysfunctional mitochondria can also exacerbate conditions of oxidative stress and neuroinflammation in PD, as these processes are intimately linked. 


\section{Neuroinflammation}

Innate immunity in the brain is directed primarily by microglia (Aloisi, 2001). Microglia are located throughout the central nervous system, account for $10-15 \%$ of all cells in the brain, and act as the resident macrophage molecules. Microglia have an integral role in immunosurveillance and direct the immune defense pathways in response to pathological processes in the brain. The microglial-mediated immune response involves signalling using both pro- and anti-inflammatory molecules, and both types of signalling molecules influence cell survival under conditions of cellular stress. Evidence suggests that activated microglia may be centrally involved in neurodegenerative pathways in disorders such as PD (Aloisi, 2001; Gao, Jiang, et al., 2002; Patrick L. McGeer \& McGeer, 2008; Smith, Das, Ray, \& Banik, 2012; Stott \& Barker, 2014). Microglial activity is diffuse, and these glial cells have been implicated in both neurodegeneration and neuroprotection. When brain tissue is healthy, microglia display a resting phenotype; however, they become activated in response to stress that disrupts the homeostatic balance of the environment (Aloisi, 2001; Hoogland, Houbolt, van Westerloo, van Gool, \& van de Beek, 2015). Microglia can assume various phenotypes corresponding to different states of activation and can be classified as ramified in their resting state, with many thin ramifications extending from the small, circular cell body. They can be further classified as intermediate, activated, or amoeboid-like, corresponding to increasing levels of microglial activation, each with a distinct phenotype (Aloisi, 2001; Mangano \& Hayley, 2009; Tang \& Le, 2016). When activated, 
the microglia's processes retract towards the cell body, which itself becomes enlarged. Recently, some concern has been raised surrounding the assignment of microglial activation state labels such as M1 (anti-inflammatory) and M2 (pro-inflammatory), as such labels limit the way researchers perceive microglial activation to a two-dimensional spectrum (Ransohoff, 2016). In this article, Ransohoff suggests there is a lack of evidence supporting the use of a binary microglial phenotype spectrum ranging from $\mathrm{M} 1 \leftrightarrow \mathrm{M} 2$. Rather, Ransohoff recommends researchers view the activation states and profiles of microglia from a multidimensional perspective, with complex profiles of reactivity which remain to be elucidated by future research (Ransohoff, 2016). Still, changes in microglial phenotype are consistently reported in response to neuronal injury and stressors in the extracellular environment (Figarella et al., 2018; Laskaris et al., 2016), and coupled with evidence of inflammatory signaling, provide a strong contextual indication of the reactivity of microglia in pathological conditions (Norden, Trojanowski, Villanueva, Navarro, \& Godbout, 2016; Paasila, Davies, Kril, Goldsbury, \& Sutherland, 2019).

Threats to homeostatic balance may be a result of pathogens, toxins, or injury; microglia respond to stress by signalling the release of growth factors, which initiate immune-related proteins to clear debris and apoptotic cells (Kaminska et al., 2016). Once the initial stress is resolved, homeostasis can be re-established - but under conditions of prolonged stress, overproduction of neurotoxic factors occurs (Surmeier et al., 2011; Taylor et al., 2013). The substantia nigra possesses a higher density of 
microglia than other brain regions, making the deleterious effects of prolonged microglial activation even more pronounced in this region (Lawson, Perry, Dri, \& Gordon, 1990). The first evidence of neuroinflammation in PD patients came from McGeer et al. (McGeer, Itagaki, Boyes, \& McGeer, 1988), who demonstrated increased numbers of activated microglia in the SNc of patients; more recently, others have confirmed this finding (Doorn, Moors, Drukarch, Berg, \& Lucassen, 2014; Gerhard et al., 2006; Ghadery et al., 2017; Koshimori et al., 2015).

Additional support for the involvement of neuroinflammatory processes in PD pathology came from the post-mortem study of the brains of three young drug addicts who were exposed to MPTP and subsequently developed a parkinsonian syndrome (Langston, Ballard, Tetrud, \& Irwin, 1983). Despite survival times ranging from 3-16 years following MPTP intoxication, researchers found evidence of gliosis and accumulation of glial cells proximal to neurons in the SNc of all three patients (Langston et al., 1999). This is an important finding, as it indicates the presence of an active pathological process of cell loss after an acute neurotoxic insult; these findings suggest that a single event can set into motion a chronic neurodegenerative process, and further implicate microglia in the perpetuation of the pathological cell loss (Langston et al., 1999).

Evidence for ongoing activation of microglia in the brains of patients with PD has been confirmed using positron emission tomography (PET) imaging in numerous studies (Banati et al., 1998; Gerhard et al., 2006; Hunot et al., 1999; Ouchi et al., 2005). 
Radioligands such as ${ }^{11}$ C-PK11195 bind to translocator proteins on the outer mitochondrial membrane, which demonstrate relatively low expression in healthy brains but are enhanced in states of neuroinflammation. As a result, binding of ${ }^{11} \mathrm{C}-\mathrm{PK} 11195$ is a widely accepted indication of activated microglia and has been used as a marker of neuroinflammation in PD (Banati, Myers, \& Kreutzberg, 1997; Edison et al., 2013; lannaccone et al., 2013; Papadopoulos, Lecanu, Brown, Han, \& Yao, 2006; Papadopoulos et al., 2006). One group of researchers monitored inflammatory processes in PD patients using PET imaging, and found increased activation of microglia in the basal ganglia, the cortex and the brainstem that was not observed in healthy controls (Gerhard et al., 2006).

Another study used ${ }^{11}$ C-PK11195 binding as an indication of microglial activation in 10 patients with PD who were early-stage and drug-naïve, and found significantly increased binding in the midbrain of patients contralateral to the clinically affected side (Ouchi et al., 2005). The ${ }^{11}$ C-PK11195 binding levels in the midbrains of patients with PD also correlated positively with motor severity as measured by the Unified Parkinson's Disease Rating Scale. The authors demonstrated activation of microglia that paralleled a decrease in dopaminergic terminal loss in the striatum in patients with PD, further implicating microglia as a central mediator in the neuroinflammatory processes underlying PD (Ouchi et al., 2005). Other studies have found increased binding of ${ }^{11} \mathrm{C}$ PK11195 in the striatum (lannaccone et al., 2013) and in multiple cortical regions of patients with PD (Edison et al., 2013). 
Soon after the development of the MPTP model of PD, an astrocytic response to the neurotoxin was reported (Schneider \& Denaro, 1988). Microglial activation has also been well-documented in this model (Huang et al., 2018; Liberatore et al., 1999; Liu et al., 2010; Luchtman, Shao, \& Song, 2009; Sugama et al., 2003). In one study, chronic administration of MPTP led to increased levels of the pro-inflammatory cytokines interleukin 1- $\beta$ (IL-1 $\beta$ ) and tumor necrosis factor- $\alpha$ (TNF- $\alpha$ ) in the striatum of C57/BI6 mice (Liu et al., 2010). In a recently published study, researchers investigated the longterm changes that occur following either an acute $(18 \mathrm{mg} / \mathrm{kg}$ every 2 hours for 4 doses) or sub-chronic (20mg/kg once daily for 5 days) regimen of MPTP administration (Huang et al., 2018). Consistent with previous studies, the authors observed a transient activation of microglial cells following acute MPTP administration (Kohutnicka, Lewandowska, Kurkowska-Jastrzebska, Członkowski, \& Członkowska, 1998; Liu et al., 2015). While initially upregulated one day and one week following MPTP administration, microglia re-establish a resting state approximately two weeks post-regimen (Huang et al., 2018; Kohutnicka et al., 1998; Liu et al., 2015). Notably, the authors reported a biphasic activation of microglia in this study, where re-activation of microglia was observed in the SNc at days 74 and 90 in the acute condition, and at day 124 in the subchronic condition (Huang et al., 2018). The authors confirmed this effect was not a result of normal aging, as they did not observe a similar activation in 8-month old mice in the saline condition. In this study, astrocyte activation was also evident and long- 
lasting in the SNc following MPTP administration, peaking at 42 days and then subsequently declining (Huang et al., 2018).

Interestingly, microglial and astrocytic activation have been found to follow independent patterns of activation, a finding supported by multiple studies (Cardenas \& Bolin, 2003; Huang et al., 2018; Martin et al., 2016). Microglial and astrocytic reactivity have also been demonstrated in multiple environmental toxin-based mouse models of PD (Gao, Hong, Zhang, \& Liu, 2002; Gao, Jiang, et al., 2002; Liu et al., 2002; Mangano et al., 2011; Mitra, Chakrabarti, \& Bhattacharyya, 2011; Purisai et al., 2007; Sherer, Betarbet, Kim, \& Greenamyre, 2003). Indeed, it has been well established that microglia and astrocytes play distinct yet notable roles in both neuronal health and pathology, resulting from their active participation in the central inflammatory response (Liddelow \& Barres, 2017; Liddelow et al., 2017; Pekny \& Pekna, 2016; Pekny, Wilhelmsson, Tatlisumak, \& Pekna, 2018; Rappold \& Tieu, 2010; Ren et al., 2017; Sofroniew, 2005).

Neuroinflammation has consistently been reported in 6-OHDA models of PD (Banati et al., 1997; Cicchetti et al., 2002; Ouchi et al., 2005; Ren et al., 2017). In one study, neuroinflammation was monitored in rats using PET imaging (Cicchetti et al., 2002). The authors observed a progressive loss of DA neurons following toxin administration and a parallel increase in microglial activation in both the striatum and SNc. PET imaging results were consistent with immunohistochemical indications that microglia were activated in both regions 3 weeks post-lesion, implying the presence of a chronic inflammatory process in response to acute 6-OHDA administration (Cicchetti et 
al., 2002). A large body of evidence supporting a prominent role of inflammation in PD pathology has led researchers to investigate the possibility of employing therapeutics that possess anti-inflammatory properties in models of the disease. One such study found that intra-striatal infusion of 6-OHDA led to increased levels of two proinflammatory factors, cyclooxygenase-2 (COX-2) and TNF- $\alpha$ (Jin, Wu, Lu, Gong, \& Shi, 2008). The authors confirmed that Resveratrol, a compound with known antiinflammatory properties, significantly reduced the levels of COX-2 and TNF- $\alpha$ in their model. Another study found that Piperidine, a compound found in black pepper and used in many medications, successfully inhibited apoptosis and induced a significant decrease in the pro-inflammatory cytokines TNF- $\alpha$ and IL-1 $\beta$ in a 6-OHDA rat model of PD (Shrivastava et al., 2013). Taken together, these results suggest that substances with anti-inflammatory properties such as Piperidine and Resveratrol may possess the ability to mediate cell death by inhibiting the release of pro-inflammatory cytokines, possibly via modulation of microglial activation.

Given the complex profile of microglia, the presence of reactive microglia alone is not enough to confirm either their harmful of helpful role in disease pathology; the immunoreactivity of microglia may be beneficial for patients. Indeed, increased levels of pro- and anti-inflammatory cytokines have been observed in the cerebrospinal fluid of patients in post-mortem evaluations (reviewed in Joers, Tansey, Mulas, \& Carta, 2017). Inflammatory responses that occur in response to microglial activation may potentiate or exacerbate neuronal cell damage through several mechanisms, one of which involves 
the production of ROS (Colton, Chernyshev, Gilbert, \& Vitek, 2000; Colton \& Gilbert, 1987; Imamura et al., 2003; Langston et al., 1999; Liu et al., 2002).

\section{Oxidative Stress}

ROS are produced naturally during cellular metabolism in eukaryotic cells, primarily by the cell's mitochondria, and are typically neutralized by endogenous antioxidants (Halliwell, 1997; Jackson, Pye, \& Palomero, 2007). Although ROS occur naturally and are involved in the maintenance of healthy cells, an excess of them is problematic - ROS are unstable molecules that have the capacity to cause damage to cell components, and ultimately lead to neuronal death (Cohen \& Heikkila, 1974; V. Kumar, Jindal, \& Ganguly, 1995). Oxidative stress is caused by an overproduction of ROS, and this state of cellular stress activates the innate immune response, which may compound the already-present and harmful oxidative stress in the brains of patients with PD (Blesa, Trigo-Damas, Quiroga-Varela, \& Jackson-Lewis, 2015).

Cells require oxygen to function optimally, but oxygen is also toxic to cells, requiring the action of antioxidants to mitigate its harmful effects. The majority of oxygen is used by the mitochondria to produce energy efficiently via oxidative phosphorylation; however, a small percentage $(<5 \%)$ of that oxygen goes on to produce ROS (Halliwell, 1997). Although ROS such as the superoxide anion $\left(\mathrm{O}_{2}^{-}\right)$and hydrogen peroxide $\left(\mathrm{H}_{2} \mathrm{O}_{2}\right)$ are not overly chemically reactive on their own, they produce the highly reactive hydroxyl radical $\left(\mathrm{OH}^{*}\right)$ upon contact with transition metals - especially copper 
and iron, which are found in high abundance in the brain. The brain consumes a large proportion of the body's oxygen, and has relatively few antioxidant molecules, which increases its vulnerability to oxidative stress (Floyd, 1999). The reactive hydroxyl radical $\left(\mathrm{OH}^{\circ}\right)$, when present, can cause damage to almost every part of the eukaryotic cell (Battino, Bullon, Wilson, \& Newman, 1999; Halliwell, 1997; Liochev \& Fridovich, 1994).

Some ROS are the by-products of natural metabolic processes, such as the metabolism of mitochondrial oxygen or oxygen-containing neurotransmitters, like DA. The substantia nigra is especially vulnerable to the harmful actions of ROS, as it contains large numbers of mitochondria (Lawson et al., 1990), an abundance of DA-producing cells, and increased concentrations of iron when compared to other regions of the brain (Drayer et al., 1986; Snyder \& Connor, 2009; Zecca et al., 1996; Zucca et al., 2017). Indeed, increased levels of iron have been detected in the SNc of patients with PD (Sofic, Paulus, Jellinger, Riederer, \& Youdim, 1991), and an iron-dependent mode of programmed cellular death termed 'ferroptosis' has been proposed to characterize DA cell loss in PD (Do Van et al., 2016; Guiney, Adlard, Bush, Finkelstein, \& Ayton, 2017). In its free state, iron can participate in the auto-oxidation of DA, yielding $\mathrm{H}_{2} \mathrm{O}_{2}$ and other oxygen-containing free radicals. To compound this, cells in the SNc of patients with PD demonstrate significantly decreased levels of glutathione (GSH) and glutathione peroxidase (GPx), both of which are important players in the antioxidant and detoxification activity of cells (Damier, Hirsch, Zhang, Agid, \& Javoy-Agid, 1993). 
ROS can stimulate pro-inflammatory responses, which are directed by microglia and perpetuate the harmful environment for vulnerable neuronal populations (Block \& Hong, 2005; Park et al., 2015). Compared to cortical or hippocampal neurons, midbrain DA neurons were found to be more vulnerable to pro-inflammatory cytokines such as TNF- $\alpha$ (McGuire et al., 2001); this increased sensitivity has been linked to oxidative stress (Ribeiro et al., 2013; Yoon et al., 2007). Gao and colleagues sought to investigate mitochondrial-mediated neurotoxicity in rat mesencephalic cultures exposed to low concentrations of lipopolysaccharide (large molecules which initiate an acute inflammatory response) and demonstrated that microglial activation and release of neurotoxic factors preceded cellular death in DA neurons (Gao et al., 2002). The authors reported increased levels of superoxide that appeared to be a prominent effector of cell death, supporting the vulnerability of DA neurons to oxidative insult (Gao et al., 2002). Broadly, an increase in ROS accompanied by suppressed antioxidant activity of cells can lead to cellular damage through lipid peroxidation, damage to proteins and genetic material, and membrane instability.

Animal models of PD have consistently implicated the role of oxidative stress in disease pathology. MPTP is thought to initiate its neurotoxicity via its reactive metabolite, $\mathrm{MPP}^{+}$, through increased ROS production and inhibition of mitochondrial complex I, decreasing the production of adenosine triphosphate (ATP) and increasing production of ROS (Adams, Klaidman, \& Leung, 1993; Gainetdinov et al., 1998; Guillot \& Miller, 2009; Guillot et al., 2008). Multiple studies using MPTP have reported increased 
levels of lipid peroxidation (Jenner, 1998; Youdim, Ben-Shachar, \& Riederer, 1993) as well as increased ROS production following toxin administration (Riederer et al., 1989; Youdim et al., 1993). In vivo studies using both mice and monkeys that have been treated with MPTP show increased levels of iron in the SNc (Mochizuki et al., 1994; Temlett, Landsberg, Watt, \& Orime, 1994), which potentiates ROS formation and exacerbates conditions of oxidative stress.

The link between oxidative stress and 6-OHDA has been long established and it is well accepted that 6-OHDA induces neurodegeneration at least in part through the production of ROS (Sachs \& Jonsson, 1975). Evidence of oxidative stress in the application of the neurotoxin 6-OHDA is abundant, as the compound itself is readily auto-oxidized to form ROS (Blum et al., 2001; Cohen \& Heikkila, 1974; Kumar, Agarwal, \& Seth, 1995; Perumal et al., 1989). Studies have shown that 6-OHDA reduces levels of GSH, GPx and other antioxidant molecules (Pearce, Owen, Daniel, Jenner, \& Marsden, 1997; Perumal et al., 1989). Rats that received an intra-striatal infusion of 6-OHDA exhibited significantly increased levels of thiobarbituric reactive species, a marker used for the estimation of lipid peroxidation - an indication of oxidative stress (Shrivastava et al., 2013). Rats also demonstrated decreased antioxidant capacities, as striatal levels of GSH were reduced by more than $30 \%$ when compared to sham animals (Shrivastava et al., 2013). More recently, researchers demonstrated increased production of ROS and decreased levels of GSH in a 6-OHDA mouse model of PD (Jing et al., 2016). These effects were reversed when animals were treated with Tanshinone-I three days prior to 
lesioning, a compound known to have anti-inflammatory and antioxidant effects (Jing et al., 2016; Lee et al., 2013). This finding has also been supported in a study investigating the effects of Tanshinone-I in murine microglial cells and MPTP-treated mice, which found that Tanshinone-I reduced dopaminergic cell death and the expression of the proinflammatory cytokine TNF- $\alpha$ both in vivo and in vitro (Wang et al., 2015). It is evident mechanisms involving apoptosis, neuroinflammation and oxidative stress are intimately linked, and more research is needed to disentangle the roles of each of these factors in the pathology of PD.

\section{Neurotrophic Factors}

Overview of Neurotrophic Factors

Protective therapy for PD is based upon identifying a mechanism by which cell death occurs and introducing an intervention which can slow or stop its progression. Removal of a specific cause would be the preferred form of treatment; however, the etiology of PD remains unknown at present and likely involves multiple stressors to the neuronal microenvironment. Consequently, treatment of PD with the objective of interfering with known pathogenetic mechanisms appears to provide the greatest chance of altering the progression of the disease (Taylor et al., 2013; Zigmond \& Smeyne, 2014). Neurotrophic factors (NTFs) are secreted proteins that play critical roles in the survival and maturation of immature neurons (Bonni, 1999; Finkbeiner, 2000;

Ghosh, Carnahan, \& Greenberg, 2018; Hyman et al., 1991; Riccio, Ahn, Davenport, 
Blendy, \& Ginty, 1999); however, NTFs also play a prominent role in the health of mature neuronal populations in the adult brain (Ji, Pang, Feng, \& Lu, 2005; Lindsay \& Harmar, 1989; Yang et al., 2009).

The first NTF discovered was nerve growth factor (NGF), a trophic factor that is critical for neuronal development and differentiation but also plays a notable role in the repair of injured tissue in mature cells, including those in the central nervous system (Levi-montalcini \& Levi-montalcini, 2016). Today, the list of identified NTFs is lengthy, and many have been examined in the context of neurological disease for their potential therapeutic properties (Bartus et al., 2013; Reddy et al., 2009; Hyman et al., 1991; Nakamura et al., 2017; Nencini, Ringuet, Kim, Greenhill, \& Ivanusic, 2018; Osborn et al., 2010; Trevaskis et al., 2017; Wang et al., 2016).

Most NTFs can be classified as members of one of four families: the neurotrophins, including NGF and brain-derived neurotrophic factor (BDNF); the glial cell-line derived NTF family ligands (GFLs), including glial cell-line derived neurotrophic factor (GDNF) and neurturin (NRTN); the neuropoietic cytokines, also known as the interleukin-6 (IL-6) family, including ciliary neurotrophic factor (CNTF), and the newer family of cerebral dopamine neurotrophic factor (CDNF) and mesencephalic astrocytederived neurotrophic factor (MANF), CDNF-MANF (Deister \& Schmidt, 2006; Lindholm \& Saarma, 2010; Voutilainen et al., 2009). Though they function in different ways, all NTFs are potent mediators of neuronal stability, plasticity and survival through a cascade of overlapping but distinct cellular signalling events. 
Neurotrophic Factors in Parkinson's Disease

Several NTFs have been examined for their potential to provide protection to dopaminergic neurons in models of PD (Aron \& Klein, 2011). GDNF has been the most studied NTF as a therapy for PD and has shown both protective and reparative effects in the nigrostriatal dopamine system. Studies demonstrating its protective and restorative effects have included in vitro protection of mesencephalic DA neurons (Eggert et al., 1999; Lin, Doherty, Lile, Bektesh, \& Collins, 1993), in vivo protection from axotomyinduced degeneration in rats (Beck et al., 1995), MPTP-toxicity in mice (Tomac et al., 1995) and monkeys (Gash et al., 1996; Grondin et al., 2002), and 6-OHDA toxicity in mice (Bensadoun et al., 2000; Fu et al., 2010) and rats (Choi-Lundberg, 1997; Kearns \& Gash, 1995; Laganiere et al., 2010; Natsume et al., 2001). Interestingly, GDNF had no neuroprotective effect in an $\alpha$-synuclein model of PD, as $\alpha$-synuclein disrupts GDNF signalling through downregulation of its signalling receptor, RET (Decressac et al., 2011; Lo Bianco, Déglon, Pralong, \& Aebischer, 2004; Takahashi, 2001). Despite the consistent benefits observed in some animal models of PD, challenges in method of delivery and ensuring proper localization of GDNF has led to inconsistent results in clinical trials (Gill et al., 2003; Lang et al., 2006; Nutt et al., 2003; Patel et al., 2005; Slevin et al., 2005). Despite these hurdles, many positive outcomes have been reported, and investigators are continuing to investigate GDNF for its protective properties and therapeutic potential in PD (Hadaczek et al., 2015; Mahato et al., 2019; Nam et al., 2015; Penttinen et al., 2018). 
The CDNF-MANF group is the newest family of NTFs which have been increasingly studied over the last 15 years. In 2003, MANF was purified and demonstrated to be a selective protector of DA neurons in culture (Petrova et al., 2003). In addition to its neurotrophic effects, there is evidence that MANF enhances GABA release in the reticulata of the substantia nigra, which may influence SNc signaling and has been posited as one potential mechanism by which MANF exerts its protective effects (Zhou, Xiao, Commissiong, Krnjević, \& Ye, 2006). CDNF, a homologue of MANF, was described later and first used in a 6-OHDA rat model of PD (Lindholm et al., 2007). In this study, rats were pre-treated with intra-striatal CDNF 6 hours before receiving 8 ug of 6-OHDA to the same location. CDNF significantly reduced amphetamine-induced ipsilateral turning behaviour and protected nigral neurons from degeneration in a dosedependent manner (Lindholm et al., 2007). To assess the neurorestorative potential of CDNF, the authors looked at the effects of CDNF when given 4 weeks after intrastriatal 6-OHDA administration (i.e. during the progressive degeneration of DA neurons). The authors reported both protection and restoration of function in DA neurons of the SNc, and a single infusion of CDNF yielded long-term motor improvements in experimental animals (Lindholm et al., 2007).

Similarly, MANF protected DA neurons from 6-OHDA-induced degeneration and resulted in improved motor outcomes in a methodologically similar rat model of PD, both when MANF was administered 6 hours prior to 6-OHDA infusion and 4 weeks after (Voutilainen et al., 2009). Later, the authors investigated the effects of chronic CDNF 
and MANF infusions (3ug/24h for 3 or 14 days) using osmotic pumps. First, a lesion was established using 6-OHDA, and two weeks later, osmotic pumps were implanted in the striatum (Voutilainen et al., 2011). Interestingly, CDNF - but not MANF - significantly reduced amphetamine-induced rotations after two weeks of daily NTF administration. The beneficial effect of CDNF was slow to begin, and demonstrated maximal effect at the end of the experimental timeline (Voutilainen et al., 2011). CDNF also inhibited 6OHDA induced toxicity of nigral neurons and protected nerve terminals in the striatum, while MANF did not.

In a recently published article, CDNF was tested in combination with deep-brain stimulation (DBS) in an advanced stage 6-OHDA rat model of PD (Huotarinen et al., 2018). DBS of the subthalamic nucleus has been shown to improve motor symptomatology in late stage PD (Castrioto, 2011; Krack et al., 2003). In this study, the combination of DBS and CDNF did not appear to improve outcomes. When given alone and after a complete lesion of the nigrostriatal pathway in the late stage model, CDNF had no effect on neuronal survival (Huotarinen et al., 2018). Previous studies supporting CDNF's trophic actions used partial lesion models of the disease, and this evidence supports that CDNF's trophic effects may only be observed when some preservation of neuronal function exists in the SNc (Domanskyi, Saarma, \& Airavaara, 2015; Huotarinen et al., 2018; Voutilainen et al., 2011).

The neurorestorative effects of CDNF were investigated in marmoset monkeys using a mild 6-OHDA lesion, and a beneficial effect was reported on dopamine 
transporter (DAT) activity (Garea-Rodríguez et al., 2016). The authors further investigated the tolerability of CDNF in a chronic administration paradigm, and reported histopathological findings in some marmosets after $15 \mathrm{ug} /$ day was delivered via osmotic pump for 28 days (Garea-Rodríguez et al., 2016). In the neurorestorative approach, the benefits observed were modest compared to those reported in rodent models using CDNF (Lindholm et al., 2007; Voutilainen et al., 2011; Voutilainen et al., 2009), and the signalling pathways for CDNF have yet to be established. Indeed, there is much research left to be done with this new family of NTFs to evaluate their therapeutic potential in PD. Still, the current evidence is encouraging, as a wide range of NTFs have been shown to alter the microenvironment of the midbrain in models of PD to restore homeostasis.

In addition to the NTFs described above, it has long been known that the neuralimmune interactions exert a notable influence over a wide range of neuronal activities. One group of factors derived from immune cells are the hematopoietic cytokines, and their neurotrophic effects have been well established in various models of neurological disease (Bartels, Späte, Krampe, \& Ehrenreich, 2008; Carelli, Marfia, Di Giulio, Ghilardi, \& Gorio, 2011; Farmer, Rudyk, Prowse, \& Hayley, 2015; Mangano et al., 2011; Tabira, Konishi, \& Gallyas, 1995). Granulocyte macrophage stimulating colony factor (GM-CSF) is a pro-inflammatory hematopoietic cytokine with neurotrophic actions (Schäbitz et al., 2008), promoting neurite outgrowth in neuronal cultures and exerting anti-apoptotic effects (Kannan et al., 2000), and stimulating astrocytic proliferation in cultures derived from simian brains (Guillemin et al., 1996). Indeed, the trophic properties of GM-CSF 
have yielded benefits in rodent models of spinal cord (SC) injury (Hayashi, Ohta, Kawakami, \& Toda, 2009; Huang et al., 2009), depression (Osborn et al., 2010) and PD (Choudhury et al., 2011; Farmer et al., 2015; Mangano et al., 2011). Another closely related hematopoietic cytokine that has been investigated for its neurotrophic potential is erythropoietin (EPO), a substance well-known for its peripheral actions and more recently for its protective effects in the central nervous system.

\section{Erythropoietin}

EPO is a hematopoietic cytokine that has gained attention over the years for its neuroprotective role in models of ischemia (Brines et al., 2000; Siren et al., 2001; Wang et al., 2007) and SC injury (Campana \& Myers, 2003; Kaptanoglu et al., 2004). EPO is a glycoprotein hormone belonging to the type I cytokine superfamily (Lin et al., 1985); the trophic cytokine contains 165 amino acids and weighs roughly 34kDa (exact weight depends on degree of glycosylation of the protein). EPO is best known for its actions in the peripheral nervous system, primarily due to its central role in red blood cell production. Due to its hematopoietic activity, EPO has long been approved for and used safely as a treatment for anemia (Kalantar-Zadeh, 2017). EPO and its receptors are also found in several cortical and sub-cortical brain regions, including the midbrain, and it is known that both neurons and astrocytes are cellular sources of EPO and express its receptor (EPOR) on their surface (Digicaylioglu et al., 1995; Masuda et al., 1994). Further, EPO can cross the blood-brain barrier (Banks, Jumbe, Farrell, Niehoff, \& 
Heatherington, 2004; Brines et al., 2000; Ehrenreich et al., 2004; Ehrenreich, Bartels, Sargin, Stawicki, \& Krampe, 2008; Osborn et al., 2013), although it does not penetrate in large quantities due to its size (Buemi et al., 2000).

EPO's neurotrophic effects were first reported 25 years ago in a study demonstrating both in vitro and in vivo trophic actions of EPO on cholinergic neurons (Konishi, Chui, Hirose, Kunishita, \& Tabira, 1993). Increasing interest in this cytokine has led researchers to investigate its potential to influence the pathology observed in various neurodegenerative diseases (Jia, Mo, Feng, Zhan, OuYang, et al., 2014; Rabie \& Marti, 2008; Signore et al., 2006; Thirthalli et al., 2016; Xue et al., 2010).

\section{EPO in animal models of disease}

Endogenous levels of EPO are upregulated in conditions of hypoxia (Digicaylioglu et al., 1995; Masuda et al., 1994), and as such, investigation into its potential therapeutic application in stroke was a logical pursuit. EPO was first reported to be beneficial in a rodent model of global ischemia, wherein EPO rescued hippocampal CA1 neurons and ameliorated learning ability in gerbils (Sakanaka et al., 1998). At the two highest doses employed in this study, however, EPO was ineffective at protecting CA1 neurons, suggesting there may be a limited concentration in which EPO's neuroprotective effects can be observed, a finding that has been reported in other studies, both in vitro and in vivo (Sakanaka et al., 1998; Shang, Chong, Wang, \& Maiese, 2011; Wu et al., 2007). Indeed, at excessively high levels EPO would be expected to potentially exacerbate 
inflammatory and/or oxidative processes by virtue of its widespread actions on a variety of cell types. In a model of focal cerebral ischemia, intracerebroventricular administration of EPO 24 hours before middle cerebral artery occlusion (MCAO) reduced the infarct volume by $47 \%$ (Bernaudin et al., 1999). Temporally, EPO was first upregulated at 12 hours following occlusion, primarily in neurons and endothelial cells, followed by an increase in both astrocytes and neurons hours later. EPO's upregulation was particularly notable in the penumbral region, which might be reflective of the astrocytic contribution to the inflammatory response in the days and weeks following ischemic insult (Bernaudin et al., 1999). Brines and colleagues reported that systemically-administered EPO was protective in a rat model of focal ischemic stroke, significantly reducing the infarct volume when a single injection of EPO was given between 24 hours before and 6 hours following MCAO (Brines et al., 2000).

Due to EPO's hematopoietic activity, systemic administration in concentrations necessary to observe its protective effects increases hematocrit levels (Brines et al., 2000). This is problematic in the context of injury, as increased levels of erythropoiesis increase the risk of a thrombotic event or can lead to adverse consequences related to the overstimulation of the peripheral EPOR. EPO's hematopoietic effects are mediated by the homodimeric EPO receptor (EPOR/EPOR), while EPO's tissue-protective effects can be observed independently of hematopoietic receptor binding (Campana, Misasi, \& O’Brien, 1998; Masuda et al., 1993). Based on this knowledge, Leist et al. (2004) hypothesized that modifications to EPO that abolish its hematopoietic effects would not necessarily 
influence its potent neuroprotective effects (Leist et al., 2004). Indeed, the authors demonstrated that the carbamylation of lysine residues in EPO, a known method of silencing erythropoiesis by altering protein conformation and function, yielded a neuroprotective effect without influencing hematopoiesis. A study by Wang and colleagues confirmed that systemic administration of carbamylated EPO (CEPO) 6 hours following MCAO reduced the infarct volume by $28 \%$ and improved functional outcomes 28 days following occlusion, but no changes in peripheral hematocrit were observed (Wang et al., 2007). Since then, many researchers have followed suit in the development of fusion proteins that link EPO to a molecular Trojan horse, allowing EPO to go undetected in the periphery to avoid hematopoiesis and cross the BBB more effectively (Shi et al., 2013; Thomas Tayra et al., 2013; Wu et al., 2007; Xue et al., 2010; Zhou, Hui, Lu, Boado, \& Pardridge, 2011).

It is now thought that EPO's tissue-protective effects may be mediated through a separate heterodimeric receptor, consisting of one EPO subunit and one beta-common receptor ( $\beta C R$ ) subunit (Brines et al., 2004; Brines \& Cerami, 2012). Still, no study to date has demonstrated the interaction of EPO with this EPOR: $\beta C R$ heterodimer, though a recently published article featuring a series of in silico experiments demonstrated the physical possibility of such an interaction based on protein and receptor conformations (Ostrowski \& Heinrich, 2018). These authors suggest there may be additional substrates for EPO that have yet to be identified, as the proposed tissue protective receptor is not found in all cells that appear to benefit from EPO stimulation (Ostrowski \& Heinrich, 
2018). Although the molecular mechanisms by which EPO exerts its tissue-protective effects remain under investigation, researchers have recently begun to evaluate EPO's therapeutic potential in combination therapies for ischemia, as EPO's neuroprotective properties are well-established (Yamanaka, Eldeiry, Aftab, Ryan, et al., 2018; Yuen et al., 2017).

Soon after its trophic effects in stroke were reported, researchers began observing protective effects of EPO in models of SC injury. In a model of SC ischemia in rabbits, systemically administered EPO resulted in markedly reduced cellular damage and improved neurological scores when injected at the time of reperfusion (Celik et al., 2002). One study assessed EPO's effects in two different models of SC injury in rats; the first model mimicked brief crush injury while the other modeled traumatic contusion (Gorio et al., 2002). In the model of crush injury, untreated animals were initially paraplegic, and showed minimal improvement over the 4-week experimental period. Animals that received a single injection of EPO one hour after crush injury demonstrated significantly better recovery within 12 hours of the injury, and improvements in this group were maintained at the end of the 4-week experiment. In the model of traumatic contusion, similar results were obtained, although animals did not begin to recover until the fourth day following injury in this model, reflective of the more severe injury induced (Gorio et al., 2002). Since then, several other studies have confirmed the benefits of EPO following SC injury in rats (Michael Brines \& Cerami, 2002; Carelli et al., 2011; Vitellaro-Zuccarello et al., 2007), and one preliminary randomized comparative trial between EPO and 
methylprednisolone for SC injury reported significant improvement in 3/11 patients following EPO administration, while $0 / 8$ patients receiving methylprednisolone demonstrated similar improvement (Costa et al., 2015). This finding demonstrates that EPO's efficacy is in line with the response rates observed with a variety of drugs, including anti-depressants (Khan \& Brown, 2015), and clearly underscores the possibility that subgroups of "responders and non-responders" occur in patients treated with EPO. As in stroke research, SC injury researchers have begun to explore the idea of combining EPO'S protective effects with those of other potential treatments, as its beneficial effects appear consistent in models of SC injury (Bader, Reinhardt, Beuthe, Röhl, \& Giri, 2017).

In experimental rodent models of PD, as in stroke and SC injury, research suggests EPO may exert neuroprotective effects by modulating the inflammatory response to decrease oxidative stress (Signore et al., 2006; Xue, Zhao, Guo, \& Duan, 2007). Studies evaluating EPO in models of PD have used inconsistent models involving different strains of both rats and mice, varying neurotoxic insults (e.g. MPTP, paraquat, 6-OHDA), different types of EPO (e.g. recombinant human EPO, CEPO, asialo-EPO) and differing methods of EPO delivery (Boado et al., 2010; Farmer et al., 2015; Genc, Kuralay, Genc, \& Akhisaroglu, 2001; Jia, Mo, Feng, Zhan, OuYang, et al., 2014; Signore et al., 2006; Thomas Tayra et al., 2013; Xue et al., 2007; Xue et al., 2010; Zhou et al., 2011).

To date, only one study has investigated central EPO in the context of a 6-OHDA mouse model of PD, and much of the work in this study was in vitro on cultured 
dopaminergic cells and primary cortical neurons. The in vivo results suggested $10 \mathrm{IU}$ and $201 \mathrm{U}$ of recombinant human EPO protected striatal terminals from 6-OHDA lesion 7 days following 6-OHDA administration, while $201 \mathrm{U}$ (but not 10IU) of EPO protected nigral cells from death 21 days following toxin administration. This study further demonstrated attenuation of rotational behaviour by EPO, and the in vitro work implicated the PI3K/Akt signaling pathway by using PI3K and Akt inhibitors in dopaminergic cells and primary cortical neurons (Signore et al., 2006). While this study's findings were useful in the design of the current set of experiments, the in vivo work conducted was limited, and more research is needed to clarify EPO's role in mitigating pathology in vivo in the 6OHDA mouse model of PD. Although several studies indicate a potential protective role of EPO in PD, no study has fully profiled EPO's effects in the 6-OHDA mouse model of PD. Most importantly, the mechanisms by which EPO may exert these protective effects in vivo remain poorly understood, although Signore et al. (2006) demonstrated EPO's influence over the Akt signaling pathway and apoptosis in their in vitro work. Since the pathology in PD involves apoptosis, neuroinflammation and oxidative stress, EPO's ability to counteract these damaging processes in vivo may provide evidence to support its protective properties in models of PD, and a finding of Akt pathway involvement in vivo would correlate with the in vitro work of Signore et al. (2006), supporting an antiapoptotic role of EPO in this model of PD. 
EPO: Possible Mechanisms of Action

\section{$\underline{\text { Anti-Apoptotic }}$}

EPO's ability to activate anti-apoptotic signalling mechanisms in vitro and in vivo has been thoroughly investigated, as apoptotic cell death is a well-established pathological feature of many neurological diseases. Activation of the EPOR/ $\beta C R$ heterodimer has been shown to activate numerous signalling pathways, including Janus kinase-2 (JAK-2) phosphorylation (Digicaylioglu, Garden, Timberlake, Fletcher, \& Lipton, 2004; Kawakami, Sekiguchi, Sato, Kozaki, \& Takahashi, 2001). Following the activation of JAK-2 by phosphorylation, several other pathways are induced downstream, including the signalling transducer and activation of transcription (STAT) pathway (Foley et al., 2015; Fu et al., 2010; Ma et al., 2018; Yamanaka, Eldeiry, Aftab, Mares, et al., 2018), the phosphatidylinositol 3-kinase (PI3K) and serine/threonine-specific kinase (Akt) pathways (Fu et al., 2010; Jia, Mo, Feng, Zhan, Ouyang, et al., 2014; Ma et al., 2018), and mitogenactivated protein kinases (MAPK) pathways (Hooshmandi et al., 2018; Park et al., 2015; Yuen et al., 2017). All of these pathways are known to participate in anti-apoptotic processes, and each has been demonstrated to be activated by EPO in both in vitro and in vivo models of several diseases (Hooshmandi et al., 2018; Yamanaka, Eldeiry, Aftab, Ryan, et al., 2018; Yuen et al., 2017).

B cell lymphoma-2 (Bcl-2) is a mitochondrial membrane protein, encoded in humans by the BCL2 gene, that disrupts apoptotic processes when activated to promote 
cell survival (Boise et al., 1993; Hockenbery, Nuñez, Milliman, Schreiber, \& Korsmeyer, 1990). EPO exerts influence over $\mathrm{Bcl}-2$ and its related proteins in the $\mathrm{Bcl}-2$ family, including B cell lymphoma-extra large (Bcl-xL), which has been shown to regulate cellular processes to inhibit apoptotic cell death as potently as Bcl-2 (Boise et al., 1993; Silva et al., 1999). Bcl-xL is thought to prevent apoptosis by decreasing the release of AIFs from the mitochondria, including cytochrome C and caspases (Gross et al., 1999). Indeed, several laboratories have reported an increase in Bcl-xL following EPO treatment in both in vitro and in vivo models of neurological disease (Ma et al., 2014; Shen et al., 2010; Wen et al., 2002; Zou et al., 2016).

In a cell culture model of Alzheimer's disease, researchers sought to investigate EPO's protective mechanisms by treating serum-starved PC12 cells with EPO (Ma et al., 2014). Phosphorylation of JAK-2 was increased as early as 30 minutes after EPO exposure, while phosphorylation of STAT5 was upregulated 3 hours following EPO treatment, and both remained elevated at the 6-hour timepoint. After one hour of pretreatment with EPO, cells were exposed to aggregated amyloid- $\beta$ protein for 6 or 12 hours and a significant increase of $\mathrm{Bcl}-\mathrm{xL}$ was evident after incubation with amyloid- $\beta$ for 12 hours (Ma et al., 2014). Bcl-xL is a protein product of the $\mathrm{Bcl}$-2-like 1 gene, whose transcriptional activation depends on the translocation of STAT5 to the cell's nucleus, so it is reasonable that it would take longer to observe increases in levels of $\mathrm{Bcl}-\mathrm{xL}$ than it would to see phosphorylation of JAK-2 or STAT5. Further, the upregulation of Bcl-xL induced by EPO was blocked by pre-treatment of cells with a JAK2 inhibitor (AG490), 
further implicating the phosphorylation of JAK2 as a necessary step to induce $\mathrm{Bcl}-\mathrm{xL}$ production in the nucleus (Ma et al., 2014). In this study, levels of caspase 3 were elevated in cells that did not receive EPO, and were repressed in those that did, an effect that was blocked with JAK2 and STAT5 inhibitors, implicating these pathways in EPO's pro-survival signalling (Ma et al., 2014). Finally, reduced apoptosis in EPO-treated cells determined by the TUNEL method and examination of nuclear morphology were reported.

More recently, Chai et al. (2016) supported these results in an in vivo model of critical limb ischemia, reporting anti-apoptotic effects of EPO via increased expression of Bcl-2 mRNA and activation of the JAK/STAT pathway, effects which were abolished when animals were pre-treated with the JAK2 inhibitor AG490 (Chai, Yip, Sun, Hsu, \& Leu, 2016). A recently published study further supports the activation of the JAK/STAT pathway and upregulation of the anti-apoptotic $\mathrm{Bcl}-2$ gene in cells exposed to oxidative stress and treated with EPO (Castillo et al., 2018). Taken together, these findings support EPO's anti-apoptotic role and blocking these effects with a JAK2 inhibitor confirms the involvement of the JAK/STAT pathway, although these findings do not exclude the involvement of other pathways in the anti-apoptotic effects of EPO.

Other researchers have found convincing evidence that EPO also acts through the PI3K/Akt signalling pathway (Ding et al., 2017; Rong \& Xijun, 2015; Yu, Zhu, \& Jiang, 2017; Yu et al., 2018). Recently, Yu et al. (2018) conducted a study to evaluate the neuroprotective potential of EPO in a rat model of epilepsy and found that EPO-treated 
animals showed increased levels of phosphorylated Akt (pAkt) along with an upregulation of $\mathrm{Bcl}-2$ protein and mRNA in hippocampal neurons. Broadly, Akt is prosurvival kinase and a direct downstream target of PI3K, and increased levels of pAkt infer the involvement of the PI3K/Akt survival pathway. Further activation of the Bcl-2 proteins confers EPO's anti-apoptotic effects on neurons. In this study, EPO also induced a downregulation of Bad protein and mRNA (Yu et al., 2018), a pro-apoptotic protein in the Bcl-2 family that is inactivated when phosphorylated by Akt (Datta et al., 1997). Indeed, other researchers have confirmed EPO's influence over Bad and pBad (Shang, Chong, Wang, \& Maiese, 2012; Shen et al., 2010).

A study examining the effects of CEPO in mice exposed to hypoxic conditions for 6 hours found simultaneous rescue of hippocampal neurons and significant increases in pAkt 30 days after hypoxic insult (Ding et al., 2017). These authors confirmed the involvement of the PI3K/Akt pathway by using the PI3K inhibitor LY294002, which significantly reduced levels of pAkt (Ding et al., 2017). This finding was supported by earlier studies using a rat model of ischemia (Zhang et al., 2006), and a study looking at the in vitro and in vivo effects of EPO in a 6-OHDA rat model of PD (Jia, Mo, Feng, Zhan, Ouyang, et al., 2014). While little is known about EPO's mechanistic actions on dopaminergic neurons specifically, one in vitro study found activation of the PI3K/Akt signaling pathway by EPO which was blocked using two different pathway inhibitors (Signore et al., 2006). Further, this study found exposure of dopamine cells to 6-OHDA led to significant increases in active fragments of caspases 3 and 9, two important 
enzymes in pro-apoptotic activity. Pre-treatment of dopaminergic cells with EPO markedly attenuated this increase in caspase activity, suggesting EPO's ability to decrease apoptotic activity in vitro. Taken together, these findings support EPO's potential to activate anti-apoptotic signaling in dopaminergic neurons in vivo, which if true, would support an anti-apoptotic role of EPO in the nigrostriatal system and a possible mechanism of its protective activity. One possibility in this regard is that EPO may be exerting anti-apoptotic effects through the $\mathrm{Bcl}-2$ family proteins via multiple signalling pathways, but EPO's effects on neuroinflammation reveals a more complex role in the neuroprotective mechanisms of this trophic factor.

\section{Anti-Inflammatory}

Several players participate in the central inflammatory response through the release of pro-inflammatory cytokines and other signalling molecules, including activated macrophages, microglia, and reactive astrocytes. EPO has been consistently reported to attenuate neuroinflammatory processes in numerous animal models of peripheral and central disease, underlining the tissue-protective role of EPO as distinct from its hematopoietic activity (Bahçekapili et al., 2014; Hellewell, Yan, Alwis, Bye, \& Morganti-Kossmann, 2013; Liu et al., 2015; Luo et al., 2016; Mateus et al., 2017; Nakamura et al., 2015; Pang et al., 2016; Villa et al., 2003). Reductions in TNF- $\alpha$ and IL-6, along with reduced astrocyte activation and microglial recruitment have also been reported in a rat model of ischemia (Villa et al., 2003). 
One study examined the inflammatory response in a rat model of acute carbon monoxide (CO) poisoning (Pang et al., 2016), as the injury inflicted by CO poisoning simulates hypoxia and yields an inflammatory response similar to what is observed in many neurological diseases, including PD (Hirsch \& Hunot, 2009; Menza et al., 2011; Niranjan, 2014; Qian et al., 2010). The authors found that CO poisoning led to significant increases in toll-like receptor 4 (TLR4), nuclear factor-kappa $\beta$ (Nf-k $\beta$ ), and inflammatory cytokines in rat hippocampal neurons (Pang et al., 2016). The toll-like receptors are a family of transmembrane proteins that play a critical role in the immune response, and their activation leads to nuclear translocation of Nf-k $\beta$ (Kong \& Le, 2011). Indeed, TLR-4 has been implicated as an inflammatory mediator of cellular death both in vitro (Hughes et al., 2018) and in a mouse model of PD (Noelker et al., 2013). Once activated and localized to the nucleus, $\mathrm{Nf}-\mathrm{k} \beta$ modulates the transcription of inflammatory response molecules including TNF- $\alpha$, IL-1 $\beta$ and IL-6, and increased levels of all three factors were observed in the CO poisoning group (Pang et al., 2016). Treatment with EPO decreased the expression levels and mRNA for both TLR-4 and Nf-k $\beta$ in hippocampal neurons 48 hours following the hypoxic event, in addition to significantly downregulating the levels of the pro-inflammatory molecules TNF- $\alpha$, IL-1 $\beta$ and IL-6 (Pang et al., 2016). These results suggest EPO may confer neuroprotection by influencing inflammatory processes through the TLR-4/Nf-k $\beta$ signalling pathway and may reduce inflammatory-associated neuronal injury by decreasing microglial and astrocytic reactivity. Considering the evidence in support of EPO's anti-apoptotic effects through the JAK2 pathway, and the 
literature identifying changes in the $\mathrm{Nf}-\mathrm{k} \beta$ cascade, one possibility is these cellular signalling pathways interact with one another. Indeed, it has been suggested that EPO's protective effects may be mediated through cross-talk between the JAK2 and Nf-k $\beta$ signalling pathways, though likely involving different cell types in each (JAK2 in neurons and TLR4/Nf-k $\beta$ in immune cells) (Digicaylioglu \& Lipton, 2001).

EPO's ability to attenuate the inflammatory response caused by 6-OHDA was assessed in a neuroprotective rat model of PD, in which rats were administered EPO either systemically or centrally before receiving a unilateral infusion of 6-OHDA (Xue et al., 2007). Groups that received intra-striatal EPO received an infusion of intra-striatal 6-OHDA one day later, and those that received 8 days of systemic EPO injections received intra-striatal 6-OHDA on day 3 of EPO injections. While neuroprotection and behavioural recovery were not reported in any measures for animals that received systemic EPO, mice treated with intra-striatal EPO demonstrated protection of SNC neurons, increased numbers of immunoreactive tyrosine hydroxylase $(\mathrm{TH})$ fibers in the striatum (the rate-limiting enzyme in DA production) and decreased rotational behaviour at 3 and 10 weeks following 6-OHDA administration. At the two-week time point, the number of major histocompatibility complex (MHC) II immunoreactive cells resembling microglia were present in lower quantities in the EPO-treated animals (Xue et al., 2007). A delayed response of glial cells following neurotoxin administration has been reported more recently in a 6-OHDA mouse model of PD (Stott \& Barker, 2014). In the only mouse study to investigate EPO using 6-OHDA, the authors focused on the anti- 
apoptotic role of EPO and did not investigate potential microglial involvement or inflammatory processes (Signore et al., 2006). However, based on the available literature, the results suggest intra-striatal EPO is protective of DA neurons and can induce behavioural recovery (which was demonstrated in the mouse study utilizing EPO), and this protective effect is mediated at least in part through anti-inflammatory processes that take place over time following the neurotoxic insult.

In an environmental toxin model of PD, rotenone was administered into the SNc of rats, and EPO was subsequently delivered systemically for 28 days. In this model, EPO attenuated increases in TNF- $\alpha$ and induced neuronal and behavioural recovery in rats (Erbaş, Çiar, Solmaz, Çavuşoğlu, \& Ateş, 2015). Another study examined the effect of EPO-releasing neural precursor cells in MPTP-treated mice, and found that EPO decreased levels of IL-6 mRNA in the striatum compared to MPTP controls (Carelli et al., 2016). Broadly, EPO has been demonstrated to exert anti-inflammatory effects in a variety of models of disease, including multiple models of PD. Still, its effects on oxidative stress are equally relevant in $\mathrm{PD}$, as the $\mathrm{SNc}$ is exceptionally vulnerable to this type of homeostatic threat.

\section{Antioxidant}

Oxidative stress has long been implicated in the pathological processes observed in PD (Damier et al., 1993; Surmeier et al., 2011); in fact, a reduction in GSH is one of the earliest observed changes in the SNc of patients with PD (Pearce et al., 1997). In a study 
using PC12 cells exposed to $\mathrm{H}_{2} \mathrm{O}_{2}$ for 45 minutes, a non-hematopoietic variant of EPO was incubated with the cells either 15, 30 or 60 minutes after oxidative stress was induced. The authors reported increased viability of the cells at all 3 time points, suggesting that EPO is protective whether it is administered 15 minutes or 1 hour after induction of oxidative stress (Castillo et al., 2018). In developing rats exposed to hyperoxic conditions for 0-48 hours, decreased levels of GSH at 12-48 hours of oxygen exposure was attenuated by systemic pre-treatment with EPO (Sifringer et al., 2010). Hypoxia additionally induced increased levels of malondialdehyde (a marker of lipid breakdown) at 24-48 hours, and EPO treatment significantly reduced the levels of this marker. In a rat model of renal ischemia, animals displayed reduced levels of GPx and superoxide dismutase (SOD), both cellular markers of antioxidant activity (Ardalan et al., 2012). Animals treated with EPO 1 hour before transient ischemia and again 6 hours later demonstrated increased levels of both GPx and SOD when compared to the ischemic group. EPO's antioxidant effects have been demonstrated in various models of peripheral and central disease, indicating its potent tissue-protective effect against oxidative stress.

EPO's antioxidant effects have also been demonstrated in a murine model of PD, in which two injections of MPTP were given 16 hours apart at a dose of $40 \mathrm{mg} / \mathrm{kg}$, and $16 I U$ of EPO were infused bilaterally directly above the SNc either 24 hours before MPTP, or immediately after the final injection (Genc, Akhisaroglu, Kuralay, \& Genc, 2002). While MPTP-treated mice exhibited decreased levels of GPx in both the striatum 
and SNc, the authors reported an increased level of GPx in the SNc of animals pretreated with EPO 24 hours before MPTP. This suggests that pre-treatment with EPO may stimulate GPx activity, leading to cellular resistance against the toxicity induced by MPTP (Genc et al., 2002). Another study examined EPO's antioxidant effects in PC12 cells exposed to $\mathrm{MPP}^{+}$and found that EPO exhibited neuroprotective effects on $\mathrm{MPP}^{+}-$ induced toxicity and significantly decreased levels of ROS in the cells, implicating EPO's antioxidant ability in its protective mechanism (Wu et al., 2007).

In a rotenone model of PD, SNc infusions of toxicant were followed by 28 days of systemic EPO administration. In addition to reducing apomorphine-induced rotations and increasing the total neuron count in the SNc and TH-immunoreactivity in the striatum, EPO treatment significantly reduced levels of TNF- $\alpha$ and markers of lipid peroxidation in the brain (Erbaş et al., 2015). Jang and colleagues supported this finding in a cellular model of PD, demonstrating that EPO protected cells from rotenoneinduced death and markedly reduced levels of ROS in cell culture (Jang et al., 2016). Accumulating evidence from a variety of models of disease, including various in vitro and in vivo models of PD, strongly suggests EPO's trophic actions may be mediated via an antioxidant mechanism, although it is more likely that its effects involve a complex combination and interaction of its anti-apoptotic, anti-inflammatory and antioxidant activities. 


\section{SIGNIFICANCE AND OVERALL CONTRIBUTION}

The purpose of this project is to characterize how EPO modulates the neuronal environment by profiling its use in a toxicant mouse model of PD. Specifically, novel aspects of this research include examining the brain region-specificity of EPO, comparing EPO's effects in models employing both a partial and complete lesion, and examining EPO's pro-survival signalling in the absence of a toxic insult. EPO's beneficial effects have consistently been demonstrated in animal models of disease, and despite a large amount of promising preclinical and clinical work using EPO, researchers have reported inconsistent findings in terms of EPO's efficacy and overall benefit in human patients (Grmec, Strnad, Kupnik, Sinkovič, \& Gazmuri, 2009; Güresir et al., 2013; Nichol et al., 2015; Sargin, Friedrichs, El-Kordi, \& Ehrenreich, 2010). Indeed, an improved understanding of EPO's modulatory effects that confer tissue protection is necessary before it can be used effectively either alone or as an adjuvant therapy in the treatment of neurological disease. 


\section{HYPOTHESIS AND RESEARCH QUESTIONS}

Hypothesis: Given that PD involves cell death resulting from homeostatic dysregulation, I hypothesize that effective disease-modifying strategies for PD will require interventions that shift this balance toward stability. Specifically, apoptotic signalling, neuroinflammation and oxidative stress disrupt the neuronal environment, compromising the stability of dopaminergic neurons in the SNc. Given its known role in the modulation of these three factors, I hypothesize that EPO is a promising candidate to promote homeostasis, and improve biological and/or functional outcomes in a 6-OHDA mouse model of PD.

\section{Research Questions}

1. Does pre-treatment with EPO protect DA terminals 21 days following 6-OHDA administration, and if so, does this translate into behavioural improvement?

2. Are EPO's effects brain-region specific?

3. Are EPO's effects dependent on lesion size?

4. What are the primary mechanisms by which EPO acts?
a. Anti-apoptotic
b. Anti-inflammatory
c. Antioxidant 


\section{SUMMARY STATEMENT}

The pathogenic mechanisms underlying Parkinson's disease have eluded researchers for many decades. In recent years, however, an increased understanding of some of these mechanisms has allowed research in this area to proliferate. Indeed, EPO is a promising prospect in the pursuit to better understand the roles of neuroinflammatory processes and oxidative stress in PD. This neuroprotective cytokine may be capable of modulating the neuronal environment to repair damaged neurons, or strengthen the remaining neurons within the SNc in a 6-OHDA mouse model of PD. This research will surely deepen our understanding of certain pathologies involved in PD, and we are hopeful that it will ultimately present us with novel intervention methods for the many individuals living with Parkinson's disease. 


\section{References}

Adams, J. D., Klaidman, L. K., \& Leung, A. C. (1993). MPP+ and MPDP+ induced oxygen radical formation with mitochondrial enzymes. Free Radical Biology and Medicine, 15(2), 181-186. https://doi.org/10.1016/0891-5849(93)90057-2

Airavaara, M., Voutilainen, M. H., Wang, Y., \& Hoffer, B. (2012). Neurorestoration. Parkinsonism \& Related Disorders, 18 Suppl 1, S143-6. https://doi.org/10.1016/S1353-8020(11)70045-1

Alberts, W. W., Wright, E. W., \& Feinstein, B. (1969). Cortical potentials and Parkinsonian tremor. Nature, 221(5181), 670-672. Retrieved from http://www.ncbi.nlm.nih.gov/pubmed/5774945

Allen, N. E., Schwarzel, A. K., \& Canning, C. G. (2013). Recurrent Falls in Parkinson' s Disease : A Systematic Review, 2013.

Aloisi, F. (2001). Immune function of microglia. Glia, 36(2), 165-179. https://doi.org/10.1002/glia.1106

Andrew, R., Watson, D. G., Best, S. A., Midgley, J. M., Wenlong, H., \& Petty, R. K. H. (1993). The determination of hydroxydopamines and other trace amines in the urine of Parkinsonian patients and normal controls. Neurochemical Research, 18(11), 1175-1177. https://doi.org/10.1007/BF00978370

Anglade, P., Vyas, S., Javoy-Agid, F., Herrero, M. T., Michel, P. P., Marquez, J., ... Agid, Y. (1997). Apoptosis and autophagy in nigral neurons of patients with Parkinson's disease. Histology and Histopathology, 12(1), 25-31. Retrieved from http://www.ncbi.nlm.nih.gov/pubmed/9046040

Antonini, A. (2011). The conundrum of neuroprotection in Parkinson's disease. The Lancet Neurology, 10(5), 396-397. https://doi.org/10.1016/S1474-4422(11)700783

Ardalan, M. R., Estakhri, R., Hajipour, B., Ansarin, K., Asl, N. A., Nasirizade, M. R., ... Esmaili, H. A. (2012). Erythropoietin ameliorates oxidative stress and tissue injury following renal ischemia/reperfusion in rat kidney and lung. Medical Principles and Practice, 22(1), 70-74. https://doi.org/10.1159/000340060

Aron, L., \& Klein, R. (2011). Repairing the parkinsonian brain with neurotrophic factors. Trends in Neurosciences, 34(2), 88-100. https://doi.org/10.1016/j.tins.2010.11.001

Bader, A., Reinhardt, M., Beuthe, A., Röhl, K., \& Giri, S. (2017). Therapy of an incomplete spinal cord injury by intrathecal injection of EPO and subcutaneous injection of EPO, vitamin C and G-CSF. Therapeutics and Clinical Risk Management, 13, 11831188. https://doi.org/10.2147/TCRM.S130627 
Bahçekapili, N., Akgün-Dar, K., Albeniz, I., Kapucu, A., Kandil, A., Yałiz, O., \& Üzüm, G. (2014). Erythropoietin pretreatment suppresses seizures and prevents the increase in inflammatory mediators during pentylenetetrazole-induced generalized seizures. International Journal of Neuroscience, 124(10), 762-770. https://doi.org/10.3109/00207454.2013.878935

Banati, R. B., Daniel, S. E., \& Blunt, S. B. (1998). Glial pathology but absence of apoptotic nigral neurons in long-standing Parkinson's disease. Movement Disorders : Official Journal of the Movement Disorder Society, 13(2), 221-227. https://doi.org/10.1002/mds.870130205

Banati, R. B., Myers, R., \& Kreutzberg, G. W. (1997). PK ('peripheral benzodiazepine') Binding sites in the CNS indicate early and discrete brain lesions: Microautoradiographic detection of [3H]PK 11195 binding to activated microglia. Journal of Neurocytology, 26(2), 77-82. https://doi.org/10.1023/A:1018567510105

Banks, W. A., Jumbe, N. L., Farrell, C. L., Niehoff, M. L., \& Heatherington, A. C. (2004). Passage of erythropoietic agents across the blood-brain barrier: a comparison of human and murine erythropoietin and the analog darbepoetin alfa. European Journal of Pharmacology, 505(1-3), 93-101. https://doi.org/10.1016/j.ejphar.2004.10.035

Bartels, C., Späte, K., Krampe, H., \& Ehrenreich, H. (2008). Recombinant human erythropoietin: Novel strategies for neuroprotective/neuroregenerative treatment of multiple sclerosis. Therapeutic Advances in Neurological Disorders, 1(3), 193206. https://doi.org/10.1177/1756285608098422

Bartus, R. T., Baumann, T. L., Brown, L., Kruegel, B. R., Ostrove, J. M., \& Herzog, C. D. (2013). Advancing neurotrophic factors as treatments for age-related neurodegenerative diseases: Developing and demonstrating "clinical proof-ofconcept" for AAV-neurturin (CERE-120) in Parkinson's disease. Neurobiology of Aging, 34(1), 35-61. https://doi.org/10.1016/j.neurobiolaging.2012.07.018

Bastide, M. F., Meissner, W. G., Picconi, B., Fasano, S., Fernagut, P. O., Feyder, M., ... Bézard, E. (2015). Pathophysiology of L-dopa-induced motor and non-motor complications in Parkinson's disease. Progress in Neurobiology, 132(July), 96-168. https://doi.org/10.1016/j.pneurobio.2015.07.002

Battino, M., Bullon, P., Wilson, M., \& Newman, H. (1999). Oxidative injury and inflammatory periodontal diseases: The challenge of anti-oxidants to free radicals and reactive oxygen species. Critical Reviews in Oral Biology and Medicine, 10(4), 458-476. https://doi.org/10.1177/10454411990100040301

Beck, K. D., Valverde, J., Alexi, T., Poulsen, K., Moffat, B., Vandlen, R. A., ... Hefti, F. (1995). Mesencephalic dopaminergic neurons protected by GDNF from axotomyinduced degeneration in the adult brain. Nature, 373, 339. Retrieved from 
http://dx.doi.org/10.1038/373339a0

Bensadoun, J. C., Déglon, N., Tseng, J. L., Ridet, J. L., Zurn, A. D., \& Aebischer, P. (2000). Lentiviral vectors as a gene delivery system in the mouse midbrain: Cellular and behavioral improvements in a 6-OHDA model of Parkinson's disease using GDNF. Experimental Neurology, 164(1), 15-24. https://doi.org/10.1006/exnr.2000.7409

Berg, D., Lang, A. E., Postuma, R. B., Maetzler, W., Deuschl, G., Gasser, T., ... Stern, M. (2013). Changing the research criteria for the diagnosis of Parkinson's disease: Obstacles and opportunities. The Lancet Neurology, 12(5), 514-524. https://doi.org/10.1016/S1474-4422(13)70047-4

Berger, K., Przedborski, S., \& Cadet, J. L. (1991). Retrograde degeneration of nigrostriatal neurons induced by intrastriatal 6-hydroxydopamine injection in rats. Brain Research Bulletin, 26(2), 301-307. https://doi.org/10.1016/0361-9230(91)90242-C

Bernaudin, M., Marti, H. H., Roussel, S., Divoux, D., Nouvelot, A., Mackenzie, E. T., \& Petit, E. (1999). A potential role for erythropoetin in focal permanent cerebral ischemia in mice. J Cereb Blood Flow Metab, 19(6), 643-651. https://doi.org/10.1097/00004647-199906000-00007

Blesa, J., Phani, S., Jackson-Lewis, V., \& Przedborski, S. (2012). Classic and new animal models of Parkinson's disease. Journal of Biomedicine and Biotechnology, 2012. https://doi.org/10.1155/2012/845618

Blesa, J., Trigo-Damas, I., Quiroga-Varela, A., \& Jackson-Lewis, V. R. (2015). Oxidative stress and Parkinson's disease. Frontiers in Neuroanatomy, 9(July), 1-9. https://doi.org/10.3389/fnana.2015.00091

Block, M. L., \& Hong, J.-S. (2005). Microglia and inflammation-mediated neurodegeneration: Multiple triggers with a common mechanism. Progress in Neurobiology, 76(2), 77-98. https://doi.org/10.1016/j.pneurobio.2005.06.004

Blum, D., Torch, S., Lambeng, N., Nissou, M., Benabid, A. L., Sadoul, R., \& Verna, J. M. (2001). Molecular pathways involved in the neurotoxicity of 6-OHDA, dopamineandMPTP: contributionto the apoptotic theory inParkinson'sdisease. Progress in Neurobiology, 65, 135-172.

Boado, R., Pardridge, W. M., Zhou, Q., Boado, R. J., Lu, J. Z., Hui, E. K., \& Pardridge, W. M. (2010). Re-Engineering Erythropoietin as an IgG Fusion Protein That Penetrates the Blood- Brain Barrier in the Mouse Re-Engineering Erythropoietin as an IgG Fusion Protein That Penetrates the Blood - Brain Barrier in the Mouse, (February 2016). https://doi.org/10.1021/mp1001763

Boise, L. H., González-García, M., Postema, C. E., Ding, L., Lindsten, T., Turka, L. A., ... Thompson, C. B. (1993). Bcl-X, a Bcl-2-Related Gene That Functions As a Dominant 
Regulator of Apoptotic Cell Death. Cell, 74(4), 597-608.

https://doi.org/10.1016/0092-8674(93)90508-N

Bonni, A. (1999). Cell Survival Promoted by the Ras-MAPK Signaling Pathway by

Transcription-Dependent and -Independent Mechanisms. Science, 286(5443), 1358-1362. https://doi.org/10.1126/science.286.5443.1358

Bose, A., \& Beal, M. F. (2016). Mitochondrial dysfunction in Parkinson's disease. Journal of Neurochemistry, 139, 216-231. https://doi.org/10.1111/jnc.13731

Bose, A., \& Beal, M. F. (2019). Mitochondrial dysfunction and oxidative stress in induced pluripotent stem cell models of Parkinson's disease. European Journal of Neuroscience, 49(4), 525-532. https://doi.org/10.1111/ejn.14264

Bové, J., Prou, D., Perier, C., \& Przedborski, S. (2005). Toxin-induced models of Parkinson's disease. NeuroRx : The Journal of the American Society for Experimental NeuroTherapeutics, 2(3), 484-494. https://doi.org/10.1602/neurorx.2.3.484

Braak, H., Del Tredici, K., Bratzke, H., Hamm-Clement, J., Sandmann-Keil, D., \& Rüb, U. (2002). Staging of the intracerebral inclusion body pathology associated with idiopathic Parkinson's disease (preclinical and clinical stages). Journal of Neurology, 249(0), 1-1. https://doi.org/10.1007/s00415-002-1301-4

Branchi, I., D’Andrea, I., Armida, M., Carnevale, D., Ajmone-Cat, M. A., Pèzzola, A., ... Alleva, E. (2010). Striatal 6-OHDA lesion in mice: Investigating early neurochemical changes underlying Parkinson's disease. Behavioural Brain Research, 208(1), 137143. https://doi.org/10.1016/j.bbr.2009.11.020

Brines, M., Grasso, G., Fiordaliso, F., Sfacteria, A., Ghezzi, P., Fratelli, M., ... Cerami, A. (2004). Erythropoietin mediates tissue protection through an erythropoietin and common -subunit heteroreceptor. Proceedings of the National Academy of Sciences, 101(41), 14907-14912. https://doi.org/10.1073/pnas.0406491101

Brines, M. L., Ghezzi, P., Keenan, S., Agnello, D., de Lanerolle, N. C., Cerami, C., ... Cerami, A. (2000). Erythropoietin crosses the blood-brain barrier to protect against experimental brain injury. Proceedings of the National Academy of Sciences of the United States of America, 97(19), 10526-10531. https://doi.org/10.1073/pnas.97.19.10526

Brines, Michael, \& Cerami, A. (2002). Chapter 9 ERYTHROPOIETIN IN SPINAL CORD INJURY Challenges for a novel neuroprotective strategy.

Brines, Michael, \& Cerami, A. (2012). The Receptor That Tames the Innate Immune Response. Molecular Medicine, 18(3), 1. https://doi.org/10.2119/molmed.2011.00414

Brooks, D. J. (2012). Parkinson's disease: diagnosis. Parkinsonism \& Related Disorders, 
18 Suppl 1, S31-3. https://doi.org/10.1016/S1353-8020(11)70012-8

Buemi, M., Allegra, A., Corica, F., Floccari, F., D’Avella, D., Aloisi, C., ... Frisina, N. (2000). Intravenous recombinant erythropoietin does not lead to an increase in cerebrospinal fluid erythropoietin concentration. Nephrology Dialysis Transplantation, 15(3), 422-423. https://doi.org/10.1093/ndt/15.3.422

Burns, R. S., Chiueh, C. C., Markey, S. P., Ebert, M. H., Jacobowitz, D. M., \& Kopin, I. J. (1983). A primate model of parkinsonism: selective destruction of dopaminergic neurons in the pars compacta of the substantia nigra by N-methyl-4-phenyl-1,2,3,6tetrahydropyridine. Proceedings of the National Academy of Sciences of the United States of America, 80(14), 4546-4550. https://doi.org/10.1073/pnas.80.14.4546

Büttner, S., Habernig, L., Broeskamp, F., Ruli, D., Vögtle, F. N., Vlachos, M., ... Madeo, F. (2013). Endonuclease $\mathrm{G}$ mediates $\alpha$-synuclein cytotoxicity during Parkinson's disease. The EMBO Journal, 32(23), 3041-3054. https://doi.org/10.1038/emboj.2013.228

Camara, C., Isasi, P., Warwick, K., Ruiz, V., Aziz, T., Stein, J., \& Bak², E. (2015). Biomedical Signal Processing and Control Resting tremor classification and detection in Parkinson' s disease patients, 16, 88-97. https://doi.org/10.1016/j.bspc.2014.09.006

Campana, W. Marie, \& Myers, R. R. (2003). Exogenous erythropoietin protects against dorsal root ganglion apoptosis and pain following peripheral nerve injury. European Journal of Neuroscience, 18(6), 1497-1506. https://doi.org/10.1046/j.14609568.2003.02875.x

Campana, W M, Misasi, R., \& O’Brien, J. S. (1998). Identification of a neurotrophic sequence in erythropoietin. International Journal of Molecular Medicine. https://doi.org/10.3892/ijmm.1.1.235

Cardenas, H., \& Bolin, L. M. (2003). Compromised reactive microgliosis in MPTP-lesioned IL-6 KO mice. Brain Research, 985(1), 89-97. Retrieved from http://www.ncbi.nlm.nih.gov/pubmed/12957371

Carelli, S., Giallongo, T., Viaggi, C., Gombalova, Z., Latorre, E., Mazza, M., ... Gorio, A. (2016). Grafted Neural Precursors Integrate Into Mouse Striatum, Differentiate and Promote Recovery of Function Through Release of Erythropoietin in MPTP-Treated Mice. ASN Neuro, 8(5). https://doi.org/10.1177/1759091416676147

Carelli, S., Giallongo, T., Viaggi, C., Latorre, E., Gombalova, Z., Raspa, A., ... Gorio, A. (2017). Recovery from experimental parkinsonism by intrastriatal application of erythropoietin or EPO-releasing neural precursors. Neuropharmacology, 119, 7690. https://doi.org/10.1016/j.neuropharm.2017.03.035 
Carelli, S., Marfia, G., Di Giulio, A. M., Ghilardi, G., \& Gorio, A. (2011). Erythropoietin: Recent developments in the treatment of spinal cord injury. Neurology Research International, 2011. https://doi.org/10.1155/2011/453179

Castillo, C., Zaror, S., Gonzalez, M., Hidalgo, A., Burgos, C. F., Cabezas, O. I., ... Toledo, J. R. (2018). Neuroprotective effect of a new variant of Epo nonhematopoietic against oxidative stress. Redox Biology, 14(July 2017), 285-294. https://doi.org/10.1016/j.redox.2017.09.010

Castrioto, A. (2011). Ten-Year Outcome of Subthalamic Stimulation in Parkinson Disease. Archives of Neurology, 68(12), 1550. https://doi.org/10.1001/archneurol.2011.182

Celik, M., Gokmen, N., Erbayraktar, S., Akhisaroglu, M., Konakc, S., Ulukus, C., ... Brines, M. (2002). Erythropoietin prevents motor neuron apoptosis and neurologic disability in experimental spinal cord ischemic injury. Proceedings of the National Academy of Sciences, 99(4), 2258-2263. https://doi.org/10.1073/pnas.042693799

Chai, H. T., Yip, H. K., Sun, C. K., Hsu, S. Y., \& Leu, S. (2016). AG490 suppresses EPOmediated activation of JAK2-STAT but enhances blood flow recovery in rats with critical limb ischemia. Journal of Inflammation (United Kingdom), 13(1), 1-11. https://doi.org/10.1186/s12950-016-0126-3

Chiu, W. H., Carlsson, T., Depboylu, C., Höglinger, G. U., Oertel, W. H., \& Ries, V. (2014). Selegiline normalizes, while I-DOPA sustains the increased number of dopamine neurons in the olfactory bulb in a 6-OHDA mouse model of Parkinson's disease. Neuropharmacology, 79, 212-221. https://doi.org/10.1016/j.neuropharm.2013.11.014

Choi-Lundberg, D. L. (1997). Dopaminergic Neurons Protected from Degeneration by GDNF Gene Therapy. Science, 275(5301), 838-841. https://doi.org/10.1126/science.275.5301.838

Choudhury, M. E., Sugimoto, K., Kubo, M., Nagai, M., Nomoto, M., Takahashi, H., ... Tanaka, J. (2011). A cytokine mixture of GM-CSF and IL-3 that induces a neuroprotective phenotype of microglia leading to amelioration of (6-OHDA)induced Parkinsonism of rats. Brain and Behavior, 1(1), 26-43.

https://doi.org/10.1002/brb3.11

Cicchetti, F., Brownell, A. L., Williams, K., Chen, Y. I., Livni, E., \& Isacson, O. (2002). Neuroinflammation of the nigrostriatal pathway during progressive 6-OHDA dopamine degeneration in rats monitored by immunohistochemistry and PET imaging. The European Journal of Neuroscience, 15(6), 991-998. Retrieved from http://www.ncbi.nlm.nih.gov/pubmed/11918659

Cohen, G., \& Heikkila, R. E. (1974). Generation of Hydrogen-Peroxide, Superoxide Radical, and Hydroxyl Radical by 6-Hydroxydopamine, Dialuric Acid, and Related 
Cytotoxic Agents. Journal of Biological Chemistry, 249(8), 2447-2452.

Colton, C. A., Chernyshev, O. N., Gilbert, D. L., \& Vitek, M. P. (2000). Microglial contribution to oxidative stress in Alzheimer's disease. Annals of the New York Academy of Sciences, 899, 292-307. Retrieved from http://www.ncbi.nlm.nih.gov/pubmed/10863548

Colton, C. A., \& Gilbert, D. L. (1987). Production of superoxide anions by a CNS macrophage, the microglia. FEBS Letters, 223(2), 284-288. Retrieved from http://www.ncbi.nlm.nih.gov/pubmed/2822487

Costa, D. D., Beghi, E., Carignano, P., Pagliacci, C., Faccioli, F., Pupillo, E., ... Redaelli, T. (2015). Tolerability and efficacy of erythropoietin (EPO) treatment in traumatic spinal cord injury: a preliminary randomized comparative trial vs. methylprednisolone (MP). Neurological Sciences, 36(9), 1567-1574. https://doi.org/10.1007/s10072-015-2182-5

Cotzias, G. C. Papavasiliou, P. S. (1967). Therapeutic studies of Parkinsonian patients: long term effects of D, L-dopa and L-dopa. In Second International Congress of Neuro-Genetics and Neuro-Ophthahnolo y of the World Federation of Neurology, Montreal, 30.

Cotzias, G. C., Van Woert, M. H., \& Schiffer, L. M. (1967). Aromatic amino acids and modification of parkinsonism. The New England Journal of Medicine, 276(7), 374379. https://doi.org/10.1056/NEJM196702162760703

Cruces-Sande, A., Rodríguez-Pérez, A. I., Herbello-Hermelo, P., Bermejo-Barrera, P., Méndez-Álvarez, E., Labandeira-García, J. L., \& Soto-Otero, R. (2019). Copper Increases Brain Oxidative Stress and Enhances the Ability of 6-Hydroxydopamine to Cause Dopaminergic Degeneration in a Rat Model of Parkinson's Disease. Molecular Neurobiology, 56(4), 2845-2854. https://doi.org/10.1007/s12035-0181274-7

Curtius, H. C., Wolfensberger, M., Steinmann, B., Redweik, U., \& Siegfried, J. (1974). Mass fragmentography of dopamine and 6-hydroxydopamine. Journal of Chromatography A, 99, 529-540. https://doi.org/10.1016/S0021-9673(00)90882-3

Damier, P., Hirsch, E. C., Zhang, P., Agid, Y., \& Javoy-Agid, F. (1993). Glutathione peroxidase, glial cells and Parkinson's disease. Neuroscience, 52(1), 1-6. Retrieved from http://www.ncbi.nlm.nih.gov/pubmed/8433802

Damier, P., Kastner, A., Agid, Y., \& Hirsch, E. C. (1996). Does monoamine oxidase type B play a role in dopaminergic nerve cell death in Parkinson's disease? Neurology, 46(5), 1262-1262. https://doi.org/10.1212/WNL.46.5.1262

Datta, S. R., Dudek, H., Tao, X., Masters, S., Fu, H., Gotoh, Y., \& Greenberg, M. E. (1997). 
Akt Phosphorylation of BAD Couples Survival Signals to the Cell-Intrinsic Death Machinery. Cell, 91(2), 231-241. https://doi.org/10.1016/S0092-8674(00)80405-5

Dauer, W., \& Przedborski, S. (2003). Parkinson 's Disease : Mechanisms and Models, 39, 889-909.

Decressac, M., Ulusoy, A., Mattsson, B., Georgievska, B., Romero-Ramos, M., Kirik, D., \& Björklund, A. (2011). GDNF fails to exert neuroprotection in a rat $\alpha$-synuclein model of Parkinson's disease. Brain : A Journal of Neurology, 134(Pt 8), 2302-2311. https://doi.org/10.1093/brain/awr149

Deister, C., \& Schmidt, C. E. (2006). Optimizing neurotrophic factor combinations for neurite outgrowth. Journal of Neural Engineering, 3(2), 172-179. https://doi.org/10.1088/1741-2560/3/2/011

Delamarre, A., \& Meissner, W. G. (2017). Epidemiology, environmental risk factors and genetics of Parkinson's disease. La Presse Médicale, 46(2), 175-181. https://doi.org/10.1016/j.lpm.2017.01.001

Di Monte, D. A., Delanney, L. E., Irwin, I., Royland, J. E., Chan, P., Jakowec, M. W., \& Langston, J. W. (1996). Monoamine oxidase-dependent metabolism of dopamine in the striatum and substantia nigra of L-DOPA-treated monkeys. Brain Research, 738(1), 53-59. Retrieved from http://www.ncbi.nlm.nih.gov/pubmed/8949927

Dickson, D. W. (2018). Neuropathology of Parkinson disease. Parkinsonism \& Related Disorders, 46, S30-S33. https://doi.org/10.1016/j.parkreldis.2017.07.033

Digicaylioglu, M., Bichet, S., Marti, H. H., Wenger, R. H., Rivas, L. A., Bauer, C., \& Gassmann, M. (1995). Localization of specific erythropoietin binding sites in defined areas of the mouse brain. Proc Natl Acad Sci U S A, 92(9), 3717-3720. https://doi.org/10.1073/pnas.92.9.3717

Digicaylioglu, M., Garden, G., Timberlake, S., Fletcher, L., \& Lipton, S. A. (2004). Acute neuroprotective synergy of erythropoietin and insulin-like growth factor I. Proceedings of the National Academy of Sciences of the United States of America, 101(26), 9855-9860. https://doi.org/10.1073/pnas.0403172101

Digicaylioglu, M., \& Lipton, S. A. (2001). Erythropoietin-mediated neuroprotection involves cross-talk between Jak2 and NF-kB signalling cascades. Nature, 412(6847), 641-647. https://doi.org/10.1038/35088074

Ding, J., Wang, J., Li, Q. Y., Yu, J. Z., Ma, C. G., Wang, X., ... Xiao, B. G. (2017). Neuroprotection and CD131/GDNF/AKT Pathway of Carbamylated Erythropoietin in Hypoxic Neurons. Molecular Neurobiology, 54(7), 5051-5060. https://doi.org/10.1007/s12035-016-0022-0

Do Van, B., Gouel, F., Jonneaux, A., Timmerman, K., Gelé, P., Pétrault, M., ... Devedjian, 
J.-C. (2016). Ferroptosis, a newly characterized form of cell death in Parkinson's disease that is regulated by PKC. Neurobiology of Disease, 94, 169-178. https://doi.org/10.1016/j.nbd.2016.05.011

Domanskyi, A., Saarma, M., \& Airavaara, M. (2015). Prospects of Neurotrophic Factors for Parkinson's Disease: Comparison of Protein and Gene Therapy. Human Gene Therapy, 26(8), 550-559. https://doi.org/10.1089/hum.2015.065

Doorn, K. J., Moors, T., Drukarch, B., Berg, W. D. J. Van De, \& Lucassen, P. J. (2014). Microglial phenotypes and toll-like receptor 2 in the substantia nigra and hippocampus of incidental Lewy body disease cases and Parkinson 's disease patients, 1-17.

Dorsey, E. R., Constantinescu, R., Thompson, J. P., Biglan, K. M., Holloway, R. G., Kieburtz, K., ... Tanner, C. M. (2007). Projected number of people with Parkinson disease in the most populous nations, 2005 through 2030. Neurology, 68(5), 384386. https://doi.org/10.1212/01.wnl.0000247740.47667.03

Drayer, B., Burger, P., Darwin, R., Riederer, S., Herfkens, R., \& Johnson, G. A. (1986). MRI of Brain iron. Methods Mol Biol, 711, 103-110. https://doi.org/10.1007/978-161737-992-5_11

Dunn, A. J. (2006). Effects of cytokines and infections on brain neurochemistry. Clinical Neuroscience Research, 6(1-2), 52-68. https://doi.org/10.1016/j.cnr.2006.04.002

Duty, S., \& Jenner, P. (2011). Animal models of Parkinson's disease: A source of novel treatments and clues to the cause of the disease. British Journal of Pharmacology, 164(4), 1357-1391. https://doi.org/10.1111/j.1476-5381.2011.01426.x

Edison, P., Ahmed, I., Fan, Z., Hinz, R., Gelosa, G., Ray Chaudhuri, K., ... Brooks, D. J. (2013). Microglia, amyloid, and glucose metabolism in parkinson's disease with and without dementia. Neuropsychopharmacology, 38(6), 938-949. https://doi.org/10.1038/npp.2012.255

Eggert, K., Schlegel, J., Oertel, W., Würz, C., Krieg, J. C., \& Vedder, H. (1999). Glial cell line-derived neurotrophic factor protects dopaminergic neurons from 6hydroxydopamine toxicity in vitro. Neuroscience Letters, 269, 178-182.

Ehrenreich, H, Degner, D., Meller, J., Brines, M., Béhé, M., Hasselblatt, M., ... Sirén, A.-L. (2004). Erythropoietin: a candidate compound for neuroprotection in schizophrenia. Molecular Psychiatry, 9(1), 42-54. https://doi.org/10.1038/sj.mp.4001442

Ehrenreich, Hannelore, Bartels, C., Sargin, D., Stawicki, S., \& Krampe, H. (2008). Recombinant Human Erythropoietin in the Treatment of Human Brain Disease: Focus on Cognition. Journal of Renal Nutrition, 18(1), 146-153. 
https://doi.org/10.1053/j.jrn.2007.10.029

Erbaş, O., Çiar, B. P., Solmaz, V., Çavuşoğlu, T., \& Ateş, U. (2015). The neuroprotective effect of erythropoietin on experimental Parkinson model in rats. Neuropeptides, 49, 1-5. https://doi.org/10.1016/j.npep.2014.10.003

Fahn, S., \& Cohen, G. (1992). The oxidant stress hypothesis in Parkinson's disease: Evidence supporting it. Annals of Neurology, 32(6), 804-812. https://doi.org/10.1002/ana.410320616

Farmer, K., Rudyk, C., Prowse, N. A., \& Hayley, S. (2015). Hematopoietic cytokines as therapeutic players in early stages Parkinson's disease. Frontiers in Aging Neuroscience, 7(JUL), 1-5. https://doi.org/10.3389/fnagi.2015.00126

Feigin, V. L., Abajobir, A. A., Abate, K. H., Abd-Allah, F., Abdulle, A. M., Abera, S. F., ... Vos, T. (2017). Global, regional, and national burden of neurological disorders during 1990-2015: a systematic analysis for the Global Burden of Disease Study 2015. The Lancet Neurology, 16(11), 877-897. https://doi.org/10.1016/S14744422(17)30299-5

Figarella, K., Uzcategui, N. L., Mogk, S., Wild, K., Fallier-Becker, P., Neher, J. J., \& Duszenko, M. (2018). Morphological changes, nitric oxide production, and phagocytosis are triggered in vitro in microglia by bloodstream forms of Trypanosoma brucei. Scientific Reports, 8(1), 1-9. https://doi.org/10.1038/s41598018-33395-x

Findley, L. J., Wood, E., Lowin, J., Roeder, C., Bergman, A., \& Schifflers, M. (2011). The economic burden of advanced Parkinson's disease: an analysis of a UK patient dataset. Journal of Medical Economics, 14(1), 130-139. https://doi.org/10.3111/13696998.2010.551164

Finkbeiner, S. (2000). CREB couples neurotrophin signals to survival messages. Neuron, 25(1), 11-14. https://doi.org/10.1016/S0896-6273(00)80866-1

Floyd, R. A. (1999). Antioxidants, oxidative stress, and degenerative neurological disorders. Proceedings of the Society for Experimental Biology and Medicine, 222(3), 236-245. https://doi.org/10.1046/j.1525-1373.1999.d01-140.x

Foley, L. S., Fullerton, D. A., Bennett, D. T., Freeman, K. A., Mares, J., Bell, M. T., ... Reece, T. B. (2015). Spinal Cord Ischemia-Reperfusion Injury Induces Erythropoietin Receptor Expression. Annals of Thoracic Surgery, 100(1), 41-46. https://doi.org/10.1016/j.athoracsur.2015.01.027

Fu, A., Zhou, Q. H., Hui, E. K. W., Lu, J. Z., Boado, R. J., \& Pardridge, W. M. (2010). Intravenous treatment of experimental Parkinson's disease in the mouse with an IgG-GDNF fusion protein that penetrates the blood-brain barrier. Brain Research, 
1352(310), 208-213. https://doi.org/10.1016/j.brainres.2010.06.059

Fu, Z. Q., Shao, Q. L., Shen, J. L., Zhang, Y. J., Zhao, X. X., \& Yao, L. (2010). Effect of carbamylated erythropoietin on major histocompatibility complex expression and neural differentiation of human neural stem cells. Journal of Neuroimmunology, 221(1-2), 15-24. https://doi.org/10.1016/j.jneuroim.2010.01.016

Gainetdinov, R. R., Fumagalli, F., Wang, Y. M., Jones, S. R., Levey, a I., Miller, G. W., \& Caron, M. G. (1998). Increased MPTP neurotoxicity in vesicular monoamine transporter 2 heterozygote knockout mice. Journal of Neurochemistry, 70(5), 19731978. https://doi.org/10.1046/j.1471-4159.1998.70051973.x

Gao, H.-M., Hong, J.-S., Zhang, W., \& Liu, B. (2002). Distinct Role for Microglia in Rotenone-Induced Degeneration of Dopaminergic Neurons. The Journal of Neuroscience, 22(3), 782-790. https://doi.org/10.1523/JNEUROSCI.22-0300782.2002

Gao, H.-M., Jiang, J., Wilson, B., Zhang, W., Hong, J.-S., \& Liu, B. (2002). Microglial activation-mediated delayed and progressive degeneration of rat nigral dopaminergic neurons: relevance to Parkinson's disease. Journal of Neurochemistry, 81(6), 1285-1297. https://doi.org/10.1046/j.14714159.2002.00928.x

Garea-Rodríguez, E., Eesmaa, A., Lindholm, P., Schlumbohm, C., König, J., Meller, B., ... Fuchs, E. (2016). Comparative Analysis of the Effects of Neurotrophic Factors CDNF and GDNF in a Nonhuman Primate Model of Parkinson's Disease. PLoS ONE, 11(2). https://doi.org/10.1371/journal.pone.0149776

Gash, D. M., Zhang, Z., Ovadia, A., Cass, W. A., Yi, A., Simmerman, L., ... Gerhard, G. A. (1996). Functional recovery in parkinsonian monkeys treated with GDNF. Nature, 380, 252. Retrieved from http://dx.doi.org/10.1038/380252a0

Gavrieli, Y. (1992). Identification of programmed cell death in situ via specific labeling of nuclear DNA fragmentation. The Journal of Cell Biology, 119(3), 493-501. https://doi.org/10.1083/jcb.119.3.493

Genc, S., Akhisaroglu, M., Kuralay, F., \& Genc, K. (2002). Erythropoietin restores glutathione peroxidase activity in 1-methyl-4-phenyl-1,2,5,6-tetrahydropyridineinduced neurotoxicity in C57BL mice and stimulates murine astroglial glutathione peroxidase production in vitro. Neuroscience Letters, 321(1-2), 73-76. https://doi.org/10.1016/S0304-3940(02)00041-1

Genc, S., Kuralay, F., Genc, K., \& Akhisaroglu, M. (2001). tetrahydropyridine-treated C57 / BL mice via increasing nitric oxide production. Neuroscience Letters, 298, 139141. 
Gerhard, A., Pavese, N., Hotton, G., Turkheimer, F., Es, M., Hammers, A., ... Brooks, D. J. (2006). In vivo imaging of microglial activation with [11C](R)-PK11195 PET in idiopathic Parkinson's disease. Neurobiology of Disease, 21(2), 404-412. https://doi.org/10.1016/j.nbd.2005.08.002

Ghadery, C., Koshimori, Y., Coakeley, S., Harris, M., Rusjan, P., Kim, J., ... Strafella, A. P. (2017). Microglial activation in Parkinson's disease using [18F]-FEPPA. Journal of Neuroinflammation, 14(1), 8. https://doi.org/10.1186/s12974-016-0778-1

Ghosh, A., Carnahan, J., \& Greenberg, M. E. (2018). Requirement for BDNF in ActivityDependent Survival of Cortical Neurons Published by : American Association for the Advancement of Science Stable URL : http://www.jstor.org/stable/2883664 REFERENCES Linked references are available on JSTOR for this articl, 263(5153), 1618-1623.

Gibrat, C., Saint-Pierre, M., Bousquet, M., Lévesque, D., Rouillard, C., \& Cicchetti, F. (2009). Differences between subacute and chronic MPTP mice models: Investigation of dopaminergic neuronal degeneration and $\alpha$-synuclein inclusions. Journal of Neurochemistry, 109(5), 1469-1482. https://doi.org/10.1111/j.14714159.2009.06072.x

Gill, S. S., Patel, N. K., Hotton, G. R., O'Sullivan, K., McCarter, R., Bunnage, M., ... Heywood, P. (2003). Direct brain infusion of glial cell line-derived neurotrophic factor in Parkinson disease. Nature Medicine, 9(5), 589-595.

https://doi.org/10.1038/nm850

Gold, R., Schmied, M., Giegerich, G., Breitschopf, H., Hartung, H. P., Toyka, K. V, \& Lassmann, H. (1994). Differentiation between cellular apoptosis and necrosis by the combined use of in situ tailing and nick translation techniques. Laboratory Investigation; a Journal of Technical Methods and Pathology, 71(2), 219-225. Retrieved from http://www.ncbi.nlm.nih.gov/pubmed/8078301

Gong, X., Wang, H., Ye, Y., Shu, Y., Deng, Y., He, X., ... Zhang, S. (2016). miR-124 regulates cell apoptosis and autophagy in dopaminergic neurons and protects them by regulating AMPK/mTOR pathway in Parkinson's disease. American Journal of Translational Research, 8(5), 2127-2137. Retrieved from http://www.ncbi.nlm.nih.gov/pubmed/27347320

Gorio, A., Gokmen, N., Erbayraktar, S., Yilmaz, O., Madaschi, L., Cichetti, C., ... Brines, M. (2002). Recombinant human erythropoietin counteracts secondary injury and markedly enhances neurological recovery from experimental spinal cord trauma. Proceedings of the National Academy of Sciences, 99(14), 9450-9455. https://doi.org/10.1073/pnas.142287899

Grealish, S., Mattsson, B., Draxler, P., \& Björklund, A. (2010). Characterisation of behavioural and neurodegenerative changes induced by intranigral 6- 
hydroxydopamine lesions in a mouse model of Parkinson's disease. European Journal of Neuroscience, 31(12), 2266-2278. https://doi.org/10.1111/j.14609568.2010.07265.x

Grmec, Š., Strnad, M., Kupnik, D., Sinkovič, A., \& Gazmuri, R. J. (2009). Erythropoietin facilitates the return of spontaneous circulation and survival in victims of out-ofhospital cardiac arrest. Resuscitation, 80(6), 631-637. https://doi.org/10.1016/j.resuscitation.2009.03.010

Grondin, R., Zhang, Z., Yi, A., Cass, W. a, Maswood, N., Andersen, A. H., ... Gash, D. M. (2002). Chronic, controlled GDNF infusion promotes structural and functional recovery in advanced parkinsonian monkeys. Brain : A Journal of Neurology, 125(Pt 10), 2191-2201. https://doi.org/12244077

Gross, A., Yin, X. M., Wang, K., Wei, M. C., Jockel, J., Milliman, C., ... Korsmeyer, S. J. (1999). Caspase cleaved BID targets mitochondria and is required for cytochrome $c$ release, while $B C L-X(L)$ prevents this release but not tumor necrosis factor-R1/Fas death. Journal of Biological Chemistry, 274(2), 1156-1163. https://doi.org/10.1074/jbc.274.2.1156

Grünblatt, E., Mandel, S., \& Youdim, M. B. (2000). MPTP and 6-hydroxydopamineinduced neurodegeneration as models for Parkinson's disease: neuroprotective strategies. Journal of Neurology, 247 Suppl, II95-I102. https://doi.org/10.1007/PL00022909

Guillemin, G., Boussin, F. D., Le Grand, R., Croitoru, J., Coffigny, H., \& Dormont, D. (1996). Granulocyte macrophage colony stimulating factor stimulates in vitro proliferation of astrocytes derived from simian mature brains. Glia, 16(1), 71-80. https://doi.org/10.1002/(SICI)1098-1136(199601)16:1<71::AID-GLIA8>3.0.CO;2-E

Guillot, T. S., \& Miller, G. W. (2009). Protective actions of the vesicular monoamine transporter 2 (VMAT2) in monoaminergic neurons. Molecular Neurobiology, 39(2), 149-170. https://doi.org/10.1007/s12035-009-8059-y

Guillot, T. S., Shepherd, K. R., Richardson, J. R., Wang, M. Z., Li, Y., Emson, P. C., \& Miller, G. W. (2008). Reduced vesicular storage of dopamine exacerbates methamphetamine-induced neurodegeneration and astrogliosis. Journal of Neurochemistry, 106(5), 2205-2217. https://doi.org/10.1111/j.14714159.2008.05568.x

Guiney, S. J., Adlard, P. A., Bush, A. I., Finkelstein, D. I., \& Ayton, S. (2017). Ferroptosis and cell death mechanisms in Parkinson's disease. Neurochemistry International, 104, 34-48. https://doi.org/10.1016/j.neuint.2017.01.004

Güresir, E., Vasiliadis, N., Konczalla, J., Raab, P., Hattingen, E., Seifert, V., \& Vatter, H. (2013). Erythropoietin prevents delayed hemodynamic dysfunction after 
subarachnoid hemorrhage in a randomized controlled experimental setting. Journal of the Neurological Sciences, 332(1-2), 128-135.

https://doi.org/10.1016/j.jns.2013.07.004

Guttman, M., Slaughter, P. M., Theriault, M., Deboer, D. P., \& Naylor, C. D. (2003). Burden of Parkinsonism : A Population-Based Study, 18(3).

Hadaczek, P., Wu, G., Sharma, N., Ciesielska, A., Bankiewicz, K., Davidow, A. L., ... Ledeen, R. W. (2015). GDNF signaling implemented by GM1 ganglioside; failure in Parkinson's disease and GM1-deficient murine model. Experimental Neurology, 263, 177-189. https://doi.org/10.1016/j.expneurol.2014.10.010

Halliwell, B. (1997). Halliwell 1997 - intro to antioxidants.pdf.

Hartmann, A., Hunot, S., Michel, P. P., Muriel, M.-P., Vyas, S., Faucheux, B. A., ... Hirsch, E. C. (2000). Caspase-3: A vulnerability factor and final effector in apoptotic death of dopaminergic neurons in Parkinson's disease. Proceedings of the National Academy of Sciences, 97(6), 2875-2880. https://doi.org/10.1073/pnas.040556597

Hayashi, K., Ohta, S., Kawakami, Y., \& Toda, M. (2009). Activation of dendritic-like cells and neural stem/progenitor cells in injured spinal cord by GM-CSF. Neuroscience Research, 64(1), 96-103. https://doi.org/10.1016/j.neures.2009.01.018

Hellewell, S. C., Yan, E. B., Alwis, D. S., Bye, N., \& Morganti-Kossmann, M. C. (2013). Erythropoietin improves motor and cognitive deficit, axonal pathology, and neuroinflammation in a combined model of diffuse traumatic brain injury and hypoxia, in association with upregulation of the erythropoietin receptor. Journal of Neuroinflammation, 10, 1-21. https://doi.org/10.1186/1742-2094-10-156

Hely, M. A., Reid, W. G. J., Adena, M. A., Halliday, G. M., \& Morris, J. G. L. (2008). The Sydney Multicenter Study of Parkinson's disease: The inevitability of dementia at 20 years. Movement Disorders, 23(6), 837-844. https://doi.org/10.1002/mds.21956

Hemachandra Reddy, P., Manczak, M., Zhao, W., Nakamura, K., Bebbington, C., Yarranton, G., \& Mao, P. (2009). Granulocyte-macrophage colony-stimulating factor antibody suppresses microglial activity: Implications for anti-inflammatory effects in Alzheimer's Disease and multiple sclerosis. Journal of Neurochemistry, 111(6), 1514-1528. https://doi.org/10.1111/j.1471-4159.2009.06432.x

Henrich, M. T., Geibl, F. F., Lee, B., Chiu, W.-H., Koprich, J. B., Brotchie, J. M., ... Oertel, W. H. (2018). A53T-\$ $\alpha \$$-synuclein overexpression in murine locus coeruleus induces Parkinson's disease-like pathology in neurons and glia. Acta Neuropathologica Communications, 6(1), 39. https://doi.org/10.1186/s40478-0180541-1 
Hersch, S. M., Yi, H., Heilman, C. J., Edwards, R. H., \& Levey, A. I. (1997). Subcellular localization and molecular topology of the dopamine transporter in the striatum and substantia nigra. The Journal of Comparative Neurology, 388(2), 211-227. Retrieved from http://www.ncbi.nlm.nih.gov/pubmed/9368838

Heuer, A., Smith, G. A., Lelos, M. J., Lane, E. L., \& Dunnett, S. B. (2012). Unilateral nigrostriatal 6-hydroxydopamine lesions in mice I: Motor impairments identify extent of dopamine depletion at three different lesion sites. Behavioural Brain Research, 228(1), 30-43. https://doi.org/10.1016/j.bbr.2011.11.027

Hirsch, E. C., \& Hunot, S. (2009). Neuroinflammation in Parkinson's disease: a target for neuroprotection? The Lancet Neurology, 8(4), 382-397. https://doi.org/10.1016/S1474-4422(09)70062-6

Hirsch, E. C., Hunot, S., \& Hartmann, A. (2005). Neuroinflammatory processes in Parkinson's disease. Parkinsonism and Related Disorders, 11(SUPPL. 1), 9-15. https://doi.org/10.1016/j.parkreldis.2004.10.013

Hirsch, L., Jette, N., Frolkis, A., Steeves, T., \& Pringsheim, T. (2016). The Incidence of Parkinson's Disease: A Systematic Review and Meta-Analysis. Neuroepidemiology, 46(4), 292-300. https://doi.org/10.1159/000445751

Hockenbery, D., Nuñez, G., Milliman, C., Schreiber, R. D., \& Korsmeyer, S. J. (1990). Bcl-2 is an inner mitochondrial membrane protein that blocks programmed cell death. Nature, 348, 334. Retrieved from http://dx.doi.org/10.1038/348334a0

Hoogland, I. C. M., Houbolt, C., van Westerloo, D. J., van Gool, W. A., \& van de Beek, D. (2015). Systemic inflammation and microglial activation: systematic review of animal experiments. Journal of Neuroinflammation, 12(1), 114. https://doi.org/10.1186/s12974-015-0332-6

Hooshmandi, E., Motamedi, F., Moosavi, M., Katinger, H., Zakeri, Z., Zaringhalam, J., ... Maghsoudi, N. (2018). CEPO-Fc (An EPO Derivative) Protects Hippocampus Against $A \beta$-induced Memory Deterioration: A Behavioral and Molecular Study in a Rat Model of $A \beta$ Toxicity. Neuroscience, 388, 405-417. https://doi.org/10.1016/j.neuroscience.2018.08.001

Hu, X., Song, Q., Li, X., Li, D., Zhang, Q., Meng, W., \& Zhao, Q. (2017). Neuroprotective effects of Kukoamine A on neurotoxin-induced Parkinson's model through apoptosis inhibition and autophagy enhancement. Neuropharmacology, 117, 352363. https://doi.org/10.1016/j.neuropharm.2017.02.022

Huang, D., Wang, Z., Tong, J., Wang, M., Wang, J., Xu, J., ... Huang, F. (2018). Long-term Changes in the Nigrostriatal Pathway in the MPTP Mouse Model of Parkinson's Disease. Neuroscience, 369, 303-313. https://doi.org/10.1016/j.neuroscience.2017.11.041 
Huang, X., Kim, J. M., Kong, T. H., Park, S. R., Ha, Y., Kim, M. H., ... Choi, B. H. (2009). GMCSF inhibits glial scar formation and shows long-term protective effect after spinal cord injury. Journal of the Neurological Sciences, 277(1-2), 87-97. https://doi.org/10.1016/j.jns.2008.10.022

Hughes, A. J., Daniel, S. E., Kilford, L., \& Lees, A. J. (1992). Accuracy of clinical diagnosis of idiopathic Parkinson's disease: A clinico-pathological study of 100 cases. Journal of Neurology Neurosurgery and Psychiatry, 55(3), 181-184. https://doi.org/10.1136/jnnp.55.3.181

Hughes, C. D., Choi, M. L., Ryten, M., Hopkins, L., Drews, A., Botía, J. A., ... Klenerman, D. (2018). Picomolar concentrations of oligomeric alpha-synuclein sensitizes TLR4 to play an initiating role in Parkinson's disease pathogenesis. Acta Neuropathologica, (0123456789). https://doi.org/10.1007/s00401-018-1907-y

Hunot, S., Dugas, N., Faucheux, B., Hartmann, A., Tardieu, M., Debré, P., ... Hirsch, E. C. (1999). FcepsilonRII/CD23 is expressed in Parkinson's disease and induces, in vitro, production of nitric oxide and tumor necrosis factor-alpha in glial cells. The Journal of Neuroscience : The Official Journal of the Society for Neuroscience, 19(9), 34403447. Retrieved from http://www.ncbi.nlm.nih.gov/pubmed/10212304

Huotarinen, A., Penttinen, A. M., Bäck, S., Voutilainen, M. H., Julku, U., Piepponen, T. P., ... Airavaara, M. (2018). Combination of CDNF and Deep Brain Stimulation Decreases Neurological Deficits in Late-stage Model Parkinson's Disease. Neuroscience, 374, 250-263. https://doi.org/10.1016/j.neuroscience.2018.01.052

Hyman, C., Hofer, M., Barde, Y.-A., Juhasz, M., Yancopoulos, G. D., Squinto, S. P., \& Lindsay, R. M. (1991). BDNF is a neurotrophic factor for dopaminergic neurons of the substantia nigra. Nature, 350, 230. Retrieved from http://dx.doi.org/10.1038/350230a0

laccarino, C., Crosio, C., Vitale, C., Sanna, G., Carrì, M. T., \& Barone, P. (2007). Apoptotic mechanisms in mutant LRRK2-mediated cell death. Human Molecular Genetics, 16(11), 1319-1326. https://doi.org/10.1093/hmg/ddm080

lancu, R., Mohapel, P., Brundin, P., \& Paul, G. (2005). Behavioral characterization of a unilateral 6-OHDA-lesion model of Parkinson's disease in mice. Behavioural Brain Research, 162(1), 1-10. https://doi.org/10.1016/j.bbr.2005.02.023

Iannaccone, S., Cerami, C., Alessio, M., Garibotto, V., Panzacchi, A., Olivieri, S., ... Perani, D. (2013). In vivo microglia activation in very early dementia with Lewy bodies, comparison with Parkinson's disease. Parkinsonism and Related Disorders, 19(1), 47-52. https://doi.org/10.1016/j.parkreldis.2012.07.002

Imamura, K., Hishikawa, N., Sawada, M., Nagatsu, T., Yoshida, M., \& Hashizume, Y. (2003). Distribution of major histocompatibility complex class II-positive microglia 
and cytokine profile of Parkinson's disease brains. Acta Neuropathologica, 106(6), 518-526. https://doi.org/10.1007/s00401-003-0766-2

Jackson, M., Pye, D., \& Palomero, J. (2007). The production of reactive oxygen and nitrogen species by skeletal muscle. Journal of Applied Physiology, 1664-1670. https://doi.org/10.1152/japplphysiol.01102.2006.

Jang, W., Kim, H. J., Li, H., Jo, K. D., Lee, M. K., \& Yang, H. O. (2016). The Neuroprotective Effect of Erythropoietin on Rotenone-Induced Neurotoxicity in SH-SY5Y Cells Through the Induction of Autophagy. Molecular Neurobiology, 53(6), 3812-3821. https://doi.org/10.1007/s12035-015-9316-x

Janssen, M. L. F., Zwartjes, D. G. M., Tan, S. K. H., Vlamings, R., Jahanshahi, A., Heida, T., ... Temel, Y. (2012). Mild dopaminergic lesions are accompanied by robust changes in subthalamic nucleus activity. Neuroscience Letters, 508(2), 101-105. https://doi.org/10.1016/j.neulet.2011.12.027

Jenner, P. (1998). Oxidative mechanisms in nigral cell death in Parkinson's disease. Movement Disorders : Official Journal of the Movement Disorder Society, 13 Suppl 1, 24-34. Retrieved from http://www.ncbi.nlm.nih.gov/pubmed/9613715

Jenner, Peter. (2008). Molecular mechanisms of L-DOPA-induced dyskinesia. Nature Reviews Neuroscience, 9(9), 665-677. https://doi.org/10.1038/nrn2471

Jenner, Peter, \& Olanow, C. W. (1998). Understanding cell death in Parkinson's disease. Annals of Neurology, 44(3 Suppl 1), S72-S84. https://doi.org/10.1002/ana.410440712

Ji, Y., Pang, P. T., Feng, L., \& Lu, B. (2005). Cyclic AMP controls BDNF-induced TrkB phosphorylation and dendritic spine formation in mature hippocampal neurons. Nature Neuroscience, 8(2), 164-172. https://doi.org/10.1038/nn1381

Jia, Y., Mo, S., Feng, Q., Zhan, M., Ouyang, L., Chen, J., ... Wu, J. (2014). EPO-Dependent Activation of PI3K / Akt / FoxO3a Signalling Mediates Neuroprotection in In Vitro and In Vivo Models of Parkinson' s Disease.

Jia, Y., Mo, S. J., Feng, Q. Q., Zhan, M. L., OuYang, L. S., Chen, J. C., ... Lei, W. L. (2014). EPO-dependent activation of PI3K/Akt/FoxO3a signalling mediates neuroprotection in in vitro and in vivo models of Parkinson's disease. Journal of Molecular Neuroscience, 53(1), 117-124. https://doi.org/10.1007/s12031-013-0208-0

Jin, F., Wu, Q., Lu, Y. F., Gong, Q. H., \& Shi, J. S. (2008). Neuroprotective effect of resveratrol on 6-OHDA-induced Parkinson's disease in rats. European Journal of Pharmacology, 600(1-3), 78-82. https://doi.org/10.1016/j.ejphar.2008.10.005

Jing, X., Wei, X., Ren, M., Wang, L., Zhang, X., \& Lou, H. (2016). Neuroprotective Effects of Tanshinone I Against 6-OHDA-Induced Oxidative Stress in Cellular and Mouse 
Model of Parkinson's Disease Through Upregulating Nrf2. Neurochemical Research, 41(4), 779-786. https://doi.org/10.1007/s11064-015-1751-6

Joers, V., Tansey, M. G., Mulas, G., \& Carta, A. R. (2017). Microglial phenotypes in Parkinson's disease and animal models of the disease. Progress in Neurobiology, 155, 57-75. https://doi.org/10.1016/j.pneurobio.2016.04.006

Johnson, M. E., Stecher, B., Labrie, V., Brundin, L., \& Brundin, P. (2019). Triggers, Facilitators, and Aggravators: Redefining Parkinson's Disease Pathogenesis. Trends in Neurosciences, 42(1), 4-13. https://doi.org/10.1016/j.tins.2018.09.007

Kalantar-Zadeh, K. (2017). History of Erythropoiesis-Stimulating Agents, the Development of Biosimilars, and the Future of Anemia Treatment in Nephrology. American Journal of Nephrology, 45(3), 235-247. https://doi.org/10.1159/000455387

Kaminska, B., Mota, M., \& Pizzi, M. (2016). Signal transduction and epigenetic mechanisms in the control of microglia activation during neuroinflammation. Biochimica et Biophysica Acta - Molecular Basis of Disease, 1862(3), 339-351. https://doi.org/10.1016/j.bbadis.2015.10.026

Kannan, Y., Moriyama, M., Sugano, T., Yamate, J., Kuwamura, M., Kagaya, A., \& Kiso, Y. (2000). Neurotrophic Action of Interleukin 3 and Granulocyte-Macrophage ColonyStimulating Factor on Murine Sympathetic Neurons. Neuroimmunomodulation, 8(3), 132-141. https://doi.org/10.1159/000054273

Kaptanoglu, E., Solaroglu, I., Okutan, O., Surucu, H. S., Akbiyik, F., \& Beskonakli, E. (2004). Erythropoietin exerts neuroprotection after acute spinal cord injury in rats: Effect on lipid peroxidation and early ultrastructural findings. Neurosurgical Review, 27(2), 113-120. https://doi.org/10.1007/s10143-003-0300-y

Kawakami, M., Sekiguchi, M., Sato, K., Kozaki, S., \& Takahashi, M. (2001). Erythropoietin Receptor-mediated Inhibition of Exocytotic Glutamate Release Confers Neuroprotection during Chemical Ischemia. Journal of Biological Chemistry, 276(42), 39469-39475. https://doi.org/10.1074/jbc.M105832200

Kearns, C. M., \& Gash, D. M. (1995). GDNF protects nigral dopamine neurons against 6hydroxydopamine in vivo. Brain Research, 672(1-2), 104-111. https://doi.org/10.1016/0006-8993(94)01366-P

Kerr, J. F. R., Wyllie, A. H., \& Currie, A. R. (1972). Apoptosis: A Basic Biological Phenomenon with Wideranging Implications in Tissue Kinetics. British Journal of Cancer, 26(4), 239-257. https://doi.org/10.1038/bjc.1972.33

Khan, A., \& Brown, W. A. (2015). Antidepressants versus placebo in major depression: an overview. World Psychiatry, 14(3), 294-300. https://doi.org/10.1002/wps.20241 
Kingsbury, A. E., David Mardsen, C., \& Foster, O. J. F. (1998). DNA fragmentation in human substantia nigra: Apoptosis or perimortem effect? Movement Disorders, 13(6), 877-884. https://doi.org/10.1002/mds.870130604

Kohutnicka, M., Lewandowska, E., Kurkowska-Jastrzebska, I., Członkowski, A., \& Członkowska, A. (1998). Microglial and astrocytic involvement in a murine model of Parkinson's disease induced by 1-methyl-4-phenyl-1,2,3,6-tetrahydropyridine (MPTP). Immunopharmacology, 39(3), 167-180. Retrieved from http://www.ncbi.nlm.nih.gov/pubmed/9754903

Koller, W. C., Glatt, S., Vetere-Overfield, B., \& Hassanein, R. (1989). Falls and Parkinson's disease. Clinical Neuropharmacology, 12(2), 98-105. Retrieved from http://www.ncbi.nlm.nih.gov/pubmed/2720700

Kong, Y., \& Le, Y. (2011). Toll-like receptors in inflammation of the central nervous system. International Immunopharmacology, 11(10), 1407-1414. https://doi.org/10.1016/j.intimp.2011.04.025

Konishi, Y., Chui, D. H., Hirose, H., Kunishita, T., \& Tabira, T. (1993). Trophic effect of erythropoietin and other hematopoietic factors on central cholinergic neurons in vitro and in vivo. Brain Res, 609(1-2), 29-35. https://doi.org/0006-8993(93)90850$\mathrm{M}$ [pii]

Kösel, S., Egensperger, R., von Eitzen, U., Mehraein, P., \& Graeber, M. B. (1997). On the question of apoptosis in the parkinsonian substantia nigra. Acta Neuropathologica, 93(2), 105-108. Retrieved from http://www.ncbi.nlm.nih.gov/pubmed/9039456

Koshimori, Y., Ko, J.-H., Mizrahi, R., Rusjan, P., Mabrouk, R., Jacobs, M. F., ... Strafella, A. P. (2015). Imaging Striatal Microglial Activation in Patients with Parkinson's Disease. Plos One, 10(9), e0138721. https://doi.org/10.1371/journal.pone.0138721

Kostrzewa, R. M., \& Jacobowitz, D. M. (1974). Pharmacological actions of 6hydroxydopamine. Pharmacological Reviews, 26(3), 199-288. Retrieved from http://www.ncbi.nlm.nih.gov/pubmed/4376244

Kowal, S. L., Dall, T. M., Chakrabarti, R., Storm, M. V., \& Jain, A. (2013). The current and projected economic burden of Parkinson's disease in the United States. Movement Disorders, 28(3), 311-318. https://doi.org/10.1002/mds.25292

Krack, P., Batir, A., Van Blercom, N., Chabardes, S., Fraix, V., Ardouin, C., ... Pollak, P. (2003). Five-Year Follow-up of Bilateral Stimulation of the Subthalamic Nucleus in Advanced Parkinson's Disease. New England Journal of Medicine, 349(20), 19251934. https://doi.org/10.1056/NEJMoa035275

Kumar, R., Agarwal, A. K., \& Seth, P. K. (1995). Free Radical-Generated Neurotoxicity of 6-Hydroxydopamine, 2-6. 
Kumar, V., Jindal, S. K., \& Ganguly, N. K. (1995). Release of reactive oxygen and nitrogen intermediates from monocytes of patients with pulmonary tuberculosis. Scandinavian Journal of Clinical and Laboratory Investigation, 55(2), 163-169. https://doi.org/10.3109/00365519509089609

Laganiere, J., Kells, A. P., Lai, J. T., Guschin, D., Paschon, D. E., Meng, X., ... Zhang, H. S. (2010). An Engineered Zinc Finger Protein Activator of the Endogenous Glial Cell Line-Derived Neurotrophic Factor Gene Provides Functional Neuroprotection in a Rat Model of Parkinson's Disease. Journal of Neuroscience, 30(49), 16469-16474. https://doi.org/10.1523/JNEUROSCI.2440-10.2010

Lang, A. E., Gill, S., Patel, N. K., Lozano, A., Nutt, J. G., Penn, R., ... Traub, M. (2006). Randomized controlled trial of intraputamenal glial cell line-derived neurotrophic factor infusion in Parkinson disease. Annals of Neurology, 59(3), 459-466. https://doi.org/10.1002/ana.20737

Langston, J. W., Ballard, P., Tetrud, J., \& Irwin, I. (1983). Chronic Parkinsonism in humans due to a product of meperidine-analog synthesis. Science, 219(4587), 979-980. https://doi.org/10.1126/science.6823561

Langston, J. W., Forno, L. S., Tetrud, J., Reeves, A. G., Kaplan, J. A., \& Karluk, D. (1999). Evidence of active nerve cell degeneration in the substantia nigra of humans years after 1-methyl-4-phenyl-1,2,3,6-tetrahydropyridine exposure. Annals of Neurology, 46(4), 598-605. Retrieved from http://www.ncbi.nlm.nih.gov/pubmed/10514096

Laskaris, L. E., Di Biase, M. A., Everall, I., Chana, G., Christopoulos, A., Skafidas, E., ... Pantelis, C. (2016). Microglial activation and progressive brain changes in schizophrenia. British Journal of Pharmacology, 173(4), 666-680. https://doi.org/10.1111/bph.13364

Latchoumycandane, C., Anantharam, V., Jin, H., Kanthasamy, A., \& Kanthasamy, A. (2011). Dopaminergic neurotoxicant 6-OHDA induces oxidative damage through proteolytic activation of PKC $\delta$ in cell culture and animal models of Parkinson's disease. Toxicology and Applied Pharmacology, 256(3), 314-323. https://doi.org/10.1016/j.taap.2011.07.021

Lawson, L. J., Perry, V. H., Dri, P., \& Gordon, S. (1990). Heterogeneity in the distribution and morphology of microglia in the normal adult mouse brain. Neuroscience, 39(1), 151-170. https://doi.org/10.1016/0306-4522(90)90229-W

Lee, J.-C., Park, J. H., Park, O. K., Kim, I. H., Yan, B. C., Ahn, J. H., ... Won, M.-H. (2013). Neuroprotective effects of tanshinone I from Danshen extract in a mouse model of hypoxia-ischemia. Anatomy \& Cell Biology, 46(3), 183-190. https://doi.org/10.5115/acb.2013.46.3.183

Leist, M., Ghezzi, P., Grasso, G., Bianchi, R., Villa, P., Fratelli, M., ... Erbayraktar, S. (2004). 
Derivatives of Erythropoietin Not Erythropoietic. Science, 305(July), 239-243. https://doi.org/10.1126/science.1098313

Lenz, F. A., Kwan, H. C., Martin, R. L., Tasker, R. R., Dostrovsky, J. O., \& Lenz, Y. E. (1994). Single unit analysis of the human ventral thalamic nuclear group. Tremor-related activity in functionally identified cells. Brain : A Journal of Neurology, 117 ( Pt 3, 531-543. Retrieved from http://www.ncbi.nlm.nih.gov/pubmed/8032863

Levi-montalcini, A. R., \& Levi-montalcini, R. (2016). Linked references are available on JSTOR for this article : the Nerve Growth Factor 35 Years Later, 237(4819), 11541162.

Liberatore, G. T., Jackson-Lewis, V., Vukosavic, S., Mandir, A. S., Vila, M., McAuliffe, W. G., ... Przedborski, S. (1999). Inducible nitric oxide synthase stimulates dopaminergic neurodegeneration in the MPTP model of Parkinson disease. Nature Medicine, 5(12), 1403-1409. https://doi.org/10.1038/70978

Liddelow, S. A., \& Barres, B. A. (2017). Reactive Astrocytes: Production, Function, and Therapeutic Potential. Immunity, 46(6), 957-967. https://doi.org/10.1016/j.immuni.2017.06.006

Liddelow, S. A., Guttenplan, K. A., Clarke, L. E., Bennett, F. C., Bohlen, C. J., Schirmer, L., ... Barres, B. A. (2017). Neurotoxic reactive astrocytes are induced by activated microglia. Nature, 541(7638), 481-487. https://doi.org/10.1038/nature21029

Lin, F. K., Suggs, S., Lin, C. H., Browne, J. K., Smalling, R., Egrie, J. C., ... Stabinsky, Z. (1985). Cloning and expression of the human erythropoietin gene. Proceedings of the National Academy of Sciences of the United States of America, 82(22), 75807584. Retrieved from http://www.ncbi.nlm.nih.gov/pubmed/3865178

Lin, L., Doherty, D., Lile, J., Bektesh, S., \& Collins, F. (1993). GDNF: a glial cell line-derived neurotrophic factor for midbrain dopaminergic neurons. Science, 260(5111), 11301132. https://doi.org/10.1126/science.8493557

Lindholm, P., \& Saarma, M. (2010). Novel CDNF/MANF family of neurotrophic factors. Developmental Neurobiology, 70(5), 360-371. https://doi.org/10.1002/dneu.20760

Lindholm, P., Voutilainen, M. H., Laurén, J., Peränen, J., Leppänen, V.-M., Andressoo, J.O., ... Saarma, M. (2007). Novel neurotrophic factor CDNF protects and rescues midbrain dopamine neurons in vivo. Nature, 448, 73. Retrieved from http://dx.doi.org/10.1038/nature05957

Lindsay, R. M., \& Harmar, A. J. (1989). Nerve growth factor regulates expression of neuropeptide genes in adult sensory neurons. Nature, 337, 362. Retrieved from http://dx.doi.org/10.1038/337362a0

Liochev, S. I., \& Fridovich, I. (1994). the Role of 02"-in the Production of Ho': in Vitro and 
in Vivo. Free Radical Biology \& Medicine, 16, 29-33.

https://doi.org/10.1016/j.ultrasmedbio.2014.05.001

Liu, B., GAO, H.-M., WANG, J.-Y., JEOHN, G.-H., COOPER, C. L., \& HONG, J.-S. (2002). Role of Nitric Oxide in Inflammation-Mediated Neurodegeneration. Annals of the New York Academy of Sciences, 962(1), 318-331. https://doi.org/10.1111/j.17496632.2002.tb04077.x

Liu, Jie, Huang, D., Xu, J., Tong, J., Wang, Z., Huang, L., ... Huang, F. (2015). Tiagabine Protects Dopaminergic Neurons against Neurotoxins by Inhibiting Microglial Activation. Scientific Reports, 5(1), 15720. https://doi.org/10.1038/srep15720

Liu, Jing, Wang, M.-W., Gu, P., Ma, Q.-Y., Wang, Y.-Y., Geng, Y., ... Zhu, A.-P. (2010). Microglial activation and age-related dopaminergic neurodegeneration in MPTPtreated SAMP8 mice. Brain Research, 1345, 213-220.

https://doi.org/10.1016/j.brainres.2010.05.043

Liu, Q. S., Cheng, Z. W., Xiong, J. G., Cheng, S., He, X. F., \& Li, X. C. (2015). Erythropoietin pretreatment exerts anti-inflammatory effects in hepatic ischemia/reperfusioninjured rats via suppression of the TLR2/NF-KB pathway. Transplantation Proceedings, 47(2), 283-289. https://doi.org/10.1016/j.transproceed.2014.10.045

Lo Bianco, C., Déglon, N., Pralong, W., \& Aebischer, P. (2004). Lentiviral nigral delivery of GDNF does not prevent neurodegeneration in a genetic rat model of Parkinson's disease. Neurobiology of Disease, 17(2), 283-289. https://doi.org/10.1016/j.nbd.2004.06.008

Luchtman, D. W., Shao, D., \& Song, C. (2009). Behavior, neurotransmitters and inflammation in three regimens of the MPTP mouse model of Parkinson's disease. Physiology \& Behavior, 98(1-2), 130-138. https://doi.org/10.1016/j.physbeh.2009.04.021

Lundblad, M., Picconi, B., Lindgren, H., \& Cenci, M. A. (2004). A model of L-DOPAinduced dyskinesia in 6-hydroxydopamine lesioned mice: Relation to motor and cellular parameters of nigrostriatal function. Neurobiology of Disease, 16(1), 110123. https://doi.org/10.1016/j.nbd.2004.01.007

Luo, B., Wang, J., Liu, Y., Liu, Z., Shen, Z., Shi, R., ... Zhang, Z. (2016). Phagocyte respiratory burst activates macrophage erythropoietin signalling to promote acute inflammation resolution. Nature Communications, 7, 1-14. https://doi.org/10.1038/ncomms12177

Ma, R., Hu, J., Huang, C., Wang, M., Xiang, J., \& Li, G. (2014). JAK2/STAT5/Bcl-xL signalling is essential for erythropoietin-mediated protection against apoptosis induced in PC12 cells by the amyloid $\beta$-peptide A $325-35$. British Journal of Pharmacology, 171(13), 3234-3245. https://doi.org/10.1111/bph.12672 
Ma, S., Chen, J., Chen, C., Wei, N., Xu, J., Yang, G., ... Xu, Z. (2018). Erratum to: Erythropoietin Rescues Memory Impairment in a Rat Model of Chronic Cerebral Hypoperfusion via the EPO-R/JAK2/STAT5/PI3K/Akt/GSK-3 $\beta$ Pathway (Molecular Neurobiology, (2018), 55, 4, (3290-3299), 10.1007/s12035-017-0568-5). Molecular Neurobiology, 55(4), 3300. https://doi.org/10.1007/s12035-017-0657-5

MacLeod, D., Dowman, J., Hammond, R., Leete, T., Inoue, K., \& Abeliovich, A. (2006). The Familial Parkinsonism Gene LRRK2 Regulates Neurite Process Morphology. Neuron, 52(4), 587-593. https://doi.org/10.1016/j.neuron.2006.10.008

Macphee, G. J. A., \& Stewart, D. A. (2012). Parkinson's disease - Pathology, aetiology and diagnosis. Reviews in Clinical Gerontology, 22(3), 165-178.

https://doi.org/10.1017/S095925981200007X

Mahato, A. K., Renko, J.-M., Kopra, J., Visnapuu, T., Korhonen, I., Pulkkinen, N., ... Saarma, M. (2019). GDNF receptor agonist supports dopamine neurons in vitro and protects their function in animal model of Parkinson\&\#039;s disease. BioRxiv, 540021. https://doi.org/10.1101/540021

Mallajosyula, J. K., Kaur, D., Chinta, S. J., Rajagopalan, S., Rane, A., Nicholls, D. G., ... Andersen, J. K. (2008). MAO-B Elevation in Mouse Brain Astrocytes Results in Parkinson's Pathology. PLoS ONE, 3(2), e1616.

https://doi.org/10.1371/journal.pone.0001616

Mallet, N. (2006). Cortical Inputs and GABA Interneurons Imbalance Projection Neurons in the Striatum of Parkinsonian Rats. Journal of Neuroscience, 26(14), 3875-3884. https://doi.org/10.1523/JNEUROSCI.4439-05.2006

Mangano, E. N., Peters, S., Litteljohn, D., So, R., Bethune, C., Bobyn, J., ... Hayley, S. (2011). Granulocyte macrophage-colony stimulating factor protects against substantia nigra dopaminergic cell loss in an environmental toxin model of Parkinson's disease. Neurobiology of Disease, 43(1), 99-112.

https://doi.org/10.1016/j.nbd.2011.02.011

Mangano, Emily N., \& Hayley, S. (2009). Inflammatory priming of the substantia nigra influences the impact of later paraquat exposure: Neuroimmune sensitization of neurodegeneration. Neurobiology of Aging, 30(9), 1361-1378.

https://doi.org/10.1016/j.neurobiolaging.2007.11.020

Marshall, J. F., \& Ungerstedt, U. (1977). Supersensitivity to apomorphine following destruction of the ascending dopamine neurons: Quantification using the rotational model. European Journal of Pharmacology, 41(4), 361-367. https://doi.org/10.1016/0014-2999(77)90256-4

Martin, H. L., Santoro, M., Mustafa, S., Riedel, G., Forrester, J. V., \& Teismann, P. (2016). Evidence for a role of adaptive immune response in the disease pathogenesis of the 
MPTP mouse model of Parkinson's disease. Glia, 64(3), 386-395.

https://doi.org/10.1002/glia.22935

Martinez-Martin, P., Chaudhuri, K. R., Rojo-Abuin, J. M., Rodriguez-Blazquez, C., AlvarezSanchez, M., Arakaki, T., ... Goetz, C. G. (2015). Assessing the non-motor symptoms of Parkinson's disease: MDS-UPDRS and NMS Scale. European Journal of Neurology, 22(1), 37-43. https://doi.org/10.1111/ene.12165

Masuda, S., Nagao, M., Takahata, K., Konishi, Y., Gallyas, F., Tabira, T., \& Sasaki, R. (1993). Functional erythropoietin receptor of the cells with neural characteristics. Comparison with receptor properties of erythroid cells. The Journal of Biological Chemistry, 268(15), 11208-11216. Retrieved from http://www.ncbi.nlm.nih.gov/pubmed/7684373

Masuda, S., Okano, M., Yamagishi, K., Nagao, M., Ueda, M., \& Sasaki, R. (1994). A novel site of erythropoietin production. Oxygen-dependent production in cultured rat astrocytes. The Journal of Biological Chemistry, 269(30), 19488-19493. Retrieved from http://www.ncbi.nlm.nih.gov/pubmed/8034718

Mateus, V., Rocha, J., Alves, P., Mota-Filipe, H., Sepodes, B., \& Pinto, R. M. A. (2017). Anti-Inflammatory Effect of Erythropoietin in the TNBS-induced Colitis. Basic and Clinical Pharmacology and Toxicology, 120(2), 138-145. https://doi.org/10.1111/bcpt.12663

McGeer, P L, Itagaki, S., Boyes, B. E., \& McGeer, E. G. (1988). Reactive microglia are positive for HLA-DR in the substantia nigra of Parkinson\&\#039;s and Alzheimer\&\#039;s disease brains. Neurology, 38(8), 1285 LP - 1285. Retrieved from http://n.neurology.org/content/38/8/1285.abstract

McGeer, Patrick L., \& McGeer, E. G. (2008). Glial reactions in Parkinson's disease. Movement Disorders, 23(4), 474-483. https://doi.org/10.1002/mds.21751

McGuire, S. O., Ling, Z. D., Lipton, J. W., Sortwell, C. E., Collier, T. J., \& Carvey, P. M. (2001). Tumor Necrosis Factor $\alpha$ Is Toxic to Embryonic Mesencephalic Dopamine Neurons. Experimental Neurology, 169(2), 219-230. https://doi.org/10.1006/exnr.2001.7688

McNaught, K. S. P., \& Olanow, C. W. (2006). Protein aggregation in the pathogenesis of familial and sporadic Parkinson's disease. Neurobiology of Aging, 27(4), 530-545. https://doi.org/10.1016/j.neurobiolaging.2005.08.012

Menza, M., Dobkin, R. D., Marin, H., Mark, M. H., Gara, M., Bienfait, K., ... Kusnekov, A. (2011). NIH Public Access, 51(6), 474-479. https://doi.org/10.1176/appi.psy.51.6.474.The

Merola, A., Zibetti, M., Angrisano, S., Rizzi, L., Ricchi, V., Artusi, C. A., ... Lopiano, L. 
(2011). Parkinson's disease progression at 30 years: A study of subthalamic deep brain-stimulated patients. Brain, 134(7), 2074-2084.

https://doi.org/10.1093/brain/awr121

Michel, P. P., \& Hefti, F. (1990). Toxicity of 6-hydroxydopamine and dopamine for dopaminergic neurons in culture. Journal of Neuroscience Research, 26(4), 428435. https://doi.org/10.1002/jnr.490260405

Mitra, S., Chakrabarti, N., \& Bhattacharyya, A. (2011). Differential regional expression patterns of alpha-synuclein, TNF-alpha, and IL-1beta; and variable status of dopaminergic neurotoxicity in mouse brain after Paraquat treatment. Journal of Neuroinflammation, 8(1), 163. https://doi.org/10.1186/1742-2094-8-163

Mochizuki, H., Goto, K., Mori, H., \& Mizuno, Y. (1996). Histochemical detection of apoptosis in Parkinson's disease. Journal of the Neurological Sciences, 137(2), 120123. https://doi.org/10.1016/0022-510X(95)00336-Z

Mochizuki, H., Imai, H., Endo, K., Yokomizo, K., Murata, Y., Hattori, N., \& Mizuno, Y. (1994). Iron accumulation in the substantia nigra of 1-methyl-4-phenyl-1,2,3,6tetrahydropyridine (MPTP)-induced hemiparkinsonian monkeys. Neuroscience Letters, 168(1-2), 251-253. https://doi.org/10.1016/0304-3940(94)90462-6

Mogi, M., Togari, A., Kondo, T., Mizuno, Y., Komure, O., Kuno, S., ... Nagatsu, T. (2000). Caspase activities and tumor necrosis factor receptor R1 (p55) level are elevated in the substantia nigra from parkinsonian brain. Journal of Neural Transmission (Vienna, Austria : 1996), 107(3), 335-341. https://doi.org/10.1007/s007020050028

Monzani, E., Nicolis, S., Dell'Acqua, S., Capucciati, A., Bacchella, C., Zucca, F. A., ... Casella, L. (2019). Dopamine, Oxidative Stress and Protein-Quinone Modifications in Parkinson's and Other Neurodegenerative Diseases. Angewandte Chemie International Edition, 58(20), 6512-6527. https://doi.org/10.1002/anie.201811122

Nakamura, H., Sasaki, Y., Sasaki, M., Kataoka-Sasaki, Y., Oka, S., Nakazaki, M., ... Honmou, O. (2017). Elevated brain derived neurotrophic factor (BDNF) levels in plasma but not serum reflect in vivo functional viability of infused mesenchymal stem cells after middle cerebral artery occlusion in rat. Journal of Neurosurgical Sciences. https://doi.org/10.23736/S0390-5616.17.03989-3

Nakamura, S., Sho, M., Koyama, F., Ueda, T., Nishigori, N., Inoue, T., ... Nakajima, Y. (2015). Erythropoietin attenuates intestinal inflammation and promotes tissue regeneration. Scandinavian Journal of Gastroenterology, 50(9), 1094-1102. https://doi.org/10.3109/00365521.2015.1020861

Nam, J. H., Leem, E., Jeon, M. T., Jeong, K. H., Park, J. W., Jung, U. J., ... Kim, S. R. (2015). Induction of GDNF and BDNF by hRheb(S16H) Transduction of SNpc Neurons: Neuroprotective Mechanisms of hRheb(S16H) in a Model of Parkinson's Disease. 
Molecular Neurobiology, 51(2), 487-499. https://doi.org/10.1007/s12035-0148729-2

Natsume, A., Mata, M., Goss, J., Huang, S., Wolfe, D., Oligino, T., ... Fink, D. J. (2001). Bcl2 and GDNF Delivered by HSV-Mediated Gene Transfer Act Additively to Protect Dopaminergic Neurons from 6-OHDA-Induced Degeneration. Experimental Neurology, 169(2), 231-238. https://doi.org/10.1006/exnr.2001.7671

Nencini, S., Ringuet, M., Kim, D.-H., Greenhill, C., \& Ivanusic, J. J. (2018). GDNF, Neurturin, and Artemin Activate and Sensitize Bone Afferent Neurons and Contribute to Inflammatory Bone Pain. The Journal of Neuroscience, 38(21), 48994911. https://doi.org/10.1523/JNEUROSCI.0421-18.2018

Nichol, A., French, C., Little, L., Haddad, S., Presneill, J., Arabi, Y., ... Bellomo, R. (2015). Erythropoietin in traumatic brain injury (EPO-TBI): a double-blind randomised controlled trial. The Lancet, 386(10012), 2499-2506. https://doi.org/10.1016/S0140-6736(15)00386-4

Niranjan, R. (2014). The Role of inflammatory and oxidative stress mechanisms in the pathogenesis of parkinson's disease: Focus on astrocytes. Molecular Neurobiology, 49(1), 28-38. https://doi.org/10.1007/s12035-013-8483-x

Noelker, C., Morel, L., Lescot, T., Osterloh, A., Alvarez-Fischer, D., Breloer, M., ... Hartmann, A. (2013). Toll like receptor 4 mediates cell death in a mouse MPTP model of Parkinson disease. Scientific Reports, 3, 1-5. https://doi.org/10.1016/j.eswa.2008.06.024

Norden, D. M., Trojanowski, P. J., Villanueva, E., Navarro, E., \& Godbout, J. P. (2016). Sequential activation of microglia and astrocyte cytokine expression precedes increased iba-1 or GFAP immunoreactivity following systemic immune challenge. Glia, 64(2), 300-316. https://doi.org/10.1002/glia.22930

Novikova, L., Garris, B. L., Garris, D. R., \& Lau, Y.-S. (2006). Early signs of neuronal apoptosis in the substantia nigra pars compacta of the progressive neurodegenerative mouse 1-methyl-4-phenyl-1,2,3,6tetrahydropyridine/probenecid model of Parkinson's disease. Neuroscience, 140(1), 67-76. https://doi.org/10.1016/j.neuroscience.2006.02.007

Nutt, J G, Burchiel, K. J., Comella, C. L., Jankovic, J., Lang, A. E., Laws, E. R., ... Wooten, G. F. (2003). Randomized, double-blind trial of glial cell line-derived neurotrophic factor (GDNF) in PD. Neurology, 60(1), 69 LP - 73. Retrieved from http://n.neurology.org/content/60/1/69.abstract

Nutt, John G, \& Wooten, G. F. (2005). Diagnosis and Initial Management of Parkinson ' s Disease. The New England Journal of Medicine, 353, 1021-1027. https://doi.org/10.1056/NEJMcp043908 
Obeso, J. A., Stamelou, M., Goetz, C. G., Poewe, W., Lang, A. E., Weintraub, D., ... Stoessl, A. J. (2017). Past, present, and future of Parkinson's disease: A special essay on the 200th Anniversary of the Shaking Palsy. Movement Disorders. https://doi.org/10.1002/mds.27115

Osborn, M., Rustom, N., Clarke, M., Litteljohn, D., Rudyk, C., Anisman, H., \& Hayley, S. (2013). Antidepressant-Like Effects of Erythropoietin: A Focus on Behavioural and Hippocampal Processes. PLoS ONE, 8(9), 1-9. https://doi.org/10.1371/journal.pone.0072813

Osborn, M., Rustom, N., Clarke, M., Litteljohn, D., Rudyk, C., Anisman, H., ... Lucassen, P. J. (2010). NIH Public Access. PLOS ONE, 33(9), 1-17. https://doi.org/10.1371/journal.pone.0072813

Ostrowski, D., \& Heinrich, R. (2018). Alternative Erythropoietin Receptors in the Nervous System. Journal of Clinical Medicine, 7(2), 24. https://doi.org/10.3390/jcm7020024

Ouchi, Y., Yoshikawa, E., Sekine, Y., Futatsubashi, M., Kanno, T., Ogusu, T., \& Torizuka, T. (2005). Microglial activation and dopamine terminal loss in early Parkinson's disease. Annals of Neurology, 57(2), 168-175. https://doi.org/10.1002/ana.20338

Paasila, P. J., Davies, D. S., Kril, J. J., Goldsbury, C., \& Sutherland, G. T. (2019). The relationship between the morphological subtypes of microglia and Alzheimer's disease neuropathology. Brain Pathology, 0(33), 1-15.

https://doi.org/10.1111/bpa.12717

Pang, L., Zhang, N., Dong, N., Wang, D. W., Xu, D. H., Zhang, P., \& Meng, X. W. (2016). Erythropoietin Protects Rat Brain Injury from Carbon Monoxide Poisoning by Inhibiting Toll-Like Receptor 4/NF-kappa B-Dependent Inflammatory Responses. Inflammation, 39(2), 561-568. https://doi.org/10.1007/s10753-015-0280-4

Papadopoulos, V., Lecanu, L., Brown, R. C., Han, Z., \& Yao, Z. X. (2006). Peripheral-type benzodiazepine receptor in neurosteroid biosynthesis, neuropathology and neurological disorders. Neuroscience, 138(3), 749-756.

https://doi.org/10.1016/j.neuroscience.2005.05.063

Papadopoulos, Vassilios, Baraldi, M., Guilarte, T. R., Knudsen, T. B., Lacapère, J. J., Lindemann, P., ... Gavish, M. (2006). Translocator protein (18 kDa): new nomenclature for the peripheral-type benzodiazepine receptor based on its structure and molecular function. Trends in Pharmacological Sciences, 27(8), 402409. https://doi.org/10.1016/j.tips.2006.06.005

Paré, D., Curro'Dossi, R., \& Steriade, M. (1990). Neuronal basis of the parkinsonian resting tremor: a hypothesis and its implications for treatment. Neuroscience, 35(2), 217-226. Retrieved from http://www.ncbi.nlm.nih.gov/pubmed/2199839 
Park, J., Min, J.-S., Kim, B., Chae, U.-B., Yun, J. W., Choi, M.-S., ... Lee, D.-S. (2015). Mitochondrial ROS govern the LPS-induced pro-inflammatory response in microglia cells by regulating MAPK and NF-KB pathways. Neuroscience Letters, 584, 191-196. https://doi.org/10.1016/j.neulet.2014.10.016

Park, S. L., Won, S. Y., Song, J.-H., Kambe, T., Nagao, M., Kim, W.-J., \& Moon, S.-K. (2015). EPO gene expression promotes proliferation, migration and invasion via the p38MAPK/AP-1/MMP-9 pathway by p21WAF1 expression in vascular smooth muscle cells. Cellular Signalling, 27(3), 470-478.

https://doi.org/10.1016/j.cellsig.2014.12.001

Patel, N. K., Bunnage, M., Plaha, P., Svendsen, C. N., Heywood, P., \& Gill, S. S. (2005). Intraputamenal infusion of glial cell line-derived neurotrophic factor in PD: A twoyear outcome study. Annals of Neurology, 57(2), 298-302. https://doi.org/10.1002/ana.20374

Patrick, K. L., Bell, S. L., Weindel, C. G., \& Watson, R. O. (2019). Exploring the "MultipleHit Hypothesis" of Neurodegenerative Disease: Bacterial Infection Comes Up to Bat. Frontiers in Cellular and Infection Microbiology, 9. https://doi.org/10.3389/fcimb.2019.00138

Pearce, R. K. B., Owen, A., Daniel, S., Jenner, P., \& Marsden, C. D. (1997). Alterations in the distribution of glutathione in the substantia nigra in Parkinson's disease. Journal of Neural Transmission, 104(6-7), 661-677. https://doi.org/10.1007/BF01291884

Pekny, M., \& Pekna, M. (2016). Reactive gliosis in the pathogenesis of CNS diseases. Biochimica et Biophysica Acta (BBA) - Molecular Basis of Disease, 1862(3), 483-491. https://doi.org/10.1016/j.bbadis.2015.11.014

Pekny, M., Wilhelmsson, U., Tatlisumak, T., \& Pekna, M. (2018). Astrocyte activation and reactive gliosis-A new target in stroke? Neuroscience Letters. https://doi.org/10.1016/j.neulet.2018.07.021

Penttinen, A.-M., Parkkinen, I., Voutilainen, M. H., Koskela, M., Bäck, S., Their, A., ... Airavaara, M. (2018). Pre- $\alpha$-pro-GDNF and Pre- $\beta$-pro-GDNF Isoforms Are Neuroprotective in the 6-hydroxydopamine Rat Model of Parkinson's Disease . Frontiers in Neurology . Retrieved from https://www.frontiersin.org/article/10.3389/fneur.2018.00457

Perier, C., \& Vila, M. (2012). Mitochondrial Biology and Parkinson's Disease. Cold Spring Harbor Perspectives in Medicine, 2(2), a009332-a009332. https://doi.org/10.1101/cshperspect.a009332

Perier, Celine, Bové, J., \& Vila, M. (2012). Mitochondria and Programmed Cell Death in Parkinson's Disease: Apoptosis and Beyond. Antioxidants \& Redox Signaling, 16(9), 
883-895. https://doi.org/10.1089/ars.2011.4074

Perumal, A. S., Tordzro, W. K., Katz, M., Jackson-Lewis, V., Cooper, T. B., Fahn, S., \& Cadet, J. L. (1989). Regional effects of 6-hydroxydopamine (6-OHDA) on free radical scavengers in rat brain. Brain Research, 504(1), 139-141. https://doi.org/10.1016/0006-8993(89)91611-9

Petrova, P. S., Raibekas, A., Pevsner, J., Vigo, N., Anafi, M., Moore, M. K., ... Commissiong, J. W. (2003). MANF: A New Mesencephalic, Astrocyte-Derived Neurotrophic Factor with Selectivity for Dopaminergic Neurons. Journal of Molecular Neuroscience, 20(2), 173-188. https://doi.org/10.1385/JMN:20:2:173

Pfeiffer, R. F. (2016). Non-motor symptoms in Parkinson's disease. Parkinsonism \& Related Disorders, 22, S119-S122. https://doi.org/10.1016/j.parkreldis.2015.09.004

Postuma, R. B., Berg, D., Adler, C. H., Bloem, B. R., Chan, P., Deuschl, G., ... Stern, M. (2016). The new definition and diagnostic criteria of Parkinson's disease. The Lancet Neurology, 15(6), 546-548. https://doi.org/10.1016/S1474-4422(16)00116-2

Postuma, R. B., Berg, D., Stern, M., Poewe, W., Olanow, C. W., Oertel, W., ... Deuschl, G. (2015). MDS clinical diagnostic criteria for Parkinson's disease. Movement Disorders, 30(12), 1591-1601. https://doi.org/10.1002/mds.26424

Przedbroski, S., Leviver, M., Jiang, H., Ferreira, M., Jackson-Lewis, V., Donaldson, D., \& Togasaki, D. M. (1995). Dose-dependent lesions of the dopaminergic nigrostriatal pathway induced by instrastriatal injection of 6-hydroxydopamine. Neuroscience, 67(3), 631-647. https://doi.org/10.1016/0306-4522(95)00066-R

Purisai, M. G., McCormack, A. L., Cumine, S., Li, J., Isla, M. Z., \& Di Monte, D. A. (2007). Microglial activation as a priming event leading to paraquat-induced dopaminergic cell degeneration. Neurobiology of Disease, 25(2), 392-400. https://doi.org/10.1016/j.nbd.2006.10.008

Qian, L., Flood, P. M., \& Hong, J.-S. (2010). Neuroinflammation is a key player in Parkinson's disease and a prime target for therapy. Journal of Neural Transmission, 117(8), 971-979. https://doi.org/10.1007/s00702-010-0428-1

Rabie, T., \& Marti, H. H. (2008). Brain Protection by Erythropoietin: A Manifold Task. Physiology, 23(5), 263-274. https://doi.org/10.1152/physiol.00016.2008

Ransohoff, R. M. (2016). A polarizing question: do M1 and M2 microglia exist? Nature Neuroscience, 19, 987. Retrieved from https://doi.org/10.1038/nn.4338

Rao, S. S., Hofmann, L. a, \& Shakil, A. (2006). Parkinson's disease: diagnosis and treatment. Am Fam Physician, 74(12), 2046-2054.

Rappold, P. M., \& Tieu, K. (2010). Astrocytes and Therapeutics for Parkinson' s Disease. 
Neurotherapeutics, 7(October), 413-423.

https://doi.org/doi:10.1016/j.nurt.2010.07.001

Ren, M., Han, M., Wei, X., Guo, Y., Shi, H., Zhang, X., ... Cenci, M. A. (2011). Behavioral characterization of a unilateral 6-OHDA-lesion model of Parkinson's disease in mice. Behavioural Brain Research, 42(1), 314-323.

https://doi.org/10.1016/j.expneurol.2007.10.012

Ren, M., Han, M., Wei, X., Guo, Y., Shi, H., Zhang, X., ... Lou, H. (2017). FTY720 Attenuates 6-OHDA-Associated Dopaminergic Degeneration in Cellular and Mouse Parkinsonian Models. Neurochemical Research, 42(2), 686-696. https://doi.org/10.1007/s11064-016-2125-4

Ribeiro, R. P., Moreira, E. L. G., Santos, D. B., Colle, D., Dos Santos, A. A., Peres, K. C., ... Farina, M. (2013). Probucol affords neuroprotection in a 6-OHDA mouse model of Parkinson's disease. Neurochemical Research, 38(3), 660-668. https://doi.org/10.1007/s11064-012-0965-0

Riccio, A., Ahn, S., Davenport, C. M., Blendy, J. A., \& Ginty, D. D. (1999). Mediation by a CREB Family Transcription Factor of NGF-Dependant Survival of Sympathetic Neurons. Science, 286(5448), 2358-2361. https://doi.org/10.1126/science.286.5448.2358

Riederer, P., Sofic, E., Rausch, W. -D, Schmidt, B., Reynolds, G. P., Jellinger, K., \& Youdim, M. B. H. (1989). Transition Metals, Ferritin, Glutathione, and Ascorbic Acid in Parkinsonian Brains. Journal of Neurochemistry, 52(2), 515-520. https://doi.org/10.1111/j.1471-4159.1989.tb09150.x

Ritz, B. R., Paul, K. C., \& Bronstein, J. M. (2016). Of Pesticides and Men: a California Story of Genes and Environment in Parkinson's Disease. Current Environmental Health Reports, 3(1), 40-52. https://doi.org/10.1007/s40572-016-0083-2

Rodriguez-Pallares, J., Parga, J. A., Muñoz, A., Rey, P., Guerra, M. J., \& LabandeiraGarcia, J. L. (2007). Mechanism of 6-hydroxydopamine neurotoxicity: The role of NADPH oxidase and microglial activation in 6-hydroxydopamine-induced degeneration of dopaminergic neurons. Journal of Neurochemistry, 103(1), 145156. https://doi.org/10.1111/j.1471-4159.2007.04699.x

Rong, R., \& Xijun, X. (2015). Erythropoietin pretreatment suppresses inflammation by activating the PI3K/Akt signaling pathway in myocardial ischemia-reperfusion injury. Experimental and Therapeutic Medicine, 10(2), 413-418. https://doi.org/10.3892/etm.2015.2534

Sachs, C., \& Jonsson, G. (1975). Mechanisms of action of 6-OHDA. Biochemical Pharmacology, 24, 1-8. https://doi.org/10.1016/0006-2952(75)90304-4 
Sakanaka, M., Wen, T. C., Matsuda, S., Masuda, S., Morishita, E., Nagao, M., \& Sasaki, R. (1998). In vivo evidence that erythropoietin protects neurons from ischemic damage. Proc Natl Acad Sci U S A, 95(8), 4635-4640.

https://doi.org/10.1073/pnas.95.8.4635

Sargin, D., Friedrichs, H., El-Kordi, A., \& Ehrenreich, H. (2010). Erythropoietin as neuroprotective and neuroregenerative treatment strategy: Comprehensive overview of 12 years of preclinical and clinical research. Best Practice and Research: Clinical Anaesthesiology, 24(4), 573-594.

https://doi.org/10.1016/j.bpa.2010.10.005

Sauer, H., \& Oertel, W. H. (1994). Progressive degeneration of nigrostriatal dopamine neurons following intrastriatal terminal lesions with 6-hydroxydopamine: A combined retrograde tracing and immunocytochemical study in the rat. Neuroscience, 59(2), 401-415. https://doi.org/10.1016/0306-4522(94)90605-X

Saura, J., Richards, J. G., \& Mahy, N. (1994). Age-related changes on MAO in Bl/C57 mouse tissues: a quantitative radioautographic study. Journal of Neural Transmission. Supplementum, 41, 89-94. Retrieved from http://www.ncbi.nlm.nih.gov/pubmed/7931270

Schäbitz, W. R., Krüger, C., Pitzer, C., Weber, D., Laage, R., Gassler, N., ... Schneider, A. (2008). A neuroprotective function for the hematopoietic protein granulocytemacrophage colony stimulating factor (GM-CSF). Journal of Cerebral Blood Flow and Metabolism, 28(1), 29-43. https://doi.org/10.1038/sj.jcbfm.9600496

Schapira, A. H. V, Chaudhuri, K. R., \& Jenner, P. (2017). Non-motor features of Parkinson disease. Nature Reviews Neuroscience, 18, 435. Retrieved from https://doi.org/10.1038/nrn.2017.62

Schneider, J. S., \& Denaro, F. J. (1988). Astrocytic responses to the dopaminergic neurotoxin 1-methyl-4-phenyl-1,2,3,6-tetrahydropyridine (MPTP) in cat and mouse brain. Journal of Neuropathology and Experimental Neurology, 47(4), 452-458.

Retrieved from http://www.ncbi.nlm.nih.gov/pubmed/2898510

Schober, A. (2004). Classic toxin-induced animal models of Parkinson's disease: 6-OHDA and MPTP. Cell and Tissue Research, 318(1), 215-224.

https://doi.org/10.1007/s00441-004-0938-y

Senoh, S., Witkop, B., Creveling, C. R., \& Udenfriend, S. (1959). 2,4,5-

TRIHYDROXYPHENETHYLAMINE, A NEW METABOLITE OF 3,4-

DIHYDROXYPHENETHYLAMINE. Journal of the American Chemical Society, 81(7), 1768-1769. https://doi.org/10.1021/ja01516a065

Senoh, Siro, Creveling, C. R., Udenfriend, S., \& Witkop, B. (1959). Chemical, Enzymatic and Metabolic Studies on the Mechanism of Oxidation of Dopamine. Journal of the 
American Chemical Society, 81(23), 6236-6240.

https://doi.org/10.1021/ja01532a030

Senoh, Siro, \& Witkop, B. (1959a). Formation and Rearrangements of Aminochromes from a New Metabolite of Dopamine and Some of its Derivatives. Journal of the American Chemical Society, 81(23), 6231-6235. https://doi.org/10.1021/ja01532a029

Senoh, Siro, \& Witkop, B. (1959b). Non-enzymatic Conversions of Dopamine to Norepinephrine and Trihydroxyphenethylamines ${ }^{1}$. Journal of the American Chemical Society, 81(23), 6222-6231. https://doi.org/10.1021/ja01532a028

Shang, Y. C., Chong, Z. Z., Wang, S., \& Maiese, K. (2011). Erythropoietin and Wnt1 govern pathways of mTOR, Apaf-1, and XIAP in inflammatory microglia. Current Neurovascular Research, 8(4), 270-285. Retrieved from http://www.ncbi.nlm.nih.gov/pubmed/22023617

Shang, Y. C., Chong, Z. Z., Wang, S., \& Maiese, K. (2012). Prevention of $\beta$-amyloid degeneration.pdf, 4(3), 187-201.

Shen, J., Wu, Y., Xu, J. Y., Zhang, J., Sinclair, S. H., Yanoff, M., ... Xu, G. T. (2010). ERK- and Akt-dependent neuroprotection by erythropoietin (EPO) against glyoxal-AGEs via modulation of $\mathrm{Bcl}-\mathrm{xL}, \mathrm{Bax}$, and $\mathrm{BAD}$. Investigative Ophthalmology and Visual Science, 51(1), 35-46. https://doi.org/10.1167/iovs.09-3544

Sherer, T. B., Betarbet, R., Kim, J.-H., \& Greenamyre, J. T. (2003). Selective microglial activation in the rat rotenone model of Parkinson's disease. Neuroscience Letters, 341(2), 87-90. https://doi.org/10.1016/S0304-3940(03)00172-1

Shi, X., Yang, J., Zhu, H., Ye, L., Feng, M., Li, J., ... Ju, D. (2013). Pharmacokinetics and pharmacodynamics of recombinant human EPO-Fc fusion protein in vivo. PLoS ONE, 8(8). https://doi.org/10.1371/journal.pone.0072673

Shrivastava, P., Vaibhav, K., Tabassum, R., Khan, A., Ishrat, T., Khan, M. M., ... Islam, F. (2013). Anti-apoptotic and Anti-inflammatory effect of Piperine on 6-OHDA induced Parkinson's Rat model. The Journal of Nutritional Biochemistry, 24(4), 680-687. https://doi.org/10.1016/j.jnutbio.2012.03.018

Sifringer, M., Brait, D., Weichelt, U., Zimmerman, G., Endesfelder, S., Brehmer, F., ... Felderhoff-Mueser, U. (2010). Erythropoietin attenuates hyperoxia-induced oxidative stress in the developing rat brain. Brain, Behavior, and Immunity, 24(5), 792-799. https://doi.org/10.1016/j.bbi.2009.08.010

Signore, A. P., Weng, Z., Hastings, T., Van Laar, A. D., Liang, Q., Lee, Y. J., \& Chen, J. (2006). Erythropoietin protects against 6-hydroxydopamine-induced dopaminergic cell death. Journal of Neurochemistry, 96(2), 428-443. 
https://doi.org/10.1111/j.1471-4159.2005.03587.x

Silva, M., Benito, A., Sanz, C., Prosper, F., Ekhterae, D., \& Fernandez-luna, J. L. (1999). Erythropoietin Can Induce the Expression of Bcl-x L through Stat5 in Erythropoietindependent Progenitor Cell Lines *. Biochemistry, 274(32), 22165-22169. https://doi.org/10.1074/jbc.274.32.22165

Siren, A.-L., Fratelli, M., Brines, M., Goemans, C., Casagrande, S., Lewczuk, P., ... Ghezzi, P. (2001). Erythropoietin prevents neuronal apoptosis after cerebral ischemia and metabolic stress. Proceedings of the National Academy of Sciences, 98(7), 40444049. https://doi.org/10.1073/pnas.051606598

Slevin, J. T., Gerhardt, G. A., Smith, C. D., Gash, D. M., Kryscio, R., \& Young, B. (2005). Improvement of bilateral motor functions in patients with Parkinson disease through the unilateral intraputaminal infusion of glial cell line-derived neurotrophic factor. Journal of Neurosurgery, 102(2), 216-222. https://doi.org/10.3171/jns.2005.102.2.0216

Smith, J. A., Das, A., Ray, S. K., \& Banik, N. L. (2012). Role of pro-inflammatory cytokines released from microglia in neurodegenerative diseases. Brain Research Bulletin, 87(1), 10-20. https://doi.org/10.1016/j.brainresbull.2011.10.004

Snyder, A. M., \& Connor, J. R. (2009). Iron, the substantia nigra and related neurological disorders. Biochimica et Biophysica Acta - General Subjects, 1790(7), 606-614. https://doi.org/10.1016/j.bbagen.2008.08.005

Sofic, E., Paulus, W., Jellinger, K., Riederer, P., \& Youdim, M. B. H. (1991). Selective Increase of Iron in Substantia Nigra Zona Compacta of Parkinsonian Brains. Journal of Neurochemistry, 56(3), 978-982. https://doi.org/10.1111/j.14714159.1991.tb02017.x

Sofroniew, M. V. (2005). Reactive Astrocytes in Neural Repair and Protection. The Neuroscientist, 11(5), 400-407. https://doi.org/10.1177/1073858405278321

Spillantini, M. G., Crowther, R. A., Jakes, R., Hasegawa, M., \& Goedert, M. (1998). alphaSynuclein in filamentous inclusions of Lewy bodies from Parkinson's disease and dementia with lewy bodies. Proceedings of the National Academy of Sciences of the United States of America, 95(11), 6469-6473. https://doi.org/10.1073/pnas.95.11.6469

Stott, S. R. W., \& Barker, R. A. (2014). Time course of dopamine neuron loss and glial response in the 6-OHDA striatal mouse model of Parkinson's disease. European Journal of Neuroscience, 39(6), 1042-1056. https://doi.org/10.1111/ejn.12459

Sugama, S., Yang, L., Cho, B. P., DeGiorgio, L. A., Lorenzl, S., Albers, D. S., ... Joh, T. H. (2003). Age-related microglial activation in 1-methyl-4-phenyl-1,2,3,6- 
tetrahydropyridine (MPTP)-induced dopaminergic neurodegeneration in C57BL/6 mice. Brain Research, 964(2), 288-294. Retrieved from http://www.ncbi.nlm.nih.gov/pubmed/12576189

Surmeier, D. J., Guzman, J. N., Sanchez-Padilla, J., \& Schumacker, P. T. (2011). The role of calcium and mitochondrial oxidant stress in the loss of substantia nigra pars compacta dopaminergic neurons in Parkinson's disease. Neuroscience, 198, 221231. https://doi.org/10.1016/j.neuroscience.2011.08.045

Tabira, T., Konishi, Y., \& Gallyas, F. (1995). Neurotrophic effect of hematopoietic cytokines on cholinergic and other neurons in vitro. International Journal of Developmental Neuroscience, 13(3-4), 241-252. https://doi.org/10.1016/07365748(94)00020-4

Takahashi, M. (2001). The GDNF/RET signaling pathway and human diseases. Cytokine \& Growth Factor Reviews, 12(4), 361-373. Retrieved from http://www.ncbi.nlm.nih.gov/pubmed/11544105

Takai, N., Nakanishi, H., Tanabe, K., Nishioku, T., Sugiyama, T., Fujiwara, M., \& Yamamoto, K. (1998). Involvement of caspase-like proteinases in apoptosis of neuronal PC12 cells and primary cultured microglia induced by 6hydroxydopamine. Journal of Neuroscience Research, 54(2), 214-222. https://doi.org/10.1002/(SICI)1097-4547(19981015)54:2<214::AID-JNR9>3.0.CO;2$\mathrm{H}$

Tang, Y., \& Le, W. (2016). Differential Roles of M1 and M2 Microglia in Neurodegenerative Diseases. Molecular Neurobiology, 53(2), 1181-1194. https://doi.org/10.1007/s12035-014-9070-5

Tatton, W. G., \& Olanow, C. W. (1999). Apoptosis in neurodegenerative diseases: the role of mitochondria. Biochimica et Biophysica Acta, 1410(2), 195-213. Retrieved from http://www.ncbi.nlm.nih.gov/pubmed/10076027

Taylor, J. M., Main, B. S., \& Crack, P. J. (2013). Neuroinflammation and oxidative stress: Co-conspirators in the pathology of Parkinson's disease. Neurochemistry International, 62(5), 803-819. https://doi.org/10.1016/j.neuint.2012.12.016

Temlett, J. A., Landsberg, J. P., Watt, F., \& Orime, G. W. (1994). Increased Iron in the Substantia Nigra Compacta of the MPTP-Lesioned Hemiparkinsonian African Green Monkey: Evidence from Proton Microprobe Elemental Microanalysis. Journal of Neurochemistry, 62(1), 134-146. https://doi.org/10.1046/j.14714159.1994.62010134.x

Thirthalli, J., Zhou, L., Kumar, K., Gao, J., Vaid, H., Liu, H., ... Nichter, M. (2016).

Traditional, complementary, and alternative medicine approaches to mental health care and psychological wellbeing in India and China. The Lancet Psychiatry, 3(7), 
660-672. https://doi.org/10.1016/S2215-0366(16)30025-6

Thomas Tayra, J., Kameda, M., Yasuhara, T., Agari, T., Kadota, T., Wang, F., ... Date, I. (2013). The neuroprotective and neurorescue effects of carbamylated erythropoietin Fc fusion protein (CEPO-Fc) in a rat model of Parkinson's disease. Brain Research, 1502, 55-70. https://doi.org/10.1016/j.brainres.2013.01.042

Tomac, A., Lindqvist, E., Lin, L.-F. H., Ögren, S. O., Young, D., Hoffer, B. J., \& Olson, L. (1995). Protection and repair of the nigrostriatal dopaminergic system by GDNF in vivo. Nature, 373, 335. Retrieved from http://dx.doi.org/10.1038/373335a0

Tompkins, M. M., Basgall, E. J., Zamrini, E., \& Hill, W. D. (1997). Apoptotic-like changes in Lewy-body-associated disorders and normal aging in substantia nigral neurons. The American Journal of Pathology, 150(1), 119-131. Retrieved from http://www.ncbi.nlm.nih.gov/pubmed/9006329

Trevaskis JL, Bittencourt Sacramento C, Jouihan H, Ali S, Le Lay J, Oldham S, Bhagroo N, B. B. et al. (2017). Role of NRTN in diabetes. Diabetes, 1-49. https://doi.org/10.2337

Truong, L., Allbutt, H., Kassiou, M., \& Henderson, J. M. (2006). Developing a preclinical model of Parkinson's disease: A study of behaviour in rats with graded 6-OHDA lesions. Behavioural Brain Research, 169(1), 1-9. https://doi.org/10.1016/j.bbr.2005.11.026

Tysnes, O. B., \& Storstein, A. (2017). Epidemiology of Parkinson's disease. Journal of Neural Transmission, 124(8), 901-905. https://doi.org/10.1007/s00702-017-1686-y

Ungerstedt, U., \& Arbuthnott, G. W. (1970). Quantitative recording of rotational behavior in rats after 6-hydroxy-dopamine lesions of the nigrostriatal dopamine system. Brain Research, 24(3), 485-493. https://doi.org/10.1016/00068993(70)90187-3

Varcin, M., Bentea, E., Mertens, B., Van Den Haute, C., Baekelandt, V., Michotte, Y., \& Sarre, S. (2011). Acute versus long-term effects of 6-hydroxydopamine on oxidative stress and dopamine depletion in the striatum of mice. Journal of Neuroscience Methods, 202(2), 128-136. https://doi.org/10.1016/j.jneumeth.2011.07.004

Venderova, K., \& Park, D. S. (2012). Programmed Cell Death in Parkinson's Disease. Cold Spring Harbor Perspectives in Medicine, 2(8), a009365-a009365. https://doi.org/10.1101/cshperspect.a009365

Vermeiren, Y., \& De Deyn, P. P. (2017). Targeting the norepinephrinergic system in Parkinson's disease and related disorders: The locus coeruleus story. Neurochemistry International, 102, 22-32. https://doi.org/10.1016/j.neuint.2016.11.009 
Vila, M., \& Perier, C. (2008). Molecular pathways of programmed cell death in experimental Parkinson's disease. Parkinsonism \& Related Disorders, 14, S176S179. https://doi.org/10.1016/j.parkreldis.2008.04.026

Villa, P., Bigini, P., Mennini, T., Agnello, D., Laragione, T., Cagnotto, A., ... Ghezzi, P. (2003). Erythropoietin Selectively Attenuates Cytokine Production and Inflammation in Cerebral Ischemia by Targeting Neuronal Apoptosis. The Journal of Experimental Medicine, 198(6), 971-975. https://doi.org/10.1084/jem.20021067

Viswanath, V., Wu, Y., Boonplueang, R., Chen, S., Stevenson, F. F., Yantiri, F., ... Andersen, J. K. (2001). Caspase-9 Activation Results in Downstream Caspase-8 Activation and Bid Cleavage in 1-Methyl-4-Phenyl-1,2,3,6-TetrahydropyridineInduced Parkinson's Disease. The Journal of Neuroscience, 21(24), 9519-9528. https://doi.org/10.1523/JNEUROSCI.21-24-09519.2001

Vitellaro-Zuccarello, L., Mazzetti, S., Madaschi, L., Bosisio, P., Gorio, A., \& De Biasi, S. (2007). Erythropoietin-mediated preservation of the white matter in rat spinal cord injury. Neuroscience, 144(3), 865-877.

https://doi.org/10.1016/j.neuroscience.2006.10.023

Voutilainen, M., Bäck, S., Peränen, J., Lindholm, P., Raasmaja, A., Männistö, P. T., ... Tuominen, R. K. (2011). Chronic infusion of CDNF prevents 6-OHDA-induced deficits in a rat model of Parkinson's disease. Experimental Neurology, 228(1), 99-108. https://doi.org/10.1016/j.expneurol.2010.12.013

Voutilainen, M. H., Back, S., Porsti, E., Toppinen, L., Lindgren, L., Lindholm, P., ... Tuominen, R. K. (2009). Mesencephalic Astrocyte-Derived Neurotrophic Factor Is Neurorestorative in Rat Model of Parkinson's Disease. Journal of Neuroscience, 29(30), 9651-9659. https://doi.org/10.1523/JNEUROSCI.0833-09.2009

Wang, J., Gao, L., Yang, Y.-L., Li, Y.-Q., Chang, T., Man, M.-H., ... Li, L.-H. (2016). Low Serum Levels of Brain-Derived Neurotrophic Factor Were Associated with Poor Short-Term Functional Outcome and Mortality in Acute Ischemic Stroke. Molecular Neurobiology, (1), 7335-7342. https://doi.org/10.1007/s12035-016-0236-1

Wang, S., Jing, H., Yang, H., Liu, Z., Guo, H., Chai, L., \& Hu, L. (2015). Tanshinone i selectively suppresses pro-inflammatory genes expression in activated microglia and prevents nigrostriatal dopaminergic neurodegeneration in a mouse model of Parkinson's disease. Journal of Ethnopharmacology, 164, 247-255. https://doi.org/10.1016/j.jep.2015.01.042

Wang, X. H., Lu, G., Hu, X., Tsang, K. S., Kwong, W. H., Wu, F. X., ... Poon, W. S. (2012). Quantitative assessment of gait and neurochemical correlation in a classical murine model of Parkinson's disease. BMC Neuroscience, 13(1).

https://doi.org/10.1186/1471-2202-13-142 
Wang, Y., Zhang, Z. G., Rhodes, K., Renzi, M., Zhang, R. L., Kapke, A., ... Chopp, M. (2007). Post-ischemic treatment with erythropoietin or carbamylated erythropoietin reduces infarction and improves neurological outcome in a rat model of focal cerebral ischemia. British Journal of Pharmacology, 151(8), 1377-1384. https://doi.org/10.1038/sj.bjp.0707285

Wei, Q., Yeung, M., Jurma, O. P., \& Andersen, J. K. (1996). Genetic elevation of monoamine oxidase levels in dopaminergic PC12 cells results in increased free radical damage and sensitivity to MPTP. Journal of Neuroscience Research, 46(6), 666-673. https://doi.org/10.1002/(SICI)1097-4547(19961215)46:6<666::AIDJNR3>3.0.CO;2-D

Wen, T. C., Sadamoto, Y., Tanaka, J., Zhu, P. X., Nakata, K., Yong-Jie, M., ... Sakanaka, M. (2002). Erythropoietin protects neurons against chemical hypoxia and cerebral ischemic injury by up-regulating $\mathrm{Bcl}$-xL expression. Journal of Neuroscience Research, 67(6), 795-803. https://doi.org/10.1002/jnr.10166

Wirdefeldt, K., Adami, H.-O., Cole, P., Trichopoulos, D., \& Mandel, J. (2011). Epidemiology and etiology of Parkinson's disease: a review of the evidence. European Journal of Epidemiology, 26 Suppl 1, S1-58. https://doi.org/10.1007/s10654-011-9581-6

Wu, Y., Shang, Y., Sun, S., \& Liu, R. (2007). Antioxidant effect of erythropoietin on 1methyl-4-phenylpyridinium-induced neurotoxicity in PC12 cells. European Journal of Pharmacology, 564(1-3), 47-56. https://doi.org/10.1016/j.ejphar.2007.02.020

Wüllner, U., Kornhuber, J., Weller, M., Schulz, J. B., Löschmann, P. A., Riederer, P., \& Klockgether, T. (1999). Cell death and apoptosis regulating proteins in Parkinson's disease--a cautionary note. Acta Neuropathologica, 97(4), 408-412. Retrieved from http://www.ncbi.nlm.nih.gov/pubmed/10208281

Xue, Y. Q., Ma, B. F., Zhao, L. R., Tatom, J. B., Li, B., Jiang, L. X., ... Duan, W. M. (2010). AAV9-mediated erythropoietin gene delivery into the brain protects nigral dopaminergic neurons in a rat model of Parkinson's disease. Gene Therapy, 17(1), 83-94. https://doi.org/10.1038/gt.2009.113

Xue, Y. Q., Zhao, L. R., Guo, W. P., \& Duan, W. M. (2007). Intrastriatal administration of erythropoietin protects dopaminergic neurons and improves neurobehavioral outcome in a rat model of Parkinson's disease. Neuroscience, 146(3), 1245-1258. https://doi.org/10.1016/j.neuroscience.2007.02.004

Yamanaka, K., Eldeiry, M., Aftab, M., Mares, J., Ryan, T. J., Meng, X., ... Reece, T. B. (2018). Optimized induction of beta common receptor enhances the neuroprotective function of erythropoietin in spinal cord ischemic injury. Journal of Thoracic and Cardiovascular Surgery, 155(6), 2505-2516. https://doi.org/10.1016/j.jtcvs.2017.12.132 
Yamanaka, K., Eldeiry, M., Aftab, M., Ryan, T. J., Mares, J., Meng, X., ... Reece, T. B. (2018). Synergistic Reduction of Apoptosis with Diazoxide and Erythropoietin in Spinal Cord Ischemic Injury. The Annals of Thoracic Surgery. https://doi.org/10.1016/j.athoracsur.2018.07.022

Yang, J., Siao, C., Nagappan, G., Marinic, T., Jing, D., Chen, Z., ... Hempstead, B. L. (2009). NIH Public Access, 12(2), 113-115. https://doi.org/10.1038/nn.2244.Neuronal

Yarnall, A., Archibald, N., \& Burn, D. (2012). Parkinson's disease. Medicine (United Kingdom), 40(10), 529-535. https://doi.org/10.1016/j.mpmed.2012.07.008

Yoon, M. C., Shin, M. S., Kim, T. S., Kim, B. K., Ko, I. G., Sung, Y. H., ... Kim, C. J. (2007). Treadmill exercise suppresses nigrostriatal dopaminergic neuronal loss in 6hydroxydopamine-induced Parkinson's rats. Neuroscience Letters, 423(1), 12-17. https://doi.org/10.1016/j.neulet.2007.06.031

Youdim, M. B., Ben-Shachar, D., \& Riederer, P. (1993). The possible role of iron in the etiopathology of Parkinson's disease. Movement Disorders : Official Journal of the Movement Disorder Society, 8(1), 1-12. https://doi.org/10.1002/mds.870080102

Yu, D. F., Zhu, L. H., \& Jiang, L. (2017). Recombinant human erythropoietin augments neovascularization responses in a neonatal rat model of premature brain damage by phosphatidylinositol 3 kinase/akt pathway. Chinese Medical Journal, 130(7), 854-858. https://doi.org/10.4103/0366-6999.202744

Yu, J., Shi, Z., Su, X., Zhou, Y., Li, B., Wang, S., ... Wang, W. (2018). Expression of Bcl-2 and Bad in hippocampus of status epileptic rats and molecular mechanism of intervened recombinant human erythropoietin. Experimental and Therapeutic Medicine, 847-855. https://doi.org/10.3892/etm.2018.6250

Yue, P., Gao, L., Wang, X., Ding, X., \& Teng, J. (2018). Pretreatment of glial cell-derived neurotrophic factor and geranylgeranylacetone ameliorates brain injury in Parkinson's disease by its anti-apoptotic and anti-oxidative property. Journal of Cellular Biochemistry, 119(7), 5491-5502. https://doi.org/10.1002/jcb.26712

Yuen, C. M., Yeh, K. H., Wallace, C. G., Chen, K. H., Lin, H. S., Sung, P. H., ... Yip, H. K. (2017). EPO-cyclosporine combination therapy reduced brain infarct area in rat after acute ischemic stroke: Role of innate immune-inflammatory response, microRNAs and MAPK family signaling pathway. American Journal of Translational Research, 9(4), 1651-1666.

Zecca, L., Shima, T., Stroppolo, A., Goj, C., Battiston, G. A., Gerbasi, R., ... Swartz, H. M. (1996). Interaction of neuromelanin and iron in substantia nigra and other areas of human brain. Neuroscience, 73(2), 407-415. https://doi.org/10.1016/03064522(96)00047-4 
Zhang, F., Signore, A. P., Zhou, Z., Wang, S., Cao, G., \& Chen, J. (2006). Erythropoietin protects CA1 neurons against global cerebral ischemia in rat: potential signaling mechanisms. Journal of Neuroscience Research, 83(7), 1241-1251.

https://doi.org/10.1002/jnr.20816

Zhao, R., Lu, W., Fang, X., Guo, L., Yang, Z., Ye, N., ... Zhen, X. (2014). 6aR-11-Amino-Npropyl-noraporphine, a new dopamine D2and serotonin 5-HT1Adual agonist, elicits potent antiparkinsonian action and attenuates levodopa-induced dyskinesia in a 6OHDA-lesioned rat model of Parkinson's disease. Pharmacology Biochemistry and Behavior, 124, 204-210. https://doi.org/10.1016/j.pbb.2014.06.011

Zhou, C., Xiao, C., Commissiong, J. W., Krnjević, K., \& Ye, J. H. (2006). Mesencephalic astrocyte-derived neurotrophic factor enhances nigral gamma-aminobutyric acid release. Neuroreport, 17(3), 293-297. https://doi.org/10.1097/01.wnr.0000201504.23255.bc

Zhou, Q.-H., Hui, E. K.-W., Lu, J. Z., Boado, R. J., \& Pardridge, W. M. (2011). Brain penetrating IgG-erythropoietin fusion protein is neuroprotective following intravenous treatment in Parkinson's disease in the mouse. Brain Research, 1382, 315-320. https://doi.org/10.1016/j.brainres.2011.01.061

Zigmond, M. J., \& Smeyne, R. J. (2014). Exercise: Is it a neuroprotective and if so, how does it work? Parkinsonism and Related Disorders, 20(SUPPL.1), S123-S127. https://doi.org/10.1016/S1353-8020(13)70030-0

Zou, Y.-R., Zhang, J., Wang, J., Peng, L., Li, G.-S., \& Wang, L. (2016). Erythropoietin Receptor Activation Protects the Kidney From Ischemia/Reperfusion-Induced Apoptosis by Activating ERK/p53 Signal Pathway. Transplantation Proceedings, 48(1), 217-221. https://doi.org/10.1016/j.transproceed.2016.01.009

Zucca, F. A., Segura-Aguilar, J., Ferrari, E., Muñoz, P., Paris, I., Sulzer, D., ... Zecca, L. (2017). Interactions of iron, dopamine and neuromelanin pathways in brain aging and Parkinson's disease. Progress in Neurobiology, 155, 96-119. https://doi.org/10.1016/j.pneurobio.2015.09.012

Zuch, C. L., Nordstroem, V. K., Briedrick, L. A., Hoernig, G. R., Granholm, A. C., \& Bickford, P. C. (2000). Time course of degenerative alterations in nigral dopaminergic neurons following a 6-hydroxydopamine lesion. The Journal of Comparative Neurology, 427(3), 440-454. Retrieved from http://www.ncbi.nlm.nih.gov/pubmed/11054705 


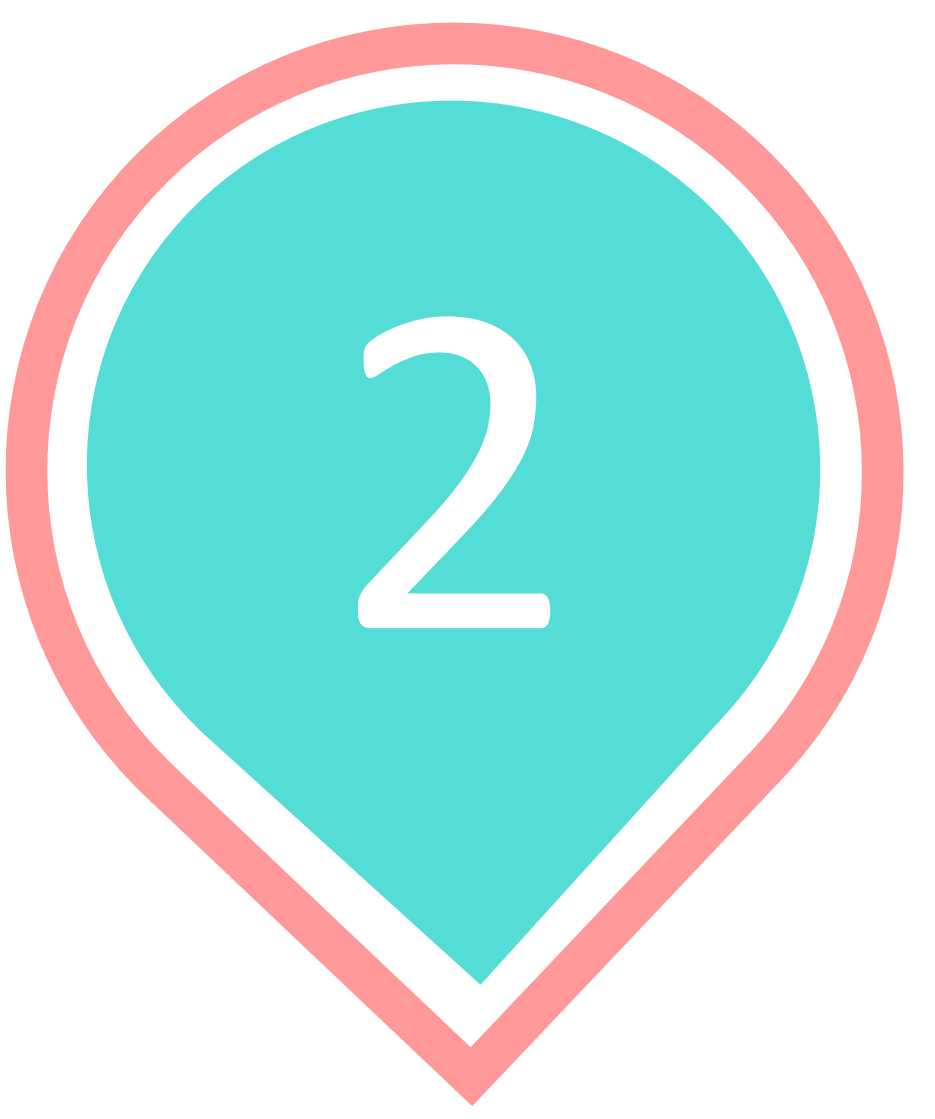

CHAPTER 2: METHODS 
Table of Contents

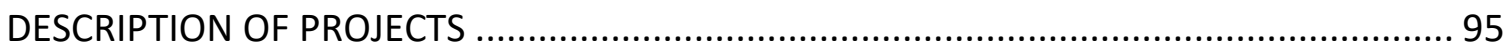

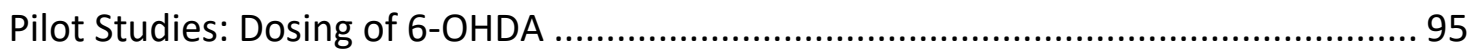

Study 1: Investigating EPO's pro-survival signalling in the first 24 hours ....................95

Study 2: Investigating the effects of EPO administration in the substantia nigra ........ 96

Study 3: Investigating the effects of two doses of EPO administered to the striatum 96

Study 4: Investigating the effects of EPO with a partial 6-OHDA Lesion ..................... 97

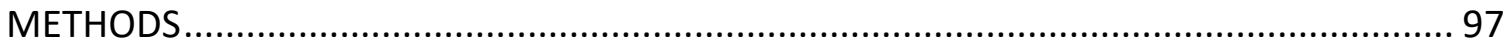

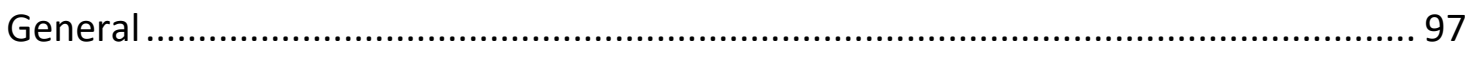

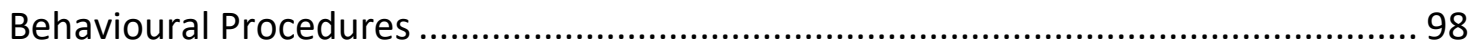

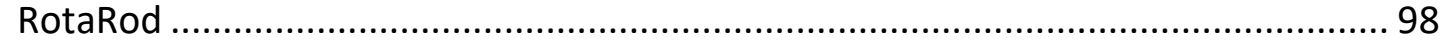

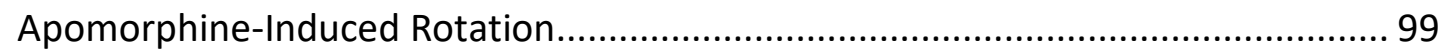

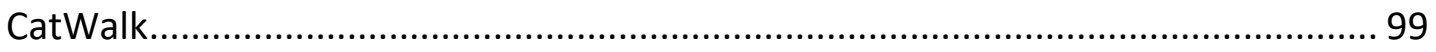

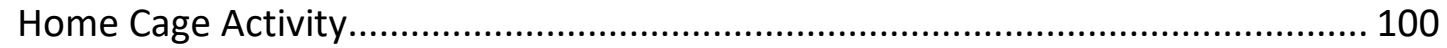

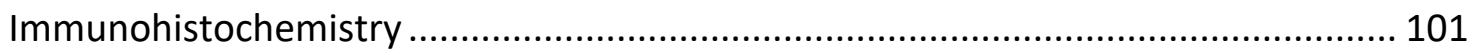

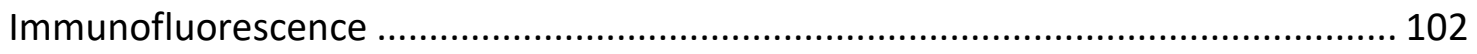

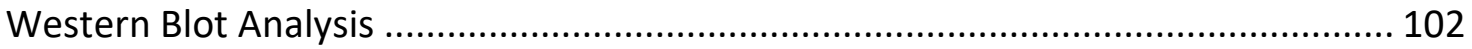

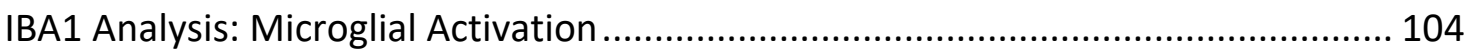

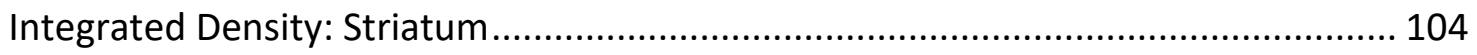

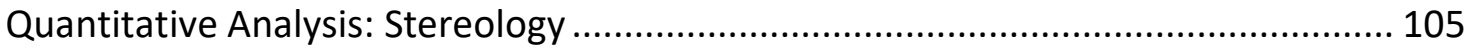

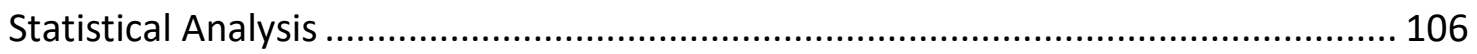




\section{DESCRIPTION OF PROJECTS}

\section{Pilot Studies: Dosing of 6-OHDA}

In these studies, male C57/BI6 mice underwent stereotaxic surgery, and using a cannula, received an infusion of 6-OHDA into the left dorsolateral striatum (coordinates: $-1.75,+1.0,+3.0)$. Multiple pilot studies were required to accurately determine the dose of 6-OHDA that produced a consistent moderate striatal lesion. Between 3 and 5 mice were used for each pilot dose, and once a dose was found that produced a lesion of the desired size (approximately 40\%-60\% loss of dopaminergic cell bodies in the SNc), this dose was confirmed using a larger sample size $(n=8)$ and two control animals (sham surgeries).

\section{Study 1: Investigating EPO's pro-survival signalling in the first 24 hours}

In this study, we sought to gain a better understanding of EPO's mechanisms of action. To this end, animals were cannulated, and following a one-week recovery, EPO was centrally infused into the striatum. Animals were euthanized at $1 \mathrm{~h}, 6 \mathrm{~h}$ or $12 \mathrm{~h}$ following EPO administration. Subsequent analyses were performed using western blot to investigate a wide range of changes at the molecular level at various time points following EPO administration. EPO's ability to modulate proteins involved in neuroinflammatory processes, oxidative stress and apoptotic signalling were assessed. 


\section{Study 2: Investigating the effects of EPO administration in the substantia nigra}

In this study, we sought to investigate the effects of intra-nigral EPO

administration when 6-OHDA is infused into the striatum to reveal any potential differences in cell survival, immune-mediated responses and/or motor outcomes. To date, only two papers have investigated the effects of central EPO administration within the context of a mouse model of PD (Genc et al., 2001; Signore et al., 2006); only Signore et al. employed the 6-OHDA model of neurotoxicity, and much of their work involved in vitro manipulations. In this study, the dose of EPO of 20IU was selected; this dose was chosen based on EPO doses used in the relevant literature (Genc et al., 2001; Signore et al., 2006). Mice underwent stereotaxic surgery during which they received two central infusions: first, they received either saline or 20IU EPO (EPO20) into the SNC, and 20 minutes later, mice were infused with either saline or 6-OHDA into the left dorsolateral striatum. Behavioural tests were performed, and tissue was collected for immunohistochemical analysis 3 weeks following the initial surgery.

\section{Study 3: Investigating the effects of two doses of EPO administered to the striatum}

This study assessed the influence of EPO when its action is co-localized with that of the neurotoxin, ranging from potential protection against 6-OHDA toxicity to potential compensatory behavioural regulation. To this end, animals first received either saline, or one of two doses of EPO (10IU EPO or 20IU EPO), centrally into the striatum, and 20 minutes later, 6-OHDA was infused at the same coordinates. This study looked at 
EPO's influence on the subsequent survival of DA neurons in the SNc, motor outcomes, and central immune response by investigating microglial activation. In addition, we examined EPO's influence on apoptotic signalling, neuroinflammatory processes, and oxidative stress in response to intra-striatal 6-OHDA.

\section{Study 4: Investigating the effects of EPO with a partial 6-OHDA Lesion}

In this study, we largely replicated the methods from Study 3, with the only

difference being the use of a much lower dose of 6-OHDA. EPO20 was injected centrally into the striatum 20 minutes before the 6-OHDA infusion into the same location. To investigate EPO's effects when there is a partial lesion, the dose of 6-OHDA selected for this study was $1 / 4$ of the dose used in the previous studies (3ug versus 12 ug used in previous studies). Ultimately, the findings from this study were compared with the results from studies 2 and 3 to characterize any differences in EPO's actions dependent on lesion magnitude in the striatum.

METHODS

\section{General}

All experiments were conducted using male C57BL/6 mice purchased from Charles River Laboratories (LaPrairie, Quebec, Canada) at 8-10 weeks of age. Mice were singly housed in individually ventilated polypropylene cages and maintained on a 12hour light/dark cycle with lights on at 8am. Mice were housed in a temperature $\left(21^{\circ} \mathrm{C}\right)$ 
and humidity-controlled room and provided with food and water ad libitum. Mice were acclimated for a period of 5 days before any experimental testing was performed. Care was taken to ensure all behavioural tests were conducted at approximately the same time of day for all animals. All experimental procedures were approved by the Carleton University Committee for Animal Care (AUPs: 101283, 108886) and carried out in accordance with the guidelines outlined by the Canadian Council for the Use and Care of Animals in Research.

\section{Behavioural Procedures}

\section{RotaRod}

The RotaRod apparatus is used to provide an overall assessment of balance, motor coordination and strength (Ogura et al., 2005; Monville et al., 2006; AlvarezFischer et al., 2008). The RotaRod protocol takes place over three days. On the first day, mice are trained on the apparatus at a speed of 12 rotations per minute (rpm). Each time the animal falls from the rod, the experimenter places the animal back on the rod and restarts the rotation. This continues for 300 seconds, and three separate trials, each separated by one hour to avoid fatigue, are conducted. On day 2 , the speed profile is increased to $22 \mathrm{rpm}$ and the procedures from day 1 are repeated. On the third day (test day), an accelerating profile is used that increases steadily from 4 to 44 rpm over a period of 300 seconds. On this day, the time until the first fall is recorded, and an 
average of the two best trials from the test day for each animal is used for statistical analysis.

Apomorphine-Induced Rotation

In this test, animals are injected with apomorphine, a non-selective dopamine agonist that acts on the post-synaptic receptors. In the lesioned hemisphere, surviving dopamine receptors become super-sensitized, and as a result, stimulation of those receptors results in the animal's rotation away from the side with more dopamine activity (in this case, to the right, since the left side is lesioned). First, animals receive apomorphine subcutaneously at a dose of $0.1 \mathrm{mg} / \mathrm{kg}$. Then, they are placed in a chamber and recorded from above using a video camera. Animals are recorded for 30 minutes, and minutes 5-25 of each video are assessed in 5-minute intervals. During each interval, the number of $360^{\circ}$ rotations in the ipsilateral (left) and contralateral (right) directions is counted, and the total number of net contralateral rotations is recorded for each animal.

CatWalk

The CatWalk ${ }^{\mathrm{TM}} \mathrm{XT}$ (Noldus) apparatus measures more than 100 variables relating to gait and locomotion. An animal's footprints are captured by the system as it walks across a glass platform, and a multitude of statistics are provided relating to locomotion. In studies 2 and 3, the CatWalk was used to assess any changes in gait resulting from 
6-OHDA infusion, and how treatment with EPO may modulate these changes. Mice were exposed to the apparatus for 4 consecutive training days, during which they learned to cross the platform. On day 5, a baseline score was captured for each animal. Following recovery from surgery, two additional trials were completed on days 18 and 25 . The variables analyzed included the following:

Table 1: Description of CatWalk Variables Analyzed

\begin{tabular}{|c|l|}
\hline \multicolumn{1}{|c|}{$\begin{array}{c}\text { Variable } \\
\text { Max Contact Area }\end{array}$} & $\begin{array}{l}\text { Description } \\
\text { Stride Length }\end{array}$ \\
\hline contact with the glass plate \\
\hline Regularity Index & $\begin{array}{l}\text { The distance between successive placements of } \\
\text { the same paw }\end{array}$ \\
\hline Base of Support (Front and Hind) & $\begin{array}{l}\text { The number of normal step sequence patterns } \\
\text { relative to the total number of paw placements } \\
\text { (expressed as a \%) }\end{array}$ \\
\hline
\end{tabular}

Home Cage Activity

Home cage activity is assessed using the Micromax apparatus, which consists of a setup in which multiple laser beams are passed through the home cages of animals. When the animal moves, the beams 'break', and the total number of beam breaks are recorded over a 12-hour period during the animal's waking cycle (8pm - 8am). The number of beam breaks is an indicator of locomotor activity; thus, a higher number of beam breaks indicates a greater amount of locomotor activity (more overall movement). 


\section{Immunohistochemistry}

Frozen brains were sectioned using a cryostat, and free-floating coronal sections of the striatum $(40 \mu \mathrm{m})$ and the substantia nigra $(40 \mu \mathrm{m})$ were collected for analyses. For TH and CD68-immunohistochemistry, sections were exposed to $0.3 \% \mathrm{H}_{2} \mathrm{O}_{2}$ and blocked in 5\% normal goat serum (NGS; Sigma, cat \#G9023) and 0.3\% Triton-X-100 (Sigma Aldrich, cat \#9002-93-1) in phosphate buffered saline (PBS) for one hour. Sections were incubated in anti-TH at a dilution of 1:2000 (TH, Immunostar, 22941; CD68, Bio Rad, cat \#MCA1957) at room temperature overnight in primary dilution solution (blocker $85 \%$, 2\% BSA 15\%). TH sections were incubated in anti-mouse HRP (Sigma Aldrich, cat \#A5906) at a dilution of 1:200 in TH secondary solution for 4 hours at room temperature. CD68 sections were incubated in biotinylated anti-rat IgG secondary (Jackson Immuno Labs, cat \#112-065-003) at a dilution of 1:500 for two hours at room temperature. CD68 sections were then incubated with Strepavidin-HRP complex (Jackson Immuno Labs, cat \#016-030-84) at a dilution of 1:1000 for 90 minutes at room temperature. To visualize the HRP, a diaminobenzidine (DAB; Sigma Aldrich) reaction was performed, and sections were reacted with $\mathrm{H}_{2} \mathrm{O}_{2}$ for 10 minutes $\left(1 \% \mathrm{H}_{2} \mathrm{O}_{2}\right.$ for striatal sections; $2 \% \mathrm{H}_{2} \mathrm{O}_{2}$ for $\mathrm{SNc}$ sections). Sections were then mounted, dehydrated with serial alcohol washes, cleared with Clearene, and cover slipped using DPX. 


\section{Immunofluorescence}

Frozen brains were sectioned using a cryostat, and free-floating coronal sections of the striatum $(40 \mu \mathrm{m})$ and the substantia nigra $(40 \mu \mathrm{m})$ were collected for analyses. Sections were blocked in 5\% normal goat serum (NGS; Sigma, cat \#G9023) and 0.3\% Triton-X (Sigma Aldrich, cat \#9002-93-1) for one hour. Sections were incubated in mouse anti-TH and rabbit anti-IBA1 at a dilution of 1:2000 (TH, Immunostar, cat \#22941; IBA1, AbCam, cat \#178846) at room temperature overnight in primary dilution solution (blocker - 85\%, 2\% BSA - 15\%). Sections were incubated with an appropriate fluorophore (mouse 488, Invitrogen, cat \#A21204; rabbit 647, Invitrogen, cat \#A21246) at a dilution of 1:1000 in for 2 hours at room temperature, covered. Sections were then mounted, and cover slipped using Fluoromount (Sigma Aldrich, cat \#F4680).

\section{Western Blot Analysis}

Flash-frozen tissue was homogenized in RIPA (radioimmunoprecipitation assay) buffer (1\% NP40, 0.5\% sodium deoxycholate, 0.1\% SDS, 1 mM EDTA, 1 mM EGTA, 1 mM $\mathrm{Na}_{3} \mathrm{VO}_{4}, 20 \mathrm{mM} \mathrm{NaF}, 0.5 \mathrm{mM}$ DTT, $1 \mathrm{mM} \mathrm{PMSF}$ and protease inhibitor cocktail in PBS, pH 7.4). The homogenate was centrifuged at 6000PM (3300g) at $4^{\circ} \mathrm{C}$ for 10 minutes. After collecting the supernatant, protein concentrations were determined using the bicinchoninic acid kit (Thermo Scientific, 23227). Protein extracts were denatured in Laemmli sample loading buffer at $95^{\circ} \mathrm{C}$, separated by $10 \%$ sodium dodecyl sulfate polyacrylamide gel electrophoresis (run at 140V for 1 hour) and transferred in cold 
transfer buffer to a polyvinylidene difluoride membrane at $100 \mathrm{~V}$ for 1 hour $(0.45 \mu \mathrm{m}$ pore, Millipore-Sigma, IPFL00010). Membranes were dried for 10 minutes, reactivated with methanol, rinsed with $\mathrm{dH}_{2} \mathrm{O}$, and incubated in Fast Green FCF (Sigma Aldrich, F7252-5G; 0.0005\% Fast Green, 30\% methanol, 6.7\% acetic acid) for 5 minutes. Membranes were then washed twice for 1 minute with revert wash $30 \%$ methanol, 6.7\% acetic acid) and imaged using the LI-COR system (LI-COR Biosciences, Lincoln, Nebraska, USA) at IR700 for 2 minutes. Nonspecific protein binding was prevented by treating the membrane with $0.5 \%$ fish gel in Tris-buffered saline for 1 hour at room temperature. The membrane was incubated overnight at room temperature with $\mathrm{Bcl}-\mathrm{xL}$ (54H6) rabbit monoclonal antibody (1:2000; Cell Signaling Technology, cat \#2764, Danvers, MA, USA), GPx-1/2 mouse monoclonal antibody (Santa Cruz, cat \#133160, Dallas, TX, USA), Phospho-Bad (Ser112) (7E11) mouse monoclonal antibody (Cell Signaling, cat \#9296, Danvers, MA, USA), or phospho-Akt (S473, Cell Signaling, cat \#D9E, Danvers, MA, USA). Secondary incubation was performed with the appropriate IR800 antibodies (1:20k, LI-COR Biosciences, Lincoln, Nebraska, USA) in 0.5\% fish gel + 20uL/mL 10\% Tween + 1uL/mL SDS.

Membranes were finally imaged on the LI-COR system at IR800 for 10 minutes, and membranes were stored at $-20^{\circ} \mathrm{C}$. Densitometric analysis of the blots was performed with the image analysis program Image Studio Lite 5.2 (LI-COR Biosciences, Lincoln, Nebraska, USA). For stripping, membranes were incubated with stripping buffer (1X NewBLOT IR stripping buffer diluted $5 \mathrm{X}$ in $\mathrm{dH}_{2} \mathrm{O}$, LI-COR, C80110-04) and forceful 
shaking for 10 minutes, then washed, blocked and re-probed overnight at $4{ }^{\circ} \mathrm{C}$ with Bad mouse polyclonal antibody (1:2000; Cell Signaling, cat \#9292, Danvers, MA, USA) or Akt rabbit polyclonal antibody (1:2000; Cell Signaling, cat \#9272, Danvers, MA, USA).

\section{IBA1 Analysis: Microglial Activation}

Microglial reactivity was semi-quantitatively evaluated by two blind raters (>90\% inter-rater reliability) that assessed the degree of morphological change using a 0-3 rating scale previously described by our lab (Mangano and Hayley, 2009). A rating of 0 is given to glial cells in a resting state (described as highly ramified with thin processes), while a rating of 1 reflects an intermediate reactive state in which less than 10 cells in the SNc could be considered moderately activated (appearance includes thickened, short processes with a compact soma). A rating of 2 was given when the majority of cells were intermediately activated with occasional highly activated cells (these cells display an amoeboid, macrophage-like appearance, being spherical in shape and lacking processes), and a rating of 3 was given when a large number of cells displayed the most highly activated amoeboid shape.

\section{Integrated Density: Striatum}

The density of the $\mathrm{TH}+$ terminals within the striatum was quantified using a software program available for free download from the National Institutes of Health (NIH; ImageJ). In all cases, analyses were performed by an individual unaware of the 
experimental treatments and each tissue sample was quantified relative to its own nonlesioned hemisphere. Integrated density is expressed as a ratio of lesioned/non-lesioned side for each animal and then compared to other treatment groups.

\section{Quantitative Analysis: Stereology}

To define the border between the SNc (A9 cell group) and the VTA (A10 cell group), a vertical line was drawn from the medial tip of the cerebral peduncle, and counting was performed caudally until the substantia nigra pars reticulata disappeared. Sections were cut at a thickness of $40 \mu \mathrm{m}$, and every second slice counted for each brain, yielding approximately 6-8 sections per brain. Briefly, the SNc region was outlined at 2.5x magnification, and $\mathrm{TH}+$ neurons were counted using a $64 \mathrm{x}$ oil immersion objective, The SNc was sampled in a systematic random fashion according to the optical fractionator method outlined by MicroBrightField Inc. Cells were quantified in 3dimensional counting frames using a counting grid size of $90 \times 90 \mu m$ and a counting frame size of $60 \times 60 \mu \mathrm{m}$ with a $15 \mu \mathrm{m}$ dissector height and $3 \mu \mathrm{m}$ upper and lower guard zones. Only the portion of the SNc ipsilateral to the infusion site was quantified. All analyses were conducted with the counter blind to the treatment conditions. 
Table 2: Summary of behavioural and biological methodologies employed

\begin{tabular}{|l|l|}
\hline Stain & UMNed to Evaluate \\
\hline TH-positive cells & Lesion in striatum; cell counts in SNc \\
\hline Fluorescence (TH-IBA1) & $\begin{array}{l}\text { Activation of microglia (possibly indicative of Inflammation); } \\
\text { Proximity of microglia to DA cells }\end{array}$ \\
\hline
\end{tabular}

\begin{tabular}{|l|l|}
\hline \multicolumn{2}{|c|}{ BEHAVIOURAL TESTS } \\
\hline Test & Used to Evaluate \\
\hline Rotarod & Gait; motor ability \\
\hline $\begin{array}{l}\text { Apomorphine- } \\
\text { induced rotations }\end{array}$ & $\begin{array}{l}\text { Dopaminergic cell } \\
\text { loss; extent of lesion }\end{array}$ \\
\hline Home cage activity & Locomotor activity \\
\hline
\end{tabular}

\begin{tabular}{|l|l|}
\hline \multicolumn{2}{|c|}{ WESTERN BLOT } \\
\hline Protein & Modulates \\
\hline Akt/RAkt & Pro-survival signalling \\
\hline $\mathrm{Bad} / \mathrm{RBad}$ & Apoptotic activity \\
\hline Bcl- $_{\mathrm{xL}}$ & Apoptotic activity \\
\hline
\end{tabular}

\section{Statistical Analysis}

All data were analyzed by analysis of variance (ANOVA) followed by Fisher planned comparisons, as appropriate (mixed model ANOVA used for CatWalk, data not shown). Data were analyzed using SPSS Version 25.0 (Chicago, IL, USA) available from Carleton University, and unless otherwise indicated, all results are expressed as means \pm S.E.M. for all experiments. 
References

Alvarez-Fischer D, Henze C, Strenzke C, Westrich J, Ferger B, Höglinger GU, Oertel WH, Hartmann A (2008) Characterization of the striatal 6-OHDA model of Parkinson's disease in wild type and $\alpha$-synuclein-deleted mice. Exp Neurol 210:182-193 Available at: http://dx.doi.org/10.1016/j.expneurol.2007.10.012.

Genc S, Kuralay F, Genc K, Akhisaroglu M (2001) tetrahydropyridine-treated C57 / BL mice via increasing nitric oxide production. Neurosci Lett 298:139-141.

Mangano EN, Hayley S (2009) Inflammatory priming of the substantia nigra influences the impact of later paraquat exposure: Neuroimmune sensitization of neurodegeneration. Neurobiol Aging 30:1361-1378 Available at: http://linkinghub.elsevier.com/retrieve/pii/S0197458007004496.

Monville C, Torres EM, Dunnett SB (2006) Comparison of incremental and accelerating protocols of the rotarod test for the assessment of motor deficits in the 6-OHDA model. J Neurosci Methods 158:219-223.

Ogura T, Ogata M, Akita H, Jitsuki S, Akiba L, Noda K, Hoka S, Saji M (2005) Impaired acquisition of skilled behavior in rotarod task by moderate depletion of striatal dopamine in a pre-symptomatic stage model of Parkinson's disease. Neurosci Res 51:299-308.

Signore AP, Weng Z, Hastings T, Van Laar AD, Liang Q, Lee YJ, Chen J (2006) Erythropoietin protects against 6-hydroxydopamine-induced dopaminergic cell death. J Neurochem 96:428-443. 


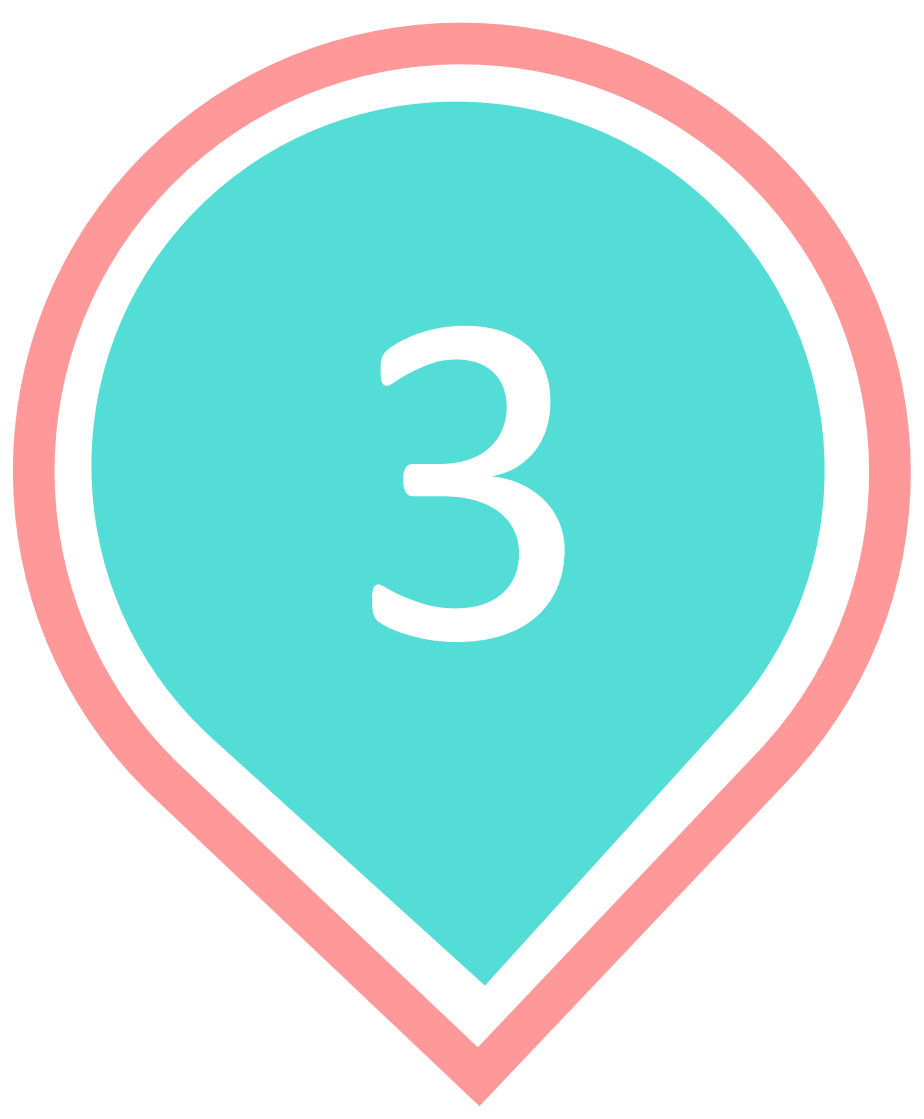

CHAPTER 3: MANUSCRIPT 


\section{Table of Contents}

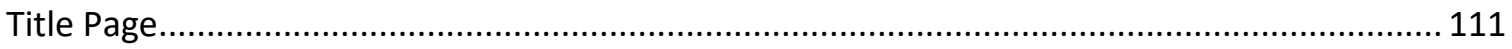

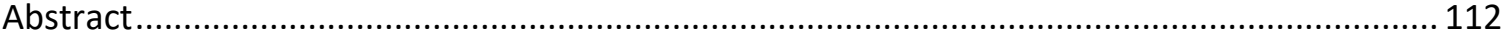

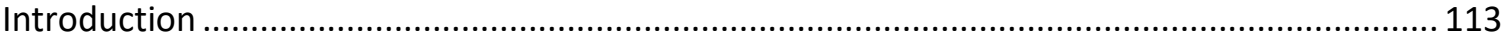

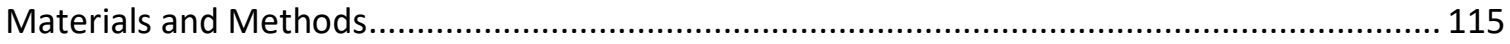

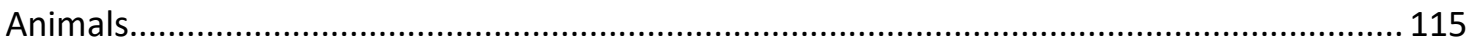

General Stereotaxic Procedures: Cannulations and Infusions of 6-OHDA and EPO ............... 115

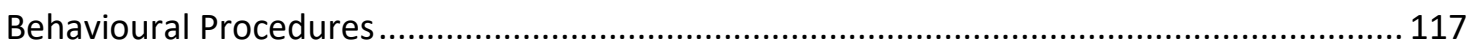

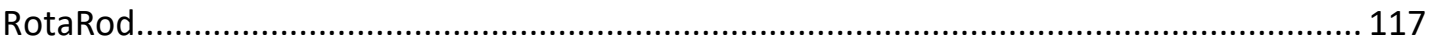

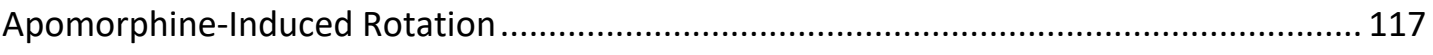

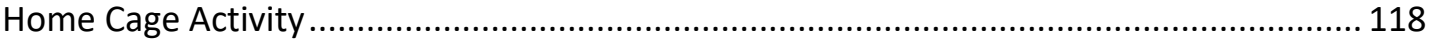

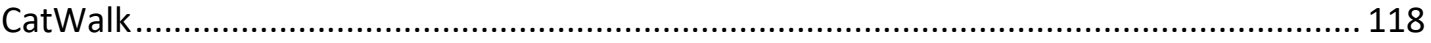

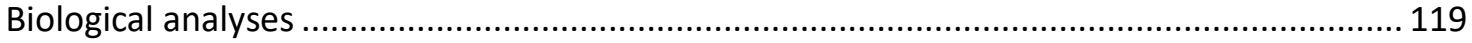

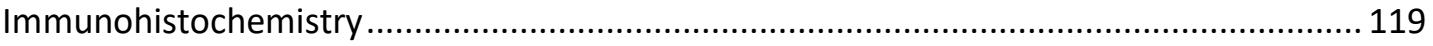

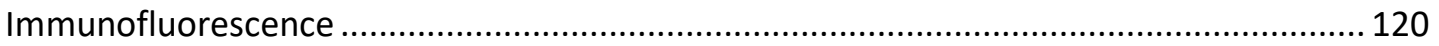

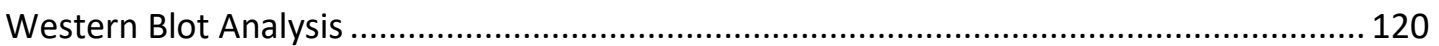

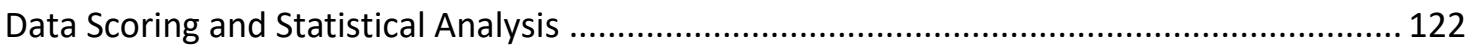

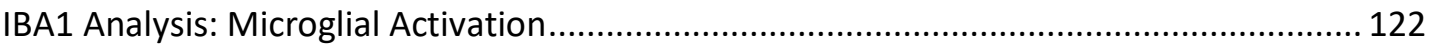

Integrated Density: Striatal TH+ terminals .................................................................... 123

Quantitative Analysis: Stereological assessment of TH-positive neurons in the substantia

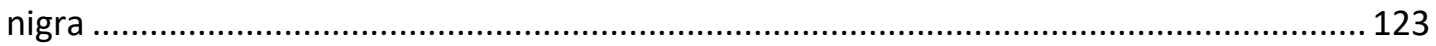

Pilot study: Determination of 6-OHDA dose to produce clinically relevant lesion.................. 124

Experiment 1: Investigating the acute pro-survival signalling of erythropoietin ................... 124

Experiment 2: Investigating the potential neuroprotective effects of EPO in the substantia

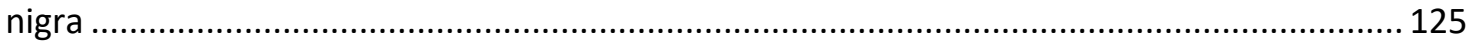

Experiment 3: Investigating the neuroprotective properties of two EPO doses in the striatum

Experiment 4: Investigating the effects of EPO with a partial 6-OHDA Lesion........................ 126

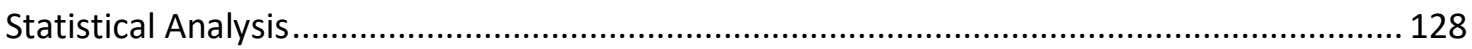

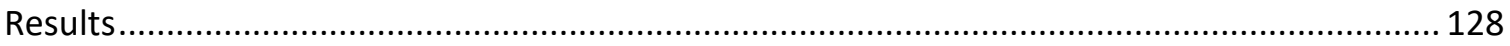

Experiment 1 Results: Investigating the acute pro-survival signalling of erythropoietin........ 128

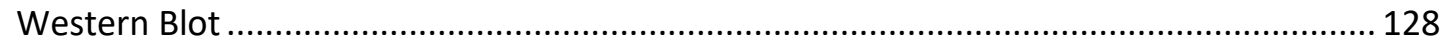


Experiment 2 Results: Investigating the neuroprotective effects of EPO in the substantia nigra

131

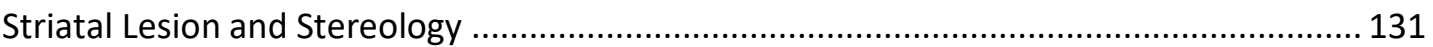

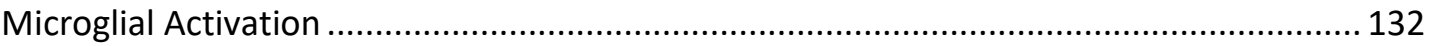

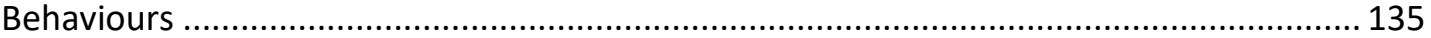

Experiments 3 and 4: Comparing two doses of 6-OHDA when EPO is administered in the

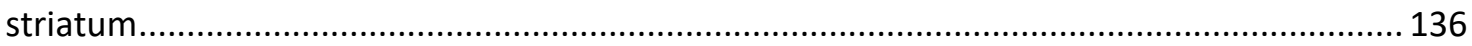

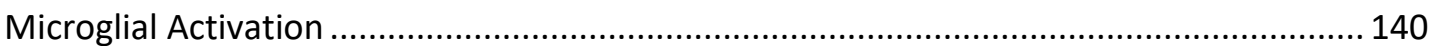

Behaviours: Rotarod and Apomorphine-Induced Rotations .......................................... 144

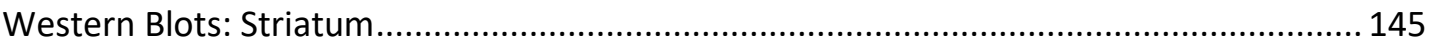

Western Blots: Substantia Nigra ................................................................................. 149

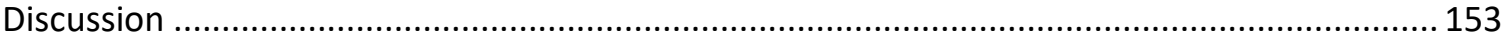

EPO's pro-survival effects are region- and lesion size-dependent ....................................... 155

Evidence for EPO's anti-apoptotic, anti-inflammatory and antioxidant actions ..................... 156

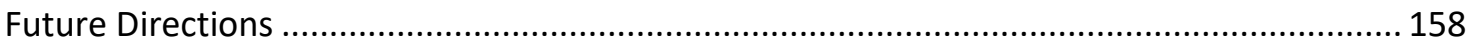

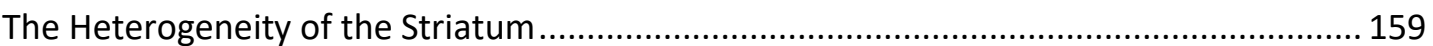

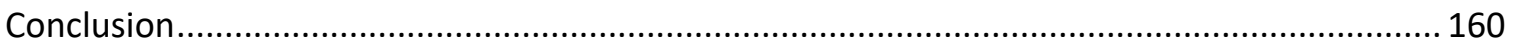

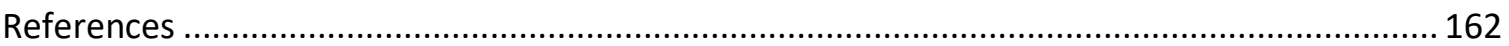


Title Page

Characterization of erythropoietin's influence on pro-survival signalling in a 6-OHDA mouse model of Parkinson's disease: evidence for lesion size-dependence and regional differences in activation of anti-apoptotic, anti-inflammatory and antioxidant mechanisms.

Abbreviated Title: EPO signalling mechanisms in a mouse 6-OHDA model of PD

Ashley M. E. Thompson, Kyle Farmer, Alexa Derksen, Elyn Rowe, and Shawn Hayley Corresponding Author: Ashley Thompson, Ashley.thompson3@carleton.ca Department of Neuroscience, Carleton University, Ottawa, ON, Canada K1S 5B6 


\begin{abstract}
The current studies sought to profile the pro-survival effects of erythropoietin (EPO) in a 6-hydroxydopamine (6-OHDA) mouse model of Parkinson's disease (PD). Male $\mathrm{C} 57 \mathrm{Bl} / 6$ mice were used in a series of experiments investigating the potential antiapoptotic, anti-inflammatory and antioxidant effects of the trophic cytokine. EPO's ability to protect dopaminergic terminals in the striatum, cell bodies in the substantia nigra (SNc) and modulate 6-OHDA-induced motor deficits was characterized at different doses of 6-OHDA and EPO. Our results demonstrated EPO's ability to exert pro-survival effects via all three mechanisms across the different experimental models and indicated a region- and lesion size- dependence of the pro-survival effects of EPO. While intranigral EPO was not effective at preventing terminal degeneration or SNc cell loss, intrastriatal EPO preserved terminals and soma at two doses of 6-OHDA and two doses of EPO. EPO further attenuated apomorphine-induced rotations at two doses of 6-OHDA. Taken together, the results of the current set of experiments indicate EPO's potential for use as an adjuvant therapy in the treatment of PD due to its anti-apoptotic signalling through pAkt and the Bcl-2 associated proteins, its anti-inflammatory activity through modulation of microglial morphology, and its antioxidant activity through locally elevated levels of striatal glutathione peroxidase as well as retrograde signalling resulting in elevated levels of glutathione peroxidase in the SNc in response to EPO treatment. The tissue-protective effects of EPO should be harnessed and considered for future preclinical and clinical work involving combination therapy in PD.
\end{abstract}




\section{Introduction}

Parkinson's disease (PD) involves the loss of dopaminergic neurons in the substantia nigra pars compacta (SNc) and the associated depletion of dopamine (DA) in the striatum. The loss of these neurons and their connections results in the observable motor symptoms of the disease, including resting tremor, rigidity, bradykinesia and postural instability (Dauer \& Przedborski, 2003). It is well established that apoptotic signalling, neuroinflammation, and oxidative stress play a significant role in the pathology of PD, each contributing to the disruption of cellular homeostasis and neuronal degeneration observed in the disorder (Hirsch \& Hunot, 2009; Latchoumycandane, Anantharam, Jin, Kanthasamy, \& Kanthasamy, 2011; McGeer \& McGeer, 2008).

Erythropoietin (EPO) is a hematopoietic cytokine that has gained attention over the years for its neurotrophic actions in models of ischemia (Brines et al., 2000; Wang et al., 2007) and spinal cord injury (Campana \& Myers, 2003; Kaptanoglu et al., 2004). Importantly, unlike other factors with trophic actions, such as BDNF and GDNF, EPO is known to cross the blood brain barrier (BBB) to exert its effects centrally (Brines et al., 2000; Ehrenreich et al., 2004; Ehrenreich, Bartels, Sargin, Stawicki, \& Krampe, 2008; Osborn et al., 2013). The hematopoietic effects of EPO in the periphery can be avoided using modified forms of EPO that silence the hematopoietic regions of the molecule, which are distinct from the regions of EPO that confer tissue-protective effects (Boado et al., 2010; Shi et al., 2013; Thomas Tayra et al., 2013; Xue et al., 2010). EPO and its 
receptors are found on neurons and astrocytes in several cortical and sub-cortical brain regions, including the midbrain, and both neurons and astrocytes are cellular sources of EPO (Digicaylioglu et al., 1995; Masuda et al., 1994). EPO's neurotrophic effects have been well documented in various models of neurological disease and animal species (Bartels, Späte, Krampe, \& Ehrenreich, 2008; Carelli, Marfia, Di Giulio, Ghilardi, \& Gorio, 2011; Farmer, Rudyk, Prowse, \& Hayley, 2015; Mangano et al., 2011). Critically, despite promising preclinical and clinical work, there are inconsistent reports regarding EPO's efficacy in human patients (Güresir et al., 2013; Nichol et al., 2015; Sargin, Friedrichs, ElKordi, \& Ehrenreich, 2010).

Oxidative stress has long been implicated in PD pathology (Damier, Hirsch, Zhang, Agid, \& Javoy-Agid, 1993; Wei, Li, Li, Liu, \& Cheng, 2018) and may be one mechanism through which EPO could beneficially influence the disease (Castillo et al., 2018; Li et al., 2016). In fact, a reduction in the powerful antioxidant, GSH, is thought to occur early in disease progression in the SNc of PD patients (Pearce et al., 1997). Although it can exert complex effects that impact apoptotic and inflammatory processes (Ding et al., 2017; Pang et al., 2016), accumulating evidence suggests EPO's neuroprotective actions may be mediated primarily via an antioxidant mechanism (Castillo et al., 2018; Erbaş, Çiar, Solmaz, Çavuşoğlu, \& Ateş, 2015; Jang et al., 2016). Specifically, EPO's ability to increase levels of glutathione peroxidase (GPx), a potent antioxidant enzyme, may lead to decreased levels of toxic reactive oxygen species (ROS) and promote the survival of vulnerable neuronal populations. 
We currently sought to assess whether EPO would modify the impact of the dopaminergic toxicant, 6-hydroxydopamine (6-OHDA), whether such effects would be brain-region specific, and EPO's mechanisms of action in this model.

\section{Materials and Methods}

\section{Animals}

C57BL/6 male mice were purchased from Charles River Laboratories (LaPrairie, Quebec, Canada) at 8-10 weeks of age, single-housed in individually ventilated polypropylene cages and maintained on a 12-h light/dark cycle. Mice were housed in a temperature $\left(21^{\circ} \mathrm{C}\right)$ and humidity-controlled room and provided with food and water ad libitum. Animals were acclimatized for a period of 5 days prior to the commencement of any experimental testing. All experimental procedures were approved by the Carleton University Committee for Animal Care and adhered to the guidelines outlined by the Canadian Council for the Use and Care of Animals in Research. The procedures used in all studies described were conducted according to the following specifications, unless otherwise indicated.

General Stereotaxic Procedures: Cannulations and Infusions of 6-OHDA and EPO

Animals were anesthetized using inhaled isoflurane, and a $1 \mathrm{~cm}$ incision was made on the scalp in the anterior-posterior plane. For infusions and cannula implantations into the left dorsolateral striatum, the following coordinates were used to 
drill small holes in the skull: $-1.80 \mathrm{~mm}$ lateral, $+1.10 \mathrm{~mm}$ anterior/posterior, $+3.00 \mathrm{~mm}$ ventral. For cannulations, an additional hole was drilled $3.20 \mathrm{~mm}$ posterior to the striatal coordinates for insertion of a screw to secure the cannula to the skull (PlasticsOne, 0096X1-16-39052). Guide cannulae were cut 2.50mm below the pedestal (PlasticsOne, cat\# C315GS-5/spc) and secured at the striatal coordinates using dental cement (GET INFO) around the cannula and screw, allowing 20 minutes for the cement to dry. Injectors extending $3.00 \mathrm{~mm}$ below the pedestal were used for infusions into the striatum at the appropriate ventral coordinates. For infusions into the left SNc, the following coordinates were used: $-1.20 \mathrm{~mm}$ lateral, $-3.16 \mathrm{~mm}$ anterior/posterior, $+4.00 \mathrm{~mm}$ ventral.

In experiments using 6-OHDA, the toxin was prepared in $0.02 \%$ ascorbic acid (in $0.9 \%$ saline) immediately before infusion, and all infusions of toxin were administered at the striatal coordinates indicated above. For all infusions, a total of $2 \mu$ l of fluid was delivered to the striatum or SNc over a period of 5 minutes from polyethylene tubing connected to a $10 \mu \mathrm{l}$ Hamilton microliter syringe secured to the PicoPlus pump (Harvard Apparatus, MA, USA). Following any infusion (either direct or via a cannula), needles were left in place for 5 minutes before removal. For cannulations, dummy cannulae (PlasticsOne, cat\# C315DCS-5/spc) were used to prevent debris from entering the guide. Following cannula implantation or infusion, animals were sutured, xylocaine was applied to the site of incision, and animals were allowed given one week to recover before further experimental testing occurred. 


\section{Behavioural Procedures}

\section{$\underline{\text { RotaRod }}$}

The RotaRod apparatus is used to provide an overall assessment of balance, motor coordination and strength (Alvarez-Fischer et al., 2008; Monville, Torres, \& Dunnett, 2006; Ogura et al., 2005). The RotaRod protocol took place over three days. On the first day, mice are trained on the apparatus at a speed of 12 rotations per minute (rpm), with an experimenter placing animals back on the rod and restarting the rotation after each fall for a period of 300 seconds. Three separate trials, each separated by one hour to avoid fatigue, are conducted each day. On Day 2, the speed profile is increased to $22 \mathrm{rpm}$ and the procedures from day 1 are repeated. On test day (day 3), an accelerating profile is used that increases steadily from 4 to $44 \mathrm{rpm}$ over a period of 300 seconds. On this day, the time until the first fall is recorded, and an average of the two best trials from the test day are used for statistical analysis.

\section{Apomorphine-Induced Rotation}

Apomorphine is a non-selective dopamine agonist that acts on the post-synaptic receptors. In the lesioned hemisphere, surviving dopamine receptors become supersensitized, and as a result, stimulation of those receptors results in the animal's rotation away from the side with more dopamine activity (i.e. away from the lesion). The apomorphine-induced rotation test is a robust indicator of the presence of a unilateral dopaminergic lesion and was used as an estimate of the extent of DA depletion. Animals 
were injected subcutaneously with apomorphine (Millipore Sigma, cat\# 41372-20-7) at a dose of $0.1 \mathrm{mg} / \mathrm{kg}$ (dissolved in $0.9 \%$ saline), placed in a chamber and recorded from above using a video camera for a total of 30 minutes. Animals were allowed to habituate in the chambers for 5 minutes following injections before the recording of rotations began. Thereafter, the number of $360^{\circ}$ rotations in the ipsilateral (left) and contralateral (right) directions were counted between minutes 5-25 of each video, and the total number of net contralateral rotations were recorded.

\section{Home Cage Activity}

Home cage activity was assessed using the Micromax apparatus, consisting of a setup in which multiple laser beams are passed through the home cages of animals. When the animal moves, the beams will 'break', and the total number of beam breaks will be recorded over a 12-hour period during the animal's waking cycle (8pm - 8am). The number of beam breaks is an indicator of locomotor activity; thus, a higher number of beam breaks indicates a greater amount of overall movement.

\section{CatWalk}

The CatWalk ${ }^{\mathrm{TM}}$ XT (Noldus) apparatus measures more than 100 variables relating to gait and locomotion. An animal's footprints are captured by the system as it walks across a glass platform, and a multitude of statistics are provided relating to locomotion. In Experiments 2 and 3, the CatWalk was used to assess any changes in gait resulting 
from 6-OHDA infusion, and how treatment with EPO may modulate these changes. Mice were exposed to the apparatus for 4 consecutive training days, during which they learned to cross the platform. On day 5, a baseline score was captured for each animal. Following recovery from surgery, two additional trials were completed on days 18 and 25. The variables analyzed included the following: max contact area, stride length, regulatory index, and base of support.

\section{Biological analyses}

$\underline{\text { Immunohistochemistry }}$

Frozen brains were sectioned using a cryostat, and free-floating coronal sections of the striatum $(40 \mu \mathrm{m})$ and the substantia nigra $(40 \mu \mathrm{m})$ were collected for analyses. For Tyrosine Hydroxylase (TH), sections were exposed to $0.3 \% \mathrm{H}_{2} \mathrm{O}_{2}$ and blocked in $5 \%$ normal goat serum (NGS; Millipore Sigma, cat \#G9023) and 0.3\% Triton-X-100 (Millipore Sigma, cat \#9002-93-1) in phosphate buffered saline (PBS, pH 7.4) for one hour. Sections were incubated in anti-TH at a dilution of 1:2000 (TH, Immunostar, 22941) at room temperature overnight in primary dilution solution (blocker, $85 \% ; 2 \% \mathrm{BSA}, 15 \%$ ). TH sections were incubated in anti-mouse horseradish peroxidase (HRP; Millipore Sigma, cat \#A5906) at a dilution of 1:200 in secondary solution for 4 hours at room temperature. To visualize the HRP, a diaminobenzidine (DAB; Millipore Sigma) reaction was performed, and sections reacted with $2 \% \mathrm{H}_{2} \mathrm{O}_{2}$ for 10 minutes. Sections were 
washed in PBS, mounted, dehydrated with serial alcohol washes, cleared with Clearene, and cover slipped using DPX.

$\underline{\text { Immunofluorescence }}$

Frozen brains were sectioned using a cryostat, and free-floating coronal sections of the striatum $(40 \mu \mathrm{m})$ and the substantia nigra $(40 \mu \mathrm{m})$ were collected for analyses. Sections were blocked in 5\% normal goat serum (NGS; Sigma, cat \#G9023) and 0.3\% Triton-X for one hour. Sections were incubated in mouse anti-TH and rabbit anti-IBA1 at a dilution of 1:2000 (IBA1, AbCam, cat \#178846) at room temperature overnight in primary dilution solution (same composition as above). Sections were incubated with an appropriate fluorophore (mouse 488, Invitrogen, cat \#A21204; rabbit 647, Invitrogen, cat \#A21246) at a dilution of 1:1000 in for 2 hours at room temperature, covered. Sections were then washed in PBS, mounted and cover slipped using Fluoromount (Sigma Aldrich, cat \#F4680).

\section{Western Blot Analysis}

Flash-frozen tissue was homogenized in RIPA (radioimmunoprecipitation assay) buffer (1\% NP40, 0.5\% sodium deoxycholate, 0.1\% SDS, 1 mM EDTA, 1 mM EGTA, 1 mM Na3VO4, 20 mM NaF, 0.5 mM DTT, 1 mM PMSF and protease inhibitor cocktail in PBS, $\mathrm{pH}$ 7.4). The homogenate was centrifuged at 6000PM (3300g) at $4^{\circ} \mathrm{C}$ for 10 minutes. After collecting the supernatant, protein concentrations were determined using the 
bicinchoninic acid kit (Thermo Scientific, 23227). Protein extracts were denatured in Laemmli sample loading buffer at $95^{\circ} \mathrm{C}$, separated by $10 \%$ sodium dodecyl sulfate polyacrylamide gel electrophoresis (run at $140 \mathrm{~V}$ for 1 hour) and transferred in cold transfer buffer to a polyvinylidene difluoride membrane at $100 \mathrm{~V}$ for 1 hour $(0.45 \mu \mathrm{m}$ pore, Millipore-Sigma, IPFL00010). Membranes were dried for 10 minutes, reactivated with methanol, rinsed with $\mathrm{dH}_{2} \mathrm{O}$, and incubated in Fast Green FCF (Sigma Aldrich, F7252-5G; 0.0005\% Fast Green, 30\% methanol, 6.7\% acetic acid) for 5 minutes. Membranes were then washed twice for 1 minute with revert wash $30 \%$ methanol, 6.7\% acetic acid) and imaged using the LI-COR system (LI-COR Biosciences, Lincoln, Nebraska, USA) at IR700 for 2 minutes. Nonspecific protein binding was prevented by treating the membrane with $0.5 \%$ fish gel in Tris-buffered saline for $1 \mathrm{~h}$ at room temperature. Membranes were incubated overnight at room temperature with $\mathrm{Bcl}-\mathrm{XL}$ (54H6) rabbit monoclonal antibody (1:2000; Cell Signaling Technology, cat \#2764, Danvers, MA, USA), GPx-1/2 mouse monoclonal antibody (Santa Cruz, cat \#133160, Dallas, TX, USA), Phospho-Bad (Ser112) (7E11) mouse monoclonal antibody (Cell Signaling, cat \#9296, Danvers, MA, USA), or phospho-Akt (S473, Cell Signaling, cat \#D9E, Danvers, MA, USA). Secondary incubation was performed with the appropriate IR800 antibodies (1:20k, LI-COR Biosciences, Lincoln, Nebraska, USA) in 0.5\% fish gel + 20uL/mL 10\% Tween + 1uL/mL SDS.

Membranes were finally imaged on the LI-COR system at IR800 for 10 minutes, and membranes were subsequently stored at $-20^{\circ} \mathrm{C}$. Densitometric analysis of the blots 
was performed with the image analysis program Image Studio Lite 5.2 (LI-COR

Biosciences, Lincoln, Nebraska, USA). For stripping, membranes were incubated with stripping buffer (1X NewBLOT IR stripping buffer diluted in dH2O, LI-COR, C80110-04) and forceful shaking for 10 minutes, washed 3 times with TBS, blocked and re-probed overnight at $4^{\circ} \mathrm{C}$ with Bad mouse polyclonal antibody (1:2000; Cell Signaling, cat \#9292, Danvers, MA, USA) or Akt rabbit polyclonal antibody (1:2000; Cell Signaling, cat \#9272, Danvers, MA, USA).

\section{Data Scoring and Statistical Analysis}

\section{IBA1 Analysis: Microglial Activation}

Microglial reactivity was semi-quantitatively evaluated by two blind raters ( $>90 \%$ inter-rater reliability) that assessed the degree of morphological change using a 0-3 rating scale previously described by our lab (Mangano \& Hayley, 2009). A rating of 0 is given to glial cells in a resting state (described as highly ramified with thin processes), while a rating of 1 reflects an intermediate reactive state in which less than 10 cells in the SNc could be considered moderately activated (appearance includes thickened, short processes with a compact soma). A rating of 2 was given when the majority of cells were intermediately activated with occasional highly activated cells (these cells display an amoeboid, macrophage-like appearance, being spherical in shape and lacking processes), and a rating of 3 was given when a large number of cells displayed the most highly activated amoeboid shape. 
Integrated Density: Striatal TH+ terminals

The density of the $\mathrm{TH}+$ terminals within the striatum was quantified using a software program available for free download from the National Institutes of Health (NIH; ImageJ). In all cases, analyses were performed by an individual unaware of the experimental treatments and each tissue sample was quantified relative to its own nonlesioned hemisphere. Integrated density is expressed as a ratio of lesioned/non-lesioned side for each animal and then compared to other treatment groups.

Quantitative Analysis: Stereological assessment of TH-positive neurons in the SNc

To define the border between the SNc ( $\mathrm{A} 9$ cell group) and the VTA (A10 cell group), a vertical line was drawn from the medial tip of the cerebral peduncle, and counting was performed caudally until the substantia nigra pars reticulata disappeared (bregma levels ranging from -3.08 to -3.40 ). Sections were cut at a thickness of $40 \mu \mathrm{m}$, and every second slice counted for each brain, yielding approximately 6-8 sections per brain. Briefly, the SNc region was outlined at 2.5x magnification, and $\mathrm{TH}+$ neurons were counted using a $64 x$ oil immersion objective, The SNc was sampled in a systematic random fashion according to the optical fractionator method outlined by MicroBrightField Inc. Cells were quantified in 3-dimensional counting frames using a counting grid size of $90 \times 90 \mu \mathrm{m}$ and a counting frame of $60 \times 60 \mu \mathrm{m}$ with a $15 \mu \mathrm{m}$ dissector height and $3 \mu \mathrm{m}$ upper and lower guard zones. Only the portion of the SNc ipsilateral to 
the infusion site was quantified. All analyses were conducted with the counter blind to the treatment conditions.

Pilot study: Determination of 6-OHDA dose to produce clinically relevant lesion

Studies involving the use of 6-OHDA in mice are limited and employ varying doses of toxin injected into the SNc (Chiu et al., 2014; Grealish, Mattsson, Draxler, \& Björklund, 2010), medial forebrain bundle (Lundblad, Picconi, Lindgren, \& Cenci, 2004), and multi-site injections in the striatum (Jing et al., 2016; Ren et al., 2017). As such, we conducted several pilot studies to determine an optimal single intra-striatal dose of 6-OHDA that would establish a consistent and clinically relevant lesion (approximately 40-60\% cell loss) while minimizing animal mortality. Pilots were conducted using 5 animals per dose, and a dose of 12 ug was determined to produce a moderate lesion with minimal mortality $(<5 \%)$, and as such, was selected for use in our subsequent investigations.

Experiment 1: Investigating the acute pro-survival signalling of erythropoietin

Given the ongoing investigation into EPO's trophic mechanisms in various models of disease, we sought to establish a baseline model in which to investigate a wide range of changes at the molecular level at various time points following EPO administration. EPO's ability to modulate proteins involved in neuroinflammatory processes, oxidative stress and apoptotic signalling was assessed in adult C57/B16 mice. To this end, a cannula was implanted into the left dorsolateral striatum of animals at the 
following coordinates: $-1.80 \mathrm{M} / \mathrm{L},+1.1 \mathrm{~A} / \mathrm{P},+3.00 \mathrm{D} / \mathrm{V}$. Importantly, animals were given one week to recover from the initial surgery, as stereotaxic surgery and cannula implantation can induce an acute inflammatory response. Thereafter, $201 \mathrm{U}$ of recombinant human EPO (Calbiochem, cat\# 329871) in 0.9\% saline or vehicle were infused through the cannula at a rate of $0.4 \mathrm{uL} / \mathrm{min}$. A total of $2 \mathrm{uL}$ of liquid was infused and the cannula was left in place for 5 minutes before removal. Animals were rapidly decapitated $1 \mathrm{~h}, 6 \mathrm{~h}$ or $12 \mathrm{~h}$ following EPO administration and the striatum and SNc were collected via micropunch dissection. Tissue samples were stored at $-80^{\circ} \mathrm{C}$ until Western blot analysis.

Experiment 2: Investigating the potential neuroprotective effects of EPO in the substantia nigra

To date, only two papers have investigated the effects of central EPO administration within the context of a mouse model of PD (Genc et al., 2001; Signore et al., 2006), and only Signore et al. employed the 6-OHDA model of neurotoxicity, and most of their work involved in vitro manipulations. We sought to investigate the potential protective effects of intra-SNc EPO administration prior to the infusion of 6-OHDA into the striatum. Mice underwent stereotaxic surgery, as described in a previous section, during which they received two central infusions: first, either saline or $20 I U$ EPO (EPO20) was infused into the SNc, and 20 minutes later, either saline or 12ug of 6-OHDA was infused into the striatum. Behavioural tests, including the RotaRod and 
apomorphine-induced rotations took place 3 weeks following the surgery, following which mice were perfused with $4 \%$ paraformaldehyde (PFA) and tissue was prepared for immunohistochemical analysis.

Experiment 3: Investigating the neuroprotective properties of two EPO doses in the striatum

In contrast to the previous study that involved intra-SNc infusion, this experiment assessed whether intra-striatal EPO infusion would be neuroprotective. To this end, animals underwent stereotaxic surgery, and first received an infusion of either saline, 10IU EPO, or 20IU EPO centrally into the striatum. Then, animals received an infusion of 12 ug of $6-\mathrm{OHDA}$ into the same location 20 minutes later. Behavioural tests were carried out 3 weeks following the initial surgery and included apomorphineinduced rotations, Rotarod, and home cage activity. Following all behavioural testing, half of the animals $(n=8-10)$ were perfused with 4\% PFA and sections were prepared for immunohistochemistry, while the other half $(n=8-10)$ were rapidly decapitated and tissue was prepared for Western blot analysis.

Experiment 4: Investigating the effects of EPO with a partial 6-OHDA Lesion

The current study utilized a lower dose of 6-OHDA to assess whether the neuroprotective potential of EPO varies as a function of toxicant dose. To this end, we replicated the methods from Experiment 3 with the only difference being that we used 
3ug of 6-OHDA (as opposed to $12 \mathrm{ug}$ ). Briefly, EPO was injected centrally into the striatum 20 minutes before the 6-OHDA infusion into the same location. Behavioural tests were conducted 3 weeks after surgery, including rotational asymmetry and Rotarod. Half of the animals ( $n=6-8$ per group) were perfused with $4 \%$ PFA and prepared for immunohistochemical analysis, and the other half were rapidly decapitated and prepared for Western blot analysis.

Table 3: Summary of behavioural and biological methodologies employed

\begin{tabular}{|l|l|}
\hline \multicolumn{2}{|c|}{ IMMUNOHISTOCHEMISTRY } \\
\hline Stain & Used to Evaluate \\
\hline $\begin{array}{l}\text { TH-positive } \\
(\mathrm{TH}+\text { ) cells }\end{array}$ & $\begin{array}{l}\text { Lesion in striatum; } \\
\text { Cell counts in SNc }\end{array}$ \\
\hline $\begin{array}{l}\text { Fluorescence } \\
\text { (TH-IBA1) }\end{array}$ & $\begin{array}{l}\text { Inflammation; Proximity } \\
\text { of microglia to DA cells }\end{array}$ \\
\hline
\end{tabular}

\begin{tabular}{|l|l|}
\hline \multicolumn{2}{|c|}{ WESTERN BLOT } \\
\hline Protein & Modulates \\
\hline pAkt/Akt & Pro-survival signalling \\
\hline pBad/Bad & Apoptotic activity \\
\hline Bcl-xL & Apoptotic activity \\
\hline GPx & $\begin{array}{l}\text { Oxidative Stress } \\
\text { (antioxidant) }\end{array}$ \\
\hline
\end{tabular}

\begin{tabular}{|l|l|}
\hline \multicolumn{2}{|c|}{ BEHAVIOURAL TESTS } \\
\hline Test & Used to Evaluate \\
\hline Rotarod & Gait; motor ability \\
\hline Apomorphine-induced rotations & $\begin{array}{l}\text { Dopaminergic cell loss; extent of } \\
\text { lesion }\end{array}$ \\
\hline Home cage activity & Locomotor activity \\
\hline CatWalk & Gait \\
\hline
\end{tabular}




\section{Statistical Analysis}

All data were analyzed by analysis of variance (ANOVA) followed by Fisher planned comparisons, as appropriate (mixed model ANOVA used for CatWalk, data not shown). Data were analyzed using SPSS Version 25.0 (Chicago, IL, USA) available from Carleton University, and unless otherwise indicated, all results are expressed as means \pm S.E.M. for all experiments.

\section{Results}

Experiment 1 Results: Investigating the acute pro-survival signalling of erythropoietin

To investigate EPO's acute actions in the absence of a toxicant, 2OIU of EPO were centrally administered to the striatum of male C57BI/6 mice. Tissue was collected 1 hour, 6 hours or 12 hours following EPO administration and analyzed using blotting.

\section{Western Blot}

Centrally administered EPO activated pro-survival signalling through the phosphorylation of Akt in the striatum (Fig. 1A; one-way ANOVA, $F(2,19)=6.528$, $p=0.0069)$. The significant elevation of pAkt peaked at 6 hours following EPO administration $(p<0.01)$ and began to subside at 12 hours $(p>0.05)$. This finding is consistent with the notion of activation of the PI3K/Akt pathway in the pro-survival actions of EPO. 
As well, EPO acutely modulated levels of the pro-apoptotic $\mathrm{BCl}$-2-associated death promoter (Bad) protein. In its free state, Bad dimerizes with the anti-apoptotic Bcell lymphoma-extra large $(\mathrm{Bcl}-\mathrm{xL})$ protein, preventing its pro-survival action and leading to a signalling cascade in the mitochondria that results in the release of caspases and apoptotic cell death (Zha, Harada, Yang, Jockel, \& Korsmeyer, 1996). Upon activation, pAkt phosphorylates Bad, leading to sequestration of pBad by a 14-3-3 protein in the cytosol, preventing its dimerization with $\mathrm{Bcl}-\mathrm{xL}$. The $\mathrm{pBad} / \mathrm{Bad}$ ratio was observed to be significantly altered among the groups (Fig 1B; one-way ANOVA, $F(2,21)=6.029$, $p=0.0085)$. Specifically, significantly upregulated levels were observed 12 hours after EPO administration $(p<0.05)$. However, levels of $B c l-x L$ did not change significantly in the first 12 hours following EPO administration (Fig 1E; one-way ANOVA, $F(2,21)=1.517$, $p=0.2424)$.

In addition to variations of anti-apoptotic signalling, antioxidant activity, as assessed by GPx, was also altered in the striatum (Fig 1C; one-way ANOVA, $F(2$, $18)=8.216, p=0.0029)$ and in the SNc (Fig 1D; one-way ANOVA, $F(2,17)=4.021$, $p=0.0372$ ). Indeed, in both brain regions, EPO significantly increased GPx levels after 12 hours ( $p<0.01$ in the striatum, $p<0.05$ in the SNc). Normally, GPx catalyzes the reaction that neutralizes hydrogen peroxide $\left(\mathrm{H}_{2} \mathrm{O}_{2}\right)$ to water $\left(\mathrm{H}_{2} \mathrm{O}\right)$, thereby reducing oxidative stress. Hence, EPO's ability to increase levels of this antioxidant in suggests it may increase a cellular buffering capacity against ROS. 
Figure 1: Activation of pro-survival signalling pathways

A

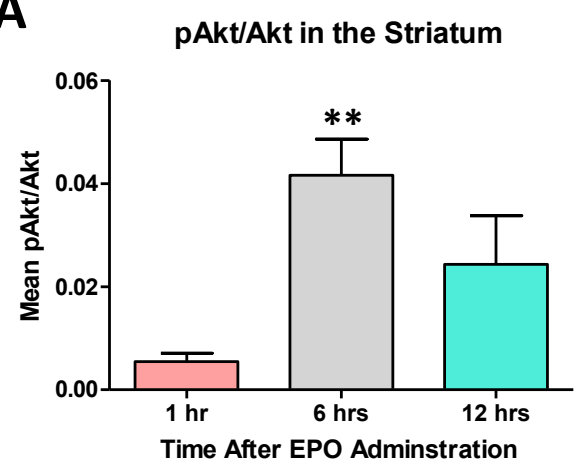

C

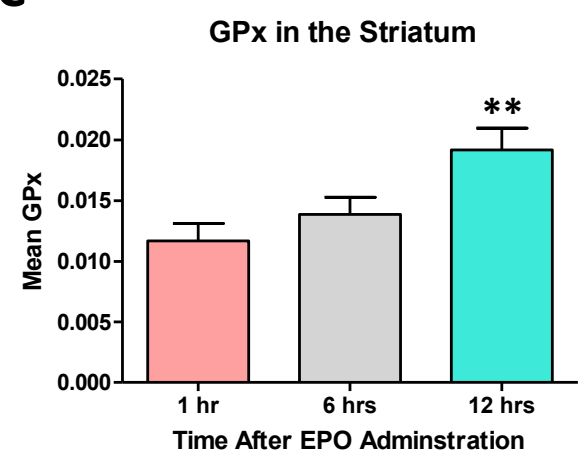

$\mathbf{E}$

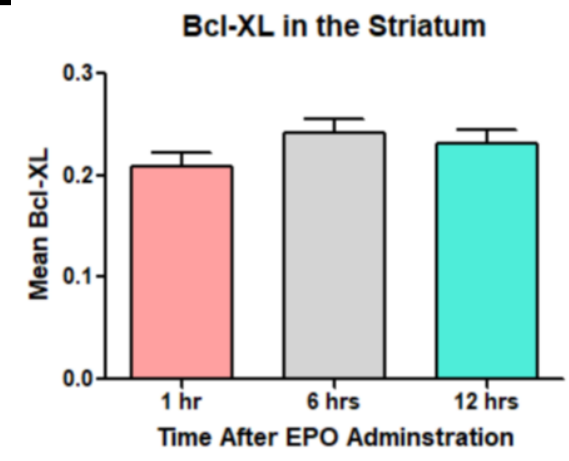

B

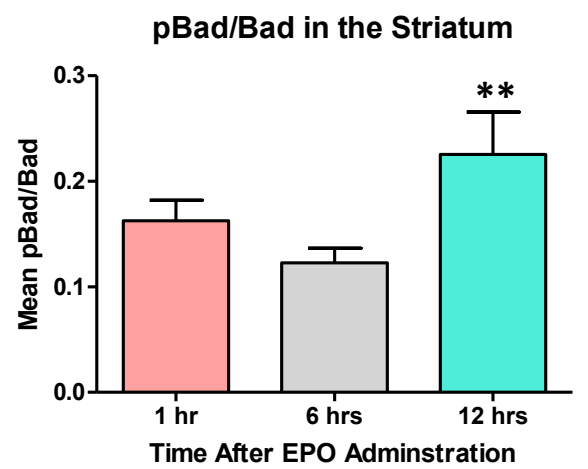

D
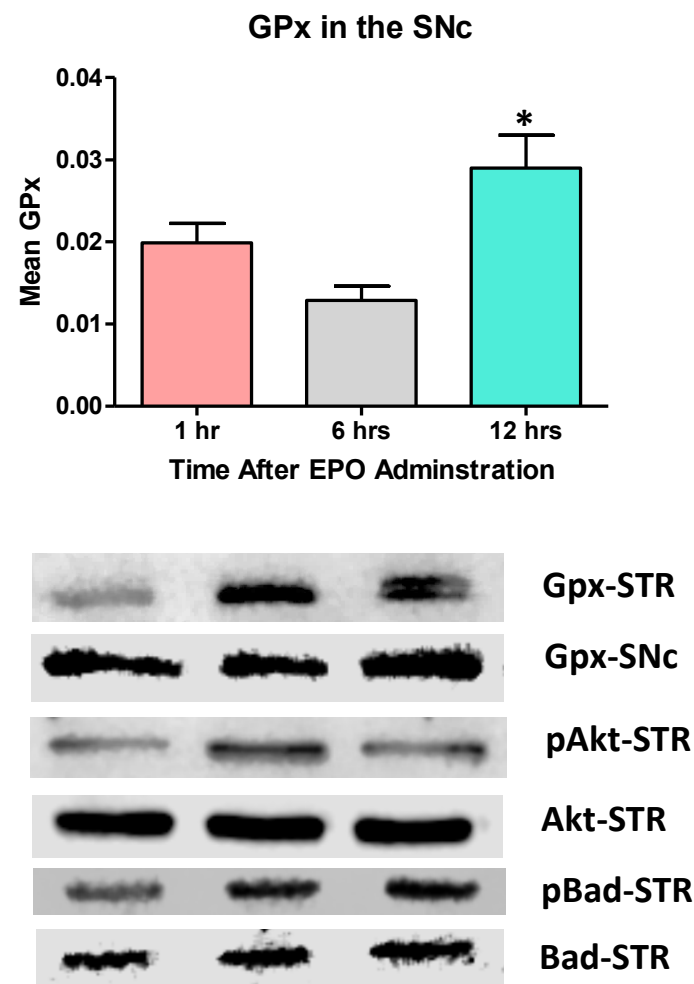

Figure 1. Central EPO administration results in acute activation of pro-survival signalling pathways. Western blot analysis demonstrating influence of intra-striatal EPO on pAkt/Akt, pBad/Bad, GPx and Bcl-xL in the striatum, and GPx in the SNc. A. The ratio of pAkt/Akt peaked 6 hours after EPO administration. B. The ratio of pBad/Bad increased 12 hours after EPO administration. C-D. Levels of GPx were up-regulated 12 hours after EPO administration in both the striatum and the substantia nigra. E. No significant changes were observed in levels of $\mathrm{Bcl}-\mathrm{xL}$ in the striatum. F. Representative 
Western blots for A-E. All signals were normalized against total protein to control for any variations in loading. Data are expressed as mean $\pm S E M ; n=8 .{ }^{*} p<0.05,{ }^{* *} p<0.01$

Experiment 2 Results: Investigating the neuroprotective effects of EPO in the SNc

\section{Striatal Lesion and Stereology}

To investigate EPO's ability to protect dopaminergic neurons in the SNc following 6-OHDA, 20IU of EPO was administered in the SNc followed by a single infusion of $12 \mathrm{ug}$ of 6-OHDA to the left dorsolateral striatum. Administration of 6-OHDA resulted in a dramatic and significant loss of $\mathrm{TH}+$ fibers in the striatal terminals (Fig $\mathbf{2 A}$; one-way ANOVA, $F(2,19)=19.97, \mathrm{p}<0.0001)$ and subsequent loss of $\mathrm{TH}+$ neurons in the SNc three weeks post-infusion (Fig 2B; one-way ANOVA, $F(2,18)=12.39, p=0.0004$ ). However, posthoc analysis indicated administration of 20IU EPO to the SNc did not prevent either of the TH-fiber or soma loss ( $p>0.05)$. 
Figure 2: Striatal Lesion and Stereology
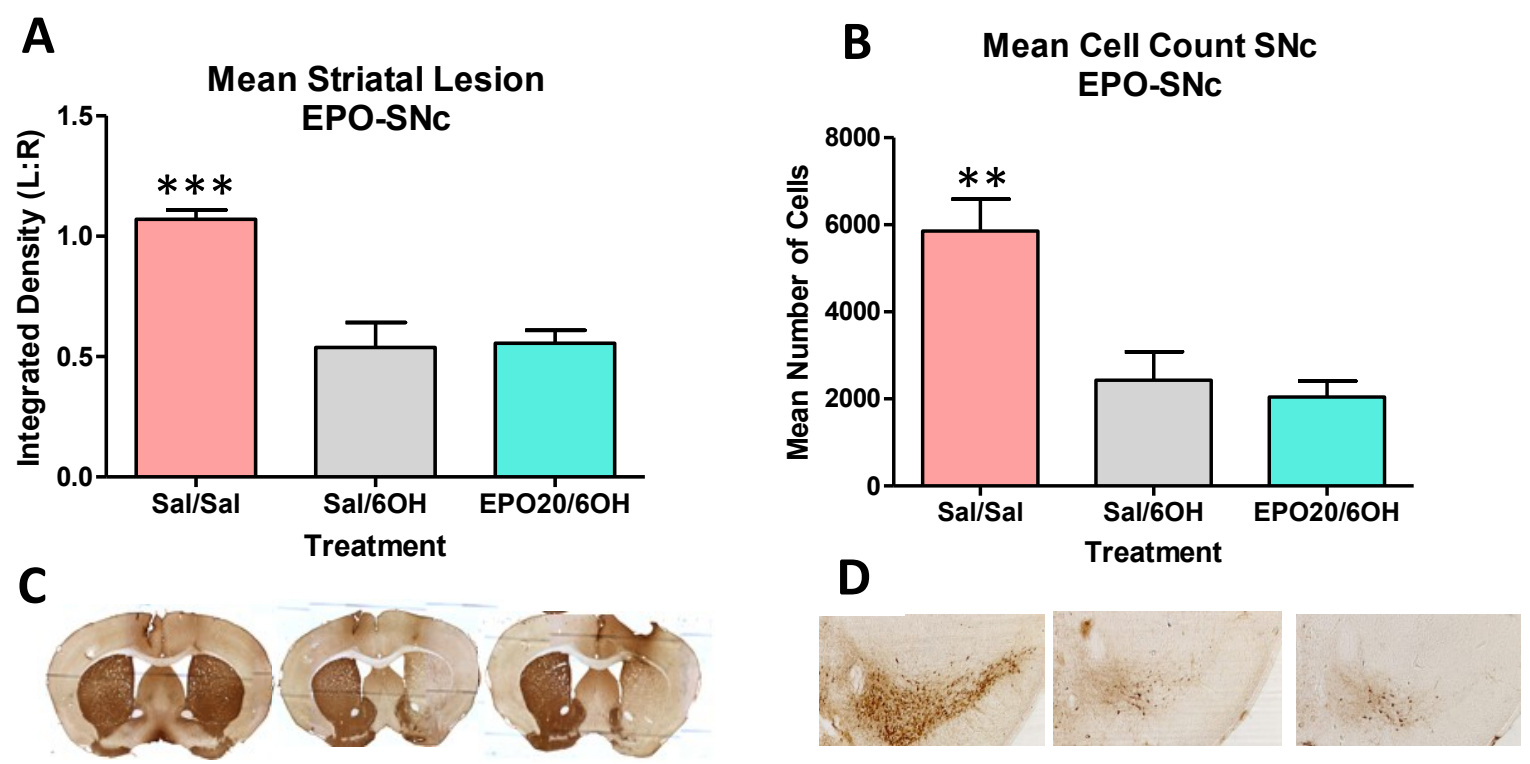

Figure 2. Intra-nigral EPO administration does not attenuate striatal lesion or nigral cell loss induced by intra-striatal 6-OHDA administration. Integrated density in the striatum and cell counts in the SNc. A. Mean integrated density in the striatum expressed as a ratio of lesioned/unlesioned hemisphere. 6-OHDA induced significant loss of TH-fiber density which was not attenuated by $201 \mathrm{U}$ EPO. B. Mean cell counts in the SNc showing a significant loss of $\mathrm{TH}+$ cells after 6-OHDA administration which was not attenuated by 20IU EPO. C. Representative images from each group showing immunostaining for $\mathrm{TH}+$ cells in the striatum ( $\mathrm{n}=8$ per group). $\mathbf{D}$. Representative images from each group showing immunostaining for $\mathrm{TH}+$ cells in the $\mathrm{SNc}(\mathrm{n}=8$ per group). Data are expressed as mean $\pm S E M ; n=8 .{ }^{*} p<0.05$.

\section{$\underline{\text { Microglial Activation }}$}

To assess EPO's ability to modulate neuroinflammatory processes in response to 6-OHDA, we employed a scale previously validated by our lab to determine morphology of microglia in the striatum and SNc (Mangano et al., 2011; Mangano \& Hayley, 2009). In the striatum, administration of 12 ug of 6-OHDA led to a significant change in microglial 
morphology indicative of an activated state (Fig 3A; one-way ANOVA, $F(2,18)=14.40$, $\mathrm{p}=0.0002$ ). However, much like the $\mathrm{TH}+$ neurons, this effect was not significantly influenced by pre-treatment with intra-nigral EPO ( $p>0.05)$. In the SNc, a similar change in microglial morphological state was evident with intra-striatal 6-OHDA treatment (Fig 3B; one-way ANOVA, $F(2,19)=14.97, \mathrm{p}=0.0001)$. However, in this case, post-hoc analysis indicated 20IU EPO did significantly attenuate microglial activation scores at 3 weeks post-lesion $(p<0.05)$, suggesting a possible anti-inflammatory effect of EPO on microglia in the SNc which was insufficient to protect nigral cells from 6-OHDA-induced toxicity.

Figure 3: Assessing microglial activation in the striatum and substantia nigra

A

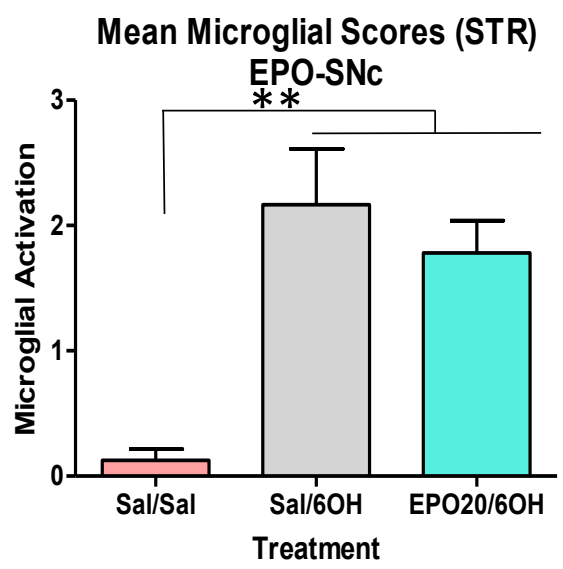

B

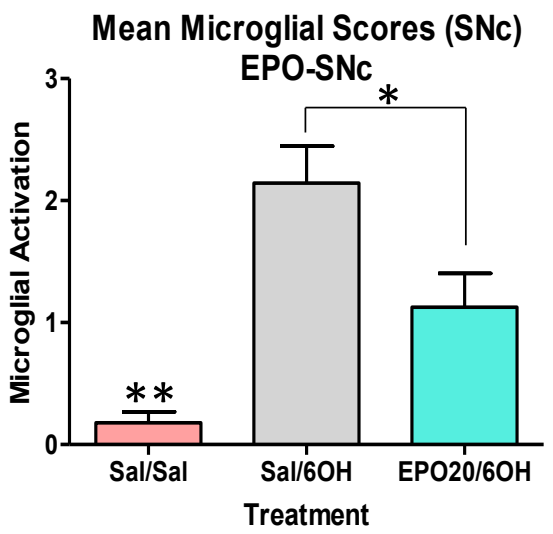




\section{C}
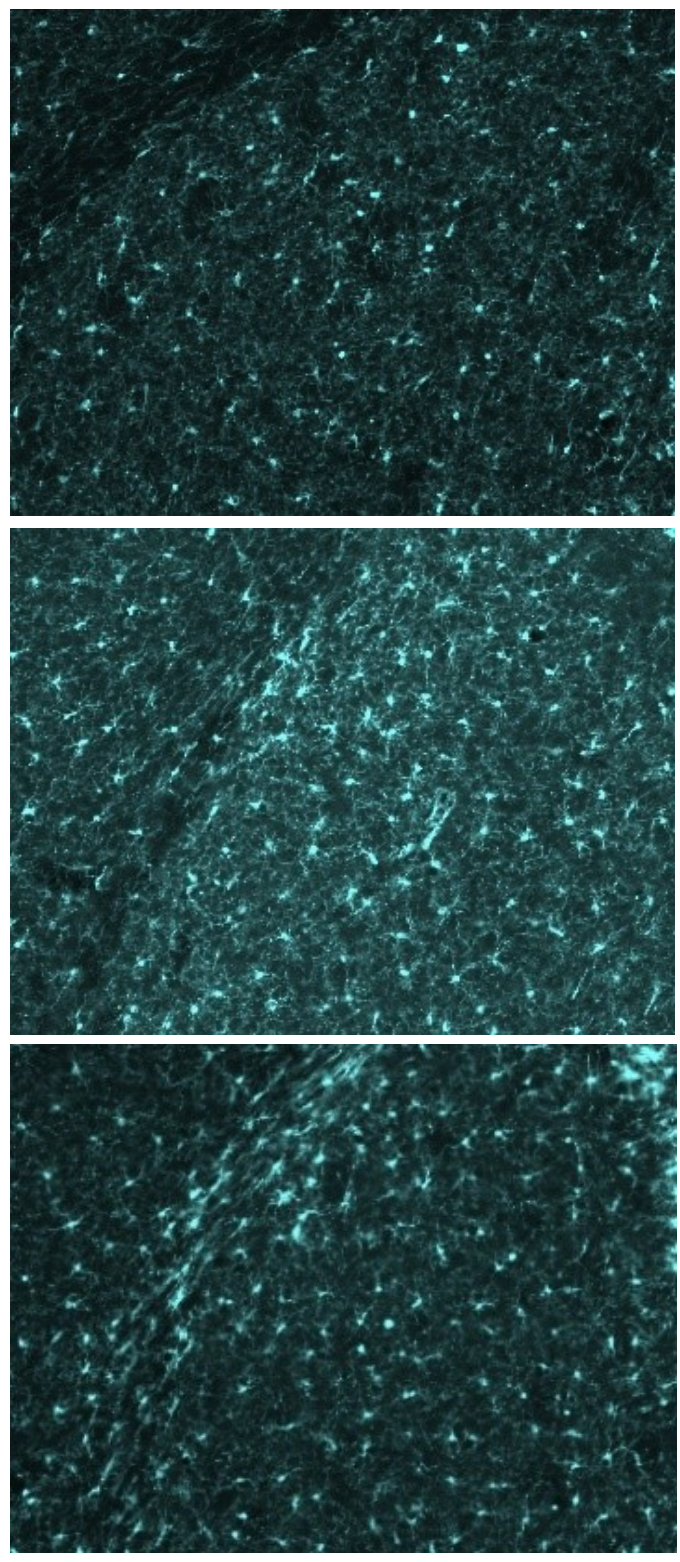

D

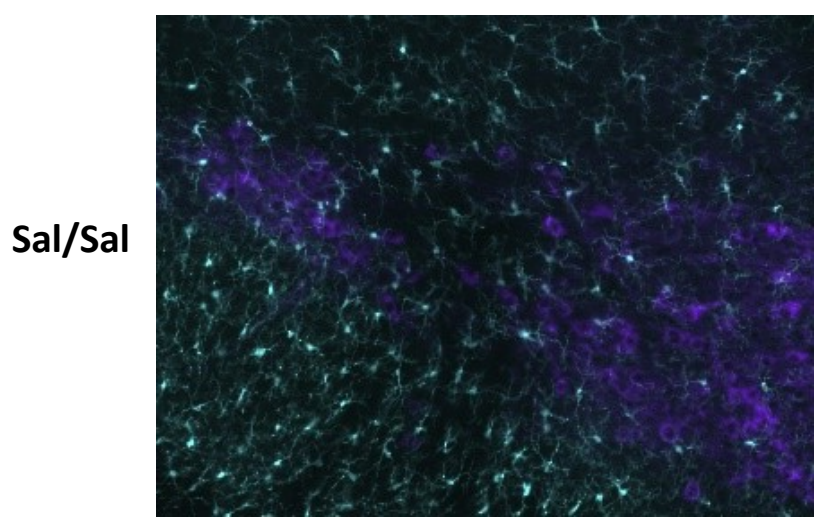

Sal/6OH

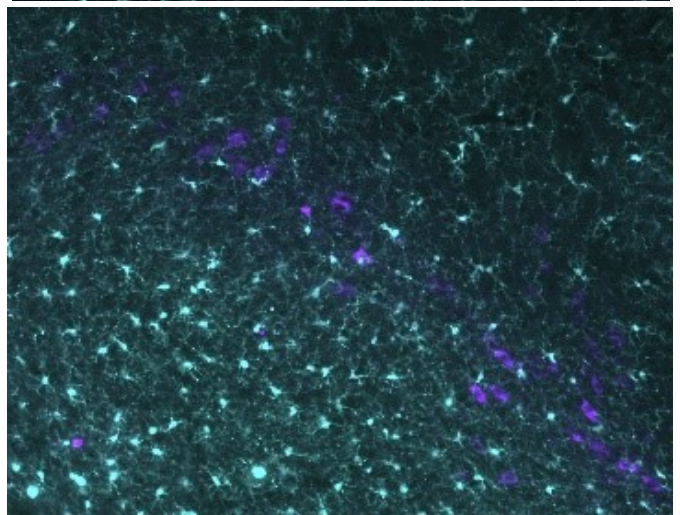

EPO20/

$60 \mathrm{H}$

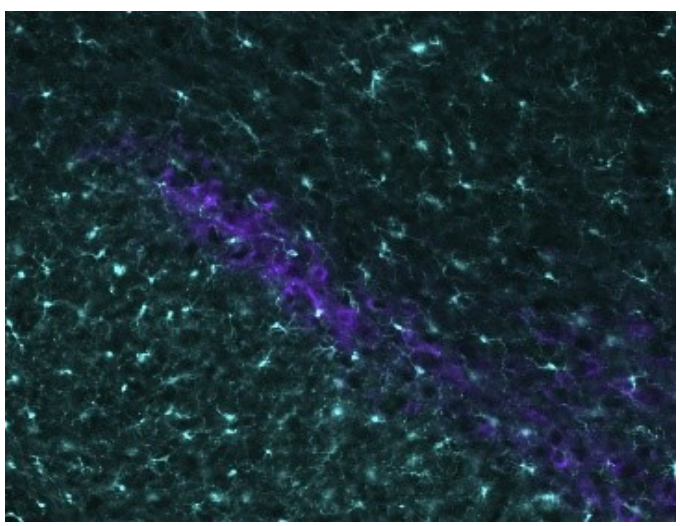

Figure 3. Microglial activation as determined by morphological rating scale as previously described (0-3). In both the striatum (A) and SNc (B), 6-OHDA induced significant morphological changes in microglia, indicating increased activation. In the SNc, but not in the striatum, EPO attenuated this activation, indicating a potential anti-inflammatory effect of EPO when administered into the SNc. C-D. Representative images of microglia (stained using IBA1, teal) in the striatum (C) and SNc (D). Tyrosine hydroxylase staining of $\mathrm{SNc}$ neurons is shown in purple. Data are expressed as mean $\pm \mathrm{SEM} ; n=8 .{ }^{*} p<0.05$, $* * p<0.01$. 


\section{Behaviours}

Rotarod

Animals were assessed for balance and motor coordination using the Rotarod, and mean latency to fall was determined using the best $2 / 3$ trials on the test day. Intrastriatal administration of 12 ug of 6-OHDA led to a decreased latency to fall (Fig 4; $F(2,19)=7.002, p=0.0053)$, but administration of $201 \mathrm{U}$ of EPO did not improve performance on this motor task $(p>0.05)$.

Figure 4: Assessing Gait and Balance using the Rotarod Apparatus

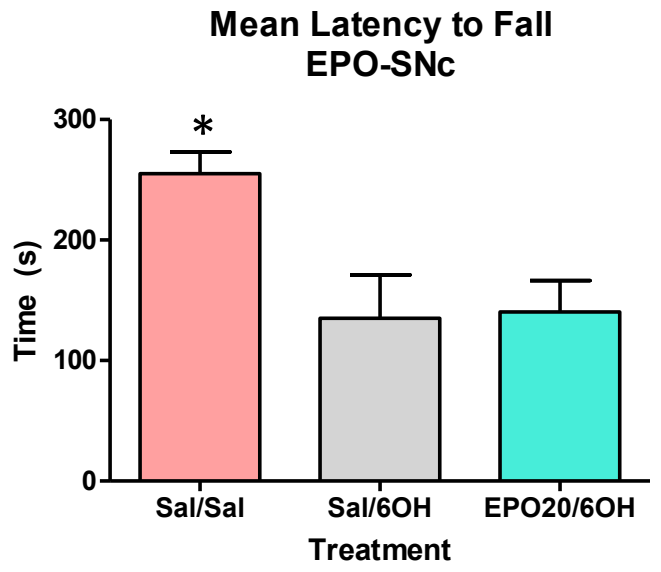

Figure 4. Mean latency to fall from accelerating rod (4-44 rotations per minute over 300 seconds) by treatment. Administration of 6-OHDA led to a decreased latency to fall, but EPO did not mitigate this effect.

Catwalk

The CatWalk apparatus was used to assess four characteristics of the animals' gait that were expected to be impaired by 6-OHDA prior to stereotaxic surgery and 
again 10 and 17 days post-operatively. No significant changes were observed (data not shown, see Appendix A).

Home Cage Activity

The Micromax apparatus was used to assess overall locomotor activity of animals for 12 hours during their waking cycle (8pm-8am) in their home cages. No significant changes were observed in the overall motor activity of mice (data not shown, see Appendix B).

Experiments 3 and 4: Comparing two doses of 6-OHDA when EPO is administered in the striatum

Next, we sought to assess the impact of EPO when administered into the striatum in the context of two 6-OHDA-induced lesions of different magnitudes. To this end, in Study 3, two doses of EPO were used (10IU and 20IU) with a dose of 12ug of 6OHDA. In Study 4, only the higher of $201 \mathrm{U}$ dose of EPO was used, but with a lower 3 ug dose of 6-OHDA.

As found in our earlier study, the 12ug dose of 6-OHDA induced a significant loss of $\mathrm{TH}+$ terminals in the striatum, inducing a greater than $50 \%$ reduction in density in the lesioned hemisphere (Fig 5A; one-way ANOVA, $F(4,23)=12.23, p<0.0001$ ). As previously observed by Signore et al. (2006), both the 10IU and 20IU dose of EPO were equally effective in significantly attenuating the loss of striatal fibers $(p<0.05$, relative to 
Sal/6-OHDA treatment). In Study 4, administration of 3ug of 6-OHDA resulted in a more modest (approximately $30 \%$ ) but statistically significant loss of $\mathrm{TH}+$ fibers in the striatum (Fig 5B; $F(2,13)=8.475, p=0.0044)$. With EPO pre-treatment, the loss of striatal fibers was no longer significantly different from control animals, indicating a mild protective effect $(p>0.05)$. This represents a different finding from that of Signore and colleagues, who found 3ug of 6-OHDA induced substantial loss of striatal fibers (more than $50 \%$ ), which may be explained by differing methodologies between the studies (e.g. these authors used a different strain of mouse, and infused at a more medial site in the striatum, which may have influenced signaling and cell death via limbic inputs or different populations of medium spiny neurons and interneurons).

In the SNc, a significant and marked (approximately 50\%) loss of TH+ neurons was induced by intra-striatal infusion of 12ug 6-OHDA (Fig 6A; $F(4,26)=11.20, p<0.0001$ ). The follow-up comparisons indicated this loss was significantly reduced by both 10IU and $201 \mathrm{U}$ doses of EPO $(p<0.05)$. This finding differs from the results obtained by Signore et al. (2006), who found a $50 \%$ loss of SNc DA neurons was attenuated by $201 \mathrm{U}$ of EPO, but not by 10 IU of EPO. When the lower 3ug dose of 6-OHDA was administered, a more modest (approximately 30\%) but statistically significant loss of $\mathrm{TH}+$ soma in the SNc was evident (Fig 6B; $F(2,15)=12.25, p=0.0007)$. The 20 IU dose of EPO significantly attenuated this SNc loss of TH+ neurons $(p<0.05)$. 
Figure 5. Striatal Lesions

A

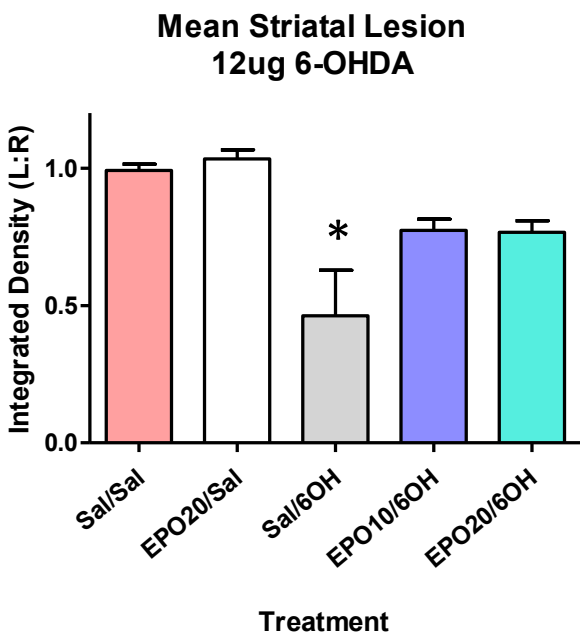

C

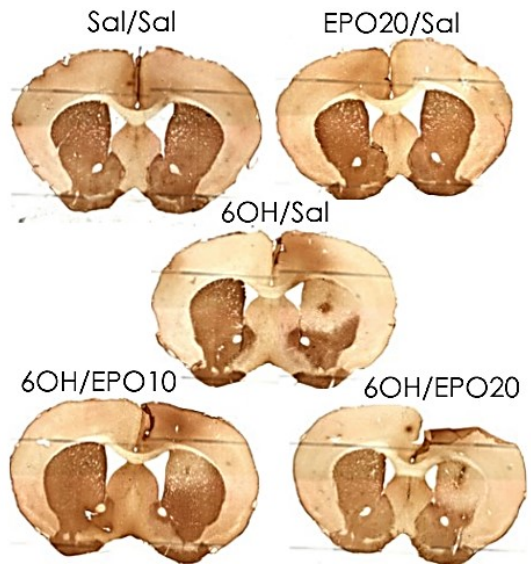

B

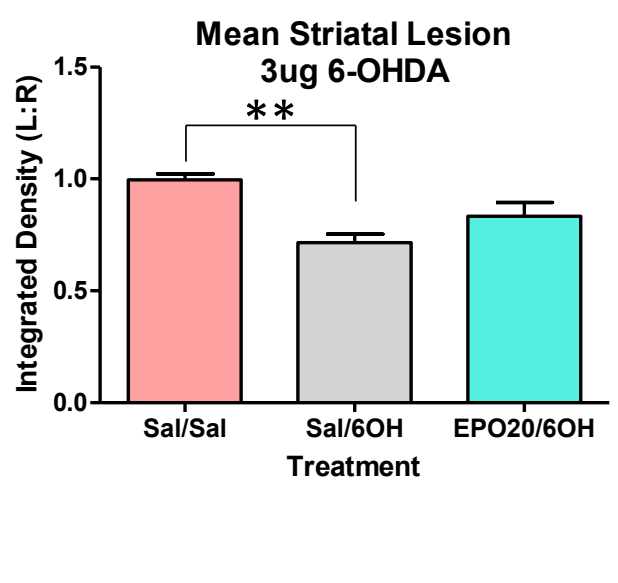

D

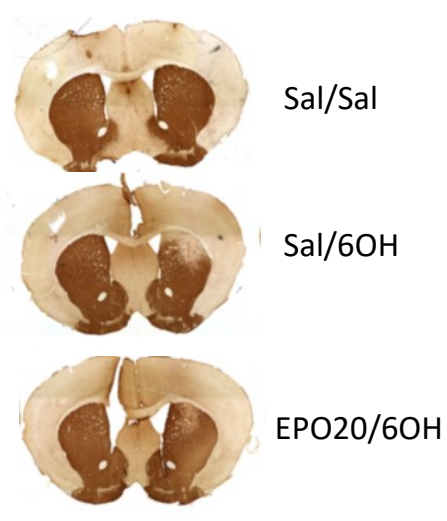

Figure 5. Intra-striatal EPO administration attenuates striatal lesion. Integrated density of $\mathrm{TH}+$ fibers was assessed in the striatum. A. Mean integrated density in the striatum expressed as a ratio of lesioned/unlesioned hemisphere when 12ug of 6-OHDA were infused unilaterally into the striatum. 6-OHDA induced significant loss of TH-fiber density which was attenuated by both $10 \mathrm{IU}$ and $20 \mathrm{IU}$ of EPO. B. Mean integrated density in the striatum expressed as a ratio of lesioned/unlesioned hemisphere when 3ug of 6-OHDA were infused unilaterally into the striatum. 6-OHDA induced significant loss of TH-fiber density which was attenuated by $201 \mathrm{U}$ of EPO. C-D. Representative images from each group showing immunostaining for $\mathrm{TH}+$ cells in the striatum $(n=8-10$ per group). 
Figure 6. Stereological assessment of neuronal loss

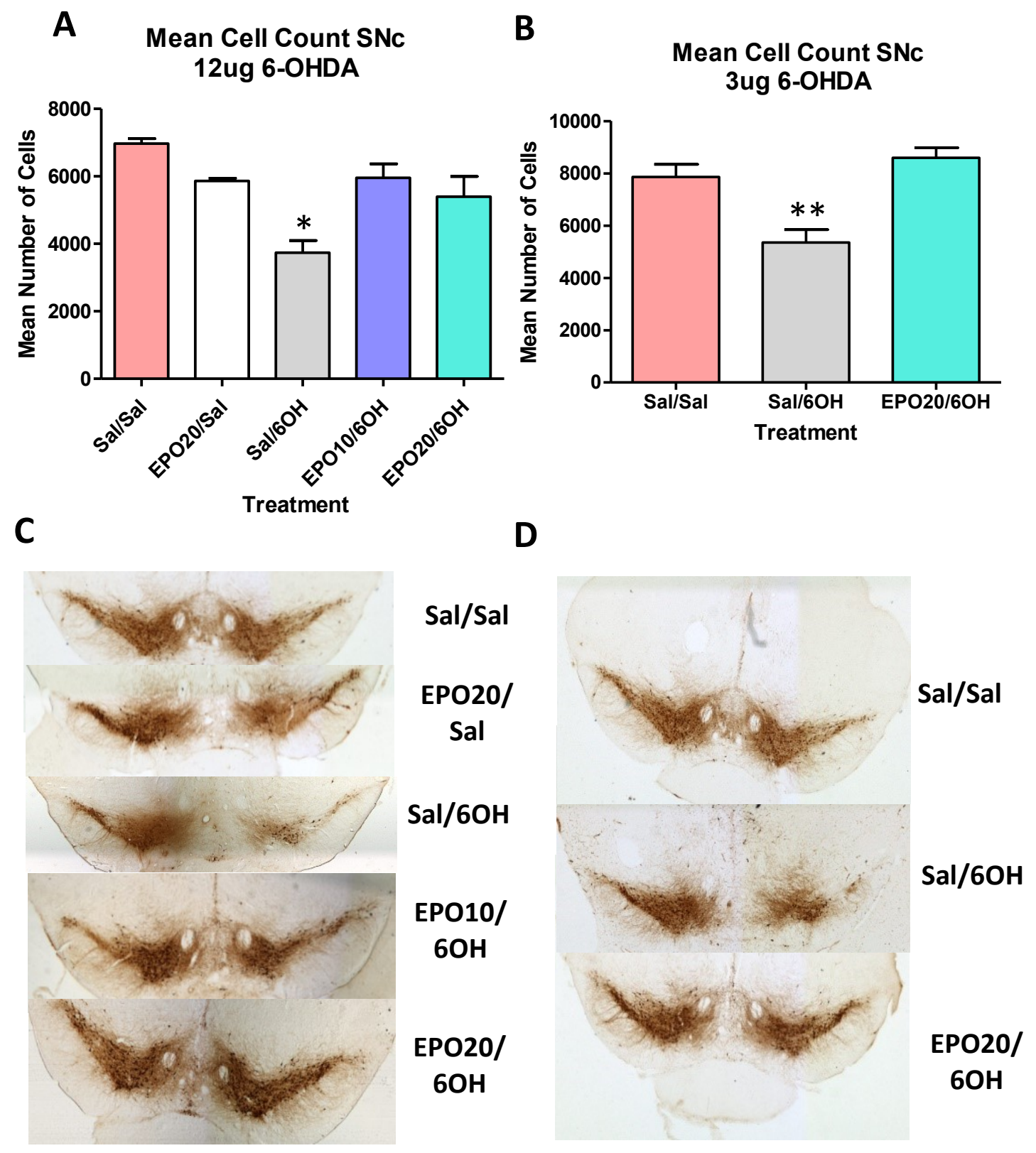


Figure 6. Intra-striatal EPO administration attenuates nigral cell loss induced by intrastriatal 6-OHDA administration. Cell counts in the SNc when 12ug and 3ug 6-OHDA adminstered. A. Mean integrated density in the striatum expressed as a ratio of lesioned/unlesioned hemisphere. 6-OHDA induced significant loss of TH-fiber density which was attenuated by both $10 \mathrm{IU}$ and $20 \mathrm{IU}$ of EPO. B. Mean cell counts in the SNC showing a significant loss of $\mathrm{TH}+$ cells after 6-OHDA administration which was attenuated by 20IU EPO. C-D. Representative images from each group showing immunostaining for $\mathrm{TH}+$ cells in the $\mathrm{SNc}$ ( $\mathrm{n}=8$ per group). Data are expressed as mean \pm SEM; $n=8 .{ }^{*} p<0.05, * * p<0.001$.

\section{$\underline{\text { Microglial Activation }}$}

Administration of both 3ug (Fig 7A; one-way ANOVA, $F(2,14)=10.27, p=0.0018$ )

and 12ug (Fig 7B; one-way ANOVA, $F(4,23)=9.415, p=0.0001$ ) of 6-OHDA led to a significant change in microglial morphology indicating activation. Importantly, at both doses of toxin, this was completely reversed in animals that received $10 \mathrm{IU}$ or $20 \mathrm{IU}$ of intra-striatal EPO $(p<0.01)$. Similarly, microglial activation morphology scores in the SNc were significantly elevated 3 weeks post-lesion in the 6-OHDA group at 3ug (Fig 7C; one-way ANOVA, $F(2,14)=5.069, \mathrm{p}=0.0221$ ) and 12ug (Fig 7D; one-way ANOVA, $F(4,27)=21.39, p<0.0001)$. Once again, treatment with either $10 I U$ or $20 I U$ EPO completed reversed this effect at both doses of toxin $(p<0.05)$, indicating a potent chronic effect of EPO on microglial activity. 
Figure 7. Assessing microglial activation in the striatum and substantia nigra

A

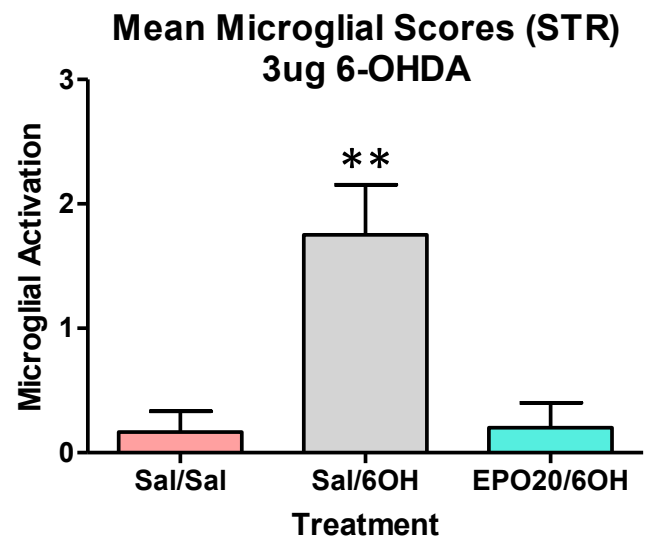

C

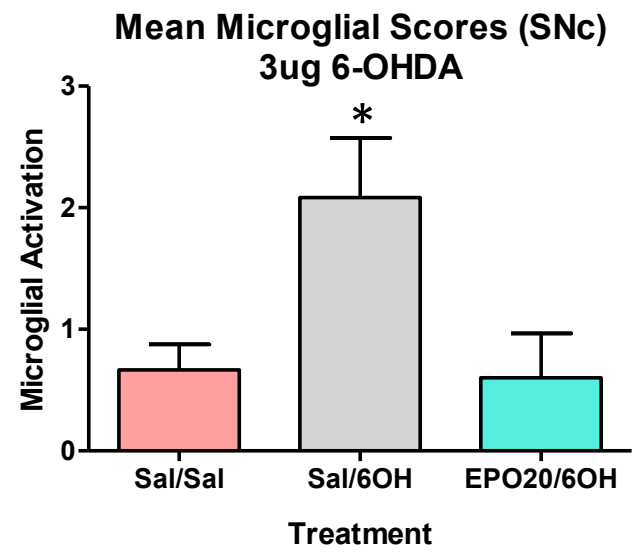

B

Mean Microglial Scores (STR) 12ug 6-OHDA

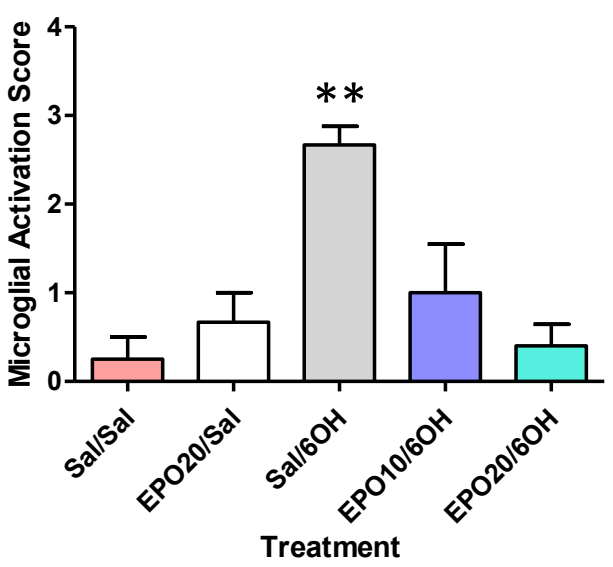

D

$$
\text { Mean Microglial Scores (SNc) }
$$
12ug 6-OHDA

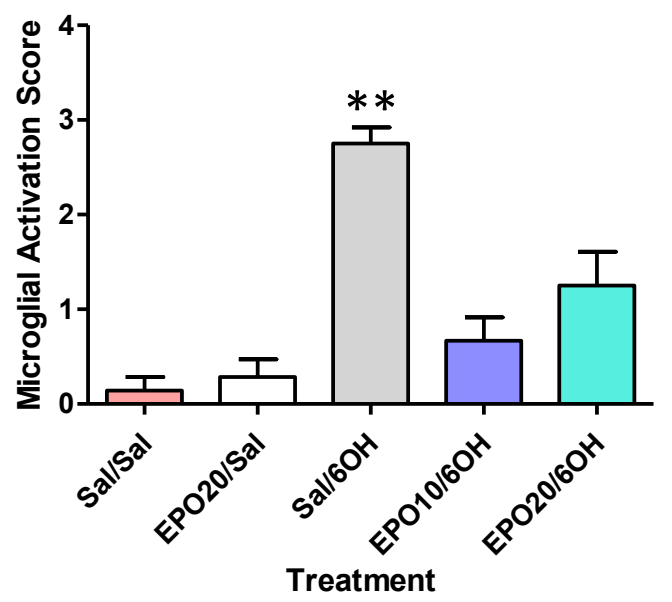


E
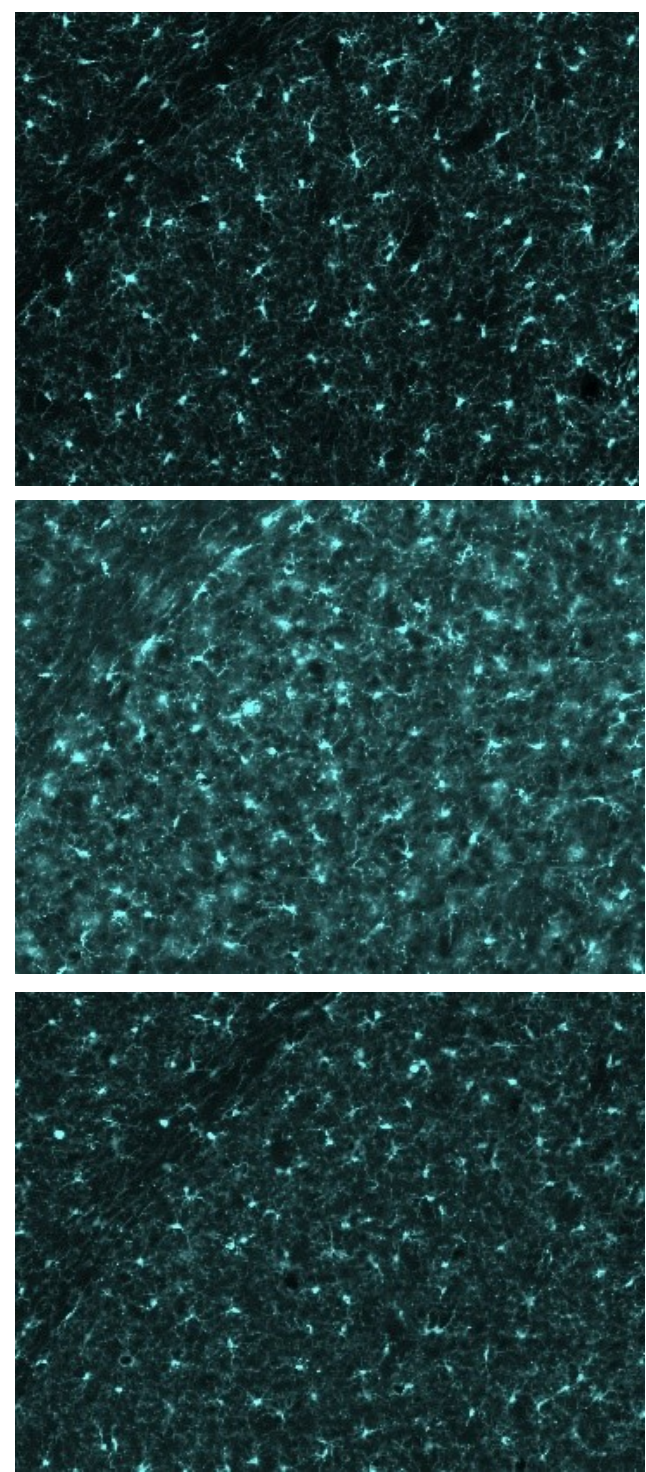

F

Sal/Sal

Sal/6OH

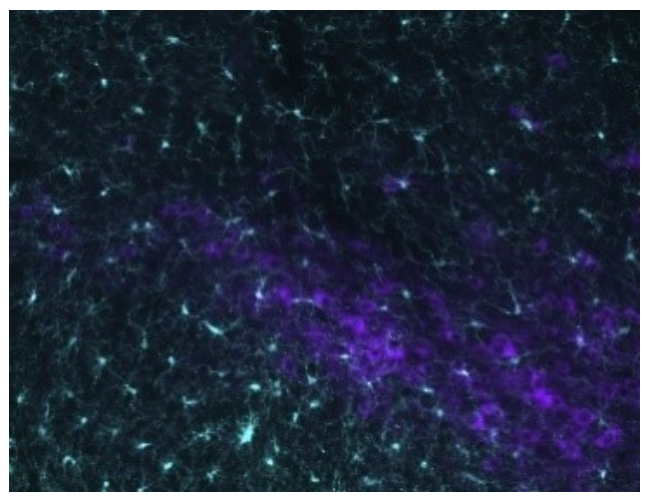

EPO20/

$60 \mathrm{H}$

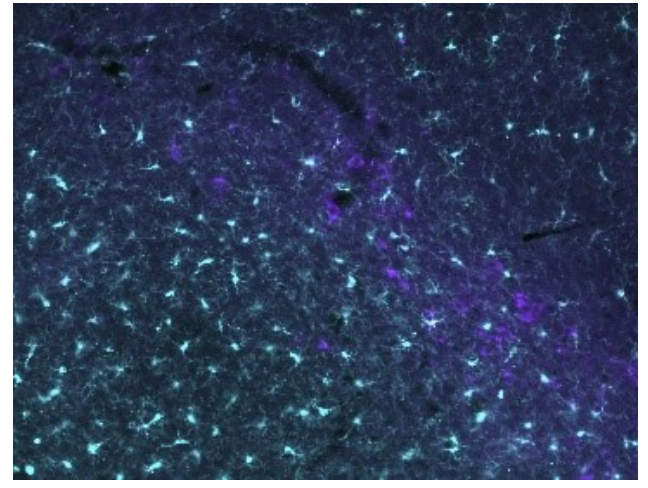

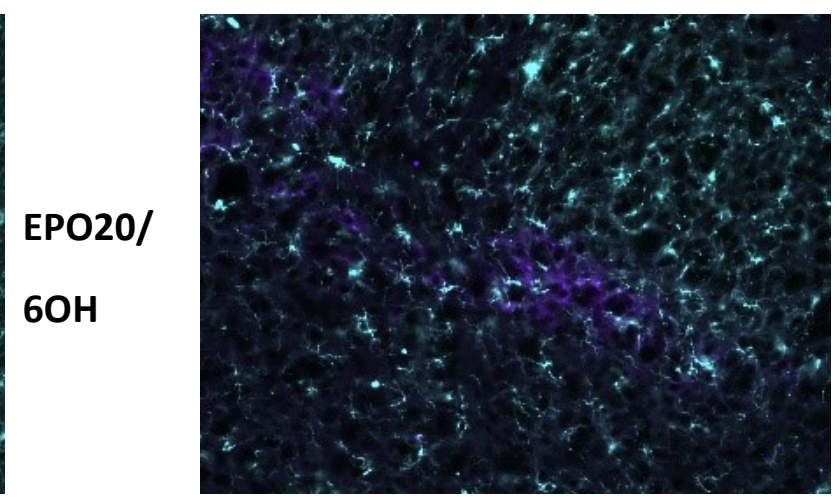


G
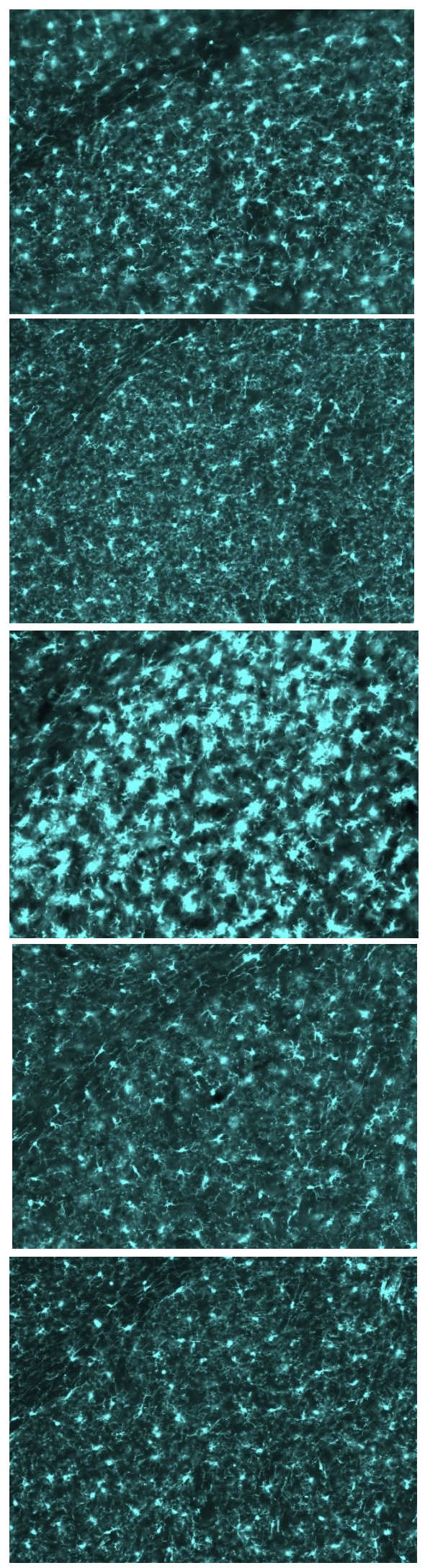

H

Sal/Sal

EP020/Sal

Sal/6OH

EP010

/6OH
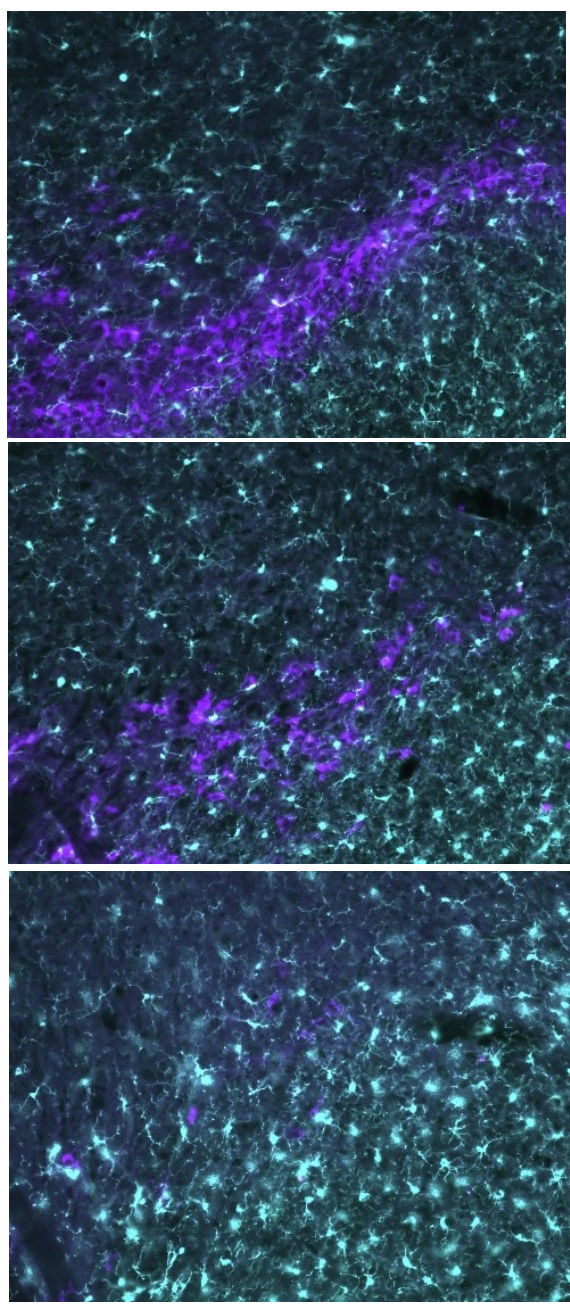

EPO20

$/ 60 \mathrm{H}$

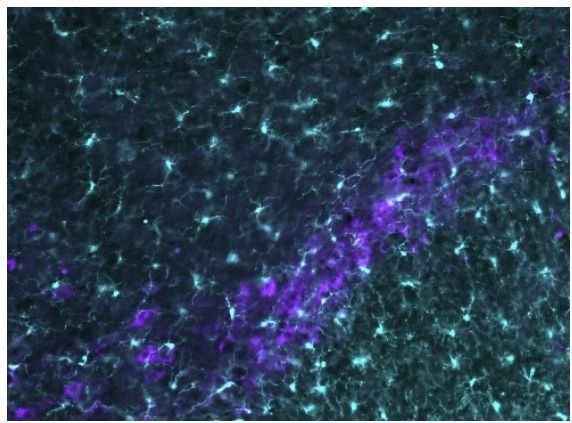

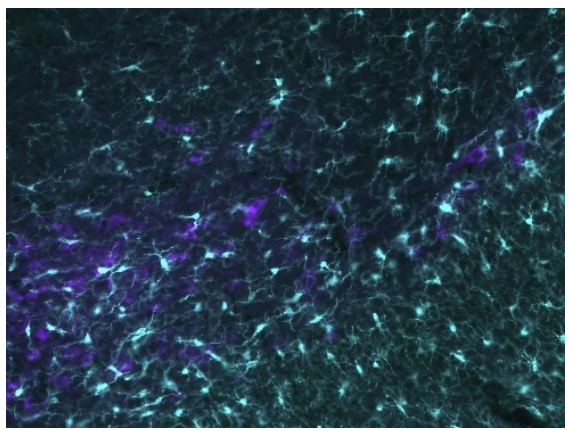


Figure 7. Microglial activation as determined by morphological rating scale as previously described (0-3). In both the striatum (A-B) and SNc (C-D), 6-OHDA induced significant morphological changes in microglia, indicating increased activation. In both regions, EPO attenuated this activation significantly 3 weeks post-lesion, indicating an antiinflammatory action of EPO. E-F. Representative images of microglia in the striatum (E) and SNc (F) with 3ug of 6-OHDA. G-H Representative images of microglia (stained using IBA1, teal) in the striatum (G) and SNc (H). Tyrosine hydroxylase staining of SNc neurons is shown in purple. Data are expressed as mean $\pm S E M ; n=8 .{ }^{*} p<0.05,{ }^{*} p<0.01$.

\section{Behaviours: Rotarod and Apomorphine-Induced Rotations}

When 12 ug of 6-OHDA were infused into the striatum, the mean latency to fall from the Rotarod was significantly affected (Fig 8A; one-way ANOVA, $F(4,87)=6.222$, $p=0.0002$ ). Specifically, the 6-OHDA lesion reduced time on the Rotarod before falling $(p<0.05)$ but treatment with $10 \mathrm{IU}$ or $20 \mathrm{IU}$ EPO did not improve this performance deficit. While 6-OHDA reduced latency to fall in a statistically significant manner on the $300 \mathrm{~s}$ task, the majority of animals in all groups remained on the Rotarod for more than 200s, suggesting the sensitivity of this task to measure motor deficits may be limited in our model.

Apomorphine-induced rotations provide a robust measure of dopaminergic responsiveness and an indication of the presence of a unilateral lesion in rodent models of PD (Heuer, Smith, Lelos, Lane, \& Dunnett, 2012; Hudson et al., 1993; Hughes, Lees, \& Stern, 1990). Infusion of 12ug of 6-OHDA significantly increased apomorphine-induced contralateral rotations in mice (Fig 8B; one-way ANOVA, $F(4,84)=50.97, p<0.0001$ ). This effect was blunted significantly with the $201 \mathrm{I}$ treatment with EPO $(p<0.05$, relative to Sal/6-OHDA). While some animals demonstrated almost no rotation, the variability was 
large in both EPO groups, suggesting a possible difference in responsiveness to the treatment (Fig $\mathbf{8 C}$ ). When the lower dose of 6-OHDA was administered, no impairments were observed on the Rotarod test (Fig 8D; $p>0.05$ ). The rotational behaviour induced by 3ug of 6-OHDA, however, was decreased significantly by $201 \mathrm{U}$ of EPO in this study, again highlighting the potentially greater sensitivity of this test over the Rotarod to capture motor deficits in this model (Fig 8E; one-way ANOVA, $F(2,19)=11.11, p=0.0006$ ). Hence, EPO may differentially affect motor behaviour in mice as a function of lesion size.

\section{$\underline{\text { Western Blots: Striatum }}$}

We assessed pro-survival signalling of EPO in the striatum three weeks after lesions were established. In Study 3 (using 12ug 6-OHDA), no significant changes in pAkt were observed 3 weeks post-lesion, although the variability in the two EPO-treated groups once again suggests the possibility of a difference in response rate to EPOtreatment (Fig 9A, p>0.05). In Study 4 (using 3ug of 6-OHDA), there were no differences in pAkt/Akt between groups 3 weeks post-lesion (Fig 9B, p>0.05); however, the large variability in response to EPO was not observed at the lower dose of 6-OHDA. When 12ug of 6-OHDA were used, significant differences in levels of GPx were observed between groups (Fig 9E; one-way ANOVA, $F(4,35)=5.743, p=0.0012$ ). Specifically, GPx was increased in response to both $10 \mathrm{IU}$ and $20 \mathrm{IU}$ of EPO $(p<0.05)$. When 3ug of 6-OHDA 
were used, however, no changes in GPx were observed in response to EPO treatment (Fig 9F, $p>0.05$ ).

Interestingly, when 12ug of 6-OHDA were used, no differences in the levels of $\mathrm{Bcl}-\mathrm{xL}$ were observed between groups three weeks post-lesion (Fig 9I, $\mathrm{p}>0.05$ ). In the case of the 3ug dose of 6-OHDA, however, levels of $\mathrm{Bcl}-\mathrm{xL}$ were significantly upregulated in response to EPO-treatment three weeks post-lesion (Fig 9J; one-way ANOVA, $F(2,19)=6.358, p=0.0077)$. This result suggests EPO may activate different pro-survival pathways depending on the extent of lesion, cellular stress, or microenvironment, all of which may differ with different doses of 6-OHDA. 
Figure 8. Assessing Motor Activity with the Rotarod and Rotational Behaviour

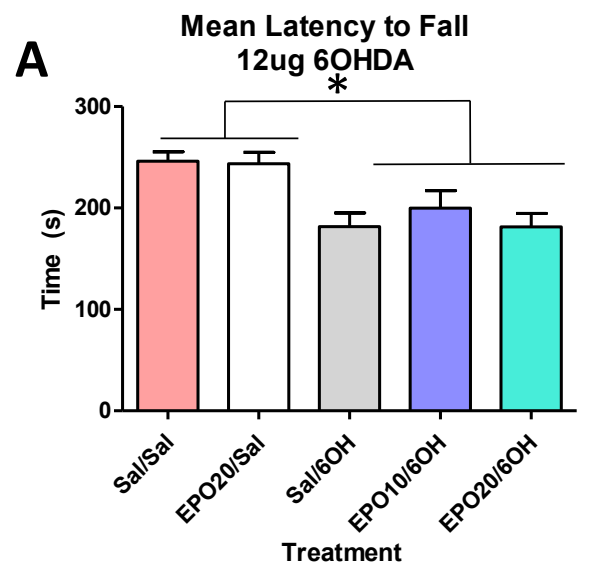

B Apomorphine-Induced Rotations
12ug 6-OHDA

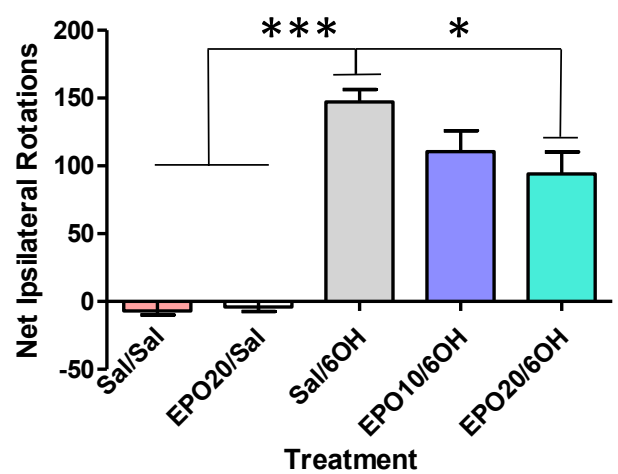

APO-Induced Rotations

C 12ug 6-OHDA

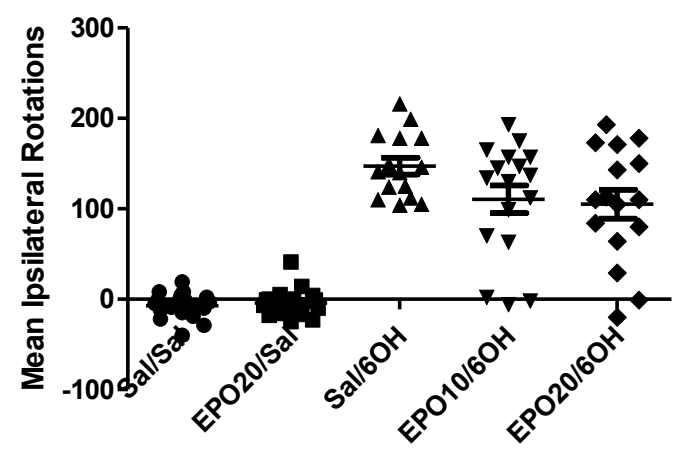

Mean Latency to Fall 3ug 6OHDA

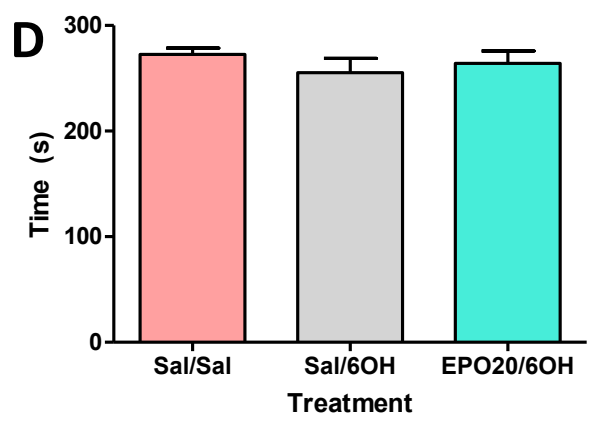

Apomorphine-Induced Rotations 3ug 6-OHDA

E

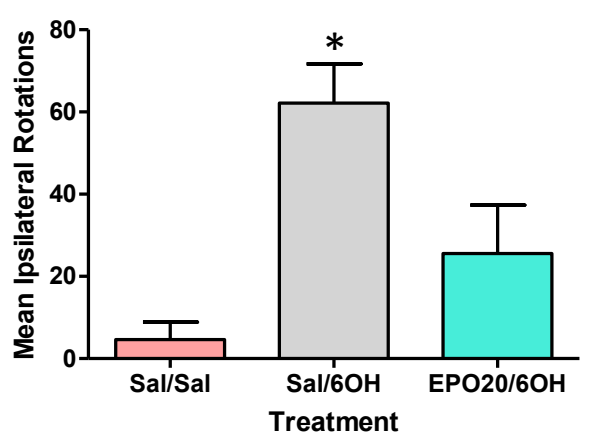

Figure 8. Mean latency to fall from accelerating rod (4-44 rotations per minute over 300 seconds) by treatment in Study 3 (A) and Study 4 (D). Administration of 6-OHDA led to a decreased latency to fall, but EPO did not mitigate this effect $(p>0.05)$. Net contralateral rotations induced by apomorphine were decreased in EPO-treated groups in Study 3 (B) and Study 4 (E). Data are expressed as mean \pm SEM; $n=17-19$ for Study 3; $n=10-12$ for Study 4. ${ }^{*} p<0.05$. 
Figure 9. Western blots in the striatum
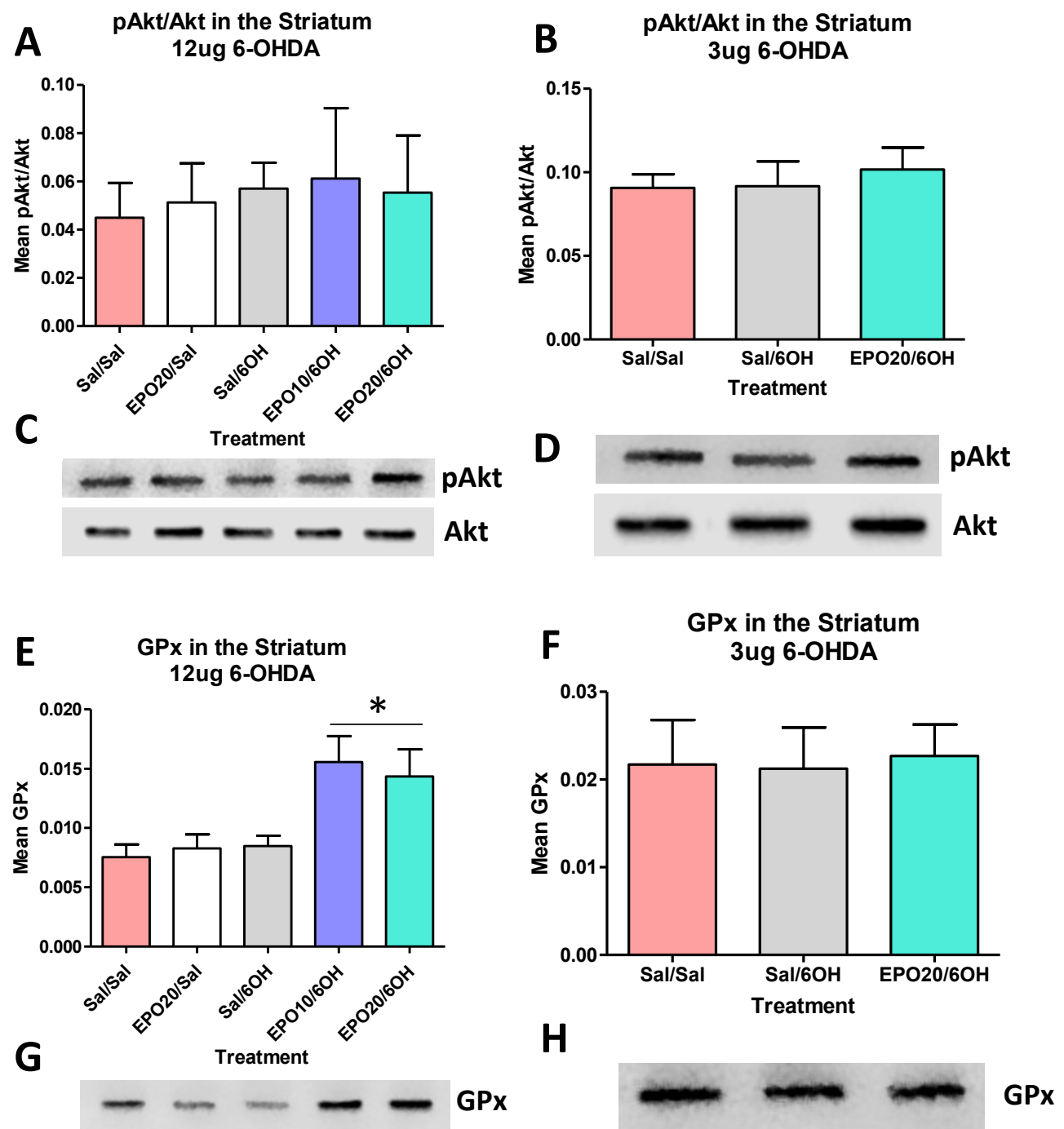

Bcl-xL in the Striatum 12ug 6-OHDA
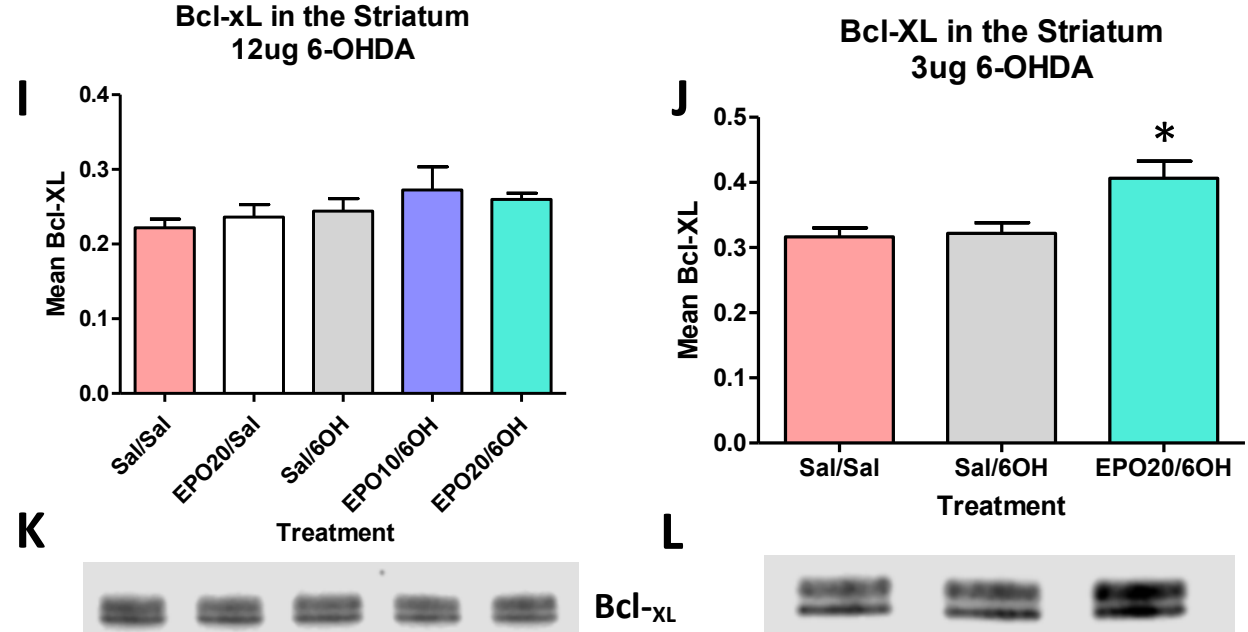

$\mathrm{BCl}-\mathrm{xL}$

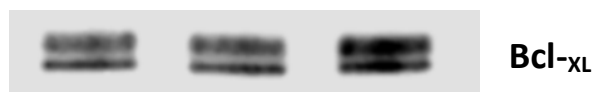


Figure 9. Intra-striatal EPO administration results in chronic activation of pro-survival signalling pathways. Western blot analysis demonstrating influence of EPO on pAkt/Akt, GPx and $\mathrm{BCl}-\mathrm{XL}$ in the striatum. A-B. The ratio of pAkt/Akt did not change significantly in response to 6-OHDA or EPO. C-D. Representative Western blots for pAkt and Akt in studies 3 (C) and 4 (D). E-F. Levels of GPx were up-regulated in groups that received EPO in study 3 (E) but not in study 4 (F). G-H. Representative Western blots for GPx in study 3 (E) and study 4 (F). I-J. No significant changes were observed in levels of $\mathrm{Bcl}-\mathrm{xL}$ in the striatum when 12ug 6-OHDA were used (I), but a significant increase in $\mathrm{Bcl}$-xL was observed when 3ug of 6-OHDA were used (J). K-L. Representative Western blots for $\mathrm{Bcl}-\mathrm{xL}$ in the striatum for study $3(\mathrm{~K})$ and study $4(\mathrm{~L})$. All signals were normalized against total protein to control for any variations in loading. Data are expressed as mean $\pm \mathrm{SEM}$; $\mathrm{n}=8-10 .{ }^{*} \mathrm{p}<0.05$.

\section{Western Blots: Substantia Nigra}

To investigate the pro-survival signalling of EPO in the SNc three weeks after lesions were established in the striatum, Western blots were performed on nigral tissue. In the SNc, 12ug of 6-OHDA caused a significant reduction in pAkt/Akt, which was completely reversed by both doses of intra-striatal EPO (Fig 10A; one-way ANOVA, $F(4,35)=3.687, p=0.0132)$. This finding confirms that intra-striatal EPO can influence prosurvival signalling in the SNc for as long as three weeks post-infusion in the presence of a high dose of 6-OHDA. When 3ug of 6-OHDA were administered, no significant changes in levels of pAkt/Akt were observed between groups (Fig 10B, p>0.05). In the SNc, no changes in GPx were observed at either 12ug (Fig 10E) or 3ug (Fig 10F), while GPx was increased in the striatum 3 weeks post-lesion using 12ug of 6-OHDA. It is possible GPx is increased in non-dopaminergic cells in the striatum, such as astrocytes and microglia, to influence striatal terminal survival (Lindenau, Noack, Asayama, \& Wolf, 1998). 
Alternatively, this may suggest anti-apoptotic or anti-inflammatory (as opposed to antioxidant) mechanisms may exert more influence over cell survival in the SNc three weeks post-lesion. When 12ug (Fig 10I) 6-OHDA were used, $\mathrm{Bcl}$-xL demonstrated a trend toward increase in the EPO-treated groups that was not statistically significant $(p>0.05)$. When 3ug of 6-OHDA were used, however, no changes in Bcl-xL were noted (Fig 10J). Together, these results suggest EPO's chronic activation of pro-survival signalling may be dependent on the extent of lesion, cellular microenvironment, or both, with a higher dose of 6-OHDA producing a prolonged activation of pro-survival pathways. 
Figure 10: Western blots in the SNC

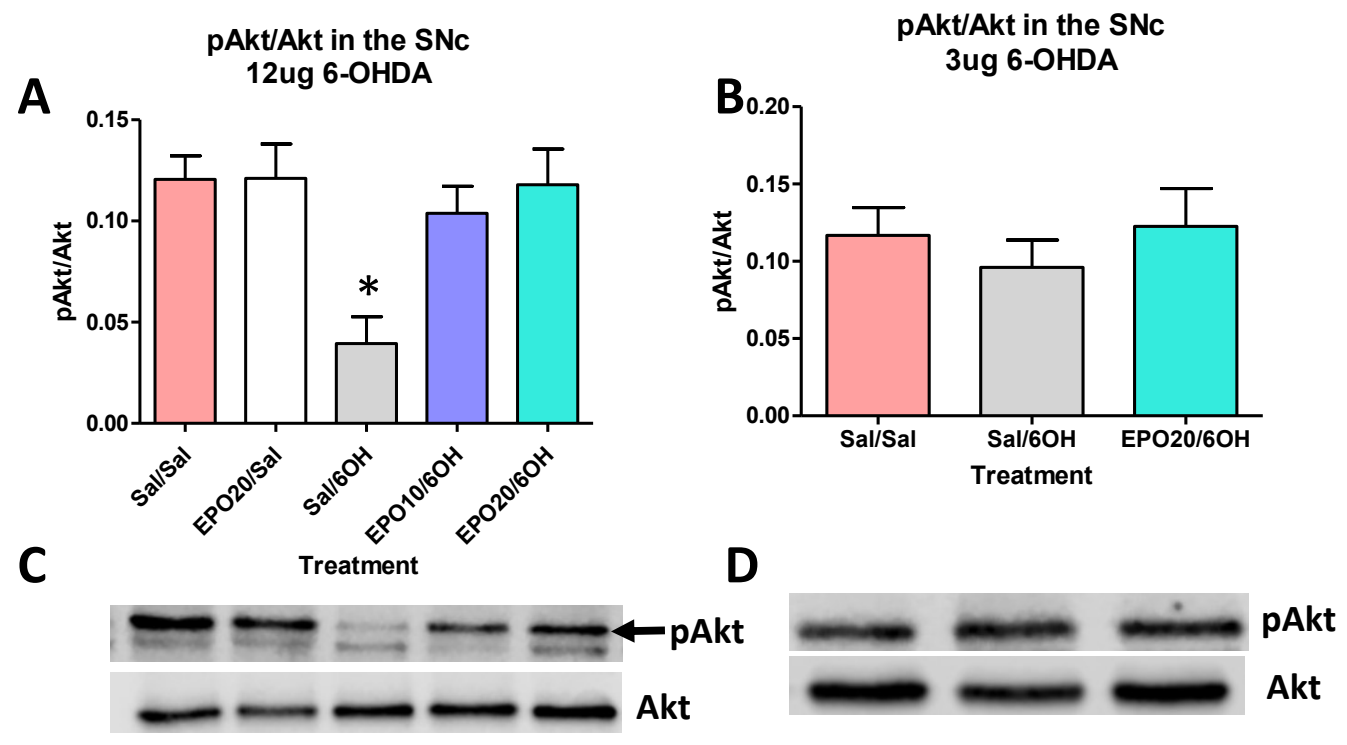

E
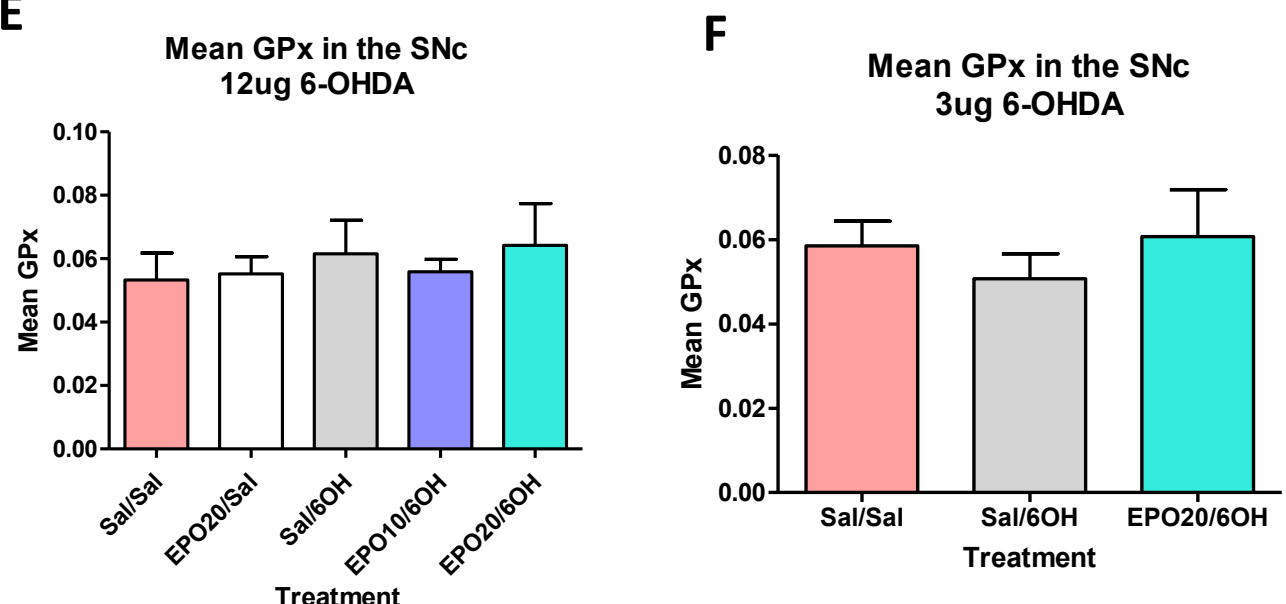

G

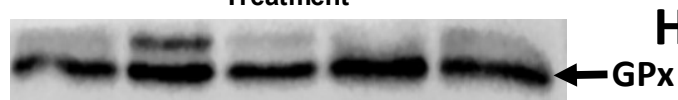

$\underset{P x}{H}$

GPx 

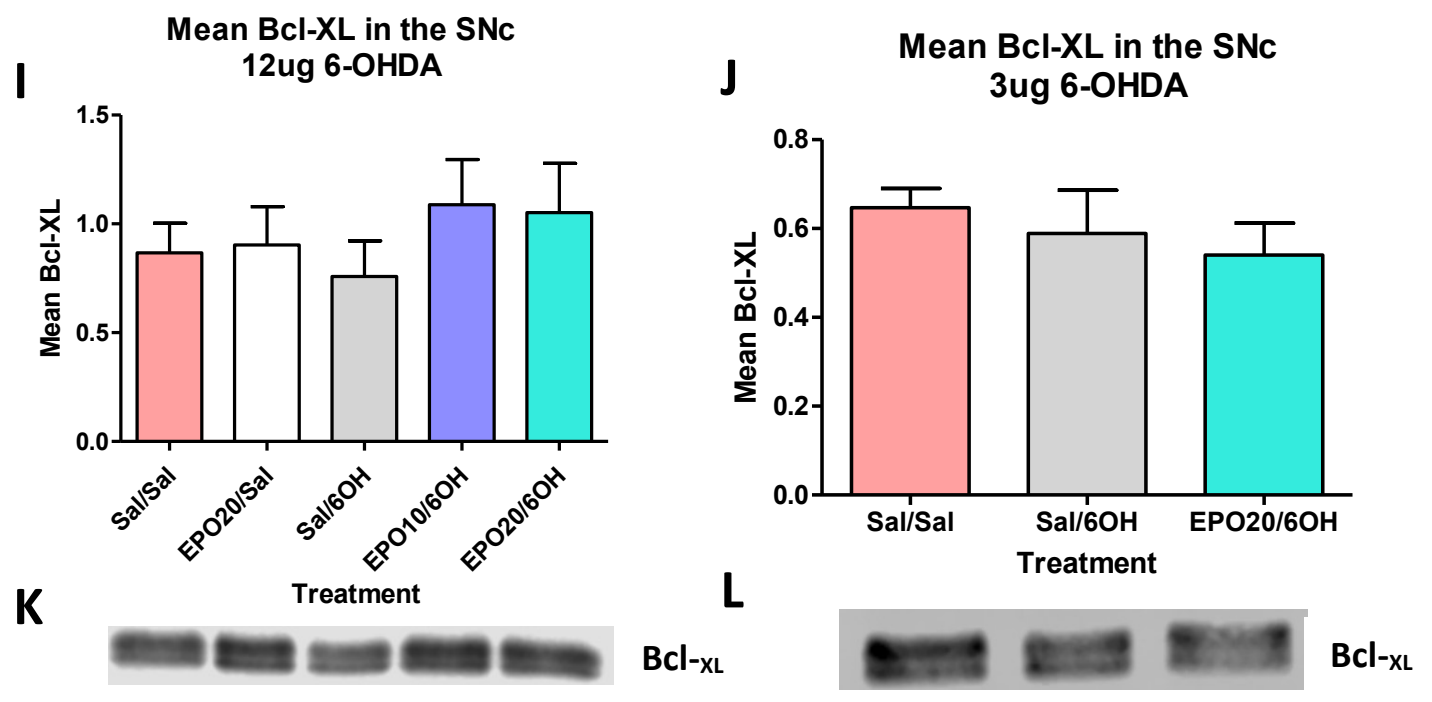

Figure 10. Intra-striatal EPO administration results in chronic activation of pro-survival signalling when 12ug, but not 3ug, of 6-OHDA are administered. Western blot analysis demonstrating influence of EPO on pAkt/Akt, GPx and Bcl-XL in the SNc. A-B. The ratio of pAkt/Akt decreased significantly in response to 6-OHDA, an effect which was reversed by EPO. C-D. Representative Western blots for pAkt and Akt in studies 3 (C) and 4 (D). EF. Levels of GPx were unchanged in response to 6-OHDA or EPO when either 12ug (E) or 3ug (F) of 6-OHDA were administered. G-H. Representative Western blots for GPx in study $3(E)$ and study 4 (F). I-J. No significant changes were observed in levels of $\mathrm{BCl}-\mathrm{xL}$ in the SNc when either 12ug (I) or 3ug (J) 6-OHDA were used. K-L. Representative Western blots for $\mathrm{Bcl}-\mathrm{xL}_{\mathrm{L}}$ in the striatum for study $3(\mathrm{~K})$ and study 4 (L). All signals were normalized against total protein to control for any variations in loading. Data are expressed as mean \pm SEM; $n=7-9 .{ }^{*} p<0.05$. 


\section{Discussion}

While the locus of neuronal degeneration in PD is known, the processes underlying the deterioration of the cellular microenvironment in the disease remain poorly understood. Broadly, the mechanisms underlying PD pathology are likely complex and multi-faceted, involving factors such as genetic mutations, environmental stressors, and inhibition of neural protection. Evidence supporting each of these contributors led to the development of the multiple-hit hypothesis of PD (Antony, Diederich, Krüger, \& Balling, 2013; Berry, La Vecchia, \& Nicotera, 2010; Carvey, Punati, \& Newman, 2006; Sadasivan, Sharp, Schultz-Cherry, \& Smeyne, 2017; Sulzer, 2007), which suggests exposure to multiple risk factors (or multiple 'hits') increases an individual's likelihood of developing the disease. Indeed, the multiple-hit hypothesis has been increasingly implicated in several neurodegenerative diseases in recent years (Bansal, Salaria, \& Singh, 2019; Garden \& La Spada, 2012; Gong, Liu, \& Iqbal, 2018; Heinemann, Posimo, Mason, Hutchison, \& Leak, 2016; Patrick, Bell, Weindel, \& Watson, 2019). The emerging research implicating multiple hits in various neurodegenerative diseases suggests researchers have only begun to understand the interactions between genetics, environment, and cellular responses to stress in the context of neurodegeneration, rendering the study of all neurodegenerative diseases, including PD, a notable challenge for researchers.

For more than 20 years, trophic factors have demonstrated a potential for neuroprotection in a variety of neurodegenerative diseases (Bilang-Bleuel et al., 1997; 
Costa et al., 2015; Kirik, Georgievska, \& Björklund, 2004; Lindholm et al., 2016; Littrell, Granholm, Gerhardt, \& Boger, 2013; Paul \& Sullivan, 2019; Sauer, Rosenblad, Bjorklund, \& Changeaux, 1995). Still, researchers have yet to identify a single trophic factor with the ability to halt, reverse, or even slow down the progression of PD. Due to the involvement of multiple neurotransmitter systems leading to a variety of motor and non-motor symptoms, it is unlikely that any one factor will successfully alter disease course in human patients; a multitude of approaches tested on imperfect animal models has yielded disappointing results when tested clinically (Kordower \& Burke, 2018).

In addition to imperfect animal models, the time of NTF administration presents an obvious problem when discussing the applicability of PD models in a clinical setting. Most studies involving trophic factors, including the studies described herein, administer NTFs close in time to toxic insults, which does not mimic the reality encountered by clinicians dealing with human PD patients. Clinically, the damage to DA neurons is often extensive and well established by the time individuals are diagnosed with PD, due to the brain's impressive compensatory mechanisms that delay the onset of the cardinal motor symptoms (Cheng, Ulane, \& Burke, 2010). Importantly, individuals symptomatic for a number of years are those taking part in clinical trials (Costa-Ribeiro et al., 2017; David et al., 2015; Martin-Bastida et al., 2017); as such, researchers should routinely consider how NTFs employed in preclinical models of PD may benefit human PD patients in more advanced stages of disease development. For example, researchers 
should consider how a novel therapeutic strategy may interact with DA replacement therapy when assessing the applicability of the new technique.

In addition to the current evidence in support of EPO's use as an adjuvant treatment in PD, there is an increasing body of literature - including evidence from our own lab - demonstrating EPO's ability to modulate the non-motor symptoms of PD, such as depression-relevant behaviours and problems with memory and cognition (Almaguer-Melian et al., 2016; Girgenti et al., 2009; Jang et al., 2014; Leconte et al., 2011; Ma et al., 2016; Osborn et al., 2013; Saad et al., 2019). In the current studies, EPO's trophic effects were demonstrated in various experimental conditions using the 6-OHDA mouse model of PD. EPO's pro-survival signalling appeared to depend on numerous factors, including brain region, lesion size and individual variability in response to EPO treatment.

EPO's pro-survival effects are region- and lesion size-dependent

One of the most novel findings of the current research involves the regional specificity of EPO's actions in the nigrostriatal system. The results from this study confirmed a moderate striatal lesion induced by 6-OHDA as well as an associated loss of cell bodies in the SNc, neither of which were restored with intra-nigral EPO treatment. To contrast, EPO was found to protect striatal terminals and cell bodies in the SNc when administered to the striatum prior to an intra-striatal lesion. EPO's pro-survival signalling 
pathways also varied in response to brain region, with different patterns of protein upregulation apparent in the striatum when compared to the SNc. This suggests the degree of stress in the cellular microenvironment influences the pro-survival signaling of EPO, which appeared to have prolonged protective effects at the higher dose of 6-OHDA (12ug).

EPO's survival signalling was also influenced by lesion size, with proteins differentially upregulated when 12ug of 6-OHDA was used versus 3ug 6-OHDA. At the higher dose of 6-OHDA, dual activation of anti-apoptotic and antioxidant pathways was observed, whereas at the lower dose of 6-OHDA, only anti-apoptotic pathways were influenced significantly. At both doses of 6-OHDA, EPO reduced the number of apomorphine-induced rotations when administered into the striatum, but not when administered into the SNc, further demonstrating EPO's ability to protect nigrostriatal neurons from damage and death is region-dependent in the 6-OHDA mouse model. While intra-nigral EPO did not preserve nigrostriatal neurons, striatal terminals or motor behaviours, it did induce significant changes in microglial activation in the SNc, suggesting an anti-inflammatory mechanism involved in EPO's tissue protective qualities.

Evidence for EPO's anti-apoptotic, anti-inflammatory and antioxidant actions We hypothesized that EPO acts to protect neurons via anti-apoptotic, antiinflammatory, and/or antioxidant mechanisms. In the studies conducted, evidence for 
each of these protective pathways was observed, but not all within the same experimental conditions. The antioxidant effects of EPO, like the anti-apoptotic and antiinflammatory effects, were observed in multiple studies in this investigation. Perhaps the most salient finding in the studies conducted was the upregulation of GPx, a powerful antioxidant, in response to EPO. GPx was increased in both the striatum and the SNc 12 hours following EPO administration when no toxicant was administered, and in the striatum three weeks after the highest dose of 6-OHDA (12ug) was administered.

GPx is a potent antioxidant whose presence in response to EPO is a strong indication of the antioxidant activity of this trophic cytokine. In fact, EPO upregulated levels of GPx both acutely in the absence of 6-OHDA and chronically when 12ug were administered, suggesting antioxidant activity may be a typical cellular response to EPO whether cells are experiencing stress or not. As changes in GPx were not observed chronically in the SNc when animals were pre-treated with EPO in the 12ug 6-OHDA condition, EPO's effects on antioxidant activity may depend on the degree of cellular stress, which is significantly influenced by 6-OHDA. When the highest dose of 6-OHDA was employed, levels of striatal GPx were found to be increased chronically ( 3 weeks post-lesion), suggesting a prolonged antioxidant effect of EPO in this model. Changes in GPx were not observed when the low dose of 6-OHDA was used, suggesting antioxidant activity may not be EPO's primary protective mechanism at this dose of toxin. Indeed, increased levels of $\mathrm{Bcl}-\mathrm{xL}$ in this study - a finding which was not observed at the higher 
dose of 6-OHDA - supports an anti-apoptotic role of EPO under these cellular conditions.

\section{Future Directions}

As researchers continue to study the effects of EPO in neurological disease, it is important to consider that trophic factors do not inherently have positive or negative qualities - instead, they modulate the pathways which influence the cellular microenvironment in response to the characteristics of that environment. While this can lead to cell survival, it can also lead to cell death, a factor which complicates the study of PD.

In addition, researchers should consider the possibility of functional lateralization between hemispheres when employing a unilateral lesion model. Recent evidence suggests functional lateralization in the hippocampus for novel object exploration (Jordan, Shanley, \& Pytte, 2019). The authors used immediate early gene imaging and c-Fos and found interhemispheric differences in neuronal activation in the dentate gyrus. The left hemisphere appeared to be preferentially recruited for the novel object task when compared to controls (Jordan et al., 2019), providing evidence that motor tasks may demonstrate hemispheric preference, a finding which would have important consequences for PD. 


\section{The Heterogeneity of the Striatum}

In addition to the possibility of hemispheric preference, there is a strong need to learn more about the minority cell populations in the striatum and how they may be influencing PD pathology. For example, the cell populations in the striatum are very different from those in the SNc, and the neurons in the striatum have more complex roles and interactions than was once thought. In the striatum, there are both D1 and D2 receptors - the functional antagonism between two DA receptor types in the striatum extends to the regulation of synaptic plasticity, and long-term changes in DA signalling can certainly alter the connectivity and function of the MSNs in the striatum (Plenz \& Wickens, 2017). Recent evidence further suggests MSNs with both D1 and D2 receptors represent a distinct neuronal population in the striatum that respond differently to 6-OHDA than MSNs containing only D1 or D2 receptors (Gagnon et al., 2017). They are morphologically distinct with a smaller soma and fewer dendritic arborizations, along with fewer spines; interestingly, the degree of dendritic arborization in D1/D2 MSNs is unaltered by 6-OHDA (in contrast, arborization is significantly reduced in both D1 and D2 MSNs).

Accumulating evidence suggests the striatum is much more complex of an environment than researchers once imagined, including complexities in cell composition and signalling within the striatum, such as the complex cholinergic and GABAergic interneuron populations (Lozovaya et al., 2018; Lozovaya, Ben-Ari, \& Hammond, 2018), 
striosome-matrix differences in signalling and receptor localization (Brimblecombe \& Cragg, 2017; Ren et al., 2017). Using the newly reported information herein regarding EPO's signalling and survival effects, in conjunction with recent advances and emerging technologies, future research should seek to better understand these distinct minority cell populations in each of the affected brain regions in PD to study their possible contributions to the disease.

\section{Conclusion}

The findings from the current studies strongly suggest EPO has a protective effect in the 6-OHDA mouse model of PD but cautions its premature use in a clinical setting based on the novel findings indicating its differential influence as a response of brain region and lesion size. Further research should be conducted to confirm EPO's potential protective properties in cases of mild lesions, including further investigation into its mechanisms of cellular protection. Several groups of researchers have acknowledged the potential beneficial effects of EPO when used in combination with a secondary factor, such as in studies of spinal cord injury (Li et al., 2017; Yamanaka, Eldeiry, Aftab, Mares, et al., 2018; Yamanaka, Eldeiry, Aftab, Ryan, et al., 2018; Yamanaka et al., 2019; Zhao et al., 2016), cerebral ischemia (Chai, Yip, Sun, Hsu, \& Leu, 2016; Lv et al., 2017; Shin \& Cho, 2016; Wang et al., 2016; Yuen et al., 2017), perinatal hypoxia-related injuries (Luan et al., 2016; Wu \& Gonzalez, 2015; Zhang et al., 2016), and even traumatic brain injury (Duan et al., 2015). 
Future research should focus on the most salient protective properties of EPO and seek to combine these properties with other prospective treatments to evaluate their combined efficacy in preclinical models of PD. For instance, the current pharmacotherapy for PD involves DA replacement via administration of levodopa (L-DOPA). While it effectively replaces DA initially, its effects wane over time, requiring increasing doses to be administered to achieve relief of motor symptoms. It can be challenging to titrate the dose of L-DOPA properly to ensure effective DA replacement without causing excessive DA production, as too much DA leads to increased production of ROS through its regular metabolism. This creates conditions of oxidative stress, which could potentially be mitigated by a non-hematopoietic form of EPO administered concurrently with L-DOPA through increased GPx.

The current set of experiments revealed novel information about EPO, an important trophic cytokine, in a murine model of PD. This research contributes several new pieces of information to the growing body of literature studying EPO's neurotrophic effects, including its pro-survival signalling in the absence of a toxicant, its regional specificity, and its potential to work through different protective pathways depending on the cellular microenvironment. Further research should be done to fully characterize EPO's protective effects in PD, including establishing its protective pathways, evaluating how it may differentially influence specific sub-populations of cells in the striatum, and how its anti-inflammatory, anti-apoptotic and antioxidant properties may be best harnessed in the treatment of PD and many other neurological disorders in the future. 


\section{References}

Almaguer-Melian, W., Mercerón-Martínez, D., Delgado-Ocaña, S., Pavón-Fuentes, N., Ledón, N., \& Bergado, J. A. (2016). EPO induces changes in synaptic transmission and plasticity in the dentate gyrus of rats. Synapse, 70(6), 240-252.

https://doi.org/10.1002/syn.21895

Antony, P. M. A., Diederich, N. J., Krüger, R., \& Balling, R. (2013). The hallmarks of Parkinson's disease. FEBS Journal, 280(23), 5981-5993.

https://doi.org/10.1111/febs.12335

Bansal, A., Salaria, M., \& Singh, T. R. (2019). Tau Pathology (pp. 217-234). https://doi.org/10.4018/978-1-5225-5282-6.ch010

Bartels, C., Späte, K., Krampe, H., \& Ehrenreich, H. (2008). Recombinant human erythropoietin: Novel strategies for neuroprotective/neuroregenerative treatment of multiple sclerosis. Therapeutic Advances in Neurological Disorders, 1(3), 193206. https://doi.org/10.1177/1756285608098422

Berry, C., La Vecchia, C., \& Nicotera, P. (2010). Paraquat and Parkinson's disease. Cell Death \& Differentiation, 17(7), 1115-1125. https://doi.org/10.1038/cdd.2009.217

Bilang-Bleuel, A., Revah, F., Colin, P., Locquet, I., Robert, J.-J., Mallet, J., \& Horellou, P. (1997). Intrastriatal injection of an adenoviral vector expressing glial-cell-linederived neurotrophic factor prevents dopaminergic neuron degeneration and behavioral impairment in a rat model of Parkinson disease. Proceedings of the National Academy of Sciences, 94(16), 8818-8823. https://doi.org/10.1073/pnas.94.16.8818

Boado, R., Pardridge, W. M., Zhou, Q., Boado, R. J., Lu, J. Z., Hui, E. K., \& Pardridge, W. M. (2010). Re-Engineering Erythropoietin as an IgG Fusion Protein That Penetrates the Blood- Brain Barrier in the Mouse Re-Engineering Erythropoietin as an IgG Fusion Protein That Penetrates the Blood - Brain Barrier in the Mouse, (February 2016). https://doi.org/10.1021/mp1001763

Brimblecombe, K. R., \& Cragg, S. J. (2017). The Striosome and Matrix Compartments of the Striatum: A Path through the Labyrinth from Neurochemistry toward Function. ACS Chemical Neuroscience, 8(2), 235-242. https://doi.org/10.1021/acschemneuro.6b00333 
Brines, M. L., Ghezzi, P., Keenan, S., Agnello, D., de Lanerolle, N. C., Cerami, C., ... Cerami, A. (2000). Erythropoietin crosses the blood-brain barrier to protect against experimental brain injury. Proceedings of the National Academy of Sciences of the United States of America, 97(19), 10526-10531. https://doi.org/10.1073/pnas.97.19.10526

Campana, W. M., \& Myers, R. R. (2003). Exogenous erythropoietin protects against dorsal root ganglion apoptosis and pain following peripheral nerve injury. European Journal of Neuroscience, 18(6), 1497-1506. https://doi.org/10.1046/j.14609568.2003.02875.x

Carelli, S., Marfia, G., Di Giulio, A. M., Ghilardi, G., \& Gorio, A. (2011). Erythropoietin: Recent developments in the treatment of spinal cord injury. Neurology Research International, 2011. https://doi.org/10.1155/2011/453179

Carvey, P. M., Punati, A., \& Newman, M. B. (2006). Progressive Dopamine Neuron Loss in Parkinson's Disease: The Multiple Hit Hypothesis. Cell Transplantation, 15(3), 239-250. https://doi.org/10.3727/000000006783981990

Castillo, C., Zaror, S., Gonzalez, M., Hidalgo, A., Burgos, C. F., Cabezas, O. I., ... Toledo, J. R. (2018). Neuroprotective effect of a new variant of Epo nonhematopoietic against oxidative stress. Redox Biology, 14(July 2017), 285-294. https://doi.org/10.1016/j.redox.2017.09.010

Chai, H. T., Yip, H. K., Sun, C. K., Hsu, S. Y., \& Leu, S. (2016). AG490 suppresses EPOmediated activation of JAK2-STAT but enhances blood flow recovery in rats with critical limb ischemia. Journal of Inflammation (United Kingdom), 13(1), 1-11. https://doi.org/10.1186/s12950-016-0126-3

Cheng, H.-C., Ulane, C. M., \& Burke, R. E. (2010). Clinical progression in Parkinson disease and the neurobiology of axons. Annals of Neurology, 67(6), 715-725. https://doi.org/10.1002/ana.21995

Chiu, W. H., Carlsson, T., Depboylu, C., Höglinger, G. U., Oertel, W. H., \& Ries, V. (2014). Selegiline normalizes, while I-DOPA sustains the increased number of dopamine neurons in the olfactory bulb in a 6-OHDA mouse model of Parkinson's disease. Neuropharmacology, 79, 212-221. https://doi.org/10.1016/j.neuropharm.2013.11.014 
Costa-Ribeiro, A., Maux, A., Bosford, T., Aoki, Y., Castro, R., Baltar, A., ... Monte-Silva, K. (2017). Transcranial direct current stimulation associated with gait training in Parkinson's disease: A pilot randomized clinical trial. Developmental Neurorehabilitation, 20(3), 121-128. https://doi.org/10.3109/17518423.2015.1131755

Costa, D. D., Beghi, E., Carignano, P., Pagliacci, C., Faccioli, F., Pupillo, E., ... Redaelli, T. (2015). Tolerability and efficacy of erythropoietin (EPO) treatment in traumatic spinal cord injury: a preliminary randomized comparative trial vs. methylprednisolone (MP). Neurological Sciences, 36(9), 1567-1574. https://doi.org/10.1007/s10072-015-2182-5

Damier, P., Hirsch, E. C., Zhang, P., Agid, Y., \& Javoy-Agid, F. (1993). Glutathione peroxidase, glial cells and Parkinson's disease. Neuroscience, 52(1), 1-6. Retrieved from http://www.ncbi.nlm.nih.gov/pubmed/8433802

Dauer, W., \& Przedborski, S. (2003). Parkinson 's Disease : Mechanisms and Models, 39, 889-909.

David, F. J., Robichaud, J. A., Leurgans, S. E., Poon, C., Kohrt, W. M., Goldman, J. G., ... Corcos, D. M. (2015). Exercise improves cognition in Parkinson's disease: The PRETPD randomized, clinical trial. Movement Disorders, 30(12), 1657-1663. https://doi.org/10.1002/mds.26291

Digicaylioglu, M., Bichet, S., Marti, H. H., Wenger, R. H., Rivas, L. A., Bauer, C., \& Gassmann, M. (1995). Localization of specific erythropoietin binding sites in defined areas of the mouse brain. Proc Natl Acad Sci U S A, 92(9), 3717-3720. https://doi.org/10.1073/pnas.92.9.3717

Ding, J., Wang, J., Li, Q. Y., Yu, J. Z., Ma, C. G., Wang, X., ... Xiao, B. G. (2017). Neuroprotection and CD131/GDNF/AKT Pathway of Carbamylated Erythropoietin in Hypoxic Neurons. Molecular Neurobiology, 54(7), 5051-5060. https://doi.org/10.1007/s12035-016-0022-0

Duan, H., Hao, C., Lu, G., Li, S., Wang, S., \& Liu, Y. (2015). Impacts of Granulocyte-Colony Stimulating Factor combined with Erythropoietin on neural regeneration after traumatic brain injury in rats. The FASEB Journal, 29(1_supplement), 727.2. https://doi.org/10.1096/fasebj.29.1_supplement.727.2 
Ehrenreich, H, Degner, D., Meller, J., Brines, M., Béhé, M., Hasselblatt, M., ... Sirén, A.-L. (2004). Erythropoietin: a candidate compound for neuroprotection in schizophrenia. Molecular Psychiatry, 9(1), 42-54.

https://doi.org/10.1038/sj.mp.4001442

Ehrenreich, Hannelore, Bartels, C., Sargin, D., Stawicki, S., \& Krampe, H. (2008). Recombinant Human Erythropoietin in the Treatment of Human Brain Disease: Focus on Cognition. Journal of Renal Nutrition, 18(1), 146-153. https://doi.org/10.1053/j.jrn.2007.10.029

Erbaş, O., Çiar, B. P., Solmaz, V., Çavuşoğlu, T., \& Ateş, U. (2015). The neuroprotective effect of erythropoietin on experimental Parkinson model in rats. Neuropeptides, 49, 1-5. https://doi.org/10.1016/j.npep.2014.10.003

Farmer, K., Rudyk, C., Prowse, N. A., \& Hayley, S. (2015). Hematopoietic cytokines as therapeutic players in early stages Parkinson's disease. Frontiers in Aging Neuroscience, 7(JUL), 1-5. https://doi.org/10.3389/fnagi.2015.00126

Gagnon, D., Petryszyn, S., Sanchez, M. G., Bories, C., Beaulieu, J. M., De Koninck, Y., ... Parent, M. (2017). Striatal Neurons Expressing D1 and D2 Receptors are Morphologically Distinct and Differently Affected by Dopamine Denervation in Mice. Scientific Reports, 7(January), 9-17. https://doi.org/10.1038/srep41432

Garden, G. A., \& La Spada, A. R. (2012). Intercellular (Mis)communication in Neurodegenerative Disease. Neuron, 73(5), 886-901. https://doi.org/10.1016/j.neuron.2012.02.017

Girgenti, M. J., Hunsberger, J., Duman, C. H., Sathyanesan, M., Terwilliger, R., \& Newton, S. S. (2009). Erythropoietin Induction by Electroconvulsive Seizure, Gene Regulation, and Antidepressant-Like Behavioral Effects. Biological Psychiatry, 66(3), 267-274. https://doi.org/10.1016/j.biopsych.2008.12.005

Gong, C.-X., Liu, F., \& Iqbal, K. (2018). Multifactorial Hypothesis and Multi-Targets for Alzheimer's Disease. Journal of Alzheimer's Disease, 64(s1), S107-S117. https://doi.org/10.3233/JAD-179921 
Grealish, S., Mattsson, B., Draxler, P., \& Björklund, A. (2010). Characterisation of behavioural and neurodegenerative changes induced by intranigral 6hydroxydopamine lesions in a mouse model of Parkinson's disease. European Journal of Neuroscience, 31(12), 2266-2278. https://doi.org/10.1111/j.14609568.2010.07265.x

Güresir, E., Vasiliadis, N., Konczalla, J., Raab, P., Hattingen, E., Seifert, V., \& Vatter, H. (2013). Erythropoietin prevents delayed hemodynamic dysfunction after subarachnoid hemorrhage in a randomized controlled experimental setting. Journal of the Neurological Sciences, 332(1-2), 128-135. https://doi.org/10.1016/j.jns.2013.07.004

Heinemann, S. D., Posimo, J. M., Mason, D. M., Hutchison, D. F., \& Leak, R. K. (2016). Synergistic stress exacerbation in hippocampal neurons: Evidence favoring the dual-hit hypothesis of neurodegeneration. Hippocampus, 26(8), 980-994. https://doi.org/10.1002/hipo.22580

Heuer, A., Smith, G. A., Lelos, M. J., Lane, E. L., \& Dunnett, S. B. (2012). Unilateral nigrostriatal 6-hydroxydopamine lesions in mice I: Motor impairments identify extent of dopamine depletion at three different lesion sites. Behavioural Brain Research, 228(1), 30-43. https://doi.org/10.1016/j.bbr.2011.11.027

Hirsch, E. C., \& Hunot, S. (2009). Neuroinflammation in Parkinson's disease: a target for neuroprotection? The Lancet Neurology, 8(4), 382-397. https://doi.org/10.1016/S1474-4422(09)70062-6

Hudson, J. L., van Horne, C. G., Strömberg, I., Brock, S., Clayton, J., Masserano, J., ... Gerhardt, G. A. (1993). Correlation of apomorphine- and amphetamine-induced turning with nigrostriatal dopamine content in unilateral 6-hydroxydopamine lesioned rats. Brain Research, 626(1-2), 167-174. https://doi.org/10.1016/00068993(93)90576-9

Hughes, A. ., Lees, A. ., \& Stern, G. . (1990). Apomorphine test to predict dopaminergic responsiveness in parkinsonian syndromes. The Lancet, 336(8706), 32-34. https://doi.org/10.1016/0140-6736(90)91531-E

Jang, W., Kim, H. J., Li, H., Jo, K. D., Lee, M. K., \& Yang, H. O. (2016). The Neuroprotective Effect of Erythropoietin on Rotenone-Induced Neurotoxicity in SH-SY5Y Cells Through the Induction of Autophagy. Molecular Neurobiology, 53(6), 3812-3821. https://doi.org/10.1007/s12035-015-9316-x 
Jang, W., Park, J., Shin, K. J., Kim, J. S., Kim, J. S., Youn, J., ... Kim, H. T. (2014). Safety and efficacy of recombinant human erythropoietin treatment of non-motor symptoms in Parkinson's disease. Journal of the Neurological Sciences, 337(1-2), 47-54. https://doi.org/10.1016/j.jns.2013.11.015

Jing, X., Wei, X., Ren, M., Wang, L., Zhang, X., \& Lou, H. (2016). Neuroprotective Effects of Tanshinone I Against 6-OHDA-Induced Oxidative Stress in Cellular and Mouse Model of Parkinson's Disease Through Upregulating Nrf2. Neurochemical Research, 41(4), 779-786. https://doi.org/10.1007/s11064-015-1751-6

Jordan, J. T., Shanley, M. R., \& Pytte, C. L. (2019). Behavioral state-dependent lateralization of dorsal dentate gyrus c-Fos expression in mice. Neuronal Signaling, 3(1), NS20180206. https://doi.org/10.1042/NS20180206

Kaptanoglu, E., Solaroglu, I., Okutan, O., Surucu, H. S., Akbiyik, F., \& Beskonakli, E. (2004). Erythropoietin exerts neuroprotection after acute spinal cord injury in rats: Effect on lipid peroxidation and early ultrastructural findings. Neurosurgical Review, 27(2), 113-120. https://doi.org/10.1007/s10143-003-0300-y

Kirik, D., Georgievska, B., \& Björklund, A. (2004). Localized striatal delivery of GDNF as a treatment for Parkinson disease. Nature Neuroscience, 7(2), 105-110. https://doi.org/10.1038/nn1175

Kordower, J. H., \& Burke, R. E. (2018). Disease Modification for Parkinson's Disease: Axonal Regeneration and Trophic Factors. Movement Disorders, 33(5), 678-683. https://doi.org/10.1002/mds.27383

Latchoumycandane, C., Anantharam, V., Jin, H., Kanthasamy, A., \& Kanthasamy, A. (2011). Dopaminergic neurotoxicant 6-OHDA induces oxidative damage through proteolytic activation of PKC $\delta$ in cell culture and animal models of Parkinson's disease. Toxicology and Applied Pharmacology, 256(3), 314-323. https://doi.org/10.1016/j.taap.2011.07.021

Leconte, C., Bihel, E., Lepelletier, F.-X., Bouët, V., Saulnier, R., Petit, E., ... SchumannBard, P. (2011). Comparison of the effects of erythropoietin and its carbamylated derivative on behaviour and hippocampal neurogenesis in mice.

Neuropharmacology, 60(2-3), 354-364. https://doi.org/10.1016/j.neuropharm.2010.09.025 
Li, J., Guo, W., Xiong, M., Zhang, S., Han, H., Chen, J., ... Zeng, Y. (2017). Erythropoietin facilitates the recruitment of bone marrow mesenchymal stem cells to sites of spinal cord injury. Experimental and Therapeutic Medicine, 13(5), 1806-1812. https://doi.org/10.3892/etm.2017.4182

Li, X., Chen, Y., Shao, S., Tang, Q., Chen, W., Chen, Y., \& Xu, X. (2016). Oxidative stress induces the decline of brain EPO expression in aging rats. Experimental Gerontology, 83, 89-93. https://doi.org/10.1016/j.exger.2016.07.012

Lindenau, J., Noack, H., Asayama, K., \& Wolf, G. (1998). Enhanced cellular glutathione peroxidase immunoreactivity in activated astrocytes and in microglia during excitotoxin induced neurodegeneration. Glia, 24(2), 252-256. https://doi.org/10.1002/(SICI)1098-1136(199810)24:2<252::AID-GLIA10>3.0.CO;2-Z

Lindholm, D., Mäkelä, J., Di Liberto, V., Mudò, G., Belluardo, N., Eriksson, O., \& Saarma, M. (2016). Current disease modifying approaches to treat Parkinson's disease. Cellular and Molecular Life Sciences, 73(7), 1365-1379. https://doi.org/10.1007/s00018-015-2101-1

Littrell, O. M., Granholm, A. C., Gerhardt, G. A., \& Boger, H. A. (2013). Glial cell-line derived neurotrophic factor (GDNF) replacement attenuates motor impairments and nigrostriatal dopamine deficits in 12-month-old mice with a partial deletion of GDNF. Pharmacology Biochemistry and Behavior, 104(1), 10-19. https://doi.org/10.1016/j.pbb.2012.12.022

Lozovaya, N., Eftekhari, S., Cloarec, R., Gouty-Colomer, L. A., Dufour, A., Riffault, B., ... Hammond, C. (2018). GABAergic inhibition in dual-transmission cholinergic and GABAergic striatal interneurons is abolished in Parkinson disease. Nature Communications, 9(1). https://doi.org/10.1038/s41467-018-03802-y

Lozovaya, Natalia, Ben-Ari, Y., \& Hammond, C. (2018). Striatal dual cholinergic /GABAergic transmission in Parkinson disease: friends or foes? Cell Stress, 2(6), 147-149. https://doi.org/10.15698/cst2018.06.142

Luan, Y., Zhang, L., Chao, S., Liu, X., Li, K., Wang, Y., \& Zhang, Z. (2016). Mesenchymal stem cells in combination with erythropoietin repair hyperoxia-induced alveoli dysplasia injury in neonatal mice via inhibition of TGF-\&amp;\#x3B2;1 signaling. Oncotarget, 7(30). https://doi.org/10.18632/oncotarget.9314 
Lundblad, M., Picconi, B., Lindgren, H., \& Cenci, M. A. (2004). A model of L-DOPAinduced dyskinesia in 6-hydroxydopamine lesioned mice: Relation to motor and cellular parameters of nigrostriatal function. Neurobiology of Disease, 16(1), 110123. https://doi.org/10.1016/j.nbd.2004.01.007

Lv, H., Wu, S., Wang, Q., Yang, L., Ren, P., Qiao, B., ... Li, L. (2017). Effect of erythropoietin combined with hypothermia on serum tau protein levels and neurodevelopmental outcome in neonates with hypoxic-ischemic encephalopathy. Neural Regeneration Research, 12(10), 1655. https://doi.org/10.4103/16735374.217338

Ma, C., Cheng, F., Wang, X., Zhai, C., Yue, W., Lian, Y., \& Wang, Q. (2016). Erythropoietin Pathway: A Potential Target for the Treatment of Depression. International Journal of Molecular Sciences, 17(5), 677. https://doi.org/10.3390/ijms17050677

Mangano, E. N., Peters, S., Litteljohn, D., So, R., Bethune, C., Bobyn, J., ... Hayley, S. (2011). Granulocyte macrophage-colony stimulating factor protects against substantia nigra dopaminergic cell loss in an environmental toxin model of Parkinson's disease. Neurobiology of Disease, 43(1), 99-112.

https://doi.org/10.1016/j.nbd.2011.02.011

Mangano, Emily N., \& Hayley, S. (2009). Inflammatory priming of the substantia nigra influences the impact of later paraquat exposure: Neuroimmune sensitization of neurodegeneration. Neurobiology of Aging, 30(9), 1361-1378. https://doi.org/10.1016/j.neurobiolaging.2007.11.020

Martin-Bastida, A., Ward, R. J., Newbould, R., Piccini, P., Sharp, D., Kabba, C., ... Dexter, D. T. (2017). Brain iron chelation by deferiprone in a phase 2 randomised doubleblinded placebo controlled clinical trial in Parkinson's disease. Scientific Reports, 7(1), 1398. https://doi.org/10.1038/s41598-017-01402-2

Masuda, S., Okano, M., Yamagishi, K., Nagao, M., Ueda, M., \& Sasaki, R. (1994). A novel site of erythropoietin production. Oxygen-dependent production in cultured rat astrocytes. The Journal of Biological Chemistry, 269(30), 19488-19493. Retrieved from http://www.ncbi.nlm.nih.gov/pubmed/8034718

McGeer, P. L., \& McGeer, E. G. (2008). Glial reactions in Parkinson's disease. Movement Disorders, 23(4), 474-483. https://doi.org/10.1002/mds.21751 
Nichol, A., French, C., Little, L., Haddad, S., Presneill, J., Arabi, Y., ... Bellomo, R. (2015). Erythropoietin in traumatic brain injury (EPO-TBI): a double-blind randomised controlled trial. The Lancet, 386(10012), 2499-2506. https://doi.org/10.1016/S0140-6736(15)00386-4

Osborn, M., Rustom, N., Clarke, M., Litteljohn, D., Rudyk, C., Anisman, H., \& Hayley, S. (2013). Antidepressant-Like Effects of Erythropoietin: A Focus on Behavioural and Hippocampal Processes. PLoS ONE, 8(9), 1-9. https://doi.org/10.1371/journal.pone.0072813

Pang, L., Zhang, N., Dong, N., Wang, D. W., Xu, D. H., Zhang, P., \& Meng, X. W. (2016). Erythropoietin Protects Rat Brain Injury from Carbon Monoxide Poisoning by Inhibiting Toll-Like Receptor 4/NF-kappa B-Dependent Inflammatory Responses. Inflammation, 39(2), 561-568. https://doi.org/10.1007/s10753-015-0280-4

Patrick, K. L., Bell, S. L., Weindel, C. G., \& Watson, R. O. (2019). Exploring the "MultipleHit Hypothesis" of Neurodegenerative Disease: Bacterial Infection Comes Up to Bat. Frontiers in Cellular and Infection Microbiology, 9. https://doi.org/10.3389/fcimb.2019.00138

Paul, G., \& Sullivan, A. M. (2019). Trophic factors for Parkinson's disease: Where are we and where do we go from here? European Journal of Neuroscience, 49(4), 440-452. https://doi.org/10.1111/ejn.14102

Plenz, D., \& Wickens, J. R. (2017). The Striatal Skeleton: Medium Spiny Projection Neurons and Their Lateral Connections. Handbook of Behavioral Neuroscience, 24, 121-136. https://doi.org/10.1016/B978-0-12-802206-1.00006-4

Ren, K., Guo, B., Dai, C., Yao, H., Sun, T., Liu, X., ... Wu, S. (2017). Striatal Distribution and Cytoarchitecture of Dopamine Receptor Subtype 1 and 2: Evidence from DoubleLabeling Transgenic Mice. Frontiers in Neural Circuits, 11(August), 1-13. https://doi.org/10.3389/fncir.2017.00057

Ren, M., Han, M., Wei, X., Guo, Y., Shi, H., Zhang, X., ... Lou, H. (2017). FTY720 Attenuates 6-OHDA-Associated Dopaminergic Degeneration in Cellular and Mouse Parkinsonian Models. Neurochemical Research, 42(2), 686-696. https://doi.org/10.1007/s11064-016-2125-4 
Saad, M. A., El-Sahar, A. E., Sayed, R. H., Elbaz, E. M., Helmy, H. S., \& Senousy, M. A. (2019). Venlafaxine Mitigates Depressive-Like Behavior in Ovariectomized Rats by Activating the EPO/EPOR/JAK2 Signaling Pathway and Increasing the Serum Estradiol Level. Neurotherapeutics, 16(2), 404-415. https://doi.org/10.1007/s13311-018-00680-6

Sadasivan, S., Sharp, B., Schultz-Cherry, S., \& Smeyne, R. J. (2017). Synergistic effects of influenza and 1-methyl-4-phenyl-1,2,3,6-tetrahydropyridine (MPTP) can be eliminated by the use of influenza therapeutics: experimental evidence for the multi-hit hypothesis. Npj Parkinson's Disease, 3(1), 18. https://doi.org/10.1038/s41531-017-0019-z

Sargin, D., Friedrichs, H., El-Kordi, A., \& Ehrenreich, H. (2010). Erythropoietin as neuroprotective and neuroregenerative treatment strategy: Comprehensive overview of 12 years of preclinical and clinical research. Best Practice and Research: Clinical Anaesthesiology, 24(4), 573-594. https://doi.org/10.1016/j.bpa.2010.10.005

Sauer, H., Rosenblad, C., Bj6rklund, A., \& Changeaux, J.-P. (1995). Glial cell line-derived neurotrophic factor but not transforming growth factor 03 prevents delayed degeneration of nigral dopaminergic neurons following striatal 6-hydroxydopamine lesion. Cell Biology, 92(September), 8935-8939.

Shi, X., Yang, J., Zhu, H., Ye, L., Feng, M., Li, J., ... Ju, D. (2013). Pharmacokinetics and pharmacodynamics of recombinant human EPO-Fc fusion protein in vivo. PLoS ONE, 8(8). https://doi.org/10.1371/journal.pone.0072673

Shin, Y.-K., \& Cho, S.-R. (2016). Exploring Erythropoietin and G-CSF Combination Therapy in Chronic Stroke Patients. International Journal of Molecular Sciences, 17(4), 463. https://doi.org/10.3390/ijms17040463

Sulzer, D. (2007). Multiple hit hypotheses for dopamine neuron loss in Parkinson's disease. Trends in Neurosciences, 30(5), 244-250. https://doi.org/10.1016/j.tins.2007.03.009

Thomas Tayra, J., Kameda, M., Yasuhara, T., Agari, T., Kadota, T., Wang, F., ... Date, I. (2013). The neuroprotective and neurorescue effects of carbamylated erythropoietin Fc fusion protein (CEPO-Fc) in a rat model of Parkinson's disease. Brain Research, 1502, 55-70. https://doi.org/10.1016/j.brainres.2013.01.042 
Wang, R., Wu, X., Zhao, H., Min, L., Tao, Z., Ji, X., \& Luo, Y. (2016). Effects of erythropoietin combined with tissue plasminogen activator on the rats following cerebral ischemia and reperfusion. Brain Circulation, 2(1), 54.

https://doi.org/10.4103/2394-8108.178552

Wang, Y., Zhang, Z. G., Rhodes, K., Renzi, M., Zhang, R. L., Kapke, A., ... Chopp, M. (2007). Post-ischemic treatment with erythropoietin or carbamylated erythropoietin reduces infarction and improves neurological outcome in a rat model of focal cerebral ischemia. British Journal of Pharmacology, 151(8), 1377-1384. https://doi.org/10.1038/sj.bjp.0707285

Wei, Z., Li, X., Li, X., Liu, Q., \& Cheng, Y. (2018). Oxidative Stress in Parkinson's Disease: A Systematic Review and Meta-Analysis. Frontiers in Molecular Neuroscience, 11. https://doi.org/10.3389/fnmol.2018.00236

Wu, Y. W., \& Gonzalez, F. F. (2015). Erythropoietin: a novel therapy for hypoxicischaemic encephalopathy? Developmental Medicine \& Child Neurology, 57, 34-39. https://doi.org/10.1111/dmcn.12730

Xue, Y. Q., Ma, B. F., Zhao, L. R., Tatom, J. B., Li, B., Jiang, L. X., ... Duan, W. M. (2010). AAV9-mediated erythropoietin gene delivery into the brain protects nigral dopaminergic neurons in a rat model of Parkinson's disease. Gene Therapy, 17(1), 83-94. https://doi.org/10.1038/gt.2009.113

Yamanaka, K., Eldeiry, M., Aftab, M., Mares, J., Ryan, T. J., Meng, X., ... Reece, T. B. (2018). Optimized induction of beta common receptor enhances the neuroprotective function of erythropoietin in spinal cord ischemic injury. Journal of Thoracic and Cardiovascular Surgery, 155(6), 2505-2516. https://doi.org/10.1016/j.jtcvs.2017.12.132

Yamanaka, K., Eldeiry, M., Aftab, M., Ryan, T. J., Mares, J., Meng, X., ... Reece, T. B. (2018). Synergistic Reduction of Apoptosis with Diazoxide and Erythropoietin in Spinal Cord Ischemic Injury. The Annals of Thoracic Surgery. https://doi.org/10.1016/j.athoracsur.2018.07.022

Yamanaka, K., Eldeiry, M., Aftab, M., Ryan, T. J., Meng, X., Weyant, M. J., ... Reece, T. B. (2019). Synergetic Induction of NGF With Diazoxide and Erythropoietin Attenuates Spinal Cord Ischemic Injury. Journal of Surgical Research, 233, 124-131. https://doi.org/10.1016/j.jss.2018.07.021 
Yuen, C. M., Yeh, K. H., Wallace, C. G., Chen, K. H., Lin, H. S., Sung, P. H., ... Yip, H. K. (2017). EPO-cyclosporine combination therapy reduced brain infarct area in rat after acute ischemic stroke: Role of innate immune-inflammatory response, microRNAs and MAPK family signaling pathway. American Journal of Translational Research, 9(4), 1651-1666.

Zha, J., Harada, H., Yang, E., Jockel, J., \& Korsmeyer, S. J. (1996). Serine Phosphorylation of Death Agonist BAD in Response to Survival Factor Results in Binding to 14-3-3 Not BCL-XL. Cell, 87(4), 619-628. https://doi.org/10.1016/S0092-8674(00)81382-3

Zhang, Z.-H., Pan, Y.-Y., Jing, R.-S., Luan, Y., Zhang, L., Sun, C., ... Wang, Y.-B. (2016). Protective effects of BMSCs in combination with erythropoietin in bronchopulmonary dysplasia-induced lung injury. Molecular Medicine Reports, 14(2), 1302-1308. https://doi.org/10.3892/mmr.2016.5378

Zhao, Y., Zuo, Y., Jiang, J., Yan, H., Wang, X., Huo, H., \& Xiao, Y. (2016). Neural stem cell transplantation combined with erythropoietin for the treatment of spinal cord injury in rats. Experimental and Therapeutic Medicine, 12(4), 2688-2694. https://doi.org/10.3892/etm.2016.3677 


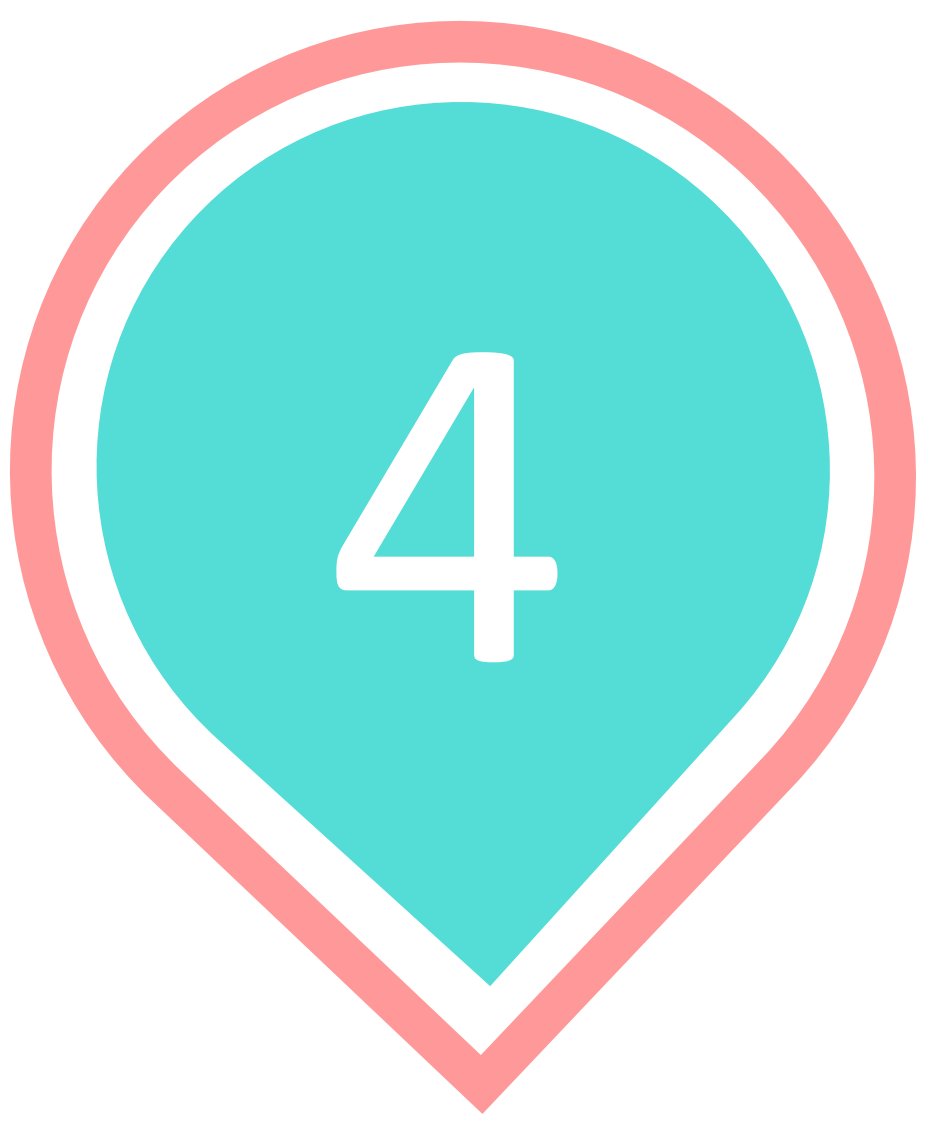

CHAPTER 4:

\section{GENERAL DISCUSSION}




\section{Table of Contents}

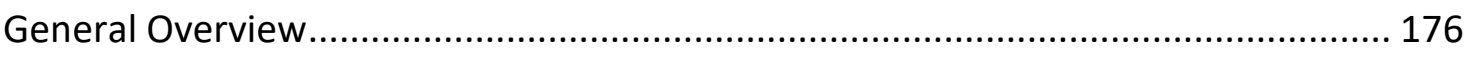

Limitations of Animal Models of PD.............................................................. 180

EPO activates pro-survival signalling acutely in the absence of a toxicant ............... 183

EPO's pro-survival effects are region-dependent .................................................. 185

EPO protects nigrostriatal neurons from partial and moderate 6-OHDA lesions ...... 188

EPO's influence on motor behaviour is inconsistent .......................................... 192

Evidence for EPO's anti-apoptotic, anti-inflammatory and antioxidant actions ........ 194

EPO's hematopoietic effects in the periphery .................................................... 196

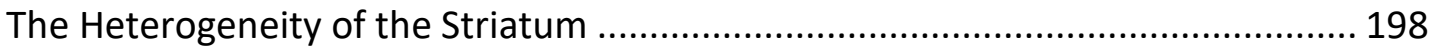

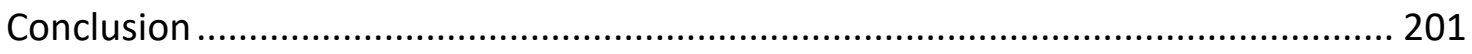

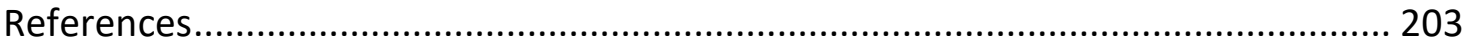




\section{General Overview}

The core pathological mechanisms involved in Parkinson's disease (PD) have eluded researchers for decades, and to date, few studies have identified clinically relevant advancements in the areas of PD pathology and treatment. This critical and unmet need should be of great concern to researchers, as the aging population implies the growth of this disease will be exponential in the coming years. Based on the available epidemiological data, the number of individuals with PD is expected to double to 14.2 million people worldwide by 2040 , even using conservative estimates (Dorsey \& Bloem, 2018; Feigin et al., 2017). In a systematic analysis of the global burden of disease, the rate of growth of PD was found to be surpassing that of Alzheimer disease, with the prevalence (and thus the associated disabilities and deaths) doubling between 1990-2015 (Feigin et al., 2017). This staggering growth rate leads one article to ask those in the PD community to take this growth as seriously as they would an infectious condition (Dorsey \& Bloem, 2018). While ageing is the primary risk factor for the development of PD (Buchman et al., 2012; Collier, Kanaan, \& Kordower, 2011; Driver, Logroscino, Gaziano, \& Kurth, 2009; Rodriguez et al., 2014), the degree of cellular damage present when motor symptoms appear - including the variable but significant loss of striatal terminals and dopaminergic cells in the substantia nigra (SNc) - suggests the pathogenesis of this disease begins years before diagnosis (Cheng, Ulane, \& Burke, 2010). 
While the locus of neuronal degeneration is known, the processes underlying the deterioration of the cellular microenvironment in the disease remain poorly understood. Broadly, the mechanisms underlying PD pathology are likely complex and multi-faceted, involving factors such as genetic mutations, environmental stressors, and inhibition of neural protection. Evidence supporting each of these contributors led to the development of the multiple-hit hypothesis of PD (Antony, Diederich, Krüger, \& Balling, 2013; Berry, La Vecchia, \& Nicotera, 2010; Carvey, Punati, \& Newman, 2006; Sadasivan, Sharp, Schultz-Cherry, \& Smeyne, 2017; Sulzer, 2007), which suggests exposure to multiple risk factors (or multiple 'hits') increases an individual's likelihood of developing the disease. Indeed, the multiple-hit hypothesis has been increasingly applied to several neurodegenerative diseases in recent years, (Bansal, Salaria, \& Singh, 2019; Garden \& La Spada, 2012; Gong, Liu, \& Iqbal, 2018; Heinemann, Posimo, Mason, Hutchison, \& Leak, 2016; Patrick, Bell, Weindel, \& Watson, 2019) The emerging research implicating multiple hits in various neurodegenerative diseases suggests researchers have only begun to understand the interactions between genetics, environment, and cellular responses to stress in the context of neurodegeneration.

Recently, Johnson and colleagues proposed a new conceptual model for understanding PD, describing: (1) disease triggers, (2) facilitators, and (3) aggravators (Johnson, Stecher, Labrie, Brundin, \& Brundin, 2019). The three categories exist on a continuum in this model, each contributing to the course of the disease differently at various stages of the disease. The authors argue that the model provides a framework 
within which therapeutic strategies can be evaluated by examining when certain factors are most likely to play a critical role in the disease (Johnson et al., 2019). Triggers refer to events necessary to spark the initiation of disease processes, but which alone are generally insufficient to lead to PD onset, including environmental toxicants, head trauma and infection. Disease facilitators allow the spread of the disease through the central nervous system, including increased sensitivity of cells to toxicity which can promote propagation of the disease. Examples of facilitators may include aging, peripheral inflammation, and genetic variants and mutations. Aggravators represent a category of factors that worsen or exacerbate cellular conditions, leading to cellular stress and death both within and outside of the basal ganglia, including $\alpha$-synuclein ( $\alpha$ syn) propagation, neuroinflammation and oxidative stress. At the very least, this model provides insight into the complexity of the disease, and highlights the challenges faced by researchers in the search for novel therapeutic targets for PD. Many therapeutic candidate factors have emerged (Cederfjäll et al., 2013; Gibson, Gao, McDonagh, \& Shen, 2012; Martínez-Morales \& Liste, 2012), but one group of factors has consistently recurred as potential therapeutic agents for PD: neurotrophic factors (NTFs).

For more than 20 years, trophic factors have been demonstrated to have neuroprotective effects in a variety of animal models of neurodegenerative diseases, including PD (Bartus et al., 2013, 2011; Bilang-Bleuel et al., 1997; Boado, Hui, Lu, \& Pardridge, 2010; Costa et al., 2015; Grondin et al., 2002; Kirik, Georgievska, \& Björklund, 2004; Kordower \& Bjorklund, 2013; Lindholm et al., 2016; Littrell, Granholm, Gerhardt, 
\& Boger, 2013; Patel et al., 2005; Paul \& Sullivan, 2019; Peterson \& Nutt, 2008; Hansjorg Sauer, Rosenblad, Bj6rklund, \& Changeaux, 1995). Still, researchers have yet to identify a single trophic factor with the ability to halt, reverse, or even slow down the progression of PD in actual clinical trials with human patients. Due to the involvement of multiple neurotransmitter systems leading to a variety of motor and non-motor symptoms, it is unlikely that any one factor will successfully alter disease course in human patients. Indeed, a multitude of approaches tested on imperfect animal models has yielded disappointing results when tested clinically (Kordower \& Burke, 2018). NTFs, including brain-derived neurotrophic factor (BDNF), glial cell-line derived neurotrophic factor (GDNF), and neurturin have been extensively studied for their ability to influence the motor and non-motor symptoms of PD using a variety of animal models (Bartus et al., 2013; Ghosal et al., 2018; Grondin et al., 2002; Kirkeby \& Barker, 2019; Marks et al., 2010; Hansjorg Sauer et al., 1995; Sullivan \& O’Keeffe, 2016). These and other NTFs have indeed shown potent protective effects in the nigrostriatal system when employed in the context of toxin-based models of PD (Airavaara, Voutilainen, Wang, \& Hoffer, 2012; Paul \& Sullivan, 2019; Thomas Tayra et al., 2013; Yacoubian \& Standaert, 2009) Still, none of these have stood the test of time in proper wellcontrolled clinical trials, which speaks to the fact that all animal models developed to date possess limitations when translating findings to the clinical population afflicted with PD. 


\section{Limitations of Animal Models of PD}

One of the greatest challenges encountered by researchers studying PD using animal models is the inability to produce all pathological hallmarks of the disease in rodents. Specifically, simulating the synucleinopathy (the accumulation of $\alpha$-syn) observed in PD - which occurs prior to the disruption of dopaminergic systems - has been an ongoing challenge (Blesa, Phani, Jackson-Lewis, \& Przedborski, 2012; Paul \& Sullivan, 2019). The ideal rodent model would replicate most, if not all, of the neuropathological and behavioural features of the disease, including the progressive development of both motor and non-motor symptoms. A rodent model that produces the primary synucleinopathy in a predictive topographical fashion followed by the induction of a progressive lesion to dopaminergic neurons in the nigrostriatal system has yet to be developed, ensuring all animal models fall short of reproducing the human condition. Still, there is much to be learned about the cellular microenvironment in PD with the available animal models of PD, and as such, they remain valuable tools for the assessment of disease mechanisms and in the search for novel therapeutic candidates.

The development of models centered around $\alpha$-syn pathology represents an important advancement in the study of PD and provides additional opportunities to explore the potential benefit of NTFs in the treatment of PD. As the major component of Lewy bodies and with known links to familial forms of PD, $\alpha$-syn rodent models are a promising candidate for the development of improved animal models to study PD in the future (Volpicelli-Daley, Kirik, Stoyka, Standaert, \& Harms, 2016). However, $\alpha$-syn 
models are faced with similar challenges as toxin-based models of PD: a great deal of variability exists between individual studies in terms of the degree of $\alpha$-syn aggregation and pathology in relevant brain regions, as well as the extent of dopamine (DA) neuron damage, and the degree of motor impairment observed (reviewed in Volpicelli-Daley et al., 2016). The large variability in the $\alpha$-syn models may be reflective of variations in the experimental methods used to create the models, which center around using viral vectors to deliver the $\alpha$-syn gene (Paul \& Sullivan, 2019). Further, some studies use overexpression of the wild-type $\alpha$-syn protein (M. Decressac et al., 2012; Mickael Decressac et al., 2011; Gombash et al., 2013; Sanchez-Guajardo, Febbraro, Kirik, \& Romero-Ramos, 2010; L.-K. Song et al., 2015), while others use mutant forms of the protein, such as A53T, in their study designs (Bourdenx et al., 2015; Davies et al., 2014; Rocha et al., 2015; Salganik et al., 2015). There are strengths and weaknesses with any animal model of disease, and it has been suggested that any potential treatment for PD would benefit from being tested in both toxin-based models (such as the 6-OHDA model used in our studies) and $\alpha$-syn models before being applied to the clinical population (Paul \& Sullivan, 2019).

Another caveat of therapeutic NTF treatments involves the timing of administration in relation to the extent of the dopaminergic lesion. Most studies involving trophic factors, including the studies described herein, administer NTFs close in time to the toxic insults used to recapitulate the PD-like pathology (Bartus et al., 2011; Fu et al., 2010; Jia, Mo, Feng, Zhan, OuYang, et al., 2014; Paul \& Sullivan, 2019; 
Signore et al., 2006; Xue, Zhao, Guo, \& Duan, 2007). Administering NTFs concurrently with toxins or shortly after toxin administration does not mimic the reality encountered by clinicians dealing with human PD patients. Clinically, the damage to DA neurons is extensive and well established, often showing a $60-80 \%$ loss of striatal DA, by the time individuals are diagnosed with PD (reviewed in Cheng et al., 2010). The fact that motor symptoms are not present earlier suggests an impressive capacity for the brain to display compensatory mechanisms that offset symptom emergence (Cheng et al., 2010; Kuter et al., 2016; Navntoft \& Dreyer, 2016).

Notably, individuals who have been symptomatic for several years are most often those taking part in clinical trials (Costa-Ribeiro et al., 2017; David et al., 2015; Fu et al., 2010; Laganiere et al., 2010; Lang et al., 2006; Martin-Bastida et al., 2017; Patel et al., 2005); as such, preclinical models of PD need to consider disease stage in the context of any treatments being applied. For example, it might be advantageous to consider how a novel therapeutic strategy may interact with DA replacement therapy when assessing the applicability of the new techniques. In the present thesis, we present a series of studies assessing the impact of the hematopoietic cytokine, erythropoietin (EPO), which has well-documented neurotrophic effects (Foley et al., 2015; Li et al., 2016; Shang, Chong, Wang, \& Maiese, 2011; Subiras, Del Barco, \& Coro Antich, 2012; Thomas Tayra et al., 2013). With respect to EPO, many promising findings from the current research will be discussed that lend support to its use, possibly in 
combination with other therapies, to address the multiple systems involved in PD pathology.

Several studies have suggested that EPO can modulate apoptosis, inflammation and oxidative stress to prevent cellular death in models of stroke, spinal cord injury, traumatic brain injury and PD (Chen, Chen, Yang, \& Zhang, 2016; Dhanushkodi et al., 2013; Farmer, Rudyk, Prowse, \& Hayley, 2015; Foley et al., 2015; Ponce, Navarro, Ahmed, \& Robertson, 2013; Sekiguchi, Kikuchi, Myers, \& Campana, 2003; Subiras et al., 2012). Further, there is increasing evidence that EPO can modulate non-motor symptoms of PD, such as depression-relevant behaviours and problems with memory and cognition, making it a particularly attractive therapeutic candidate (AlmaguerMelian et al., 2016; Girgenti et al., 2009; Jang et al., 2014; Leconte et al., 2011; Ma et al., 2016; Osborn et al., 2013; Saad et al., 2019). However, to date, no study has fully characterized EPO's pro-survival potential in the 6-OHDA mouse model from a behavioural and biological perspective.

\section{EPO activates pro-survival signalling acutely in the absence of a toxicant}

While many studies have reported beneficial effects of EPO in the context of a variety of neurological insults, the methodologies used to demonstrate its positive effects have been variable and inconsistent (Farmer et al., 2015; Signore et al., 2006; Thomas Tayra et al., 2013; Xue et al., 2007; Zhou, Hui, Lu, Boado, \& Pardridge, 2011). In order to first assess EPO's acute signaling effects, we performed intra-striatal EPO 
infusions and collected nigrostriatal regions 1, 6, or 12 hours thereafter. Our finding that EPO time-dependently upregulated pAkt adds to the already convincing evidence from various neurological conditions implicating the PI3K/Akt signalling pathway in EPO's trophic actions (Ding et al., 2017; Lee, Koh, Song, Seol, \& Park, 2016; Rong \& Xijun, 2015; Shang et al., 2011; Shen et al., 2010; Yu, Zhu, \& Jiang, 2017; Yu et al., 2018). In the context of a neurological challenge, such as ischemia, EPO has consistently been found to increase pAkt levels (Ding et al., 2017; Gan et al., 2012; Yuan, Wang, Lu, Maeda, \& Dowling, 2015; Zhang et al., 2006). In an in vitro model of cerebral ischemia, EPO increased levels of pAkt in neuronal cultures as early as 30 minutes post-exposure, sustaining elevated levels for 24 hours (Gan et al., 2012). In a rat model of ischemia, central infusion of EPO 20 minutes following ischemic insult resulted in increased pAkt at 1 hour and 12 hours following reperfusion (Zhang et al., 2006) and a similar model reported that levels of pAkt were still elevated 30 days following reperfusion in the EPOtreated group (Ding et al., 2017). In each of these studies, the use of the PI3K inhibitor, LY294002, blocked Akt induction and confirmed the involvement of the PI3K/Akt pathway in EPO's pro-survival signalling (Ding et al., 2017; Gan et al., 2012; Zhang et al., 2006).

In the case of PD, one study employing the rat in vitro and in vivo models confirmed that PI3K/Akt signalling was altered by EPO (Jia, Mo, Feng, Zhan, Ouyang, et al., 2014). In the current study, we found that EPO acutely upregulated levels of pAkt in the striatum of mice, peaking 6 hours after its application and beginning to subside at 
the 12-hour timepoint. Moreover, our results support previous findings that EPO also modulates the $\mathrm{Bcl}-2$ family of proteins by increasing phosphorylation and thus, inactivating the pro-apoptotic Bad (Castillo et al., 2018; Chai, Yip, Sun, Hsu, \& Leu, 2016; Ma et al., 2014; Shen et al., 2010). Indeed, EPO provoked a delayed upregulation of pBad (after 12 hours) in the striatum. Phosphorylation of Bad is a direct target of pAkt and normally acts to prevent its pro-apoptotic activity via sequestration of $p B a d$ in the cytosol. Hence, our observed pBad elevation suggests a possible anti-apoptotic mechanism of action of EPO. This is also consistent with the results from an in vitro model of Alzheimer disease, in which levels of $\mathrm{Bcl}-{ }_{x L}$ were found to be increased 6 hours following EPO exposure and remained elevated at the 12-hour timepoint (Ma et al., 2014). Interestingly, an in vitro model of retinal neuronal loss, EPO treatment increased pBad and Bcl-xL and this effect was found to be Akt dependent (Shen et al., 2010), suggesting a further linking between these two pathways in the protective effects of EPO.

\section{EPO's pro-survival effects are region-dependent}

Part of the impetus for the present study was that lesion of the striatum would result in a retrograde signal that resulted in a delayed loss of SNc soma. In fact, Sauer and Oertel (1994) found that one week following unilateral 6-OHDA administration to the striatum (20ug), $96 \%$ of nigral soma remained, but cell body counts dropped to $59 \%$ at two weeks, and $35 \%$ at four weeks. This study indicated there was an approximate 
14-day time period before the nigral soma suffer a substantial loss (Sauer \& Oertel, 1994). Indeed, intra-striatal delivery of 6-OHDA is the preferred model to achieve a progressive loss of DA neurons in the nigrostriatal system (Fu et al., 2010; RodriguezPallares et al., 2007; Signore et al., 2006; Xue et al., 2007; Zhou et al., 2011). We reasoned that this delayed and progressive spread of pathology would be somewhat analogous to early to moderate stages of PD disease and that this would be a reasonable model for early interventions.

One of the most novel findings of the current research involves the regional specificity of EPO's actions in the nigrostriatal system. To investigate how EPO's prosurvival effects are mediated by brain region, we conducted parallel studies that involved infusion of EPO either in the SNc or the striatum. In short, we found that intrastriatal but not intra-nigral EPO treatment had a neuroprotective effect against the 6-OHDA lesion. Administration of 6-OHDA also produced predictable behavioural deficits on the rotarod (coordination deficits) and the apomorphine-induced rotation test. However, while intra-SNc EPO had no behavioral consequences, its infusion into the striatum induced a significant reversal of behavioral pathology for the apomorphineinduced rotations. While it is possible EPO's protective effects require some degree of cellular stress to be observed (i.e. such as that caused by co-localizing EPO and 6-OHDA in the striatum as was done in the subsequent studies), our data from the acute signaling study suggest EPO can activate pro-survival signaling in the absence of a toxin (Figure 1). Another possibility is that survival signaling is initially upregulated, but by the 
time 6-OHDA toxicity reaches the nigral region, homeostatic balance has been restored. If this were true, EPO might be protective if 6-OHDA was also administered to the SNc. However, one study investigated this in GDNF, another trophic cytokine being investigated for its therapeutic potential in PD, and found that intra-nigral GDNF was protective against 6-OHDA when the toxin was administered to either the striatum or the SNc (Kearns \& Gash, 1995). This provides evidence of a trophic factor which does not demonstrate regional specificity in a 6-OHDA rodent model of PD. Indeed, EPO's region-specific protection in the striatum may be a result of its differential influence over DA cell terminals and cell bodies based on receptor localization (Merelli, Ramos, Lazarowski, \& Auzmendi, 2019; Ott et al., 2015), but may also be a result of its influence on other types of neurons (e.g. GABAergic, glutamatergic, cholinergic), and/or its influence on other cell types that interact with DA neurons in the striatum and SNc (e.g. astrocytes, microglia, oligodendrocytes, and endothelial cells). Future research should seek to clarify the mechanisms involved in EPO's region-dependent protection of DA neurons in this model of PD (Bond \& Rex, 2014).

It will be recalled that, microglia, the resident immune cells of the brain, play a crucial role in cell survival via the release of pro- and anti-inflammatory cytokines (lannaccone et al., 2013; Kaminska, Mota, \& Pizzi, 2016; Lenz \& Nelson, 2018; Liu et al., 2015; Sherer, Betarbet, Kim, \& Greenamyre, 2003). It has been suggested that in addition to its anti-apoptotic role, EPO may also act via anti-inflammatory mechanisms to confer cellular protection. In fact, in a study employing systemically administered EPO 
to mice that received intra-striatal 6-OHDA, the authors reported a decrease in microglia-like cells two weeks following toxin administration in animals that received EPO (Xue et al., 2007). We found that even though intra-SNc infusion of EPO did not affect neuronal survival, it did significantly modify microglial morphology in the SNC. However, this raises the possibility that the observed microglial inflammatory changes might be independent of the pro-death processes impacting neuronal survival. Of course, it may also be argued that the morphological changes observed for microglial cells do not adequately reflect their inflammatory state. Indeed, some recent papers have argued that M1-like inflammatory states can be evident in microglia, even with only modest changes in morphology, and that the terms $\mathrm{M} 1$ and $\mathrm{M} 2$ are not helpful in our pursuit to understand these complex immune cells (reviewed in Ransohoff, 2016).

\section{EPO protects nigrostriatal neurons from partial and moderate 6-OHDA lesions}

Given that EPO was found to attenuate the neurovegetative response at the level of the striatum and not the SNc, we further sought to assess two doses of EPO which were previously reported to result in differing outcomes when employed in the 6-OHDA mouse model of PD (Signore et al., 2006). While the lower of these doses was previously found to be sub-effective, the higher dose did promote robust pro-survival effects (Sakanaka et al., 1998; Shang et al., 2011; Wu, Shang, Sun, \& Liu, 2007). In the current investigations, however, we found no differences between $10 \mathrm{IU}$ and $20 \mathrm{IU}$ of 
EPO: both were equally effective in acting within the striatum to block neurodegeneration.

It was interesting that intra-striatal EPO provoked the most marked neuroprotective effects in the context of the larger 6-OHDA induced lesion (12 ug), while it had more modest effects for the smaller (3 ug) lesion. Since EPO was only able to partially attenuate lesion size it could be that a floor effect occurred with the smaller lesion, such that drug efficacy was limited. Alternatively, it could be that different size lesions are being modulated by differing mechanisms - in fact, over time the higher 6-OHDA dose (and hence, larger lesion), likely recruits various pathways not evident with the more restricted lesion. Yet, several studies have reported numerous beneficial effects of EPO when only a partial 6-OHDA lesion was induced (Signore et al., 2006; Xue et al., 2007). It could be that methodological issues gave rise to the discrepancy between the present and these previous studies.

The fact that EPO protected both the nigral soma and striatal terminals when administered to the striatum suggests that EPO likely: (a) acted on local dopaminergic terminals to halt the degenerative processes or (b) acted on local GABAergic or other adjacent cells to convey the release of protective factors and these could have further (c) promoted a retrograde protective signal being sent from the terminals. Whatever the case, there is reason to believe that it is in the striatum and not the SNc that early prodeath processes become engaged in PD (Kish, Shannak, \& Hornykiewicz, 1988; Ouchi et al., 2005). Indeed, in recent years a sizeable number of studies have suggest a "dying 
back" or retrograde mechanism of nigrostriatal death (Cheng et al., 2010; Chung et al., 2016; Grosch, Winkler, \& Kohl, 2016; Kluger et al., 2019; Sterling et al., 2013).

As EPO was injected directly into the striatum, it may have exerted a local protective effect on the DAergic terminals via alterations in neurotransmitter signalling (Garzón et al., 2018). Alternatively, EPO may have acted on microglia or astrocytes, both of which possess the EPOR and respond to EPO in conditions of cellular injury (Bond \& Rex, 2014; Ott et al., 2015). 6-OHDA toxicity is known to stem from, among other things, activation of caspase-3, leading to cellular apoptosis (Ganser, Papazoglou, Just, \& Nikkhah, 2010). Activation of the PI3K/Akt pathway counters this pro-apoptotic release of caspase 3, and based on the results of the current studies, there is reason to believe EPO may have worked to reduce apoptotic signalling at the level of the DA terminals, via phosphorylation of Akt. Further support for EPO's role in anti-apoptotic activity comes from the in vitro work of Signore and colleagues, who found EPO reduced levels of caspase 3 in the presence of 6-OHDA, and demonstrated this protection was dependent on the PI3K/Akt pathway (Signore et al., 2006). The toxicity induced by 6-OHDA also involves the release of pro-inflammatory cytokines by microglia (Blum et al., 2001), and there is further evidence that EPO can mitigate the effects of pro-inflammatory cytokines, such as TNF- $\alpha$ (Brines \& Cerami, 2012). Indeed, we found EPO consistently modulated the reactive microglial phenotype across the 6-OHDA studies, regardless of 
toxin dose. Thus, EPO likely is acting to suppress the inflammatory tone of the striatal microenvironment.

It is also possible EPO acted on the largest cell population in the striatum; namely, the GABAergic medium spiny neurons (MSNs). Indeed, these make up 95\% of the cell bodies in the striatum. The loss of DA neurons normally leads to imbalances between the excitatory and inhibitory inputs of the MSNs, which ultimately leads to striatal remodeling and abnormal signaling (Deutch, Colbran, \& Winder, 2007; Segal \& Andersen, 2000; Shen, Flajolet, Greengard, \& Surmeier, 2008; Surmeier, Day, Gertler, Chan, \& Shen, 2010). Recently, one group demonstrated that 6-OHDA-induced toxicity leads to an upregulation of glutamatergic receptors in the striatum in a rat model of PD (Zheng et al., 2019), implicating possible glutamate toxicity. Treatment with EPO has previously been shown to increase the expression of the EPO receptor on GABAergic neurons in vitro and this resulted in a rescue from glutamate toxicity (Won et al., 2007). Thus, it is possible EPO is acting on GABAergic neurons to restore balance in signalling of the MSNs, preventing cellular death.

Finally, it is possible that EPO's pro-survival signaling in the striatum is transported in a retrograde fashion to confer protection at the level of the SNc. The toxicity induced by 6-OHDA causes oxidative stress in cells, and our results showed elevated levels of GPx in both the striatum and the SNc in EPO-treated groups. This indicates intra-striatal EPO was able to influence subsequent antioxidant activity in a 
retrograde fashion in the SNc three weeks after administration of the toxicant. There are a number of studies demonstrating that endosomes can carry trophic signals in a retrograde fashion to the cell body to exert protective effects (Delcroix et al., 2003; Hoeller, Volarevic, \& Dikic, 2005; York et al., 2000; Zahavi, Maimon, \& Perlson, 2017). In this regard, trophic factors can be internalized at distal sites together with their receptors, following which they are compartmentalized into signalling endosomes that engage in protein-based transport to the cell soma (Zahavi et al., 2017). Indeed, endocytosis of EPO and its receptor has been demonstrated in vitro (Bulut, Sulahian, Yao, \& Huang, 2013) and more recently in the insect nervous system (Miljus et al., 2017), suggesting this may be one possible mechanism by which intra-striatal EPO can influence cell survival in the SNc.

\section{EPO's influence on motor behaviour is inconsistent}

Although some studies have suggested EPO can improve motor function in the face of toxicant exposure (Signore et al., 2006; Xue et al., 2007), others have failed to observe motor improvements following treatment with EPO, despite reporting other therapeutic effects (Jang et al., 2014). In the current investigation, EPO's effects on behaviour were similarly inconsistent. Specifically, EPO did indeed blunt the apomorphine-induced rotational behaviour caused by both doses of 6-OHDA but had no influence on motor coordination deficits measured in the Rotarod task. Similarly, there were no significant variations of gait or home-cage activity, as measured by the CatWalk 
and Micromax, respectively (data in appendices). Apomorphine-induced rotations are a particularly robust measure of striatal lesion, and as such, probably a more sensitive assessment able to capture EPO-mediated effects.

While the 6-OHDA model of PD produces motor deficits on a variety of behavioural tasks, the severity of impairments observed are dependent on factors such as dose of 6-OHDA, injection site, and number of sites of 6-OHDA infusion within the region (Heuer, Smith, Lelos, Lane, \& Dunnett, 2012; Iancu, Mohapel, Brundin, \& Paul, 2005; Ren et al., 2011). The cardinal motor symptoms observed in human PD patients, however, such as tremor and rigidity, are not observed in mice, highlighting one of the challenges of designing behavioural tasks to assess motor impairments which can later be meaningfully translated to the clinical population of patients with PD.

Another important point to consider is the fact that PD is a disease of multiple neurotransmitter systems, each of which can affect a variety of behaviors (Buchanan et al., 2015; Grosch et al., 2016; Jankovic, 2018; Rommelfanger \& Weinshenker, 2007; Zheng et al., 2019). This fact is often overlooked in animal models of the disease, yet degeneration of the locus coeruleus in the brainstem occurs readily in PD and results in a massive loss of norepinephrine (NE) innervation throughout the brain (Rommelfanger \& Weinshenker, 2007). Indeed, NE plays an important role in the motor deficits observed in PD, and this often goes unrecognized (Heneka et al., 2010; Rommelfanger et al., 2007; S. Song et al., 2019). The profuse effects of NE throughout the nervous system, including its roles in pain, movement, mood and stress render its loss in PD important 
(Delaville, Deurwaerdère, \& Benazzouz, 2011). In fact, one study recently reported the loss of NE neurons from the locus coeruleus resulted in neuroinflammation and oxidative stress, both important pathological features of PD (Song et al., 2019). Another study presented evidence suggesting microglial responses are modulated by NE, an important factor in the inflammatory response of cells and highly implicated in PD pathology (Heneka et al., 2010).

\section{Evidence for EPO's anti-apoptotic, anti-inflammatory and antioxidant actions}

We hypothesized that EPO acts to protect neurons via a combination of antiapoptotic, anti-inflammatory and antioxidant mechanisms. In the studies conducted, evidence for each of these protective pathways was observed, but not all within the same experimental conditions. Specifically, EPO demonstrated its ability to influence anti-apoptotic processes through modulation of two proteins involved in anti-apoptotic pathways (pAkt and pBad). Despite conferring cellular protection at both 3 ug and 12ug doses of 6-OHDA, EPO's modulation of pro-survival proteins appears to be dependent both on region and dose of 6-OHDA used (for a summary, see Table 3).

EPO's anti-inflammatory actions with regards to microglial morphology was observed across all studies, demonstrating a consistent and robust effect of EPO on microglia in the models employed. When EPO was administered to the SNc, it reduced the activation of microglia locally, but did not mediate activation in the striatum (where the 6-OHDA lesion was induced). In studies where EPO was infused into the striatum, 
however, EPO attenuated microglial activation in both brain regions at both doses of 6-OHDA three weeks post-lesion. These findings imply that protection at the level of the striatal terminals can extend in a retrograde fashion to protect the cell bodies in the $\mathrm{SNc}$, but not from the SNc to the striatal terminals, suggesting the potential mechanism of endocytosis and retrograde signalling of EPO and its receptor, or an alternative mechanism involving astrocytes, microglia or oligodendrocytes (Merelli et al., 2019; Ott et al., 2015).

The antioxidant effects of EPO, like the anti-apoptotic and anti-inflammatory effects, were observed in multiple experiments in this thesis. Perhaps the most salient finding in these studies was the consistent upregulation of GPx in response to EPO. GPX is a powerful antioxidant, and its increase was observed both in the presence and absence of the 6-OHDA exposure. GPx is specifically responsible for catalyzing the reaction that turns a common contributor to oxidative stress, hydrogen peroxide $\left(\mathrm{H}_{2} \mathrm{O}_{2}\right)$, into water $\left(\mathrm{H}_{2} \mathrm{O}\right)$. As such, its presence in the nigrostriatal system in response to EPO is a strong indication of the antioxidant activity of this cytokine. Since EPO upregulated GPX independently of 6-OHDA suggests its antioxidant activity occurs whether cells are experiencing stress or not. In the acute signalling study without 6-OHDA, levels of GPx were increased in both the striatum and SNc 12 hours after EPO administration. Further, following 6-OHDA administration (12 ug), levels of striatal GPx were found to be increased ( 3 weeks post-lesion), suggesting a prolonged antioxidant effect of EPO in this model. Curiously, changes in GPx were not observed when the low dose ( 3 ug) of 
6-OHDA was used, suggesting the possibility that in the context of the less severe lesion EPO's primary protective mechanism may involve alternate pathways. Indeed, increased levels of $\mathrm{BCl}-\mathrm{xL}$ were observed with the less severe lesion- a finding which was not observed at the higher dose of 6-OHDA - supporting an anti-apoptotic role of EPO under these cellular conditions.

Table 3: Summary of changes induced by EPO-signalling observed in striatum and SNC

\begin{tabular}{|c|c|c|c|}
\hline Dose of 6-OHDA & Dose of EPO & Striatum & SNc \\
\hline N/A & $20 I U$ & 个pAkt, $\uparrow p B a d, \uparrow G P x$ & 个GPx \\
\hline 3ug & $20 I U$ & 个Bcl-xL & N/A \\
\hline 12ug & 10IU and 20IU & 个GPx & 个pAkt \\
\hline
\end{tabular}

EPO's hematopoietic effects in the periphery

In the current studies, EPO was administered centrally to assess brain region specificity and to avoid the induction of hematopoietic effects in the periphery, which can lead to increased risk of thrombosis due to increased production of red blood cells. In actual clinical practice, EPO would ideally be administered systemically to be as minimally invasive as possible. While peripheral hematopoietic effects of EPO have traditionally been a concern of its use in the treatment of disease, many groups have now developed modified EPO molecules with tissue-protective effects that are not 
hematopoietic (Thomas Tayra et al., 2013; Wang et al., 2007; Xue et al., 2010; Zhou et al., 2011). In fact, one group hypothesized that erythropoiesis and tissue protection are distinct functions of EPO that reside in different parts of the molecule (Yuan et al., 2015). Based on this hypothesis, the group isolated fragments of EPO to test their properties, and identified a small peptide (region JM-4) on the EPO molecule possessing anti-inflammatory properties without hematopoietic properties (Yuan et al., 2015). This finding underscores the possibility that the anti-inflammatory, anti-apoptotic and antioxidant capabilities of EPO may reside in different parts of the molecule, a question that certainly merits further investigation in the future.

\section{Future Directions}

It is important to consider that trophic factors, such as EPO, do not inherently have positive or negative qualities - instead, they modulate pathways which influence the cellular microenvironment in response to the characteristics of that environment. While this can lead to cell survival, it can also lead to cell death, a factor which complicates the study of PD. The present studies highlighted the relevant anti-apoptotic mechanisms of EPO; however, future studies should also consider additional protective signalling pathways, such as Wnt1 signalling in response to EPO. For example, Bcl-xL has been shown to be upregulated by EPO through Wnt1 and has been shown to be involved in EPO's mechanistic pathway by several studies (including at least one study using a Wnt1 inhibitor to confirm the involvement of Wnt1 (Maiese, Chong, Shang, \& Wang, 2012; 
Shang et al., 2011). Based on the results obtained from the current investigations, looking more closely at the Wnt1 pathway would be a logical next step to narrow down the pro-survival actions of EPO in PD.

In addition to the complexity of signalling pathways, researchers should consider the possibility of functional lateralization between hemispheres when employing a unilateral lesion model. Recent evidence suggests functional lateralization in the hippocampus for novel object exploration (Jordan, Shanley, \& Pytte, 2019). The authors used immediate early gene imaging and c-Fos to detect interhemispheric differences in neuronal activation in the dentate gyrus, a region in the hippocampus important for encoding new experiences. The authors looked at males and females in either control conditions (in the home cage), wheel running, or novel object exploration. They found no differences between males and females but found more c-Fos-expressing cells in the left hemisphere in the novel object group. The left hemisphere appeared to be preferentially recruited for the novel object task when compared to controls, whereas wheel running recruited the left and right dentate gyrus equally (Jordan et al., 2019). This provides evidence that motor tasks may demonstrate hemispheric preference, a finding which would have important consequences for PD.

The Heterogeneity of the Striatum

In addition to the possibility of hemispheric preference, there is a strong need to learn more about the minority cell populations in the striatum and how they may be 
influencing PD pathology. For example, the striatal cell populations are very different from those in the SNc, and have more complex functions and interactions than had previously been thought (Bateup et al., 2010; Plenz \& Wickens, 2017; Surmeier et al., 2010). There are both D1 and D2 receptors in the striatum - while the D1 receptors generally have the role of increasing dendritic excitability and glutamate signalling of the nigrostriatal MSNs, the D2 receptors typically serve to decrease excitability and glutamate signalling of the striatopallidal MSNs (Plenz \& Wickens, 2017). The functional antagonism between these two DA receptor types extends to the regulation of synaptic plasticity, and long-term changes in DA signalling can certainly alter the connectivity and function of the MSNs in the striatum (Bateup et al., 2010; Surmeier et al., 2010).

Recent evidence suggests MSNs with both D1 and D2 receptors represent a distinct striatal neuronal population (Gagnon et al., 2017). For example, these neurons respond differently to 6-OHDA than MSNs containing only D1 or D2 receptors (Gagnon et al., 2017). They are also morphologically distinct, with a smaller soma and fewer dendritic arborizations, along with fewer spines. They are uniformly distributed throughout the dorsal striatum (comprising 1.9\% of all MSNs) and more heterogenous in the ventral tier of this brain region (making up $14.6 \%$ of MSNs in the shell and $7.3 \%$ in the core; Gagnon et al., 2017). Interestingly, the degree of dendritic arborization in D1/D2 MSNs is unaltered by 6-OHDA (in contrast, arborization is significantly reduced in both D1 and D2 MSNs), supporting the notion that the D1/D2 MSNs are a distinct cellular sub-population (Gagnon et al., 2017). Another report showed the differences in 
action of the distinct MSN sub-populations by disrupting dopamine- and cAMPregulated phosphoprotein $\mathrm{Mr}$ 32kDa (DARPP-32), an important striatal signalling protein (Bateup et al., 2010). In striatonigral neurons, this led to decreased locomotion, while in striatopallidal neurons, it led to increased locomotion. This paper further links the ventral striatum to limbic function, which suggests that if lesions are too large and challenge neurons ventrally in the striatum (e.g. in the nucleus accumbens), emotional responses - like mood and motivation - can be affected (Bateup et al., 2010). Further, research continues to reveal additional striatal complexities, such as the striosomematrix differences in signalling and receptor localization (Brimblecombe \& Cragg, 2017; Ren et al., 2017) This type of evidence suggests a more complex environment than once thought and raises many complications when interpreting behavioural outcomes related to striatal lesions.

Further neuronal diversity of the striatum is evident when one considers the complexity of the interneuron populations. In addition to GABAergic interneurons, there are also those that release acetylcholine (Ach) or co-release both ACh and GABA (Lozovaya et al., 2018; Lozovaya, Ben-Ari, \& Hammond, 2018). Interestingly, Lozovaya et al. (2018) used the 6-OHDA model of PD in mice and demonstrated GABAergic dysfunction in the striatum in models of PD. Indeed, the loss of DA caused a shift in interneuron functioning, with an increase in the activity of dual cholinergic-GABAergic interneurons, while at the same time, attenuating the overall inhibitory GABAergic tone (Lozovaya et al., 2018; Lozovaya et al., 2018). Further, this effect was related to $\mathrm{Cl}^{-}$ion 
availability, as addition of a $\mathrm{Cl}^{-}$antagonist restored GABAergic inhibition and attenuated the apparent motor deficits in this model. Using this information in conjunction with recent emerging technologies, future research should seek to possibly selectively manipulate these distinct minority cell populations, with an eye towards more specific symptom reduction in PD.

\section{Conclusion}

The results from the current studies strongly support EPO's candidacy as an adjuvant treatment in PD. Several groups of researchers have acknowledged the potential beneficial effects of EPO when used in combination with a secondary factor, such as in studies of spinal cord injury (Li et al., 2017; Yamanaka, Eldeiry, Aftab, Mares, et al., 2018; Yamanaka, Eldeiry, Aftab, Ryan, et al., 2018; Yamanaka et al., 2019; Zhao et al., 2016). In a series of studies using a mouse model of spinal cord ischemiareperfusion, Yamanaka et al. demonstrated that diazoxide, a potassium channel activator, enhanced the anti-apoptotic neuroprotective effects of EPO. In addition, EPO's potential to be successful as an adjuvant therapy has been recognized by researchers investigating cerebral ischemia (Chai et al., 2016; Lv et al., 2017; Shin \& Cho, 2016; Wang et al., 2016; Yuen et al., 2017), perinatal hypoxia-related injuries (Luan et al., 2016; Wu \& Gonzalez, 2015; Zhang et al., 2016), and even traumatic brain injury (Duan et al., 2015). 
Future research should focus on the most salient protective properties of EPO and seek to combine these properties with other prospective treatments to evaluate their combined efficacy in preclinical models of PD. For instance, the current pharmacotherapy for PD involves DA replacement via administration of levodopa (L-DOPA). While it effectively replaces DA initially, its effects wane over time, requiring increasing doses to be administered to achieve relief of motor symptoms. It can be challenging to titrate the dose of L-DOPA properly to ensure effective DA replacement without causing excessive DA production, as too much DA itself leads to increased production of reactive oxygen species through its regular metabolism (Meiser, Weindl, \& Hiller, 2013). This creates conditions of oxidative stress, which could potentially be mitigated by a non-hematopoietic form of EPO administered concurrently with L-DOPA through increased GPx.

The current set of experiments contributes several new pieces of information to the growing body of literature studying EPO's neurotrophic effects, including its prosurvival signalling, its regional specificity, and its potential to work through different protective pathways depending on the cellular microenvironment. Much work remains to be done to fully characterize EPO's protective effects in PD, including evaluating how it may differentially influence specific sub-populations of cells in the striatum, and how its anti-inflammatory, anti-apoptotic and antioxidant properties may be best harnessed in the treatment of PD or other neurological disorders. 


\section{References}

Airavaara, M., Voutilainen, M. H., Wang, Y., \& Hoffer, B. (2012). Neurorestoration. Parkinsonism \& Related Disorders, 18 Suppl 1, S143-6. https://doi.org/10.1016/S1353-8020(11)70045-1

Almaguer-Melian, W., Mercerón-Martínez, D., Delgado-Ocaña, S., Pavón-Fuentes, N., Ledón, N., \& Bergado, J. A. (2016). EPO induces changes in synaptic transmission and plasticity in the dentate gyrus of rats. Synapse, 70(6), 240-252. https://doi.org/10.1002/syn.21895

Antony, P. M. A., Diederich, N. J., Krüger, R., \& Balling, R. (2013). The hallmarks of Parkinson's disease. FEBS Journal, 280(23), 5981-5993.

https://doi.org/10.1111/febs.12335

Bansal, A., Salaria, M., \& Singh, T. R. (2019). Tau Pathology (pp. 217-234). https://doi.org/10.4018/978-1-5225-5282-6.ch010

Bartus, R. T., Baumann, T. L., Brown, L., Kruegel, B. R., Ostrove, J. M., \& Herzog, C. D. (2013). Advancing neurotrophic factors as treatments for age-related neurodegenerative diseases: Developing and demonstrating "clinical proof-ofconcept" for AAV-neurturin (CERE-120) in Parkinson's disease. Neurobiology of Aging, 34(1), 35-61. https://doi.org/10.1016/j.neurobiolaging.2012.07.018

Bartus, R. T., Brown, L., Wilson, A., Kruegel, B., Siffert, J., Johnson, E. M., ... Herzog, C. D. (2011). Properly scaled and targeted AAV2-NRTN (neurturin) to the substantia nigra is safe, effective and causes no weight loss: Support for nigral targeting in Parkinson's disease. Neurobiology of Disease, 44(1), 38-52. https://doi.org/10.1016/j.nbd.2011.05.026

Bateup, H. S., Santini, E., Shen, W., Birnbaum, S., Valjent, E., Surmeier, D. J., ... Greengard, P. (2010). Distinct subclasses of medium spiny neurons differentially regulate striatal motor behaviors. Proceedings of the National Academy of Sciences, 107(33), 14845-14850. https://doi.org/10.1073/pnas.1009874107

Berry, C., La Vecchia, C., \& Nicotera, P. (2010). Paraquat and Parkinson's disease. Cell Death \& Differentiation, 17(7), 1115-1125. https://doi.org/10.1038/cdd.2009.217 
Bilang-Bleuel, A., Revah, F., Colin, P., Locquet, I., Robert, J.-J., Mallet, J., \& Horellou, P. (1997). Intrastriatal injection of an adenoviral vector expressing glial-cell-linederived neurotrophic factor prevents dopaminergic neuron degeneration and behavioral impairment in a rat model of Parkinson disease. Proceedings of the National Academy of Sciences, 94(16), 8818-8823. https://doi.org/10.1073/pnas.94.16.8818

Blesa, J., Phani, S., Jackson-Lewis, V., \& Przedborski, S. (2012). Classic and new animal models of Parkinson's disease. Journal of Biomedicine and Biotechnology, 2012. https://doi.org/10.1155/2012/845618

Blum, D., Torch, S., Lambeng, N., Nissou, M., Benabid, A. L., Sadoul, R., \& Verna, J. M. (2001). Molecular pathways involved in the neurotoxicity of 6-OHDA, dopamineandMPTP: contributionto the apoptotic theory inParkinson'sdisease. Progress in Neurobiology, 65, 135-172.

Boado, R. J., Hui, E. K., Lu, J. Z., \& Pardridge, W. M. (2010). Drug targeting of erythropoietin across the primate blood-brain barrier with an IgG molecular Trojan horse. The Journal of Pharmacology and Experimental Therapeutics, 333(3), 961969. https://doi.org/10.1124/jpet.109.165092

Bond, W. S., \& Rex, T. S. (2014). Evidence that erythropoietin modulates neuroinflammation through differential action on neurons, astrocytes, and microglia. Frontiers in Immunology, 5(OCT), 1-8. https://doi.org/10.3389/fimmu.2014.00523

Bourdenx, M., Dovero, S., Engeln, M., Bido, S., Bastide, M. F., Dutheil, N., ... Dehay, B. (2015). Lack of additive role of ageing in nigrostriatal neurodegeneration triggered by $\alpha$-synuclein overexpression. Acta Neuropathologica Communications, 3(1), 46. https://doi.org/10.1186/s40478-015-0222-2

Brimblecombe, K. R., \& Cragg, S. J. (2017). The Striosome and Matrix Compartments of the Striatum: A Path through the Labyrinth from Neurochemistry toward Function. ACS Chemical Neuroscience, 8(2), 235-242. https://doi.org/10.1021/acschemneuro.6b00333

Brines, M., \& Cerami, A. (2012). The Receptor That Tames the Innate Immune Response. Molecular Medicine, 18(3), 1. https://doi.org/10.2119/molmed.2011.00414 
Buchanan, R. J., Gjini, K., Darrow, D., Varga, G., Robinson, J. L., \& Nadasdy, Z. (2015). Glutamate and GABA concentration changes in the globus pallidus internus of Parkinson's patients during performance of implicit and declarative memory tasks: A report of two subjects. Neuroscience Letters, 589, 73-78. https://doi.org/10.1016/j.neulet.2015.01.028

Buchman, A. S., Shulman, J. M., Nag, S., Leurgans, S. E., Arnold, S. E., Morris, M. C., ... Bennett, D. A. (2012). Nigral pathology and parkinsonian signs in elders without Parkinson disease. Annals of Neurology, 71(2), 258-266. https://doi.org/10.1002/ana.22588

Bulut, G. B., Sulahian, R., Yao, H., \& Huang, L. J. -s. (2013). Cbl ubiquitination of p85 is essential for Epo-induced EpoR endocytosis. Blood, 122(24), 3964-3972. https://doi.org/10.1182/blood-2013-05-506212

Carvey, P. M., Punati, A., \& Newman, M. B. (2006). Progressive Dopamine Neuron Loss in Parkinson's Disease: The Multiple Hit Hypothesis. Cell Transplantation, 15(3), 239-250. https://doi.org/10.3727/000000006783981990

Castillo, C., Zaror, S., Gonzalez, M., Hidalgo, A., Burgos, C. F., Cabezas, O. I., ... Toledo, J. R. (2018). Neuroprotective effect of a new variant of Epo nonhematopoietic against oxidative stress. Redox Biology, 14(July 2017), 285-294. https://doi.org/10.1016/j.redox.2017.09.010

Cederfjäll, E., Nilsson, N., Sahin, G., Chu, Y., Nikitidou, E., Björklund, T., ... Kirik, D. (2013). Continuous DOPA synthesis from a single AAV: Dosing and efficacy in models of Parkinson's disease. Scientific Reports, 3, 1-12. https://doi.org/10.1038/srep02157

Chai, H. T., Yip, H. K., Sun, C. K., Hsu, S. Y., \& Leu, S. (2016). AG490 suppresses EPOmediated activation of JAK2-STAT but enhances blood flow recovery in rats with critical limb ischemia. Journal of Inflammation (United Kingdom), 13(1), 1-11. https://doi.org/10.1186/s12950-016-0126-3

Chen, J., Chen, J., Yang, Z., \& Zhang, X. (2016). Carbamylated Erythropoietin: A Prospective Drug Candidate for Neuroprotection. Biochemistry Insights, 8(Suppl 1), 25. https://doi.org/10.4137/BCl.S30753

Cheng, H.-C., Ulane, C. M., \& Burke, R. E. (2010). Clinical progression in Parkinson disease and the neurobiology of axons. Annals of Neurology, 67(6), 715-725. https://doi.org/10.1002/ana.21995 
Chung, S. J., Lee, J. J., Ham, J. H., Ye, B. S., Lee, P. H., \& Sohn, Y. H. (2016). Striatal Dopamine Depletion Patterns and Early Non-Motor Burden in Parkinsons Disease. PLOS ONE, 11(8), e0161316. https://doi.org/10.1371/journal.pone.0161316

Collier, T. J., Kanaan, N. M., \& Kordower, J. H. (2011). Ageing as a primary risk factor for Parkinson\&\#39;s disease: evidence from studies of non-human primates. Nature Reviews Neuroscience, 12, 359. Retrieved from https://doi.org/10.1038/nrn3039

Costa-Ribeiro, A., Maux, A., Bosford, T., Aoki, Y., Castro, R., Baltar, A., ... Monte-Silva, K. (2017). Transcranial direct current stimulation associated with gait training in Parkinson's disease: A pilot randomized clinical trial. Developmental Neurorehabilitation, 20(3), 121-128. https://doi.org/10.3109/17518423.2015.1131755

Costa, D. D., Beghi, E., Carignano, P., Pagliacci, C., Faccioli, F., Pupillo, E., ... Redaelli, T. (2015). Tolerability and efficacy of erythropoietin (EPO) treatment in traumatic spinal cord injury: a preliminary randomized comparative trial vs. methylprednisolone (MP). Neurological Sciences, 36(9), 1567-1574. https://doi.org/10.1007/s10072-015-2182-5

David, F. J., Robichaud, J. A., Leurgans, S. E., Poon, C., Kohrt, W. M., Goldman, J. G., ... Corcos, D. M. (2015). Exercise improves cognition in Parkinson's disease: The PRETPD randomized, clinical trial. Movement Disorders, 30(12), 1657-1663. https://doi.org/10.1002/mds.26291

Davies, S. E., Hallett, P. J., Moens, T., Smith, G., Mangano, E., Kim, H. T., ... Tofaris, G. K. (2014). Enhanced ubiquitin-dependent degradation by Nedd4 protects against $\alpha$ synuclein accumulation and toxicity in animal models of Parkinson's disease. Neurobiology of Disease, 64, 79-87. https://doi.org/10.1016/j.nbd.2013.12.011

Decressac, M., Kadkhodaei, B., Mattsson, B., Laguna, A., Perlmann, T., \& Bjorklund, A. (2012). -Synuclein-Induced Down-Regulation of Nurr1 Disrupts GDNF Signaling in Nigral Dopamine Neurons. Science Translational Medicine, 4(163), 163ra156163ra156. https://doi.org/10.1126/scitranslmed.3004676

Decressac, Mickael, Ulusoy, A., Mattsson, B., Georgievska, B., Romero-Ramos, M., Kirik, D., \& Björklund, A. (2011). GDNF fails to exert neuroprotection in a rat $\alpha$-synuclein model of Parkinson's disease. Brain : A Journal of Neurology, 134(Pt 8), 2302-2311. https://doi.org/10.1093/brain/awr149 
Delaville, C., Deurwaerdère, P. De, \& Benazzouz, A. (2011). Noradrenaline and Parkinson's Disease. Frontiers in Systems Neuroscience, 5. https://doi.org/10.3389/fnsys.2011.00031

Delcroix, J.-D., Valletta, J. S., Wu, C., Hunt, S. J., Kowal, A. S., \& Mobley, W. C. (2003). NGF Signaling in Sensory Neurons. Neuron, 39(1), 69-84. https://doi.org/10.1016/S0896-6273(03)00397-0

Deutch, A. Y., Colbran, R. J., \& Winder, D. J. (2007). Striatal plasticity and medium spiny neuron dendritic remodeling in parkinsonism. Parkinsonism \& Related Disorders, 13, S251-S258. https://doi.org/10.1016/S1353-8020(08)70012-9

Dhanushkodi, A., Akano, E. O., Roguski, E. E., Xue, Y., Rao, S. K., Matta, S. G., ... Mcdonald, M. P. (2013). A single intramuscular injection of rAAV-mediated mutant erythropoietin protects against MPTP-induced parkinsonism. Genes, Brain and Behavior, 12(2), 224-233. https://doi.org/10.1111/gbb.12001

Ding, J., Wang, J., Li, Q. Y., Yu, J. Z., Ma, C. G., Wang, X., ... Xiao, B. G. (2017). Neuroprotection and CD131/GDNF/AKT Pathway of Carbamylated Erythropoietin in Hypoxic Neurons. Molecular Neurobiology, 54(7), 5051-5060. https://doi.org/10.1007/s12035-016-0022-0

Dorsey, E. R., \& Bloem, B. R. (2018). The Parkinson Pandemic-A Call to Action. JAMA Neurology, 75(1), 9. https://doi.org/10.1001/jamaneurol.2017.3299

Driver, J. A., Logroscino, G., Gaziano, J. M., \& Kurth, T. (2009). Incidence and remaining lifetime risk of Parkinson disease in advanced age. Neurology, 72(5), 432-438. https://doi.org/10.1212/01.wnl.0000341769.50075.bb

Duan, H., Hao, C., Lu, G., Li, S., Wang, S., \& Liu, Y. (2015). Impacts of Granulocyte-Colony Stimulating Factor combined with Erythropoietin on neural regeneration after traumatic brain injury in rats. The FASEB Journal, 29(1_supplement), 727.2. https://doi.org/10.1096/fasebj.29.1_supplement.727.2

Farmer, K., Rudyk, C., Prowse, N. A., \& Hayley, S. (2015). Hematopoietic cytokines as therapeutic players in early stages Parkinson's disease. Frontiers in Aging Neuroscience, 7(JUL), 1-5. https://doi.org/10.3389/fnagi.2015.00126 
Feigin, V. L., Abajobir, A. A., Abate, K. H., Abd-Allah, F., Abdulle, A. M., Abera, S. F., ... Vos, T. (2017). Global, regional, and national burden of neurological disorders during 1990-2015: a systematic analysis for the Global Burden of Disease Study 2015. The Lancet Neurology, 16(11), 877-897. https://doi.org/10.1016/S14744422(17)30299-5

Foley, L. S., Fullerton, D. A., Bennett, D. T., Freeman, K. A., Mares, J., Bell, M. T., ... Reece, T. B. (2015). Spinal Cord Ischemia-Reperfusion Injury Induces Erythropoietin Receptor Expression. Annals of Thoracic Surgery, 100(1), 41-46. https://doi.org/10.1016/j.athoracsur.2015.01.027

Fu, A., Zhou, Q. H., Hui, E. K. W., Lu, J. Z., Boado, R. J., \& Pardridge, W. M. (2010). Intravenous treatment of experimental Parkinson's disease in the mouse with an IgG-GDNF fusion protein that penetrates the blood-brain barrier. Brain Research, 1352(310), 208-213. https://doi.org/10.1016/j.brainres.2010.06.059

Gagnon, D., Petryszyn, S., Sanchez, M. G., Bories, C., Beaulieu, J. M., De Koninck, Y., ... Parent, M. (2017). Striatal Neurons Expressing D1 and D2 Receptors are Morphologically Distinct and Differently Affected by Dopamine Denervation in Mice. Scientific Reports, 7(January), 9-17. https://doi.org/10.1038/srep41432

Gan, Y., Xing, J., Jing, Z., Stetler, R. A., Zhang, F., Luo, Y., ... Cao, G. (2012). Mutant Erythropoietin Without Erythropoietic Activity Is Neuroprotective Against Ischemic Brain Injury. Stroke, 43(11), 3071-3077. https://doi.org/10.1161/STROKEAHA.112.663120

Ganser, C., Papazoglou, A., Just, L., \& Nikkhah, G. (2010). Neuroprotective effects of erythropoietin on 6-hydroxydopamine-treated ventral mesencephalic dopaminerich cultures. Experimental Cell Research, 316(5), 737-746. https://doi.org/10.1016/j.yexcr.2010.01.001

Garden, G. A., \& La Spada, A. R. (2012). Intercellular (Mis)communication in Neurodegenerative Disease. Neuron, 73(5), 886-901. https://doi.org/10.1016/j.neuron.2012.02.017

Garzón, F., Coimbra, D., Parcerisas, A., Rodriguez, Y., García, J. C., Soriano, E., \& Rama, R. (2018). NeuroEPO Preserves Neurons from Glutamate-Induced Excitotoxicity. Journal of Alzheimer's Disease, 65(4), 1469-1483. https://doi.org/10.3233/JAD180668 
Ghosal, S., Bang, E., Yue, W., Hare, B. D., Lepack, A. E., Girgenti, M. J., \& Duman, R. S. (2018). Activity-Dependent Brain-Derived Neurotrophic Factor Release Is Required for the Rapid Antidepressant Actions of Scopolamine. Biological Psychiatry, 83(1), 29-37. https://doi.org/10.1016/j.biopsych.2017.06.017

Gibson, S. a J., Gao, G.-D., McDonagh, K., \& Shen, S. (2012). Progress on stem cell research towards the treatment of Parkinson's disease. Stem Cell Research \& Therapy, 3(2), 11. https://doi.org/10.1186/scrt102

Girgenti, M. J., Hunsberger, J., Duman, C. H., Sathyanesan, M., Terwilliger, R., \& Newton, S. S. (2009). Erythropoietin Induction by Electroconvulsive Seizure, Gene Regulation, and Antidepressant-Like Behavioral Effects. Biological Psychiatry, 66(3), 267-274. https://doi.org/10.1016/j.biopsych.2008.12.005

Gombash, S. E., Manfredsson, F. P., Kemp, C. J., Kuhn, N. C., Fleming, S. M., Egan, A. E., ... Sortwell, C. E. (2013). Morphological and Behavioral Impact of AAV2/5-Mediated Overexpression of Human Wildtype Alpha-Synuclein in the Rat Nigrostriatal System. PLoS ONE, 8(11), e81426. https://doi.org/10.1371/journal.pone.0081426

Gong, C.-X., Liu, F., \& Iqbal, K. (2018). Multifactorial Hypothesis and Multi-Targets for Alzheimer's Disease. Journal of Alzheimer's Disease, 64(s1), S107-S117. https://doi.org/10.3233/JAD-179921

Grondin, R., Zhang, Z., Yi, A., Cass, W. a, Maswood, N., Andersen, A. H., ... Gash, D. M. (2002). Chronic, controlled GDNF infusion promotes structural and functional recovery in advanced parkinsonian monkeys. Brain : A Journal of Neurology, 125(Pt 10), 2191-2201. https://doi.org/12244077

Grosch, J., Winkler, J., \& Kohl, Z. (2016). Early Degeneration of Both Dopaminergic and Serotonergic Axons - A Common Mechanism in Parkinson's Disease. Frontiers in Cellular Neuroscience, 10. https://doi.org/10.3389/fncel.2016.00293

Heinemann, S. D., Posimo, J. M., Mason, D. M., Hutchison, D. F., \& Leak, R. K. (2016). Synergistic stress exacerbation in hippocampal neurons: Evidence favoring the dual-hit hypothesis of neurodegeneration. Hippocampus, 26(8), 980-994. https://doi.org/10.1002/hipo.22580 
Heneka, M. T., Nadrigny, F., Regen, T., Martinez-Hernandez, A., Dumitrescu-Ozimek, L., Terwel, D., ... Kummer, M. P. (2010). Locus ceruleus controls Alzheimer's disease pathology by modulating microglial functions through norepinephrine. Proceedings of the National Academy of Sciences, 107(13), 6058-6063.

https://doi.org/10.1073/pnas.0909586107

Heuer, A., Smith, G. A., Lelos, M. J., Lane, E. L., \& Dunnett, S. B. (2012). Unilateral nigrostriatal 6-hydroxydopamine lesions in mice I: Motor impairments identify extent of dopamine depletion at three different lesion sites. Behavioural Brain Research, 228(1), 30-43. https://doi.org/10.1016/j.bbr.2011.11.027

Hoeller, D., Volarevic, S., \& Dikic, I. (2005). Compartmentalization of growth factor receptor signalling. Current Opinion in Cell Biology, 17(2), 107-111. https://doi.org/10.1016/j.ceb.2005.01.001

lancu, R., Mohapel, P., Brundin, P., \& Paul, G. (2005). Behavioral characterization of a unilateral 6-OHDA-lesion model of Parkinson's disease in mice. Behavioural Brain Research, 162(1), 1-10. https://doi.org/10.1016/j.bbr.2005.02.023

Iannaccone, S., Cerami, C., Alessio, M., Garibotto, V., Panzacchi, A., Olivieri, S., ... Perani, D. (2013). In vivo microglia activation in very early dementia with Lewy bodies, comparison with Parkinson's disease. Parkinsonism and Related Disorders, 19(1), 47-52. https://doi.org/10.1016/j.parkreldis.2012.07.002

Jang, W., Park, J., Shin, K. J., Kim, J. S., Kim, J. S., Youn, J., ... Kim, H. T. (2014). Safety and efficacy of recombinant human erythropoietin treatment of non-motor symptoms in Parkinson's disease. Journal of the Neurological Sciences, 337(1-2), 47-54. https://doi.org/10.1016/j.jns.2013.11.015

Jankovic, J. (2018). Parkinson's disease tremors and serotonin. Brain, 141(3), 624-626. https://doi.org/10.1093/brain/awx361

Jia, Y., Mo, S., Feng, Q., Zhan, M., Ouyang, L., Chen, J., ... Wu, J. (2014). EPO-Dependent Activation of PI3K / Akt / FoxO3a Signalling Mediates Neuroprotection in In Vitro and In Vivo Models of Parkinson's sisease.

Jia, Y., Mo, S. J., Feng, Q. Q., Zhan, M. L., OuYang, L. S., Chen, J. C., ... Lei, W. L. (2014). EPO-dependent activation of PI3K/Akt/FoxO3a signalling mediates neuroprotection in in vitro and in vivo models of Parkinson's disease. Journal of Molecular Neuroscience, 53(1), 117-124. https://doi.org/10.1007/s12031-013-0208-0 
Johnson, M. E., Stecher, B., Labrie, V., Brundin, L., \& Brundin, P. (2019). Triggers, Facilitators, and Aggravators: Redefining Parkinson's Disease Pathogenesis. Trends in Neurosciences, 42(1), 4-13. https://doi.org/10.1016/j.tins.2018.09.007

Jordan, J. T., Shanley, M. R., \& Pytte, C. L. (2019). Behavioral state-dependent lateralization of dorsal dentate gyrus c-Fos expression in mice. Neuronal Signaling, 3(1), NS20180206. https://doi.org/10.1042/NS20180206

Kaminska, B., Mota, M., \& Pizzi, M. (2016). Signal transduction and epigenetic mechanisms in the control of microglia activation during neuroinflammation. Biochimica et Biophysica Acta - Molecular Basis of Disease, 1862(3), 339-351. https://doi.org/10.1016/j.bbadis.2015.10.026

Kearns, C. M., \& Gash, D. M. (1995). GDNF protects nigral dopamine neurons against 6hydroxydopamine in vivo. Brain Research, 672(1-2), 104-111. https://doi.org/10.1016/0006-8993(94)01366-P

Kirik, D., Georgievska, B., \& Björklund, A. (2004). Localized striatal delivery of GDNF as a treatment for Parkinson disease. Nature Neuroscience, 7(2), 105-110. https://doi.org/10.1038/nn1175

Kirkeby, A., \& Barker, R. A. (2019). Parkinson disease and growth factors - is GDNF good enough? Nature Reviews Neurology, 15(6), 312-314. https://doi.org/10.1038/s41582-019-0180-6

Kish, S. J., Shannak, K., \& Hornykiewicz, O. (1988). Uneven Pattern of Dopamine Loss in the Striatum of Patients with Idiopathic Parkinson's Disease. New England Journal of Medicine, 318(14), 876-880. https://doi.org/10.1056/NEJM198804073181402

Kluger, B. M., Zhao, Q., Tanner, J. J., Schwab, N. A., Levy, S.-A., Burke, S. E., ... Price, C. (2019). Structural brain correlates of fatigue in older adults with and without Parkinson's disease. Neurolmage: Clinical, 22, 101730. https://doi.org/10.1016/j.nicl.2019.101730

Kordower, J. H., \& Bjorklund, A. (2013). Trophic Factor Gene Therapy for Parkinson's Disease. Movement Disorders, 28(1), 96-109. https://doi.org/10.1002/mds.25344

Kordower, J. H., \& Burke, R. E. (2018). Disease Modification for Parkinson's Disease: Axonal Regeneration and Trophic Factors. Movement Disorders, 33(5), 678-683. https://doi.org/10.1002/mds.27383 
Kuter, K., Kratochwil, M., Marx, S.-H., Hartwig, S., Lehr, S., Sugawa, M. D., \& Dencher, N. A. (2016). Native DIGE proteomic analysis of mitochondria from substantia nigra and striatum during neuronal degeneration and its compensation in an animal model of early Parkinson's disease. Archives of Physiology and Biochemistry, 122(5), 238-256. https://doi.org/10.1080/13813455.2016.1197948

Laganiere, J., Kells, A. P., Lai, J. T., Guschin, D., Paschon, D. E., Meng, X., ... Zhang, H. S. (2010). An Engineered Zinc Finger Protein Activator of the Endogenous Glial Cell Line-Derived Neurotrophic Factor Gene Provides Functional Neuroprotection in a Rat Model of Parkinson's Disease. Journal of Neuroscience, 30(49), 16469-16474. https://doi.org/10.1523/JNEUROSCI.2440-10.2010

Lang, A. E., Gill, S., Patel, N. K., Lozano, A., Nutt, J. G., Penn, R., ... Traub, M. (2006). Randomized controlled trial of intraputamenal glial cell line-derived neurotrophic factor infusion in Parkinson disease. Annals of Neurology, 59(3), 459-466. https://doi.org/10.1002/ana.20737

Leconte, C., Bihel, E., Lepelletier, F.-X., Bouët, V., Saulnier, R., Petit, E., ... SchumannBard, P. (2011). Comparison of the effects of erythropoietin and its carbamylated derivative on behaviour and hippocampal neurogenesis in mice.

Neuropharmacology, 60(2-3), 354-364. https://doi.org/10.1016/j.neuropharm.2010.09.025

Lee, H. J., Koh, S.-H., Song, K.-M., Seol, I. J., \& Park, H.-K. (2016). The Akt/mTOR/p70S6K Pathway Is Involved in the Neuroprotective Effect of Erythropoietin on Hypoxic/Ischemic Brain Injury in a Neonatal Rat Model. Neonatology, 110(2), 93100. https://doi.org/10.1159/000444360

Lenz, K. M., \& Nelson, L. H. (2018). Microglia and Beyond: Innate Immune Cells As Regulators of Brain Development and Behavioral Function. Frontiers in Immunology, 9. https://doi.org/10.3389/fimmu.2018.00698

Li, J., Guo, W., Xiong, M., Zhang, S., Han, H., Chen, J., ... Zeng, Y. (2017). Erythropoietin facilitates the recruitment of bone marrow mesenchymal stem cells to sites of spinal cord injury. Experimental and Therapeutic Medicine, 13(5), 1806-1812. https://doi.org/10.3892/etm.2017.4182

Li, X., Chen, Y., Shao, S., Tang, Q., Chen, W., Chen, Y., \& Xu, X. (2016). Oxidative stress induces the decline of brain EPO expression in aging rats. Experimental Gerontology, 83, 89-93. https://doi.org/10.1016/j.exger.2016.07.012 
Lindholm, D., Mäkelä, J., Di Liberto, V., Mudò, G., Belluardo, N., Eriksson, O., \& Saarma, M. (2016). Current disease modifying approaches to treat Parkinson's disease. Cellular and Molecular Life Sciences, 73(7), 1365-1379. https://doi.org/10.1007/s00018-015-2101-1

Littrell, O. M., Granholm, A. C., Gerhardt, G. A., \& Boger, H. A. (2013). Glial cell-line derived neurotrophic factor (GDNF) replacement attenuates motor impairments and nigrostriatal dopamine deficits in 12-month-old mice with a partial deletion of GDNF. Pharmacology Biochemistry and Behavior, 104(1), 10-19. https://doi.org/10.1016/j.pbb.2012.12.022

Liu, Q. S., Cheng, Z. W., Xiong, J. G., Cheng, S., He, X. F., \& Li, X. C. (2015). Erythropoietin pretreatment exerts anti-inflammatory effects in hepatic ischemia/reperfusioninjured rats via suppression of the TLR2/NF-kB pathway. Transplantation Proceedings, 47(2), 283-289. https://doi.org/10.1016/j.transproceed.2014.10.045

Lozovaya, N., Eftekhari, S., Cloarec, R., Gouty-Colomer, L. A., Dufour, A., Riffault, B., ... Hammond, C. (2018). GABAergic inhibition in dual-transmission cholinergic and GABAergic striatal interneurons is abolished in Parkinson disease. Nature Communications, 9(1). https://doi.org/10.1038/s41467-018-03802-y

Lozovaya, Natalia, Ben-Ari, Y., \& Hammond, C. (2018). Striatal dual cholinergic /GABAergic transmission in Parkinson disease: friends or foes? Cell Stress, 2(6), 147-149. https://doi.org/10.15698/cst2018.06.142

Luan, Y., Zhang, L., Chao, S., Liu, X., Li, K., Wang, Y., \& Zhang, Z. (2016). Mesenchymal stem cells in combination with erythropoietin repair hyperoxia-induced alveoli dysplasia injury in neonatal mice via inhibition of TGF-\&amp;\#×3B2;1 signaling. Oncotarget, 7(30). https://doi.org/10.18632/oncotarget.9314

Lv, H., Wu, S., Wang, Q., Yang, L., Ren, P., Qiao, B., ... Li, L. (2017). Effect of erythropoietin combined with hypothermia on serum tau protein levels and neurodevelopmental outcome in neonates with hypoxic-ischemic encephalopathy. Neural Regeneration Research, 12(10), 1655. https://doi.org/10.4103/16735374.217338

Ma, C., Cheng, F., Wang, X., Zhai, C., Yue, W., Lian, Y., \& Wang, Q. (2016). Erythropoietin Pathway: A Potential Target for the Treatment of Depression. International Journal of Molecular Sciences, 17(5), 677. https://doi.org/10.3390/ijms17050677 
Ma, R., Hu, J., Huang, C., Wang, M., Xiang, J., \& Li, G. (2014). JAK2/STAT5/Bcl-xL signalling is essential for erythropoietin-mediated protection against apoptosis induced in PC12 cells by the amyloid $\beta$-peptide A $\beta 25-35$. British Journal of Pharmacology, 171(13), 3234-3245. https://doi.org/10.1111/bph.12672

Maiese, K., Chong, Z. Z., Shang, Y. C., \& Wang, S. (2012). Erythropoietin: New directions for the nervous system. International Journal of Molecular Sciences, 13(9), 1110211129. https://doi.org/10.3390/ijms130911102

Marks, W. J., Bartus, R. T., Siffert, J., Davis, C. S., Lozano, A., Boulis, N., ... Olanow, C. W. (2010). Gene delivery of AAV2-neurturin for Parkinson's disease: A double-blind, randomised, controlled trial. The Lancet Neurology, 9(12), 1164-1172.

https://doi.org/10.1016/S1474-4422(10)70254-4

Martin-Bastida, A., Ward, R. J., Newbould, R., Piccini, P., Sharp, D., Kabba, C., ... Dexter, D. T. (2017). Brain iron chelation by deferiprone in a phase 2 randomised doubleblinded placebo controlled clinical trial in Parkinson's disease. Scientific Reports, 7(1), 1398. https://doi.org/10.1038/s41598-017-01402-2

Martínez-Morales, P. L., \& Liste, I. (2012). Stem cells as in vitro model of Parkinson's disease. Stem Cells International, 2012. https://doi.org/10.1155/2012/980941

Meiser, J., Weindl, D., \& Hiller, K. (2013). Complexity of dopamine metabolism. Cell Communication and Signaling, 11(1), 1-18. https://doi.org/10.1186/1478-811X-1134

Merelli, A., Ramos, A. J., Lazarowski, A., \& Auzmendi, J. (2019). Convulsive Stress Mimics Brain Hypoxia and Promotes the P-Glycoprotein (P-gp) and Erythropoietin Receptor Overexpression. Recombinant Human Erythropoietin Effect on P-gp Activity. Frontiers in Neuroscience, 13(July), 1-11. https://doi.org/10.3389/fnins.2019.00750

Miljus, N., Massih, B., Weis, M. A., Rison, J. V., Bonnas, C. B., Sillaber, I., ... Heinrich, R. (2017). Neuroprotection and endocytosis: erythropoietin receptors in insect nervous systems. Journal of Neurochemistry, 141(1), 63-74. https://doi.org/10.1111/jnc.13967

Navntoft, C. A., \& Dreyer, J. K. (2016). How compensation breaks down in Parkinson's disease: Insights from modeling of denervated striatum. Movement Disorders, 31(3), 280-289. https://doi.org/10.1002/mds.26579 
Osborn, M., Rustom, N., Clarke, M., Litteljohn, D., Rudyk, C., Anisman, H., \& Hayley, S. (2013). Antidepressant-Like Effects of Erythropoietin: A Focus on Behavioural and Hippocampal Processes. PLoS ONE, 8(9), 1-9. https://doi.org/10.1371/journal.pone.0072813

Ott, C., Martens, H., Hassouna, I., Oliveira, B., Erck, C., Zafeiriou, M. P., ... Ehrenreich, H. (2015). Widespread expression of erythropoietin receptor in brain and its induction by injury. Molecular Medicine, 21, 803-815.

https://doi.org/10.2119/molmed.2015.00192

Ouchi, Y., Yoshikawa, E., Sekine, Y., Futatsubashi, M., Kanno, T., Ogusu, T., \& Torizuka, T. (2005). Microglial activation and dopamine terminal loss in early Parkinson's disease. Annals of Neurology, 57(2), 168-175. https://doi.org/10.1002/ana.20338

Patel, N. K., Bunnage, M., Plaha, P., Svendsen, C. N., Heywood, P., \& Gill, S. S. (2005). Intraputamenal infusion of glial cell line-derived neurotrophic factor in PD: A twoyear outcome study. Annals of Neurology, 57(2), 298-302. https://doi.org/10.1002/ana.20374

Patrick, K. L., Bell, S. L., Weindel, C. G., \& Watson, R. O. (2019). Exploring the "MultipleHit Hypothesis" of Neurodegenerative Disease: Bacterial Infection Comes Up to Bat. Frontiers in Cellular and Infection Microbiology, 9. https://doi.org/10.3389/fcimb.2019.00138

Paul, G., \& Sullivan, A. M. (2019). Trophic factors for Parkinson's disease: Where are we and where do we go from here? European Journal of Neuroscience, 49(4), 440-452. https://doi.org/10.1111/ejn.14102

Peterson, A. L., \& Nutt, J. G. (2008). Treatment of Parkinson 's Disease with Trophic Factors, 5(April), 270-280.

Plenz, D., \& Wickens, J. R. (2017). The Striatal Skeleton: Medium Spiny Projection Neurons and Their Lateral Connections. Handbook of Behavioral Neuroscience, 24, 121-136. https://doi.org/10.1016/B978-0-12-802206-1.00006-4

Ponce, L. L., Navarro, J. C., Ahmed, O., \& Robertson, C. S. (2013). Erythropoietin neuroprotection with traumatic brain injury. Pathophysiology, 20(1), 31-38. https://doi.org/10.1016/j.pathophys.2012.02.005 
Ransohoff, R. M. (2016). A polarizing question: do M1 and M2 microglia exist? Nature Neuroscience, 19, 987. Retrieved from https://doi.org/10.1038/nn.4338

Ren, K., Guo, B., Dai, C., Yao, H., Sun, T., Liu, X., ... Wu, S. (2017). Striatal Distribution and Cytoarchitecture of Dopamine Receptor Subtype 1 and 2: Evidence from DoubleLabeling Transgenic Mice. Frontiers in Neural Circuits, 11(August), 1-13. https://doi.org/10.3389/fncir.2017.00057

Ren, M., Han, M., Wei, X., Guo, Y., Shi, H., Zhang, X., ... Cenci, M. A. (2011). Behavioral characterization of a unilateral 6-OHDA-lesion model of Parkinson's disease in mice. Behavioural Brain Research, 42(1), 314-323. https://doi.org/10.1016/j.expneurol.2007.10.012

Rocha, E. M., Smith, G. A., Park, E., Cao, H., Brown, E., Hayes, M. A., ... Isacson, O. (2015). Glucocerebrosidase gene therapy prevents $\alpha$-synucleinopathy of midbrain dopamine neurons. Neurobiology of Disease, 82, 495-503.

https://doi.org/10.1016/j.nbd.2015.09.009

Rodriguez-Pallares, J., Parga, J. A., Muñoz, A., Rey, P., Guerra, M. J., \& LabandeiraGarcia, J. L. (2007). Mechanism of 6-hydroxydopamine neurotoxicity: The role of NADPH oxidase and microglial activation in 6-hydroxydopamine-induced degeneration of dopaminergic neurons. Journal of Neurochemistry, 103(1), 145156. https://doi.org/10.1111/j.1471-4159.2007.04699.x

Rodriguez, M., Morales, I., Rodriguez-Sabate, C., Sanchez, A., Castro, R., Brito, J. M., \& Sabate, M. (2014). The degeneration and replacement of dopamine cells in Parkinsonâ€ $\epsilon^{\mathrm{TM}} \mathrm{S}$ disease: the role of aging. Frontiers in Neuroanatomy, 8. https://doi.org/10.3389/fnana.2014.00080

Rommelfanger, K. S., Edwards, G. L., Freeman, K. G., Liles, L. C., Miller, G. W., \& Weinshenker, D. (2007). Norepinephrine loss produces more profound motor deficits than MPTP treatment in mice. Proceedings of the National Academy of Sciences, 104(34), 13804-13809. https://doi.org/10.1073/pnas.0702753104

Rommelfanger, K. S., \& Weinshenker, D. (2007). Norepinephrine: The redheaded stepchild of Parkinson's disease. Biochemical Pharmacology, 74(2), 177-190. https://doi.org/10.1016/j.bcp.2007.01.036 
Rong, R., \& Xijun, X. (2015). Erythropoietin pretreatment suppresses inflammation by activating the PI3K/Akt signaling pathway in myocardial ischemia-reperfusion injury. Experimental and Therapeutic Medicine, 10(2), 413-418. https://doi.org/10.3892/etm.2015.2534

Saad, M. A., El-Sahar, A. E., Sayed, R. H., Elbaz, E. M., Helmy, H. S., \& Senousy, M. A. (2019). Venlafaxine Mitigates Depressive-Like Behavior in Ovariectomized Rats by Activating the EPO/EPOR/JAK2 Signaling Pathway and Increasing the Serum Estradiol Level. Neurotherapeutics, 16(2), 404-415. https://doi.org/10.1007/s13311-018-00680-6

Sadasivan, S., Sharp, B., Schultz-Cherry, S., \& Smeyne, R. J. (2017). Synergistic effects of influenza and 1-methyl-4-phenyl-1,2,3,6-tetrahydropyridine (MPTP) can be eliminated by the use of influenza therapeutics: experimental evidence for the multi-hit hypothesis. Npj Parkinson's Disease, 3(1), 18. https://doi.org/10.1038/s41531-017-0019-z

Sakanaka, M., Wen, T. C., Matsuda, S., Masuda, S., Morishita, E., Nagao, M., \& Sasaki, R. (1998). In vivo evidence that erythropoietin protects neurons from ischemic damage. Proc Natl Acad Sci U S A, 95(8), 4635-4640. https://doi.org/10.1073/pnas.95.8.4635

Salganik, M., Sergeyev, V. G., Shinde, V., Meyers, C. A., Gorbatyuk, M. S., Lin, J. H., ... Gorbatyuk, O. S. (2015). The loss of glucose-regulated protein 78 (GRP78) during normal aging or from siRNA knockdown augments human alpha-synuclein ( $\alpha$-syn) toxicity to rat nigral neurons. Neurobiology of Aging, 36(6), 2213-2223. https://doi.org/10.1016/j.neurobiolaging.2015.02.018

Sanchez-Guajardo, V., Febbraro, F., Kirik, D., \& Romero-Ramos, M. (2010). Microglia Acquire Distinct Activation Profiles Depending on the Degree of $\alpha$-Synuclein Neuropathology in a rAAV Based Model of Parkinson's Disease. PLoS ONE, 5(1), e8784. https://doi.org/10.1371/journal.pone.0008784

Sauer, H., \& Oertel, W. H. (1994). Progressive degeneration of nigrostriatal dopamine neurons following intrastriatal terminal lesions with 6-hydroxydopamine: A combined retrograde tracing and immunocytochemical study in the rat. Neuroscience, 59(2), 401-415. https://doi.org/10.1016/0306-4522(94)90605-X 
Sauer, Hansjorg, Rosenblad, C., Bj6rklund, A., \& Changeaux, J.-P. (1995). Glial cell linederived neurotrophic factor but not transforming growth factor 03 prevents delayed degeneration of nigral dopaminergic neurons following striatal 6hydroxydopamine lesion. Cell Biology, 92(September), 8935-8939.

Segal, M., \& Andersen, P. (2000). Dendritic spines shaped by synaptic activity. Current Opinion in Neurobiology, 10(5), 582-586. https://doi.org/10.1016/S09594388(00)00123-9

Sekiguchi, Y., Kikuchi, S., Myers, R. R., \& Campana, W. M. (2003). ISSLS Prize Winner: Erythropoietin Inhibits Spinal Neuronal Apoptosis and Pain Following Nerve Root Crush. Spine, 28(23), 2577-2584.

https://doi.org/10.1097/01.BRS.0000096674.12519.12

Shang, Y. C., Chong, Z. Z., Wang, S., \& Maiese, K. (2011). Erythropoietin and Wnt1 govern pathways of mTOR, Apaf-1, and XIAP in inflammatory microglia. Current Neurovascular Research, 8(4), 270-285. Retrieved from http://www.ncbi.nlm.nih.gov/pubmed/22023617

Shen, J., Wu, Y., Xu, J. Y., Zhang, J., Sinclair, S. H., Yanoff, M., ... Xu, G. T. (2010). ERK- and Akt-dependent neuroprotection by erythropoietin (EPO) against glyoxal-AGEs via modulation of $\mathrm{Bcl}-\mathrm{xL}, \mathrm{Bax}$, and $\mathrm{BAD}$. Investigative Ophthalmology and Visual Science, 51(1), 35-46. https://doi.org/10.1167/iovs.09-3544

Shen, W., Flajolet, M., Greengard, P., \& Surmeier, D. J. (2008). Dichotomous Dopaminergic Control of Striatal Synaptic Plasticity. Science, 321(5890), 848-851. https://doi.org/10.1126/science.1160575

Sherer, T. B., Betarbet, R., Kim, J.-H., \& Greenamyre, J. T. (2003). Selective microglial activation in the rat rotenone model of Parkinson's disease. Neuroscience Letters, 341(2), 87-90. https://doi.org/10.1016/S0304-3940(03)00172-1

Shin, Y.-K., \& Cho, S.-R. (2016). Exploring Erythropoietin and G-CSF Combination Therapy in Chronic Stroke Patients. International Journal of Molecular Sciences, 17(4), 463. https://doi.org/10.3390/ijms17040463

Signore, A. P., Weng, Z., Hastings, T., Van Laar, A. D., Liang, Q., Lee, Y. J., \& Chen, J. (2006). Erythropoietin protects against 6-hydroxydopamine-induced dopaminergic cell death. Journal of Neurochemistry, 96(2), 428-443. https://doi.org/10.1111/j.1471-4159.2005.03587.x 
Song, L.-K., Ma, K.-L., Yuan, Y.-H., Mu, Z., Song, X.-Y., Niu, F., ... Chen, N.-H. (2015). Targeted Overexpression of $\alpha$-Synuclein by rAAV2/1 Vectors Induces Progressive Nigrostriatal Degeneration and Increases Vulnerability to MPTP in Mouse. PLOS ONE, 10(6), e0131281. https://doi.org/10.1371/journal.pone.0131281

Song, S., Jiang, L., Oyarzabal, E. A., Wilson, B., Li, Z., Shih, Y. Y. I., ... Hong, J. S. (2019). Loss of Brain Norepinephrine Elicits Neuroinflammation-Mediated Oxidative Injury and Selective Caudo-Rostral Neurodegeneration. Molecular Neurobiology, 56(4), 2653-2669. https://doi.org/10.1007/s12035-018-1235-1

Sterling, N. W., Du, G., Lewis, M. M., Dimaio, C., Kong, L., Eslinger, P. J., ... Huang, X. (2013). Striatal shape in Parkinson's disease. Neurobiology of Aging, 34(11), 25102516. https://doi.org/10.1016/j.neurobiolaging.2013.05.017

Subiras, N., Del Barco, D. G., \& Coro Antich, R. M. (2012). Erythropoietin: Still on the neuroprotection road. Therapeutic Advances in Neurological Disorders, 5(3), 161173. https://doi.org/10.1177/1756285611434926

Sullivan, A. M., \& O’Keeffe, G. W. (2016). Neurotrophic factor therapy for Parkinson's disease: past, present and future. Neural Regeneration Research, 11(2), 205-207. https://doi.org/10.4103/1673-5374.177710

Sulzer, D. (2007). Multiple hit hypotheses for dopamine neuron loss in Parkinson's disease. Trends in Neurosciences, 30(5), 244-250. https://doi.org/10.1016/j.tins.2007.03.009

Surmeier, D. J., Day, M., Gertler, T., Chan, S., \& Shen, W. (2010). D1 and D2 Dopamine Receptor Modulation of Glutamatergic Signaling in Striatal Medium Spiny Neurons. Handbook of Behavioral Neuroscience (Vol. 20). Elsevier Inc. https://doi.org/10.1016/B978-0-12-374767-9.00006-8

Thomas Tayra, J., Kameda, M., Yasuhara, T., Agari, T., Kadota, T., Wang, F., ... Date, I. (2013). The neuroprotective and neurorescue effects of carbamylated erythropoietin Fc fusion protein (CEPO-Fc) in a rat model of Parkinson's disease. Brain Research, 1502, 55-70. https://doi.org/10.1016/j.brainres.2013.01.042

Volpicelli-Daley, L. A., Kirik, D., Stoyka, L. E., Standaert, D. G., \& Harms, A. S. (2016). How can rAAV- $\alpha$-synuclein and the fibril $\alpha$-synuclein models advance our understanding of Parkinson's disease? Journal of Neurochemistry, 139, 131-155. https://doi.org/10.1111/jnc.13627 
Wang, R., Wu, X., Zhao, H., Min, L., Tao, Z., Ji, X., \& Luo, Y. (2016). Effects of erythropoietin combined with tissue plasminogen activator on the rats following cerebral ischemia and reperfusion. Brain Circulation, 2(1), 54.

https://doi.org/10.4103/2394-8108.178552

Wang, Y., Zhang, Z. G., Rhodes, K., Renzi, M., Zhang, R. L., Kapke, A., ... Chopp, M. (2007). Post-ischemic treatment with erythropoietin or carbamylated erythropoietin reduces infarction and improves neurological outcome in a rat model of focal cerebral ischemia. British Journal of Pharmacology, 151(8), 1377-1384. https://doi.org/10.1038/sj.bjp.0707285

Won, Y. J., Yoo, J. Y., Lee, J. H., Hwang, S. J., Kim, D., \& Hong, H. N. (2007). Erythropoietin is neuroprotective on GABAergic neurons against kainic acid-excitotoxicity in the rat spinal cell cultures. Brain Research, 1154, 31-39. https://doi.org/10.1016/j.brainres.2007.04.010

Wu, Y., Shang, Y., Sun, S., \& Liu, R. (2007). Antioxidant effect of erythropoietin on 1methyl-4-phenylpyridinium-induced neurotoxicity in PC12 cells. European Journal of Pharmacology, 564(1-3), 47-56. https://doi.org/10.1016/j.ejphar.2007.02.020

Wu, Y. W., \& Gonzalez, F. F. (2015). Erythropoietin: a novel therapy for hypoxicischaemic encephalopathy? Developmental Medicine \& Child Neurology, 57, 34-39. https://doi.org/10.1111/dmcn.12730

Xue, Y. Q., Ma, B. F., Zhao, L. R., Tatom, J. B., Li, B., Jiang, L. X., ... Duan, W. M. (2010). AAV9-mediated erythropoietin gene delivery into the brain protects nigral dopaminergic neurons in a rat model of Parkinson's disease. Gene Therapy, 17(1), 83-94. https://doi.org/10.1038/gt.2009.113

Xue, Y. Q., Zhao, L. R., Guo, W. P., \& Duan, W. M. (2007). Intrastriatal administration of erythropoietin protects dopaminergic neurons and improves neurobehavioral outcome in a rat model of Parkinson's disease. Neuroscience, 146(3), 1245-1258. https://doi.org/10.1016/j.neuroscience.2007.02.004

Yacoubian, T. A., \& Standaert, D. G. (2009). Targets for neuroprotection in Parkinson's disease. Biochimica et Biophysica Acta - Molecular Basis of Disease, 1792(7), 676687. https://doi.org/10.1016/j.bbadis.2008.09.009 
Yamanaka, K., Eldeiry, M., Aftab, M., Mares, J., Ryan, T. J., Meng, X., ... Reece, T. B. (2018). Optimized induction of beta common receptor enhances the neuroprotective function of erythropoietin in spinal cord ischemic injury. Journal of Thoracic and Cardiovascular Surgery, 155(6), 2505-2516.

https://doi.org/10.1016/j.jtcvs.2017.12.132

Yamanaka, K., Eldeiry, M., Aftab, M., Ryan, T. J., Mares, J., Meng, X., ... Reece, T. B. (2018). Synergistic Reduction of Apoptosis with Diazoxide and Erythropoietin in Spinal Cord Ischemic Injury. The Annals of Thoracic Surgery. https://doi.org/10.1016/j.athoracsur.2018.07.022

Yamanaka, K., Eldeiry, M., Aftab, M., Ryan, T. J., Meng, X., Weyant, M. J., ... Reece, T. B. (2019). Synergetic Induction of NGF With Diazoxide and Erythropoietin Attenuates Spinal Cord Ischemic Injury. Journal of Surgical Research, 233, 124-131. https://doi.org/10.1016/j.jss.2018.07.021

York, R. D., Molliver, D. C., Grewal, S. S., Stenberg, P. E., McCleskey, E. W., \& Stork, P. J. (2000). Role of phosphoinositide 3-kinase and endocytosis in nerve growth factorinduced extracellular signal-regulated kinase activation via Ras and Rap1. Molecular and Cellular Biology, 20(21), 8069-8083. https://doi.org/10.1128/mcb.20.21.80698083.2000

Yu, D. F., Zhu, L. H., \& Jiang, L. (2017). Recombinant human erythropoietin augments neovascularization responses in a neonatal rat model of premature brain damage by phosphatidylinositol 3 kinase/akt pathway. Chinese Medical Journal, 130(7), 854-858. https://doi.org/10.4103/0366-6999.202744

Yu, J., Shi, Z., Su, X., Zhou, Y., Li, B., Wang, S., ... Wang, W. (2018). Expression of Bcl-2 and Bad in hippocampus of status epileptic rats and molecular mechanism of intervened recombinant human erythropoietin. Experimental and Therapeutic Medicine, 847-855. https://doi.org/10.3892/etm.2018.6250

Yuan, R. R., Wang, B., Lu, W., Maeda, Y., \& Dowling, P. (2015). A Distinct Region in Erythropoietin that Induces Immuno/Inflammatory Modulation and Tissue Protection. Neurotherapeutics, 12(4), 850-861. https://doi.org/10.1007/s13311015-0379-1 
Yuen, C. M., Yeh, K. H., Wallace, C. G., Chen, K. H., Lin, H. S., Sung, P. H., ... Yip, H. K. (2017). EPO-cyclosporine combination therapy reduced brain infarct area in rat after acute ischemic stroke: Role of innate immune-inflammatory response, microRNAs and MAPK family signaling pathway. American Journal of Translational Research, 9(4), 1651-1666.

Zahavi, E. E., Maimon, R., \& Perlson, E. (2017). Spatial-specific functions in retrograde neuronal signalling. Traffic, 18(7), 415-424. https://doi.org/10.1111/tra.12487

Zhang, F., Signore, A. P., Zhou, Z., Wang, S., Cao, G., \& Chen, J. (2006). Erythropoietin protects CA1 neurons against global cerebral ischemia in rat: potential signaling mechanisms. Journal of Neuroscience Research, 83(7), 1241-1251. https://doi.org/10.1002/jnr.20816

Zhang, Z.-H., Pan, Y.-Y., Jing, R.-S., Luan, Y., Zhang, L., Sun, C., ... Wang, Y.-B. (2016). Protective effects of BMSCs in combination with erythropoietin in bronchopulmonary dysplasia-induced lung injury. Molecular Medicine Reports, 14(2), 1302-1308. https://doi.org/10.3892/mmr.2016.5378

Zhao, Y., Zuo, Y., Jiang, J., Yan, H., Wang, X., Huo, H., \& Xiao, Y. (2016). Neural stem cell transplantation combined with erythropoietin for the treatment of spinal cord injury in rats. Experimental and Therapeutic Medicine, 12(4), 2688-2694. https://doi.org/10.3892/etm.2016.3677

Zheng, X., Huang, Z., Zhu, Y., Liu, B., Chen, Z., Chen, T., ... Lei, W. (2019). Increase in Glutamatergic Terminals in the Striatum Following Dopamine Depletion in a Rat Model of Parkinson's Disease. Neurochemical Research, 44(5), 1079-1089. https://doi.org/10.1007/s11064-019-02739-y

Zhou, Q.-H., Hui, E. K.-W., Lu, J. Z., Boado, R. J., \& Pardridge, W. M. (2011). Brain penetrating IgG-erythropoietin fusion protein is neuroprotective following intravenous treatment in Parkinson's disease in the mouse. Brain Research, 1382, 315-320. https://doi.org/10.1016/j.brainres.2011.01.061 


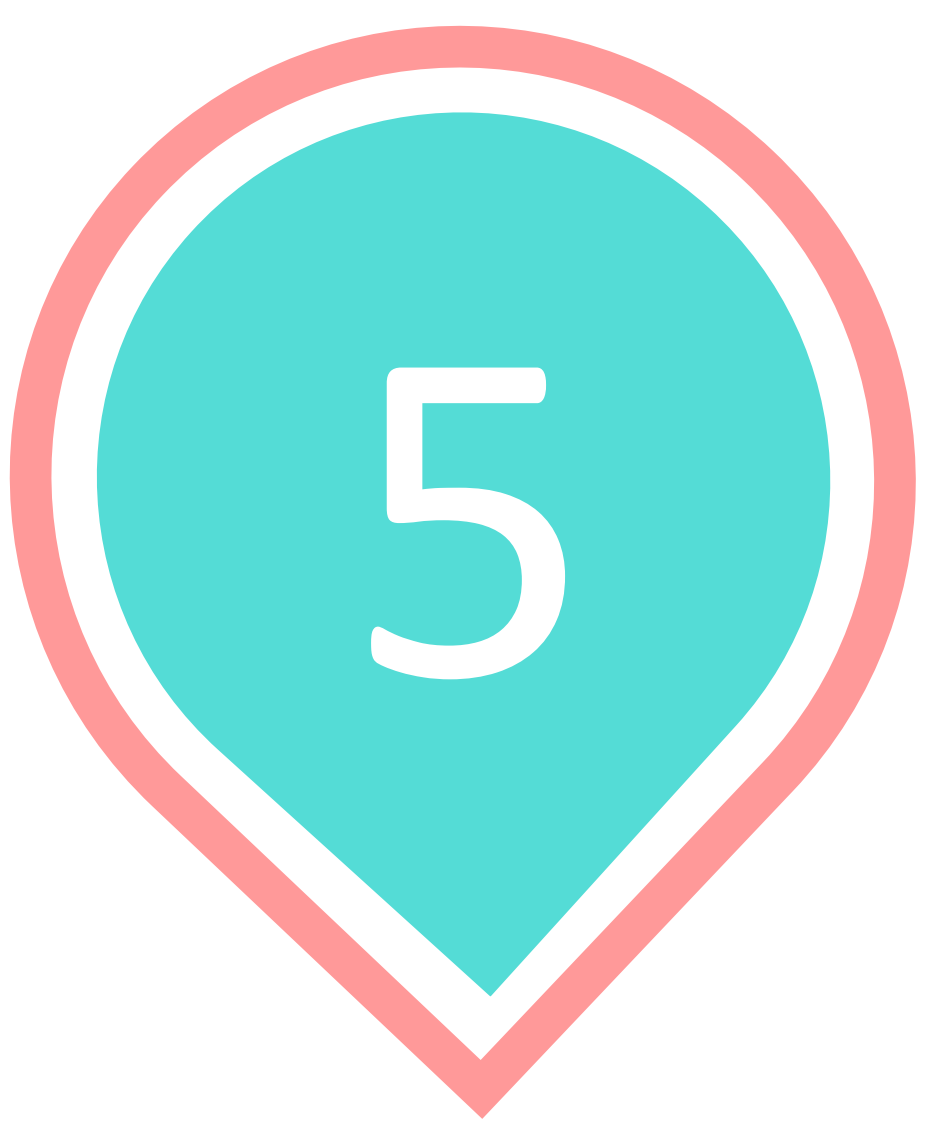

CHAPTER 5:

APPENDICES 


\section{APPENDICES}

\section{APPENDIX A: CATWALK DATA}

Right Front Limb

\section{Mean Max Contact Area}

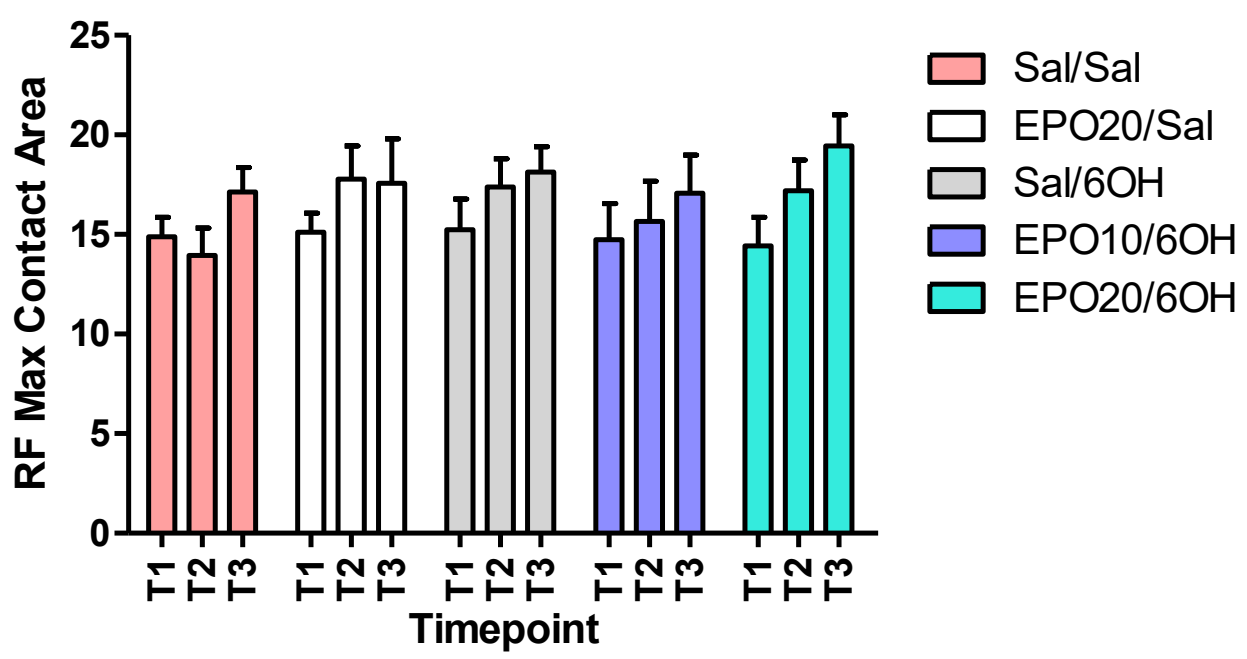

Right Hind Limb Mean Max Contact Area

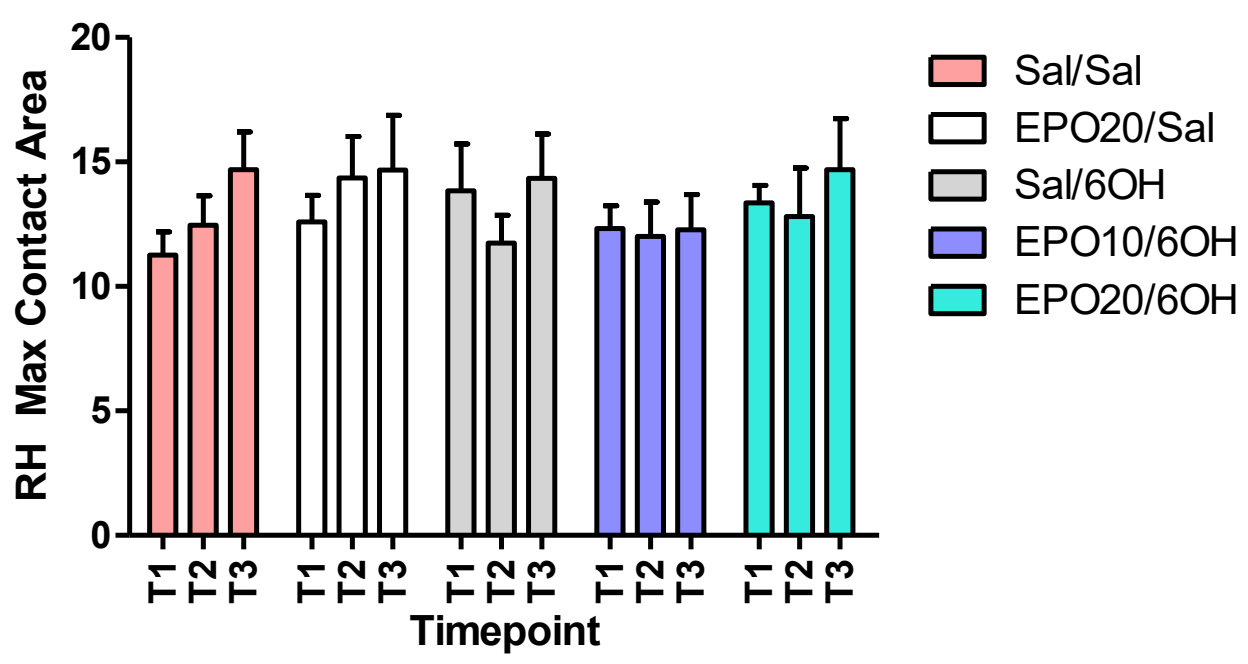


Mean Base of Support

Front Limbs

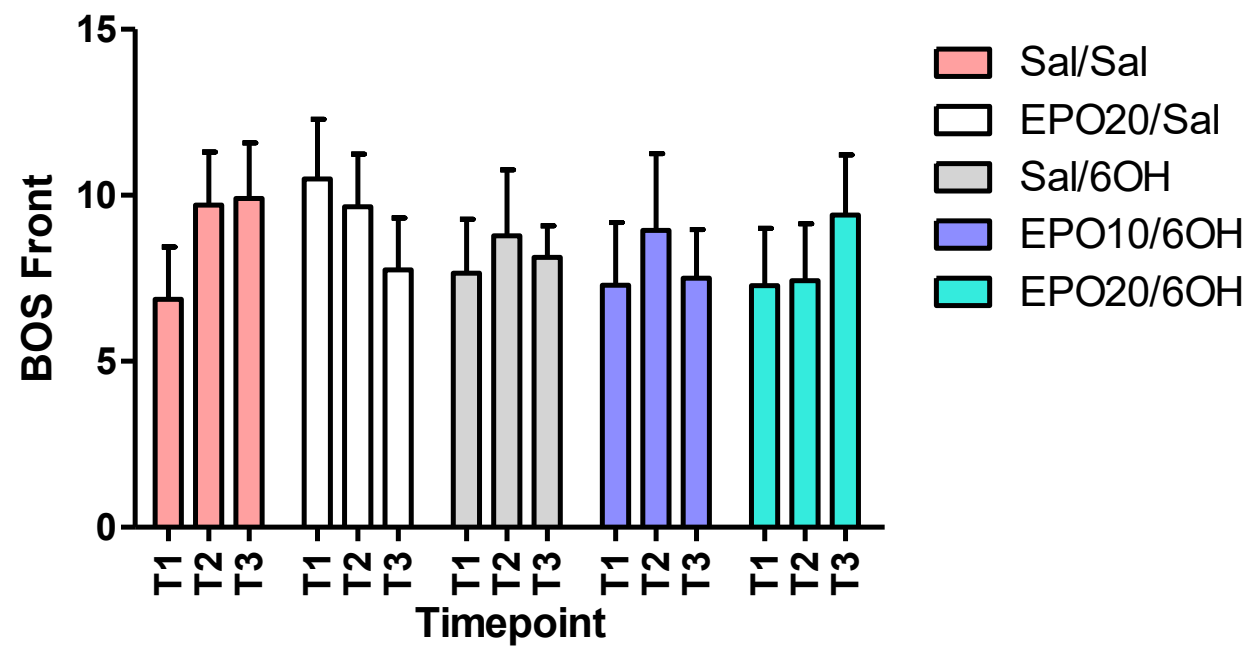

Mean Base of Support Hind Limbs

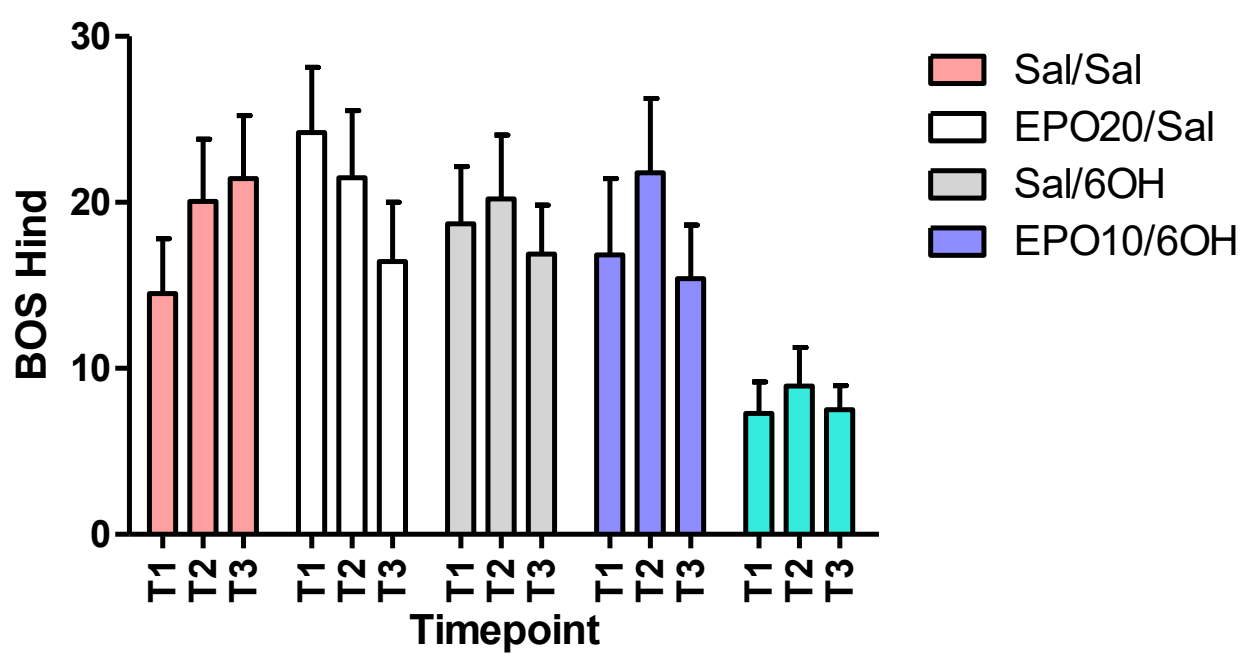


Right Front Limb

Mean Stride Length

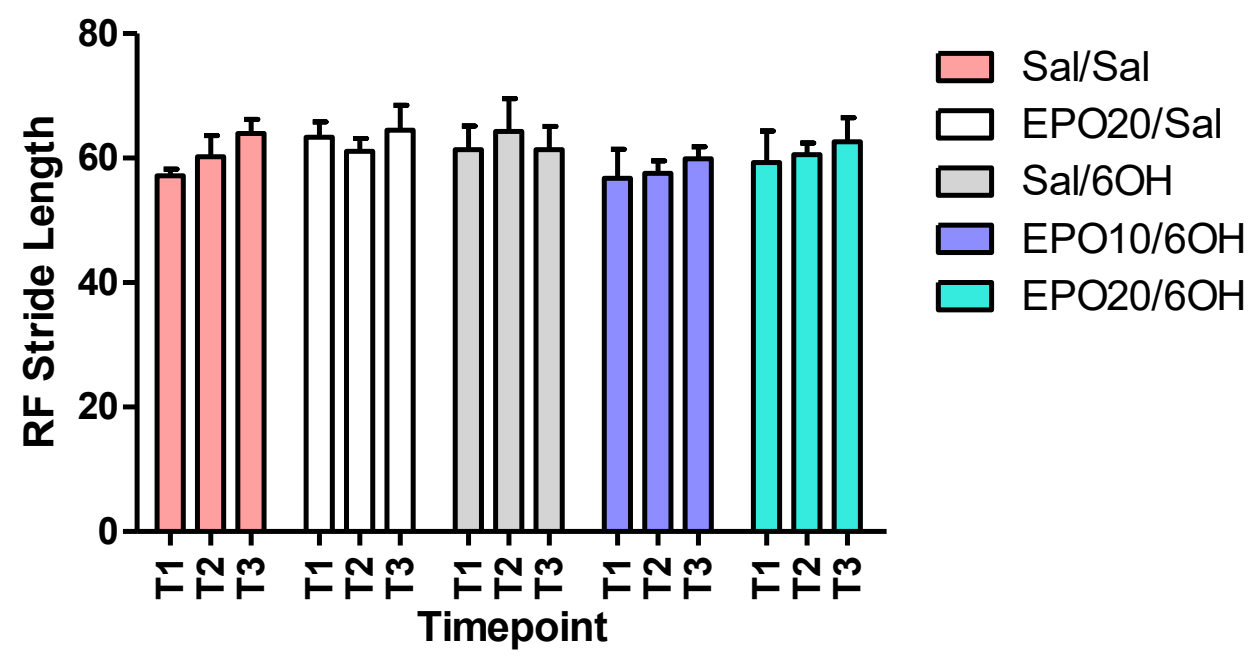

Right Hind Limb

Mean Stride Length

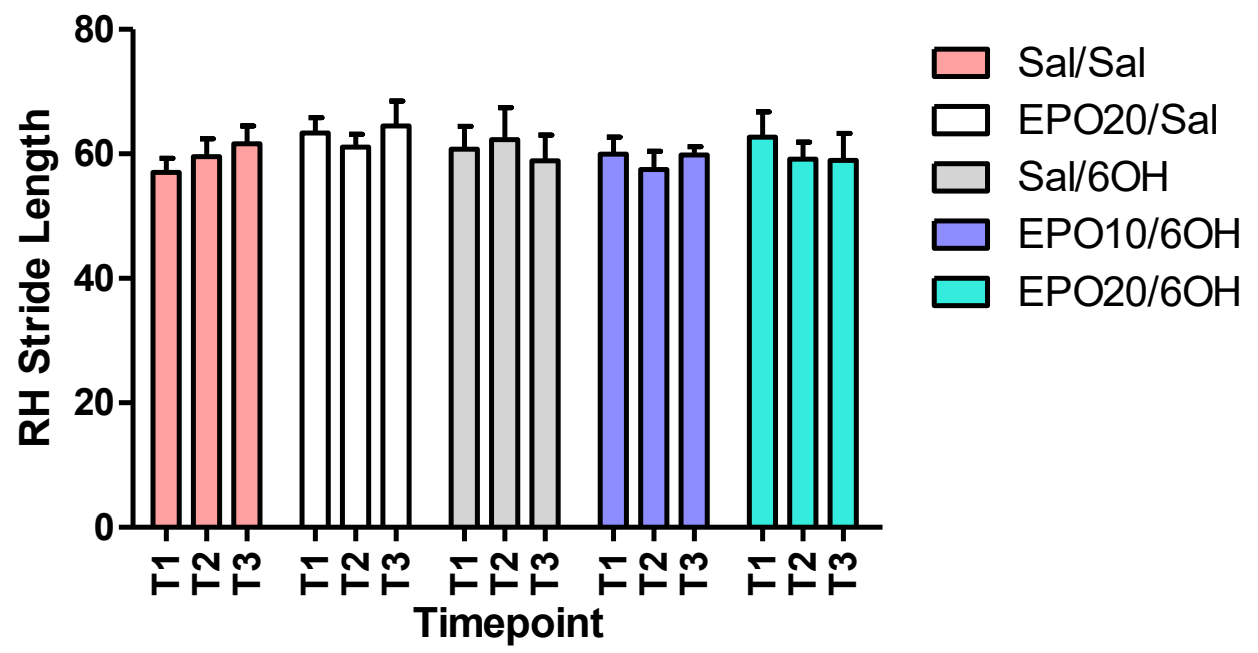




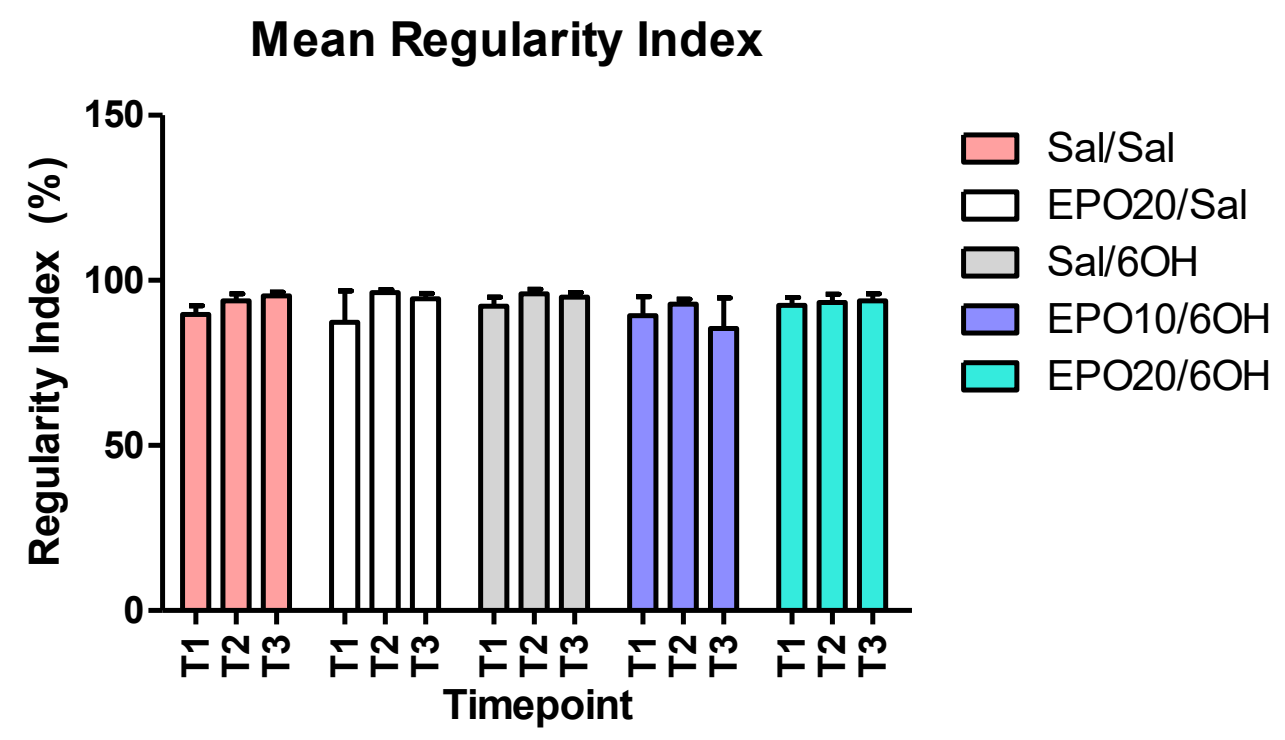

\section{Description of Variables}

Max Contact Area: The maximum area of a paw that comes into contact with the glass plate Stride Length: The distance between successive placements of the same paw

Regularity Index: The number of normal step sequence patterns relative to the total number of paw placements (expressed a \%)

BOS Front and Hind: The average width between either the front paws of the hind paws 
APPENDIX B: HOME CAGE ACTIVITY
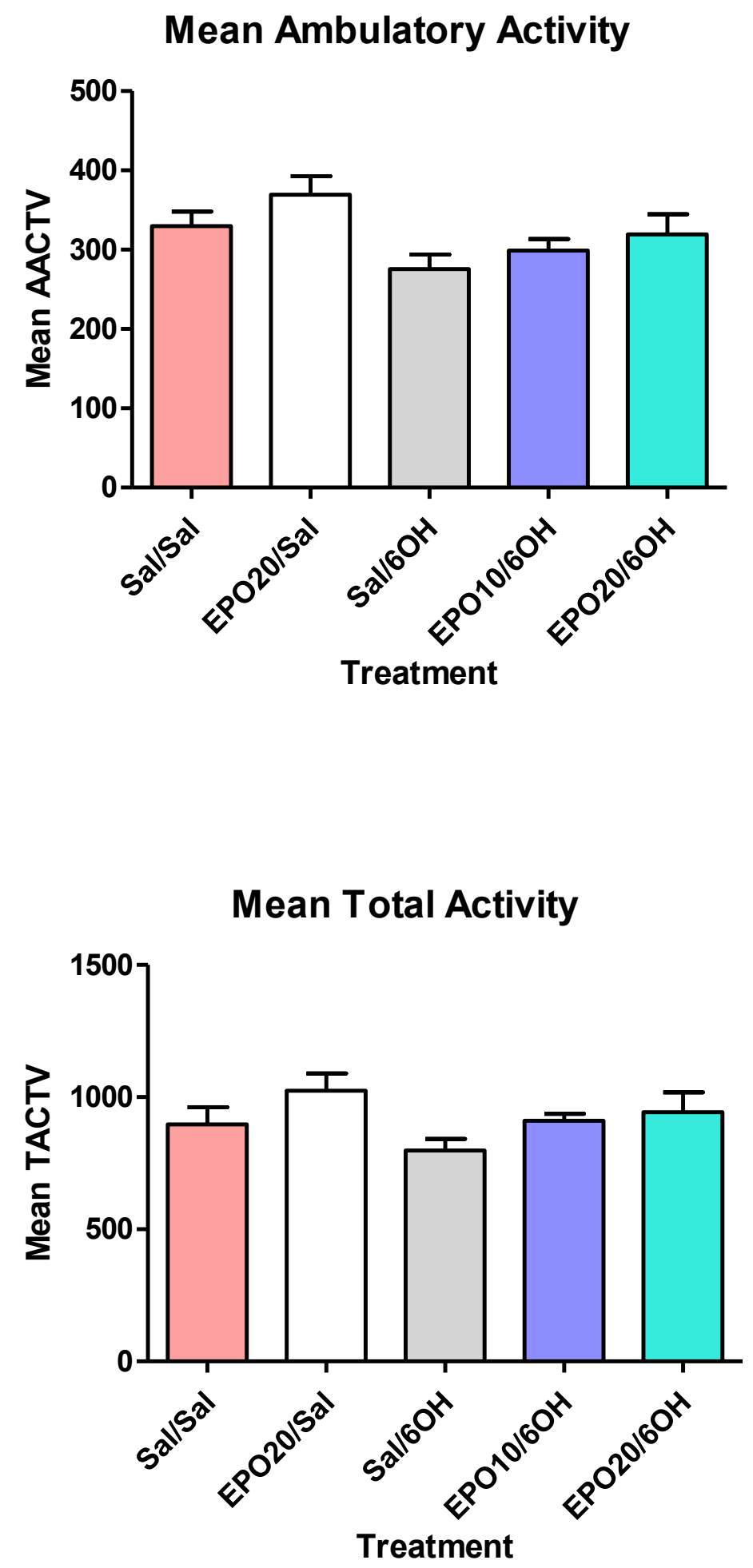